GLEISON MELHADO MATANA

Proposta de Equipamento para Medição dos Fenômenos Relativos à

Qualidade da Energia Elétrica utilizando

Conceitos de Instrumentos Virtuais

São Carlos

2008 
GLEISON MELHADO MATANA

\section{Proposta de Equipamento para Medição \\ dos Fenômenos Relativos à \\ Qualidade da Energia Elétrica utilizando \\ Conceitos de Instrumentos Virtuais}

Dissertação apresentada à Escola de Engenharia de São Carlos da Universidade de São Paulo, como parte dos requisitos para a obtenção do Título de Mestre em Engenharia Elétrica.

ÁREA DE CONCENTRAÇÃO: Sistemas Dinâmicos

ORIENTADOR: Prof. Dr. Azauri Albano de Oliveira Junior

São Carlos

2008 


\section{Dedicatória:}

A Deus, que me suportou perante todos os desafios com sua destra fiel.

A meus pais, Pedro e Sonia, que me apoiaram em todas etapas da minha vida.

A minha esposa, Nadia, pelo amor e compreensão. 


\section{Agradecimentos}

Primeiramente a DEUS pela presença diária em minha vida.

A meus pais, Pedro e Sonia, por me oferecerem a oportunidade de estudar, sempre dando forças para superar as dificuldades.

A minha esposa, Nadia, pelo carinho, apoio e compreensão durante esta etapa.

Ao Prof. Dr. Azauri Albano de Oliveira Junior por acreditar em meu potencial e pela paciência e insistência no decorrer do mestrado.

Ao Prof. Dr. Mario Oleskovicz pelo direcionamento e idéias sugeridas na execução do trabalho.

Aos meus gestores diretos na Caterpillar Brasil Ltda. por permitir meu trabalho em regime de expediente flexível, sem o qual não seria possível a realização deste mestrado.

Aos professores e funcionários do Departamento de Engenharia Elétrica EESC/USP pela atenção e disponibilidade que sempre me atenderam.

Aos meus amigos dos laboratórios de pesquisa, principalmente dos laboratórios LACEP e LSEE, que me auxiliaram e incentivaram.

Aos meus amigos pessoais que apoiaram e incentivaram sempre acreditando em mim, mesmo diante de todas dificuldades que passamos juntos. 


\section{Resumo}

MATANA, G. M. Proposta de Equipamento para Medição dos Fenômenos

Relativos à Qualidade da Energia Elétrica utilizando Conceitos de Instrumentos Virtuais. 2008. 210f. Dissertação (Mestrado) - Escola de Engenharia de São Carlos, Universidade de São Paulo, São Carlos, 2008.

Este trabalho apresenta um estudo da literatura pertinente sobre Qualidade da Energia Elétrica. O estudo apresentado está baseado na evolução do tema em nível nacional e internacional, buscando explicar o conceito dos principais fenômenos e selecionar as recentes resoluções e normas que regem os princípios de medição e os limites dos distúrbios eletromagnéticos que os caracterizam. As normas da IEC foram selecionadas para a aplicação na construção de um protótipo de um medidor de qualidade da energia elétrica, onde o princípio construtivo é o de instrumento virtual por sua flexibilidade de arquitetura. A implementação do protótipo dá-se em um microcomputador padrão de mercado pelo software LabVIEW, através de vários módulos independentes para cada distúrbio a ser medido. Os resultados numéricos das simulações executadas frente a cada distúrbio, gerando comparações entre valores aplicados e valores medidos são apresentados em forma de tabelas com seus respectivos erros percentuais para cada grandeza de cada módulo.

Palavras-chave: Medidor de Qualidade da Energia, Analisador de Qualidade da Energia, Instrumento Virtual. 


\section{Abstract}

MATANA, G. M. Power Quality Measuring Equipment Proposal based on Virtual Instruments Conception. 2008. 206p. Dissertation (Master's Degree) - School of Engineering of São Carlos, University of São Paulo, São Carlos, 2008.

This dissertation presents a study of existing literature about Power Quality. The study presented is based on a theme evolution in national and international environment, trying to explain the main phenomenon conceptions and select the most recent standards that rule the measurement conceptions and the electromagnetic disturbances limits that characterize it. The IEC standard were selected to build a prototype of a power quality measure device where the construction conception is a virtual instrument because it has a flexible architecture. The prototype implementation was made from a common computer by the LabVIEW software through some independent modules for each disturbance to be measured. The numerical results of executed simulations of each disturbance generating comparisons between applied values and measured values are presented as tables within their percentage error for each phenomenon of each module.

Keywords: Power Quality Monitor, Power Quality Analyzer, Virtual Instrument. 


\section{LISTA DE FIGURAS}

FIGURA 1.1. ONDA DE TENSÃO E CORRENTE PARA CARGA LINEAR (A - ESQUERDA) E NÃO LINEAR (B - DIREITA) ... 23

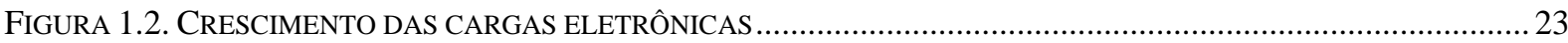

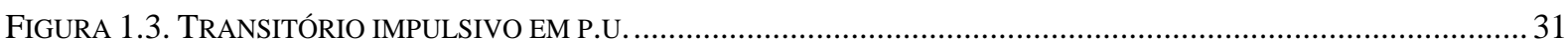

FIGURA 1.4. TRANSITÓRIO OSCILATÓRIO DEVIDO AO CHAVEAMENTO DE UM BANCO DE CAPACITORES .................. 32

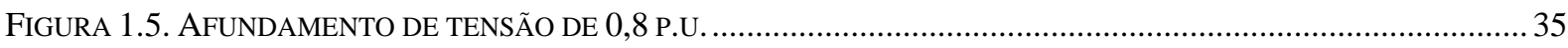

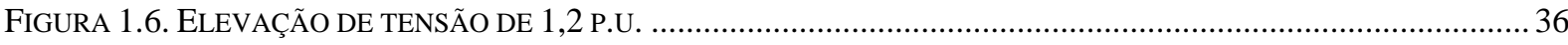

FIGURA 1.7. INTERRUPÇÃO DE CURTA DURAÇÃO DEVIDO A UM CURTO-CIRCUITO..................................................37

FigURA 1.8. DESEQUILÍBRIO NA FASE B DE 2\% (125VRMS ENQUANTO A E C = 127VRMS) .................................38

FIGURA 1.9. REPRESENTAÇÃO DA SÉRIE DE FOURIER PARA UMA ONDA DISTORCIDA ...........................................40

FIGURA 1.10. CARGA LiNEAR (A - DIREITA) E CARGA NÃO-LINEAR (B - ESQUERDA) ......................................... 41

FIGURA 1.11. ESPECTRO DE POTÊNCIA DE UM FORNO DE INDUÇÃO …….......................................................

FIGURA 1.12. RECORTES NA ONDA DE CORRENTE DE UM CONVERSOR TRIFÁSICO ...........................................45

FIGURA 1.13. RUÍDO ELÉTRICO SUPERPOSTO NA FORMA DE ONDA DA TENSÃO EM P.U........................................ 46

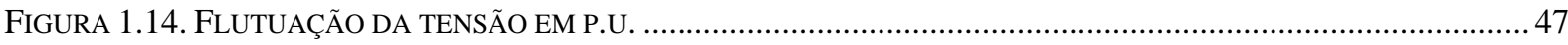

FIGURA 1.15. VARIAÇÃO DA FREQÜÊNCIA NA FORMA DE ONDA DA TENSÃO .................................................... 48

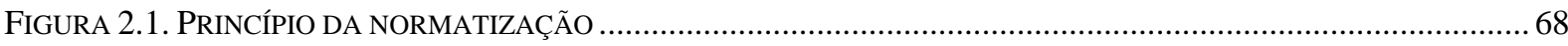

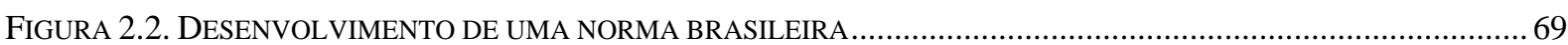

FIGURA 2.3. LIMITES DE TENSÃO PARA TENSÕES NOMINAIS IGUAIS OU INFERIORES A 1KV ................................ 76

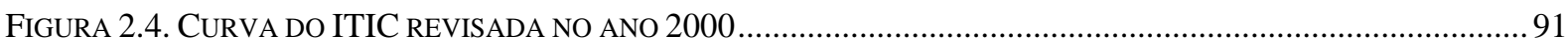

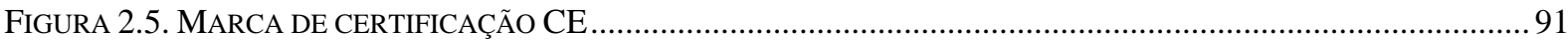

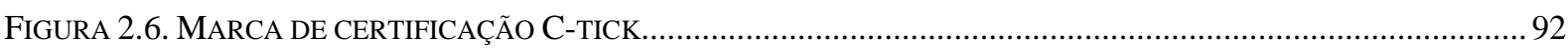

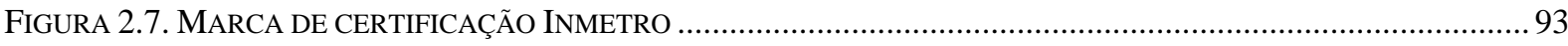

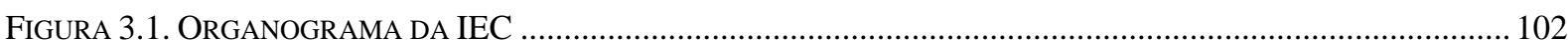

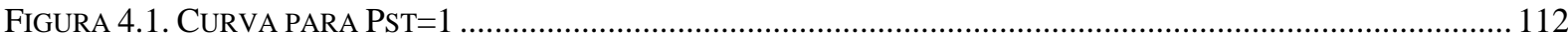

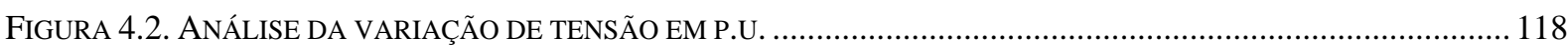

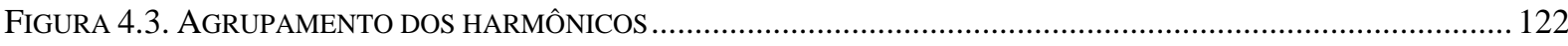

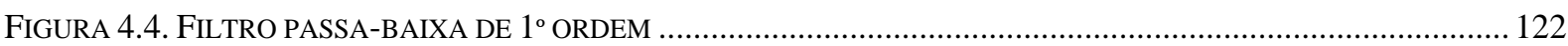


FIGURA 4.5. FLUXOGRAMA DE EQUIPAMENTO PARA MEDIÇÃO DE HARMÔNICOS SEGUNDO A IEC61000-4-7....... 123

FIGURA 4.6. NÍVEIS DE FLICKER EM FUNÇÃO DA VARIAÇÃO DO TEMPO ......................................................... 126

FIGURA 4.7. FUNÇÃO DE PROBABILIDADE CUMULATIVA DE UM SINAL CONTENDO FLICKER .............................. 126

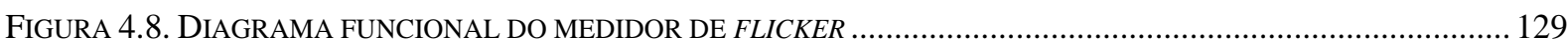

FIGURA 4.9. AGREGAÇÃO DE TEMPO DE UM INSTRUMENTO DE MEDIÇÃO ....................................................... 132

FIGURA 4.10. CONCEITO DE FLAG PARA INDICAR O ACONTECIMENTO DE UM DISTÚRBIO ...................................132

FIGURA 4.11. MEDIÇÃO DA FREQÜÊNCIA SEGUNDO IEC61000-4-30........................................................... 133

FIGURA 4.12. ANÁLISE DO VALOR EFICAZ PARA CARACTERIZAÇÃO DE SUBTENSÃO E SOBRETENSÃO ..................134

FIGURA 4.13. DIAGRAMA DE BLOCOS DO EQUIPAMENTO PROPOSTO ..................................................... 140

FIGURA 4.14. ALIMENTAÇÃO DAS PLACAS ELETRÔNICAS DA INTERFACE DE TENSÃO E CORRENTE .......................141

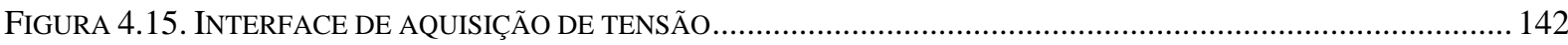

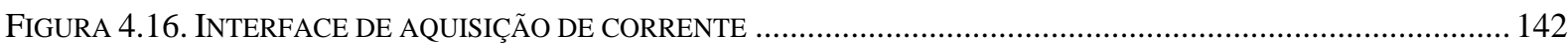

FIGURA 4.17. DIAGRAMA DE BLOCOS DO SOFTWARE DO EQUIPAMENTO PROPOSTO ....................................... 146

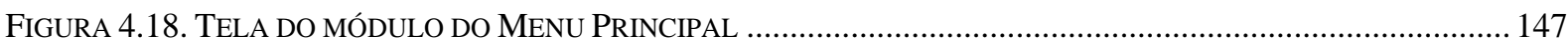

FiguRA 4.19. TELAS DE CONFIGURAÇÃo DO PRotótiPo ......................................................................... 148

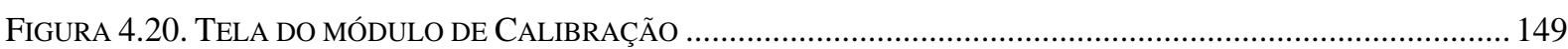

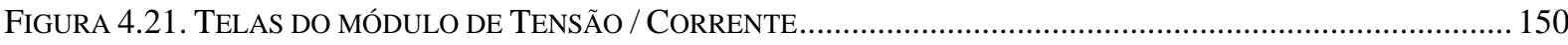

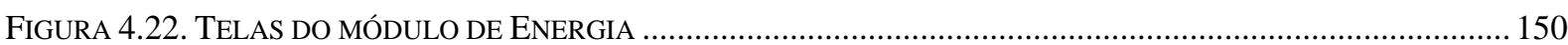

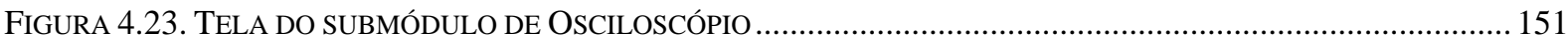

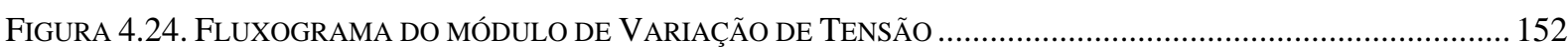

FIGURA 4.25. FLUXOGRAMA dO MÓDULO DE FLUTUAÇÃO DE TENSÃO......................................................... 153

FIGURA 4.26. TELA DO MÓDULO DE VARIAÇÕES E FLUTUAÇÃO DE TENSÃO.................................................... 154

FIGURA 4.27. FLUXOGRAMA DO MÓDULO DE DiSTORÇÕES DA FORMA DE ONDA.............................................. 155

FIGURA 4.28. TELA DO MÓDULO DE DISTORÇÕES DA FORMA DE ONDA ............................................................ 156

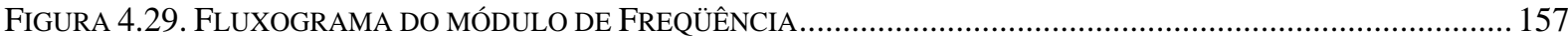

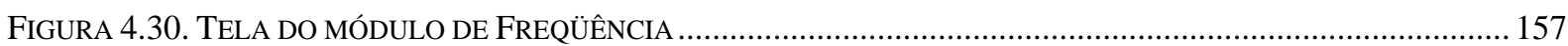

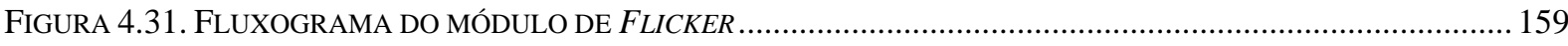

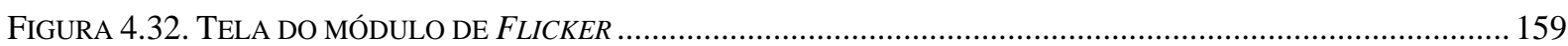

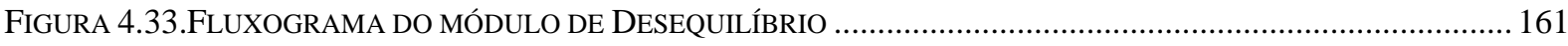

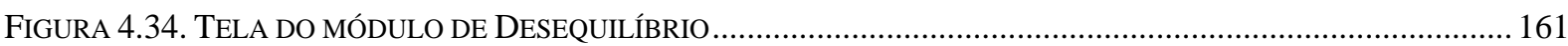


FigURA 4.35. FLUXOGRAMA DO MÓDULO DE TRANSITÓRIOS 162

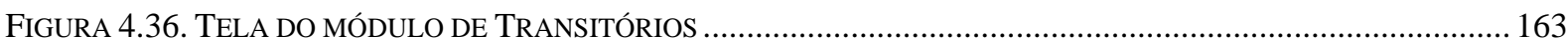

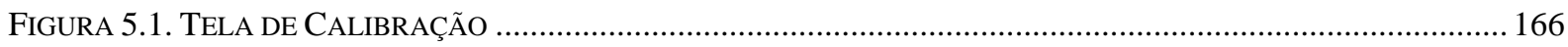

FIGURA 5.2. TELAS DE SIMULAÇÃO DO MÓDULO DE TENSÃO/CORRENTE/ENERGIA - CARGA LINEAR .....................167

FIGURA 5.3. TELA DE SIMULAÇÃO DO MÓDULO DE TENSÃO/CORRENTE/ENERGIA - CARGA NÃO-LINEAR...............168

FIGURA 5.4. TELAS DO SUBMÓDULO DE OSCILOSCÓPIO DURANTE A SIMULAÇÃO ............................................. 169

FIGURA 5.5. TELA DE SIMULAÇÃO MÓDULO VARIAÇÃO DE TENSÃO ........................................................... 171

FIGURA 5.6. RELATÓRIO DE SIMULAÇÃO DO MÓDULO DE VARIAÇÃO DE TENSÃO............................................. 171

FigURA 5.7. TELA DE SIMULAÇÃO MÓDULO FLUTUAÇÃO DE TENSÃO............................................................ 173

FigURA 5.8. RELATÓRIO DE SIMULAÇÃo DO MÓDULO DE FLUTUAÇÃo DE TENSÃO ...........................................173

FIGURA 5.9. DENSIDADE ESPECTRAL DE POTENCIAL DA CARGA LINEAR - GERADOR X PROTÓTIPO ....................... 175

FIGURA 5.10. DENSIDADE ESPECTRAL DE POTÊNCIA DA CARGA NÃO-LINEAR - GERADOR X PROTÓTIPO................175

FIGURA 5.11. TELA DE SIMULAÇÃO MÓDULO DE FREQÜÊNCIA................................................................. 178

FIGURA 5.12. RELATÓRIO DE SIMULAÇÃO DO MÓDULO DE FREQÜÊNCIA ….................................................... 178

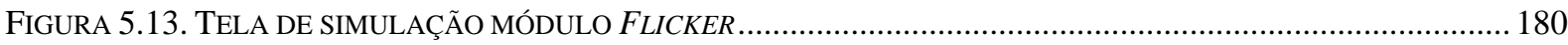

FIGURA 5.14. RELATÓRIO DE SIMULAÇão DO MÓDULO DE DESEQUILÍBRIO ..................................................... 181

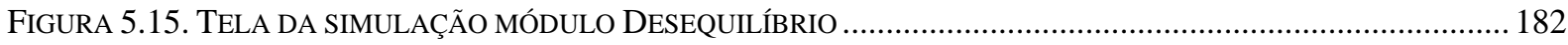

FIGURA 5.16. TENSÃO APLICADA DO PROTÓTIPO - MÓDULO DE TRANSITÓRIO ................................................. 183

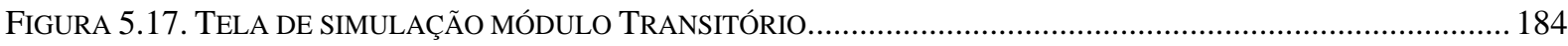

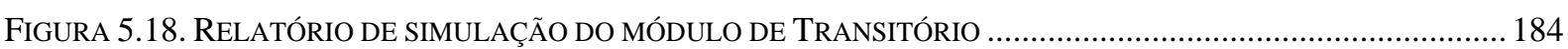

FIGURA 5.19. TELA DE SIMULAÇÃO DE ACEITAÇÃO PASSO 2 - MÓDULOS FREQÜÊNCIA E VARIAÇÃO .................... 186

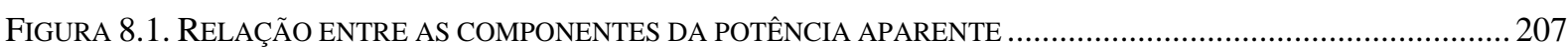

FIGURA 8.2. ESPECTRO DE POTÊNCIA DE UM SINAL RETANGULAR ...............................................................209 


\section{LISTA DE TABELAS}

TABela 1.1. Categoria E CARACTERÍsticas dos FenÔMENos Eletromagnéticos dos Sistemas de POTÊNCIA 29

TABELA 1.2. SEQÜÊNCIA DOS COMPONENTES HARMÔNICOS 40

TABELA 4.1. TABELA DE COMPATIBILIDADE ELETROMAGNÉTICA PARA EMISSÃO DE HARMÔNICOS 112

TABELA 4.2. LIMITES DE COMPONENTES HARMÔNICOS DE CORRENTE PARA EQUIPAMENTOS CLASSE A 116

TABELA 4.3. LIMITES DE COMPONENTES HARMÔNICOS DE CORRENTE PARA EQUIPAMENTOS CLASSE C 116

TABELA 4.4. LIMITES DE COMPONENTES HARMÔNICOS DE CORRENTE PARA EQUIPAMENTOS CLASSE D. 117

TABELA 5.1. ERRO ENTRE VALORES APLICADOS E MEDIDOS - MÓDULO TENSÃO / CORRENTE / ENERGIA 169

TABELA 5.2. VALORES DE TENSÃO APLICADOS AO - MÓDULO VARIAÇÃO DE TENSÃO..... 170

TABELA 5.3. ERRO ENTRE VALORES APLICADOS E VALORES REGISTRADOS - MÓDULO VARIAÇÃO DA TENSÃO ... 172

TABELA 5.4. VALORES DE TENSÃO APLICADOS AO PROTÓTIPO - MÓDULO FLUTUAÇÃO DE TENSÃO 172

TABELA 5.5. ERRO ENTRE VALORES APLICADOS E VALORES REGISTRADOS - MÓDULO FLUTUAÇÃO DE TENSÃO .174

TABELA 5.6. ERRO ENTRE MEDIÇÃO DO GERADOR E MEDIÇÃO DO PROTÓTIPO - MÓDULO DISTORÇÕES 176

TABELA 5.7. VALORES DE FREQÜÊNCIA APLICADOS AO PROTÓTIPO - MÓDULO FREQÜÊNCIA. 177

TABELA 5.8. ERRO ENTRE VALORES APLICADOS E VALORES MEDIDOS - MÓDULO FREQÜÊNCIA. 179

TABELA 5.9. VALORES PADRÕES DE TESTES DO MÓDULO FLICKER - CONFORME IEC 61000-4-15 . 179

TABELA 5.10. RESUltAdOS DOS VALORES DE PST PARA OS TESTES PADRÕES 180

TABELA 5.11. VALORES DE TENSÃO APLICAdOS E MEDIDOS - MÓDULO DESEQUiLÍBRIO DE TENSÃO. 181

TABELA 5.12. VALORES APLICADOS E MEDIDOS - TESTE DE VERIFICAÇÃO DE IMPLEMENTAÇÃO 185

TABELA 5.13. ERRO ENTRE VALORES APLICADOS E VALORES MEDIDOS - VERIFICAÇ̃̃O DA IMPLEMENTAÇÃO ... 186 


\section{SUMÁRIO}

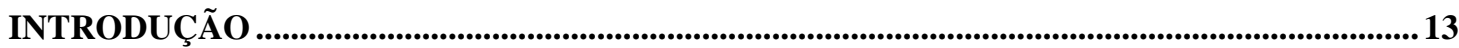

1. QUALIDADE DA ENERGIA ELÉTRICA (QEE)............................................................... 21

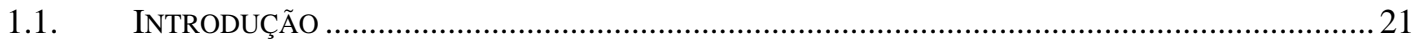

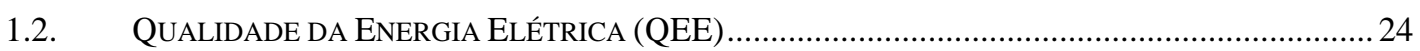

1.3. FENÔMENOS ELETROMAGNÉTICOS QUE CARACTERIZAM A QEE.............................................2

1.4. VISÃo NACIONAL SOBRE QUALIDADE DA ENERGIA ELÉTRICA .................................................. 49

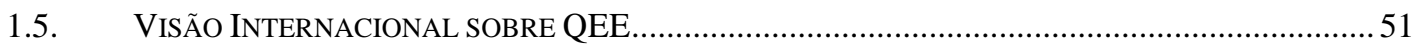

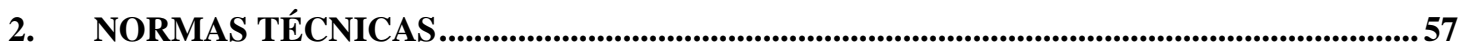

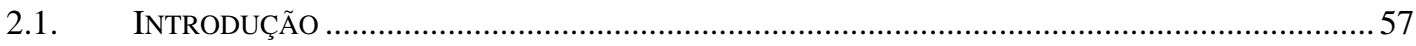

2.2. A IMPORTÂNCIA DA NORMATIZAÇÃO .............................................................................. 59

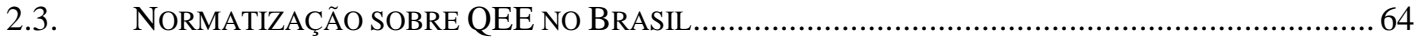

2.4. NORMATIZAÇÃo SOBRE QEE nOS DEMAis PAÍSES ........................................................ 86

3. NORMATIZAÇÃO INTERNACIONAL SOBRE QEE ............................................................. 95

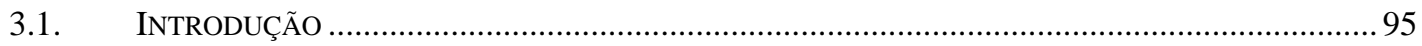

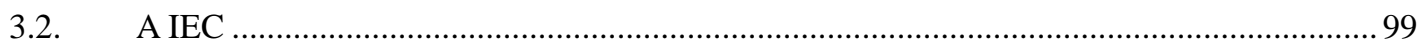

3.3. NORMAS DA IEC RELACIONADAS À QEE................................................................... 105

4. QUALÍMETRO BASEADO EM INSTRUMENTOS VIRTUAIS....................................... 109

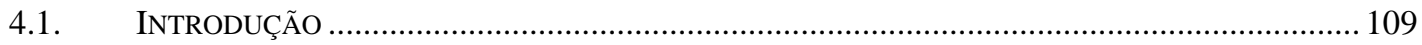

4.2. CONCEITO DAS NORMAS IEC RELACIONADAS À QEE ….................................................. 110

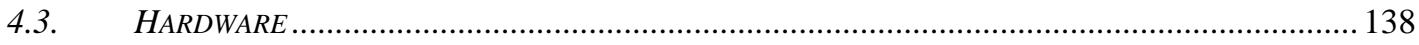

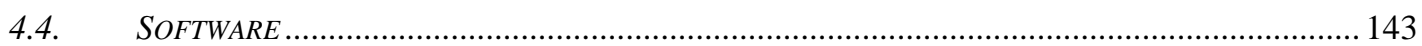

5. RESULTADOS EXPERIMENTAIS.................................................................................... 165

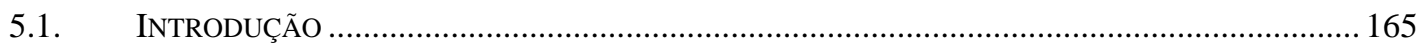

5.2. CONFIGURAÇÃO E CALIBRAÇÃO DO EQUIPAMENTO ...................................................... 165

5.3. SIMULAÇÃO NO MÓDULO DE TENSÃO / CORRENTE / ENERGIA .......................................... 167 
5.4. Simulação NO MódUlO VARIAÇão E FLUTUAÇão DE TENSÃO 170

5.5. SIMULAÇÃO NO MÓDULO DE DiSTORÇÕES DA FORMA DE ONDA ........................................174

5.6. SIMULAÇÃO NO MÓDULO DE FREQÜÊNCIA ................................................................. 177

5.7. SIMULAÇÃO NO MÓDULO DE FLICKER ....................................................................... 179

5.8. SimulaÇÃo NO MódUlO DE DESEQUILÍBRIO DE TENSÃo ................................................ 181

5.9. SiMULAÇÃO NO MÓDULO DE TRANSITÓRIO ................................................................... 183

5.10. TESTE DE VERIFICAÇÃO DE IMPLEMENTAÇÃO ............................................................. 185

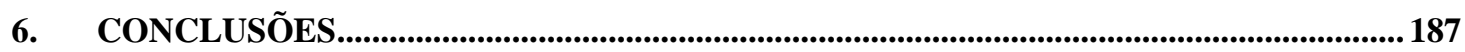

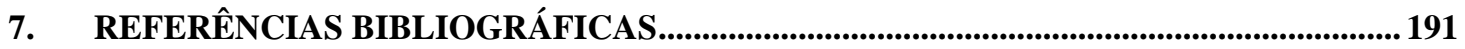

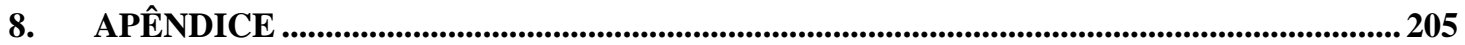

8.1. APÊNDICE A - GRANDEZAS DE DISTORÇÃO DA FORMA DE ONDA ...................................... 205 



\section{Introducão}

O principal interesse pela qualidade da energia elétrica, ou simplesmente QEE, está na procura do aumento da produtividade pelos consumidores. As indústrias buscam maquinários mais eficientes, rápidos e produtivos. As concessionárias de energia, por sua vez, encorajam estas medidas, de forma a propiciar aumento do fornecimento e conseqüente aumento nos lucros. Entretanto, os maquinários modernos utilizados na aceleração da produtividade e associados com a redução de perdas e aumento da eficiência, caracterizam-se por equipamentos mais sensíveis a falhas e distúrbios dos sistemas de potência. Ao mesmo tempo, o crescimento das economias e o aumento das condições de desenvolvimento humano trazem consigo uma tendência de crescimento na demanda de eletricidade. Afinal, pode-se dizer que o nível de consumo da energia elétrica está diretamente relacionado com o grau de desenvolvimento sócioeconômico de uma nação.

De fato, a incidência de distúrbios sobre os consumidores industriais resulta em grandes prejuízos, face aos elevados investimentos destinados às áreas de automação e modernização do parque industrial. Estas áreas, estruturadas com equipamentos constituídos essencialmente por componentes eletrônicos, são extremamente sensíveis aos efeitos de uma fonte de energia inadequada. Prejuízos enormes podem surgir, simplesmente com uma única e curta interrupção no fornecimento de energia, ou ainda com a presença de significativos níveis de distorções harmônicas e transitórios. 
Atualmente, os problemas de qualidade de energia tornaram-se habituais no vocabulário dos consumidores, preocupados com as possibilidades de queda na produção de seus insumos e por falha ou operação indevida de seus equipamentos elétricos. Dessa forma, o risco da diminuição da produtividade e do aumento das ocorrências de interrupções nas linhas de produção e nos setores de serviços em geral, apresenta-se como forte justificativa para a divulgação de metodologias e soluções adequadas ao tratamento da energia utilizada.

Desde os primórdios em que a energia elétrica foi colocada ao bem da humanidade, o suprimento e a manutenção de uma tensão puramente senoidal com amplitude e freqüência constantes, tem sido uma premissa a ser observada pelas concessionárias de energia elétrica.

O termo "Qualidade da Energia" inclui uma gama de fenômenos, abrangendo áreas de interesse de sistemas de energia elétrica, até problemas relacionados com a comunicação em redes de transmissão de dados. Dessa forma, devem ser divulgados e reconhecidos por todos os setores envolvidos com o consumo, transmissão e geração da energia elétrica. A interpretação destes fenômenos, principalmente as distorções de tensões e correntes, localizadas tanto nos PAC's (ponto de acoplamento comum) como também dentro das instalações dos próprios consumidores de energia, estão associadas diretamente à correção do fator de potência, racionalização da energia e aumento da produtividade.

Com o aumento das cargas não lineares no sistema elétrico, o problema da distorção harmônica tem se tornado cada vez mais significativo. Algumas medidas de conservação, tais como: a aplicação de inversores de freqüência para o controle da velocidade de motores, controladores de intensidade luminosa (dimmers), utilização de lâmpadas fluorescentes compactas com reatores eletrônicos, 
controladores de potência para chuveiros, entre outras, podem interferir na qualidade do sistema elétrico, de forma a aumentar as perdas e até causarem danos e prejuízo aos consumidores e à concessionária.

Os atuais programas de conservação de energia adotados pelas mais diversas empresas governamentais (Programa Nacional de Combate ao Desperdício de Energia Elétrica - PROCEL) e não governamentais (Energy Services Companies ESCOS e Consultorias em geral), são elaborados e executados considerando-se que o sistema elétrico de potência esteja trabalhando sob condições praticamente senoidais, com níveis de tensão e freqüência dentro de valores estabelecidos por normas. Desta forma, os problemas associados com a qualidade de energia elétrica não são levados em consideração.

A ocorrência destes problemas determina a necessidade de uma busca mútua de soluções, entre todas as partes que atuam no mercado de energia elétrica (as concessionárias, os consumidores, os fabricantes de equipamentos e os prestadores de serviço), para a realização de medidas práticas e econômicas. Todos estes estão cada vez mais preocupados com as características do suprimento elétrico e, o termo "Qualidade da Energia" tem se tornado a palavra chave no âmbito industrial dos últimos anos. Todavia, estes fenômenos não são necessariamente recentes e estão sendo atualmente analisados não mais como causas e efeitos isolados, mas como problemas correlacionados. Devido ao crescente interesse pelo tema, encontram-se definições distintas em função dos anseios e necessidades envolvidos no problema. Para as concessionárias de energia, a definição leva a uma equivalência com a confiabilidade do suprimento elétrico. Por sua vez, fabricantes de máquinas e equipamentos elétricos definem a qualidade do suprimento energético, a partir das características necessárias à fonte de alimentação, garantindo, sobretudo 
a operação adequada dos seus aparelhos. Quanto aos consumidores residenciais, estes não detêm conhecimento técnico para reconhecerem todos os distúrbios, entretanto, tornaram-se parte do problema em função do elevado número de aparelhos eletrônicos não-lineares instalados.

De fundamental importância é a questão cultural que envolve a utilização de energia elétrica. Nos países europeus, existe uma preocupação com o bem comum, e se paga até mais caro por uma "energia limpa". Em contrapartida, nas nações em desenvolvimento o apelo gira mais em torno da "economia" trazida pelo uso inteligente da energia, uma vez que a consciência ambiental ainda não é tão clara. Tanto nestes quanto naqueles países é imprescindível que os governos atuem no sentido de educar a população e também de incentivar instituições - a começar pelas públicas - a usar a energia de maneira eficiente.

Dentre as diversas definições sobre QEE, é notória a ausência de uma padronização comum. O que existem são muitos esclarecimentos e soluções para os diversos problemas dos sistemas elétricos.

Com isso, nestes últimos anos, tem se intensificado a investigação da qualidade de energia elétrica entre as empresas concessionárias de energia que aliadas às instituições de pesquisas, aos fabricantes de equipamentos e ainda aos consumidores, buscam minimizar os prejuízos causados pela baixa qualidade do suprimento de energia. Nessa nova realidade que o setor elétrico está entrando, baseada no mercado e na competição, a qualidade do produto eletricidade será determinante na busca de clientes que desejam ter suas expectativas de produtividade atendidas. Em geral, a investigação da qualidade de energia elétrica requer monitoração, tanto para identificar os problemas como para verificar as 
soluções implementadas que visem minimizar os efeitos danosos da má qualidade da onda de tensão ou corrente.

Devido ao crescente interesse mundial, sobre os problemas envolvendo o termo "Qualidade da Energia", as concessionárias estão desenvolvendo programas internos de forma a habilitar o pessoal técnico a responder aos anseios de seus clientes, promover uma maior divulgação do assunto e de certa forma, procurar soluções em conjunto com seus consumidores. Neste aspecto, é de extrema importância o incentivo ao desenvolvimento de novas instrumentações e ferramentas computacionais, que auxiliem na eliminação ou na atenuação destes fenômenos indesejáveis, junto ao suprimento de energia elétrica.

A medição da qualidade de energia elétrica surge, na atualidade, como um efetivo meio de obtenção de dados usados para caracterizar sistemas elétricos e solucionar os problemas vividos pelas cargas sensíveis à má qualidade de energia elétrica. Instrumentos de medição cada vez mais modernos, e desenvolvidos especificamente para a realização de medições de qualidade da energia, possibilitam o registro de uma grande variedade de fenômenos. Hoje em dia já é possível realizar essas medições de forma eficiente e confiável.

A crescente ocorrência de problemas causados pela má qualidade de energia, os respectivos prejuízos financeiros associados, bem como a perspectiva de surgimento de uma legislação regulamentando a questão, sugere um crescimento da necessidade de realização de medições dos fenômenos eletromagnéticos que envolvem a qualidade da energia elétrica.

Entretanto, a realização de uma medição de qualidade da energia, tem por característica própria requerer o conhecimento de múltiplos fatores envolvendo o sistema e os equipamentos. Estes aspectos relacionados com as metodologias de 
realização das medições encontram-se publicados de uma forma dispersa na literatura especializada.

As normas existentes mais conhecidas no mercado internacional que são adotadas pelas partes envolvidas no mercado de energia elétrica são a IEC 61000 e a IEEE 1159. Estas divergem em muitos parâmetros e procedimentos, mas focam a necessidade de se estabelecer padrões das grandezas do sistema elétrico para o bom funcionamento de todos os equipamentos. Em resumo, estas normas buscam o mesmo objetivo, complementando-se entre si. No mercado nacional existem estudos e a necessidade de se definir uma norma aplicável às necessidades do país, porém por ser um assunto complexo onde são muitas as necessidades das partes envolvidas e divergentes entre si, ainda não foi estabelecida esta norma.

Este trabalho apresenta os resultados da análise da literatura pertinente, com a finalidade da obtenção de um documento que sirva como fonte de informação sobre o assunto. Apresenta-se também uma proposta de um protótipo de um equipamento de medição dos fenômenos eletromagnéticos em faixa de freqüência até $9 \mathrm{kHz}$ envolvidos com a qualidade da energia utilizando-se o conceito de instrumentos virtuais através de software específico e que satisfaça as principais necessidades de medições padronizadas internacionalmente para análise de problemas relacionados com a QEE.

No capítulo 1 são abordados os fenômenos eletromagnéticos que caracterizam a qualidade da energia do ponto de vista dos especialistas e pesquisadores na área e as principais publicações teóricas relacionadas. É também apresentado a perspectiva do mercado nacional e internacional diante desta eminente necessidade. 
No segundo capítulo está apresentada a importância das normas e da normatização, principalmente para máquinas e equipamentos no mercado industrial nacional e internacional. Ainda neste capítulo é proporcionada uma apresentação sobre a normatização referente ao contexto de qualidade de energia no Brasil e demais países, evidenciando ainda mais a sua necessidade.

O capítulo 3 discorre sobre as normas européias de qualidade da energia. Especificamente é apresentada a International Electrotechnical Commission (IEC) e a sua contribuição para o setor elétrico. São apresentados também, os esforços da IEC para regulamentar a boa qualidade da energia elétrica e definir uma normatização específica para os equipamentos de medição dos fenômenos eletromagnéticos relacionados à QEE.

No capítulo 4 é abordada a importância da medição e do monitoramento da energia elétrica. Neste capítulo, também são apresentados os conceitos das normas escolhidas para o desenvolvimento do equipamento proposto e os fluxogramas de software de cada módulo elaborado, assim como uma apresentação em diagrama de blocos do hardware e software escolhidos para este medidor.

O capítulo 5 traz a simulação individual de cada módulo desenvolvido no protótipo do medidor. É visto nas tabelas existentes no decorrer deste capítulo o atendimento às exigências das normas da IEC, conforme as tolerâncias esperadas dos valores aplicados pelos valores medidos de cada resultado da simulação.

As conclusões e propostas para trabalhos futuros são apresentadas no capítulo 6. 


\section{Qualidade da Energia Elétrica (QEE)}

\subsection{Introdução}

Apesar dos inúmeros pensamentos e polêmicas sobre Qualidade da Energia no Brasil, pouco se define formalmente. Devido a uma falta de legislação no país sobre este assunto, os contratos de fornecimento de energia e fabricação de equipamentos não cumprem os padrões considerados suficientes pelos especialistas. Estes contratos também não obrigam as concessionárias e fabricantes a seguirem normas internacionais. Este é um problema sério, principalmente pela grande discussão da definição dos parâmetros a serem utilizados como suficientes para se garantir uma boa Qualidade da Energia Elétrica (QEE). Este capítulo tem como objetivo abordar questões importantes sobre este tema e ser fonte bibliográfica para futuras consultas.

Muito se tem lido em literatura especializada, sobre as vantagens e a necessidade da Qualidade da Energia Elétrica, escritos principalmente pelas pessoas que trabalham com elaboração de normas e pesquisadores desta área, explanando sobre as características da onda senoidal perfeita e algumas sugestões de definições de parâmetros para os problemas de Qualidade da Energia. No entanto, pouca literatura foi efetivamente publicada sobre a caracterização dos problemas de QEE gerada pelos fornecedores de energia, consumidores ou equipamentos específicos.

O conceito de Qualidade da Energia Elétrica relaciona-se a inúmeras variações que podem acontecer no sistema elétrico de potência. Uma definição 
considerada adequada por Dugan et al. (1996, p.3) e comumente adotada é "Qualquer problema manifestado na tensão, corrente ou desvio da freqüência que resulte em falha ou má operação de equipamentos elétricos dos consumidores".

Estes problemas são registrados em diversas áreas, do sistema de distribuição da energia às instalações elétricas nos consumidores. São também gerados pelos muitos equipamentos inseridos na rede de energia elétrica. Como causas comuns podemos exemplificar: partida de motores de grande potência, inclusão e retirada de unidades geradoras, manobra de banco de capacitores, chaveamento de cargas não-lineares, etc (GALAHARDO; PINHO, 2003).

O termo Qualidade da Energia Elétrica engloba qualquer variação que ocorra na magnitude, forma de onda ou freqüência da corrente ou tensão e aplica-se também às interrupções do fornecimento de energia que causam problemas na geração, distribuição e utilização da energia elétrica (CAMARGO, 2002).

Estes tipos de distúrbios elétricos vêm aumentando e se espalhando rapidamente por todo o mundo, causando perdas econômicas, por diversas razões das quais pode-se citar as duas principais:

- Aumento da instalação de cargas não-lineares

Com o aumento da conservação e racionalização da energia elétrica muitos equipamentos foram desenvolvidos para atender este mercado que, em sua grande maioria, aumentam os níveis de distorções na forma de onda da tensão (PHIPPS; NELSON; SEM, 1994). Na figura 1.1a (AFONSO, 2004) nota-se que o equipamento é linear, pois a amplitude de corrente aumenta com o aumento da amplitude da tensão. Já na figura 1.1b tem-se um equipamento 
não-linear, onde a amplitude da corrente não tem dependência direta com o aumento da tensão.

(a)
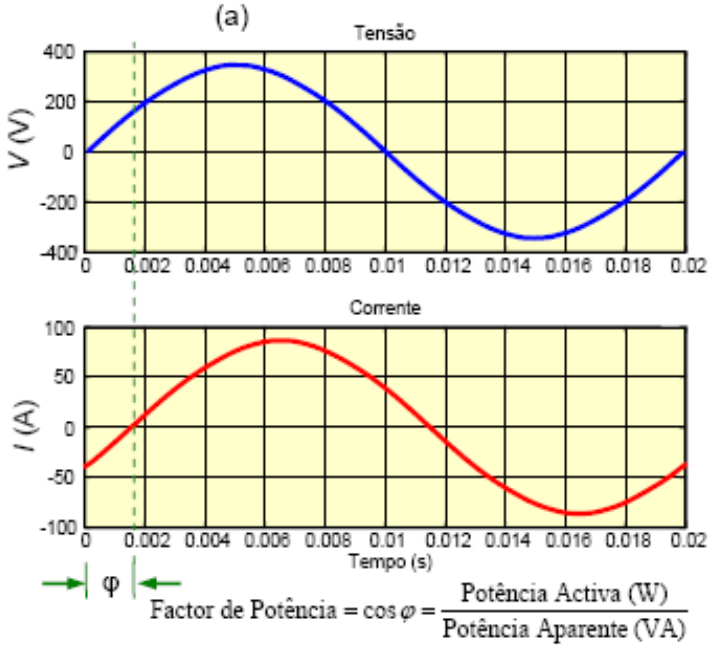

(b)
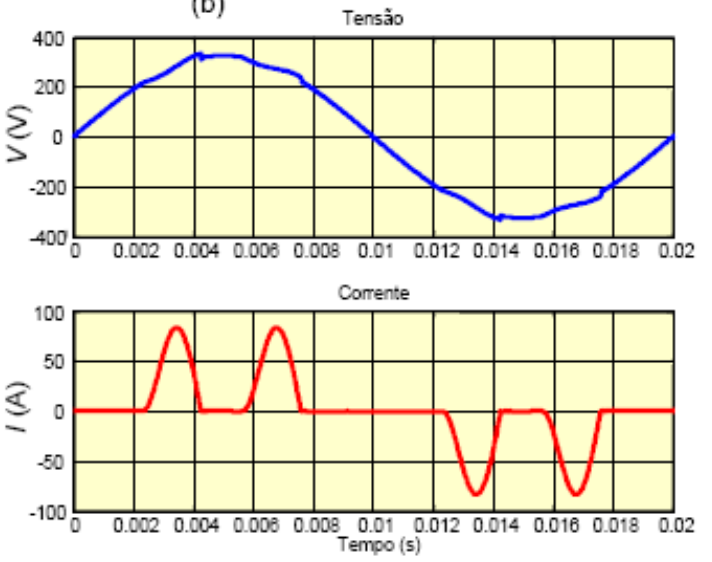

Figura 1.1. Onda de tensão e corrente para carga linear (a - esquerda) e não linear (b - direita)

- Aumento da sensibilidade dos equipamentos aos efeitos de distúrbios elétricos

Devido ao aumento de controles eletrônicos sensíveis aos diversos distúrbios estes equipamentos podem ser danificados por problemas na rede de alimentação (DUGAN et al., 1996).

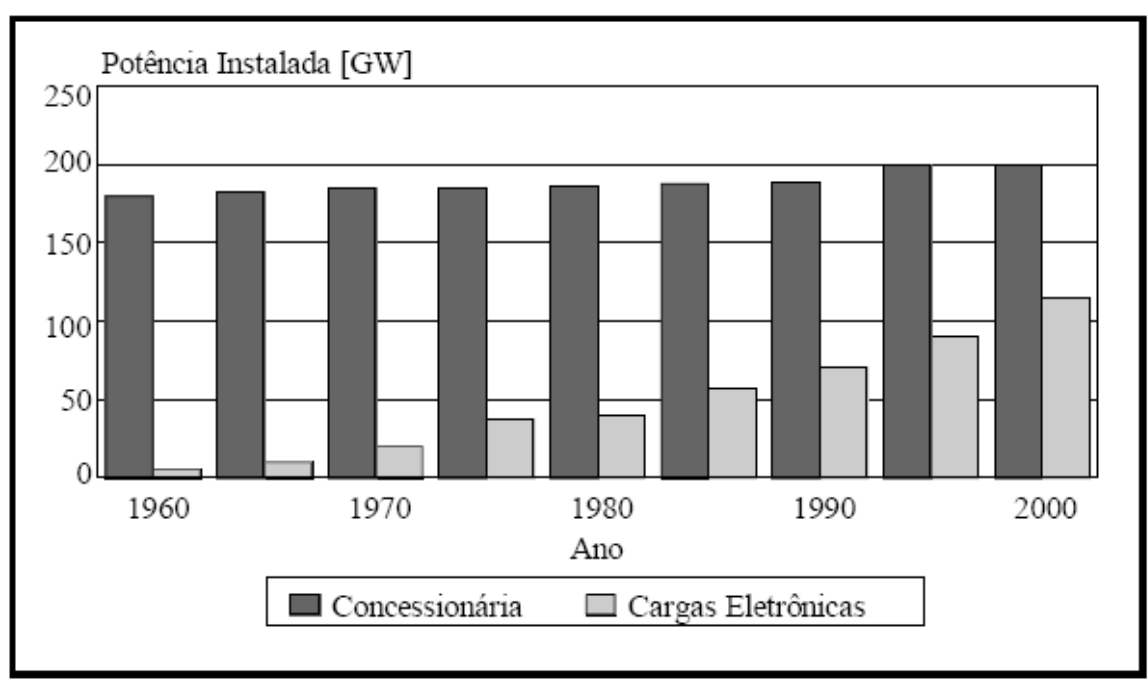

Figura 1.2. Crescimento das cargas eletrônicas 
A figura 1.2 apresenta o crescimento das cargas eletrônicas pela potência instalada no período de 1960 a 2000 nos EUA (SILVA; SOUZA; MACHADO, 2004).

Em diversas atividades os impactos econômicos da má qualidade da energia elétrica são gigantescos. Estes impactos são maiores principalmente nas indústrias de produção contínua onde a parada de uma máquina gera um gargalo na fabricação e compromete todo o processo de manufatura. Nestes ramos industriais uma interrupção de alguns segundos pode levar a prejuízos financeiros enormes. Levando em consideração o potencial destes possíveis prejuízos torna-se evidente a necessidade da análise e diagnóstico da qualidade da energia elétrica, com a finalidade de especificar as causas e as conseqüências dos problemas no sistema elétrico, apresentando também soluções técnicas viáveis economicamente para resolver ou pelo menos amenizar os problemas e seus impactos (OLESKOVICZ, 2006).

\subsection{Qualidade da Energia Elétrica (QEE)}

Apesar do contexto Qualidade da Energia Elétrica ser de difícil definição e parametrização, existe uma grande preocupação pelos consumidores, fabricantes de equipamentos e concessionárias em garantir que a energia elétrica seja recebida e utilizada da forma mais eficiente possível e que os equipamentos que a utilizem funcionem adequadamente para o fim ao qual são empregados. Tecnicamente este assunto está sendo abordado em caráter internacional emergencial. Segundo Oleskovicz (2006) e Silveira (2002), isto fundamenta-se pelos seguintes motivos: 
- A grande maioria dos aparelhos modernos têm controles microprocessados e/ou unidades eletrônicas de potência tornando-os mais sensíveis às variações de energia que os equipamentos mais robustos de antigamente.

- Com a necessidade de racionalização da energia e consequentemente o aumento da eficiência dos sistemas elétricos no mercado internacional, houve um grande incremento de equipamentos que implicam na elevação da magnitude dos componentes harmônicos das redes elétricas, que por sua vez implicam em um aumento da preocupação dos problemas gerados por estes índices cada vez mais elevados.

- Como, cada vez mais, os consumidores estão bem informados sobre o assunto da QEE e consequentemente o aumento de interesse sobre os temas interrupção, descargas elétricas, transitórios, etc., estes estão questionando as concessionárias sobre a qualidade da energia entregue. Os consumidores estão também, selecionando no mercado, os equipamentos com melhores características construtivas e funcionais que venham a se encaixar nos padrões sugeridos como aceitáveis em relação à QEE.

- Com o evidente aumento das redes de comunicação distribuídas em todas as áreas industriais, fica claro a necessidade de transações comerciais sem interrupção e a continuidade dos processos de fabricação. Indústria e comércio estão cada vez mais sensíveis às perdas de produção por interrupções de energia. 
- O fornecimento de energia, atualmente definido como produto, tem alguns parâmetros que devem ser medidos, garantidos, melhorados, etc.

- As responsabilidades referentes à qualidade de energia, que compete a cada membro do setor elétrico, não estão definidas.

Cada vez mais na indústria moderna, os equipamentos utilizados estão mais sensíveis às oscilações do fornecimento de energia elétrica. Muitos dos equipamentos utilizados acabam gerando distúrbios na rede. Estes distúrbios causam grandes problemas às concessionárias e consequentemente grandes prejuízos às indústrias, pois devido ao aumento da aplicação destes equipamentos, a deformação da forma de onda senoidal da tensão aumentou consideravelmente, levando à perda da qualidade da energia elétrica (ARRILLAGA et al., 1997).

Com a crescente competitividade entre os fabricantes de dispositivos elétricos, é explícita a necessidade dos custos de fabricação destes equipamentos serem cada vez mais reduzidos. Com base nisto, não há interesse em desenvolver produtos que sejam robustos aos distúrbios gerados na rede de alimentação elétrica, sem que haja a solicitação do consumidor. Muitos outros fabricantes desconhecem as variações das grandezas da rede elétrica ou simplesmente ignoram seus efeitos, alegando que as possíveis falhas dos seus equipamentos provêem dos distúrbios gerados na rede elétrica pela concessionária e/ou da má utilização ou instalação (SILVEIRA, 2002).

Segundo Arrillaga et al. (1997) muitos dos fenômenos da má qualidade de energia são originados nas próprias empresas consumidoras. As causas destas variações são, em alguns casos, desconhecidas, não são avaliadas devidamente ou 
estão fora do controle das indústrias. Estas causas são distintas e definidas como ação da natureza, causas aleatórias e má operação dos equipamentos. Como exemplo de causas que sofrem ação da natureza, podemos citar: tempestades, contato de animais, descargas atmosféricas, fortes ventos, inundações, etc. Exemplos de causas aleatórias podem ser: acidentes nas instalações, faltas nos equipamentos, sobrecargas em dispositivos, dentre outras. Para as causas devidas às operações normais da empresa cita-se: geração de harmônicos por utilização de equipamentos com cargas não-lineares, manobra de grandes cargas ou banco de capacitores, partidas de grandes motores, atividades de manutenção mal elaboradas (MARAFÃO, 2004).

A responsabilidade do fornecimento e manutenção da energia elétrica considerada dentro dos parâmetros de utilização dos diversos equipamentos elétricos, depende da consciência de todos os setores que fazem parte do sistema elétrico geral e necessitam de uma análise constante e detalhada da existência de todas as variações que possam ocorrer. Deve-se observar, então, que as soluções para uma boa QEE somente serão alcançadas quando as concessionárias, fabricantes de equipamentos e consumidores conscientizarem-se da necessidade do entendimento mútuo para este fim.

\subsection{Fenômenos Eletromagnéticos que caracterizam a QEE}

A forma de onda ideal para todos os usuários dos sistemas de energia elétrica em corrente alternada são ondas de tensão senoidais perfeitas com amplitudes e freqüências constantes. As normas vigentes estabelecem parâmetros para muitas 
das grandezas e distúrbios envolvidos, onde uma ocorrência fora destes limites implica em um problema na qualidade de energia. Portanto seguindo este conceito, a qualidade de energia pode ser compreendida como a ausência de variações na onda de tensão (MCGRANAGHAN, 2002).

Os distúrbios e variações apresentados nas ondas de alimentação das máquinas, dispositivos e equipamentos podem ocorrer de várias formas e apresentar diversos significados. A International Electrical Commission (IEC) vem liderando os principais grupos no sentido de definir as normas de qualidade de energia em conjunto com o Institute of Electrical and Electronics Engineers (IEEE).

Dugan et al.(1996), apresentou termos, conceitos e definições baseados na IEC e IEEE e condizentes com a maioria dos termos aceitos pelos mais conceituados pesquisadores no assunto. Nestes termos, conceitos e definições está baseada toda a explicação deste item, quando não citado autor específico.

A tabela 1.1 (DUGAN et al., 1996), mostra a caracterização dos fenômenos eletromagnéticos em função da duração e magnitude (IEEE100-1992, 1992), referente aos problemas relacionados à qualidade da energia elétrica. 


\begin{tabular}{|c|c|c|c|}
\hline Categoria & $\begin{array}{c}\text { Conteúdo Espectral } \\
\text { Típico }\end{array}$ & Duração Típica & $\begin{array}{l}\text { Magnitude de } \\
\text { Tensão Típica }\end{array}$ \\
\hline \multicolumn{4}{|l|}{1 Transitórios } \\
\hline \multicolumn{4}{|l|}{1.1 Impulsivo } \\
\hline 1.1.1 Nanosegundos & acima de $5 \mathrm{~ns}$ & $<50 \mathrm{~ns}$ & \\
\hline 1.1.2 Microsegundos & acima de $1 \mu \mathrm{s}$ & $50 \mathrm{~ns}-1 \mathrm{~ms}$ & \\
\hline 1.1.3 Milisegundos & acima de $0,1 \mathrm{~ms}$ & $>1 \mathrm{~ms}$ & \\
\hline \multicolumn{4}{|l|}{ 1.2 Oscilatório } \\
\hline 1.2.1 Baixa Freqüência & $<5 \mathrm{KHz}$ & $0,3-50 \mathrm{~ms}$ & $0-4$ p.u. \\
\hline 1.2.2 Média Freqüência & $5-500 \mathrm{KHz}$ & $20 \mu \mathrm{s}$ & 0 - 8 p.u. \\
\hline 1.2.3 Alta Freqüência & $0,5-5 \mathrm{MHz}$ & $5 \mu \mathrm{s}$ & $0-4$ p.u. \\
\hline \multicolumn{4}{|l|}{2 Variação de Curta Duração } \\
\hline \multicolumn{4}{|l|}{2.1 Instantâneas } \\
\hline 2.1.1 Interrupção & & $0,5-30$ ciclos & $<0,1$ p.u. \\
\hline 2.1.2 Afundamentos & & $0,5-30$ ciclos & $0,1-0,9$ p.u. \\
\hline 2.1.3 Elevações & & $0,5-30$ ciclos & 1,1 - 1,8 p.u. \\
\hline \multicolumn{4}{|l|}{ 2.2 Momentânea } \\
\hline 2.1.1 Interrupção & & 30 ciclos $-3 s$ & $<0,1$ p.u. \\
\hline 2.1.2 Afundamentos & & 30 ciclos $-3 s$ & $0,1-0,9$ p.u. \\
\hline 2.1.3 Elevações & & 30 ciclos $-3 s$ & 1,1 - 1,4 p.u. \\
\hline \multicolumn{4}{|l|}{ 2.3 Temporária } \\
\hline 2.1.1 Interrupção & & $3 s-1 \mathrm{~min}$ & $<0,1$ p.u. \\
\hline 2.1.2 Afundamentos & & $3 s-1 \min$ & $0,1-0,9$ p.u. \\
\hline 2.1.3 Elevações & & $3 s-1 \min$ & 1,1 - 1,2 p.u. \\
\hline \multicolumn{4}{|l|}{3 Variação de Longa Duração } \\
\hline 3.1 Interrupção Sustentada & & $>1 \min$ & 0 p.u. \\
\hline 3.2 Subtensão & & $>1 \min$ & $0,8-0,9$ p.u. \\
\hline 3.3 Sobretensão & & $>1 \min$ & 1,1 - 1,2 p.u. \\
\hline 4 Desequilíbrio de Tensão & & Regime Permanente & $0,5-2 \%$ \\
\hline \multicolumn{4}{|l|}{5 Distorção da Forma de Onda } \\
\hline 5.1 Nível CC & & Regime Permanente & $0-0,1 \%$ \\
\hline 5.2 Harmônicos & 0 - $100^{a}$ harmônica & Regime Permanente & $0-20 \%$ \\
\hline 5.3 Interharmônicos & $0-6 \mathrm{KHz}$ & Regime Permanente & $0-2 \%$ \\
\hline 5.4 Recortes & & Regime Permanente & \\
\hline 5.5 Ruídos & Banda Freqüências Largas & Regime Permanente & $0-1 \%$ \\
\hline 6 Flutuação de Tensão & $<25 \mathrm{~Hz}$ & Intermitente & $0.1-7 \%$ \\
\hline 7 Variação da Freqüência & & $<10 \mathrm{~s}$ & \\
\hline
\end{tabular}

Tabela 1.1. Categoria e Características dos Fenômenos Eletromagnéticos dos Sistemas de Potência 
Conforme Dugan et al. (1996) os fenômenos da tabela 1.1 podem ser descritos e avaliados através de alguns parâmetros específicos. Os de regime permanente podem ser descritos por:

- Amplitude

- Freqüência

- Espectro

- Modulação

- Impedância da Fonte

- Amplitude de corte

- Área de corte

Os fenômenos que não estão em regime permanente podem ser descritos por:

- Taxa de Avanço

- Amplitude

- Duração

- Espectro

- Freqüência

- Taxa de Ocorrências

- Energia Potencial

- Impedância

As categorias da tabela 1.1 quando descritas pelos parâmetros acima dão um significado muito claro do distúrbio eletromagnético em questão. Este conjunto de categorias e características são os mais utilizados para classificar as medidas e resultados e descrever os fenômenos que causam os problemas de qualidade da energia. 


\subsubsection{Transitórios}

O termo transitório refere-se às variações no sistema elétrico relacionadas a eventos repentinos e de natureza momentânea que atuam sobre as ondas de tensão e corrente.

Os transitórios podem ser divididos em duas categorias: impulsivos e oscilatórios.

\section{Transitório Impulsivo}

O transitório impulsivo é caracterizado por uma brusca mudança nas condições de regime permanente da onda de tensão, por um curto pulso unidirecional estreito de amplitude considerável podendo ser de polaridade negativa ou positiva, como exemplo da figura 1.3.

A existência de impulsos transitórios indesejáveis tem como causa principal as descargas atmosféricas.

Os impulsos transitórios são divididos dependendo do período de duração em: nanosegundos, microsegundos ou milisegundos, conforme tabela 1.1.

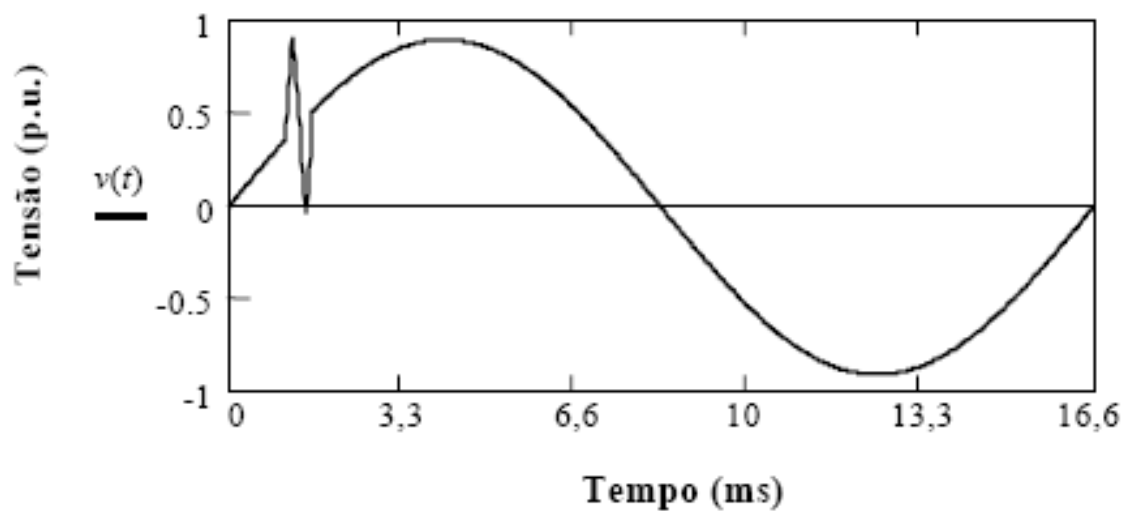

Figura 1.3. Transitório impulsivo em p.u. 


\section{$\underline{\text { Transitório Oscilatório }}$}

Um transitório oscilatório é uma rápida mudança nas condições de regime permanente da onda de tensão, por uma onda que contenha as duas polaridades e alternam suas amplitudes rapidamente (negativa e positiva). Um exemplo de transitório oscilatório pode ser visto na figura 1.4 .

Os transitórios oscilatórios são caracterizados principalmente pela variação da polaridade e podem ser divididos em: alta freqüência, média freqüência e baixa freqüência conforme definido na tabela 1.1.

Estes tipos de oscilações são comumente gerados na energização, desligamento ou chaveamento de banco de capacitores, transformadores e sistemas de distribuições.

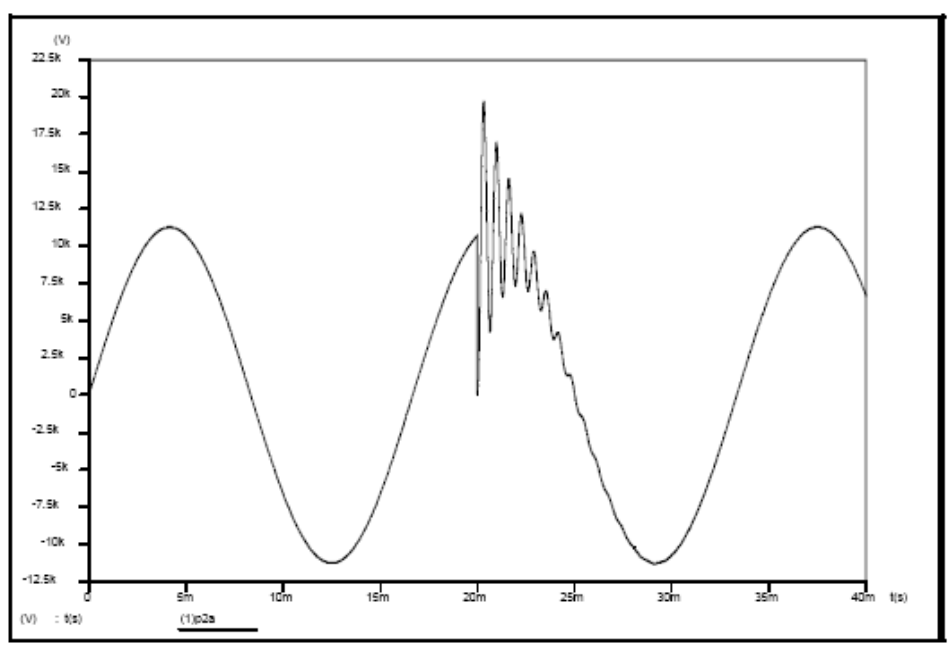

Figura 1.4. Transitório oscilatório devido ao chaveamento de um banco de capacitores 


\subsubsection{Variações de Longa Duração}

As variações de longa duração abrangem os desvios na onda de tensão por um período maior que um minuto, ocorrendo geralmente em regime permanente.

Variações de longa duração são subdivididas e classificadas em sobretensão, subtensão e interrupção sustentada.

\section{Sobretensões}

Sobretensão pode ser apontada como o aumento no valor eficaz da tensão em corrente alternada, maior que $110 \%$ na freqüência do sistema e de duração maior que um minuto, conforme tabela 1.1.

Estas são normalmente causadas por chaveamento de cargas, desligamento de grandes cargas, taps de transformadores de distribuição selecionados incorretamente, etc.

\section{$\underline{\text { Subtensões }}$}

A subtensão apresenta características contrárias à sobretensão, podendo ser caracterizada pelo decréscimo no valor eficaz da tensão de corrente alternada, menor que $90 \%$ na freqüência do sistema e de duração maior que um minuto, conforme tabela 1.1.

Estas são causadas principalmente pelo carregamento excessivo de circuitos alimentadores devido às quedas de tensões inerentes ao sistema, chaveamento de bancos de capacitores, sobrecargas de alguns equipamentos e excesso de reativo conduzido por este sistema. 


\section{$\underline{\text { Interrupções Sustentadas }}$}

Quando a tensão permanece com seu valor eficaz em zero por um período de tempo maior que um minuto, a variação de tensão de longa duração é caracterizada como interrupção sustentada, conforme definido na tabela 1.1.

Segundo Oleskovicz (2006), as interrupções sustentadas podem ser de natureza planejada ou inesperada. A primeira, interrupção sustentada planejada, vem das manutenções preventivas no sistema de distribuição ou de manobras complexas para transferência de fonte de alimentação. As interrupções sustentadas inesperadas são provenientes de falhas em disjuntores, sobrecargas no sistema, queima de fusíveis, etc.

\subsubsection{Variações de Curta Duração}

As Variações de Curta Duração englobam os desvios na onda de tensão por períodos menores ou iguais a um minuto.

Variações de curta duração são comumente causadas por manobras, falhas ou faltas em grandes cargas, que normalmente apresentam uma alta corrente. Dependendo da ocorrência causada no sistema elétrico, as variações de curta duração são separadas em afundamentos de tensão (sags ou dips), elevações de tensão (swell) ou interrupções de tensão. 


\section{Afundamentos de Tensão (Sags ou Dips)}

O conceito de afundamento de tensão é a diminuição da tensão eficaz variando entre 0,1 a 0,9 p.u. de amplitude e com duração entre meio ciclo a um minuto, como o exemplo da figura 1.5 .

As causas mais prováveis para afundamentos de tensão são faltas no sistema e manobras de grandes cargas, sendo a principal causa deste fenômeno a partida de grandes motores.

Os afundamentos de tensão são divididos em 3 categorias: instantâneo, momentâneo e temporário, conforme suas durações descritas na tabela 1.1.

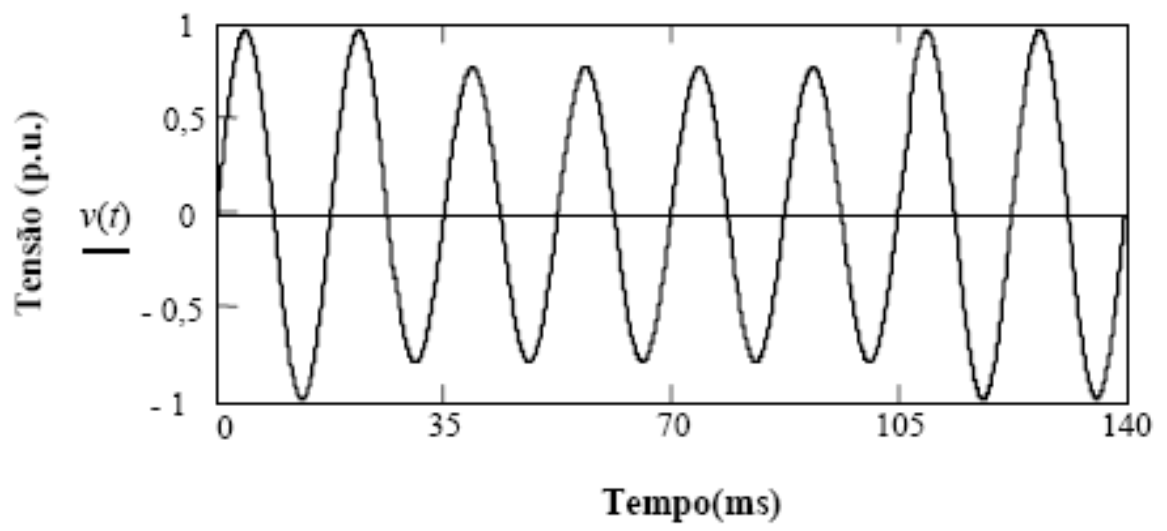

Figura 1.5. Afundamento de tensão de 0,8 p.u.

\section{Elevações de Tensão (Swells)}

O conceito de elevação da tensão é o aumento da tensão variando entre 1,1 e 1,8 p.u. de amplitude com duração entre meio ciclo a um minuto, como pode-se observar no exemplo da figura 1.6. 
As elevações de tensão são comumente causadas por desligamentos de grande cargas, energização de bancos de capacitores e faltas fase-terra.

Elevações de tensão também são divididos em 3 categorias: instantâneo, momentâneo e temporário, conforme suas durações descritas na tabela 1.1.

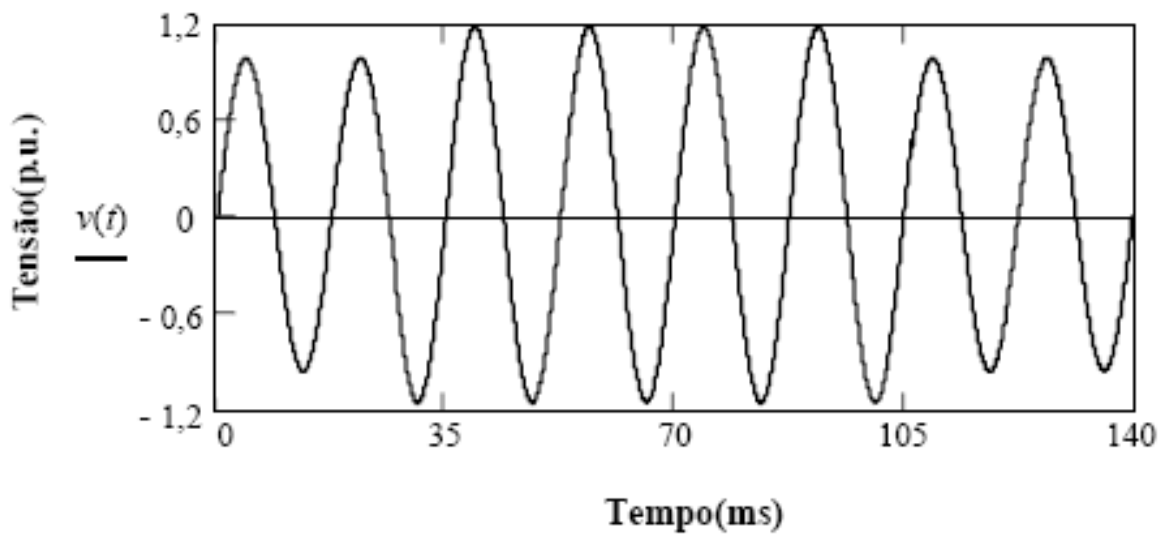

Figura 1.6. Elevação de tensão de 1,2 p.u.

\section{Interrupções}

Considera-se interrupção quando o suprimento de tensão ou corrente de carga diminuem para valores menores que 0,1 p.u. por um período menor ou igual a um minuto, como pode-se verificar no exemplo da figura 1.7.

Interrupções podem também ser classificadas como instantâneas, momentâneas e temporárias, conforme suas durações definidas na tabela 1.1.

Interrupções são resultado de faltas em sistemas de distribuição, falhas em equipamentos ou má operação de equipamentos. Normalmente a duração de uma interrupção é determinada pelo tempo de operação dos dispositivos de proteção utilizados. 


\section{Iensáo na fase B - amplïhude}

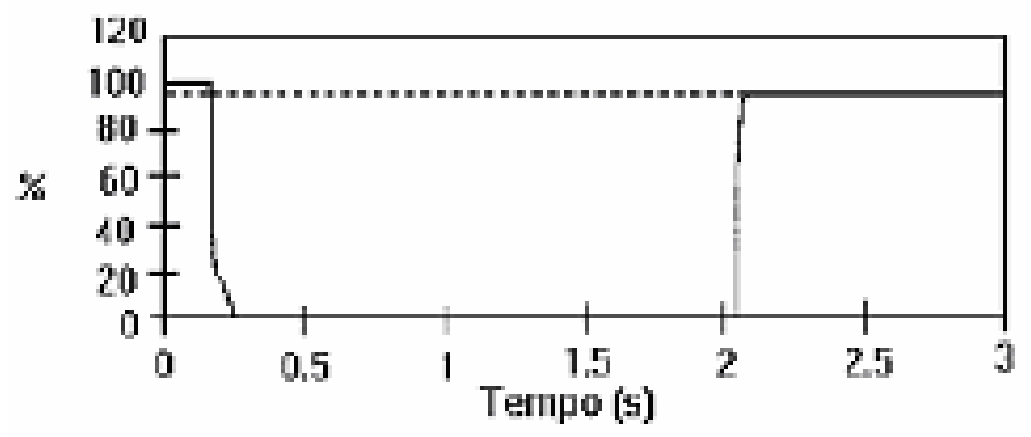

Figura 1.7. Interrupção de curta duração devido a um curto-circuito

\subsubsection{Desequilíbrio de Tensão}

Desequilíbrio de tensão é definido como o desvio máximo da média das tensões, dividido pela média das tensões das três fases, expresso em porcentagem, conforme equação 1.1. Um exemplo de desequilíbrio de tensão pode ser observado na figura 1.8.

O desequilíbrio de tensão pode ser mais rigorosamente definido pela teoria dos componentes simétricos, onde a razão entre os componentes de seqüência negativa ou zero sobre o componente de seqüência positiva é utilizado para expressar o desequilíbrio em percentual, conforme equações 1.2 e 1.3 (CORREIA; BRONZEADO, 2001).

Desequilíbrio de Tensão $=\left(\frac{\left|v_{\text {fases }_{\text {rms }}}-v_{\text {media }}\right|}{v_{\text {media }}}\right) \times 100 \quad[\%]$

Desequilibrio Tensão Negativo $=\left(\frac{\text { comp. sequência negativa }}{\text { comp. sequência positiva }}\right) \times 100 \quad[\%]$ 
Desequilíbrio Tensão Zero $=\left(\frac{\text { comp. sequência zero }}{\text { comp. sequência positiva }}\right) \times 100 \quad[\%]$

Desequilíbrios de tensão são caracterizados por variações entre 0,5 a $2 \%$ em regime permanente, como pode ser observado na tabela 1.1.

A principal fonte causadora dos desequilíbrios de tensão são as cargas monofásicas mal distribuídas no sistema de distribuição.

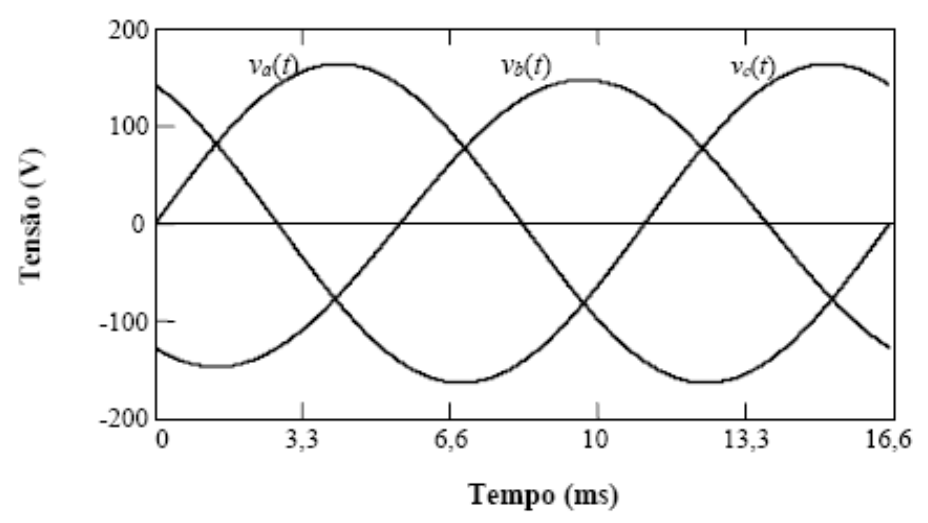

Figura 1.8. Desequilíbrio na fase $B$ de $2 \%$ (125Vrms enquanto $A$ e $C=127 \mathrm{Vrms})$

\subsubsection{Distorções na Forma de Onda}

A definição de distorção na forma de onda é o desvio em regime permanente de uma forma de onda senoidal considerada ideal, principalmente caracterizada pelo conteúdo espectral do desvio.

Conforme definido na tabela 1.1 , as distorções da forma de onda são divididas em: 
- Nível CC

- Harmônicos

- Interharmônicos

- Recortes (notching)

- Ruídos (noise)

\section{Nível CC}

Nível CC é descrito como a presença de componentes de tensão em corrente contínua (CC) em um sistema de energia de corrente alternada (CA).

Dentre vários tipos de problemas gerados pela presença de um componente CC em uma rede CA estão a saturação de transformadores, resultando em perdas e redução de sua vida útil e a corrosão eletrolítica dos eletrodos e conectores de aterramento.

\section{Harmônicos}

Harmônicos são componentes de tensão periódicos com freqüência múltipla inteira da freqüência do suprimento de energia. A freqüência da forma de onda do sistema de suprimento de energia é chamada de freqüência fundamental, usualmente $50 \mathrm{~Hz}$ ou $60 \mathrm{~Hz}$.

A classificação dos harmônicos é feita pela sua ordem, ou seja, o múltiplo da freqüência fundamental. Considerando $60 \mathrm{~Hz}$ como a freqüência fundamental a tabela 1.2 apresenta a divisão de harmônicos até o $10^{\circ}$ harmônico. 


\begin{tabular}{|c|c|}
\hline Ordem & Frequiência $(\mathrm{Hz})$ \\
\hline $1^{\circ}$ - Fundamental & 60 \\
\hline $2^{\circ}$ & 120 \\
\hline $3^{\circ}$ & 180 \\
\hline $4^{\circ}$ & 240 \\
\hline $5^{\circ}$ & 300 \\
\hline $6^{\circ}$ & 360 \\
\hline $7^{\circ}$ & 420 \\
\hline $8^{\circ}$ & 480 \\
\hline $9^{\circ}$ & 540 \\
\hline $10^{\circ}$ & 600 \\
\hline
\end{tabular}

Tabela 1.2. Seqüência dos componentes harmônicos

A somatória dos componentes senoidais harmônicos com o componente senoidal fundamental resulta em uma onda não-senoidal distorcida, conforme podese observar na figura 1.9.

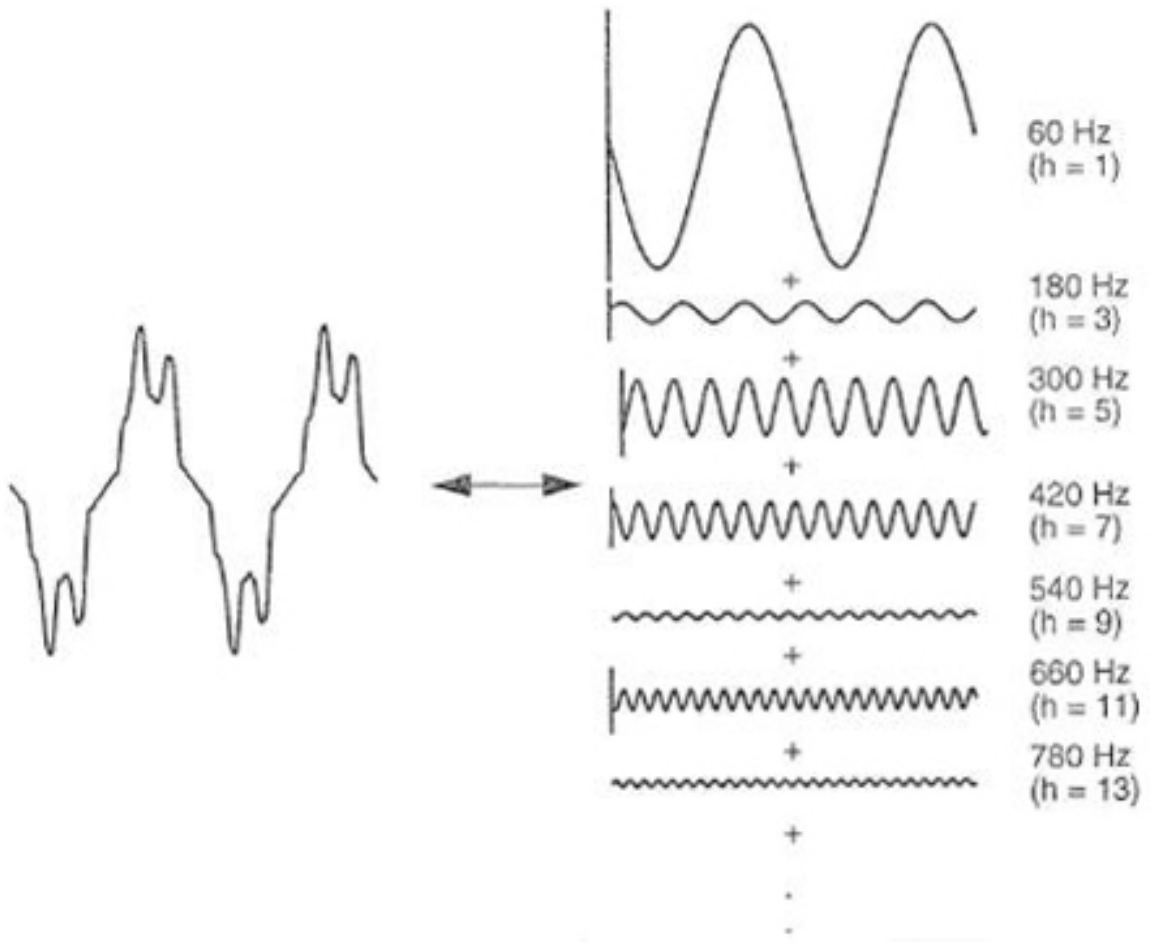

Figura 1.9. Representação da Série de Fourier para uma onda distorcida 
Estas distorções podem ser comumente geradas pela grande quantidade de cargas não-lineares e outros dispositivos eletrônicos existentes nas plantas industriais (IEEE519-1992, 1992). Conforme Ainsworth (1967), Phadke e Harlow (1968) e Bowles (1970), nas décadas anteriores a 1970 a maioria das cargas elétricas utilizadas eram cargas lineares com valor de impedância fixo (cargas de aquecimento, motores sem controle de velocidade, iluminação incandescente).

Porém, após este período, a quantidade de cargas não-lineares cresceu continuamente, tendo assim uma grande contribuição para o aumento de distorções harmônicas no sistema de distribuição de energia. Como exemplo, pode-se citar as máquinas de solda, conversores CA/CA, fontes chaveadas de computadores ou outros equipamentos de escritórios ou eletrodomésticos, no-breaks, etc.

No exemplo da figura 1.10a podemos observar uma tensão e corrente linearmente dependentes, ou seja, uma carga linear. Na figura 1.10b temos uma tensão senoidal e uma corrente não-senoidal linearmente independente, assim sendo uma carga não-linear.
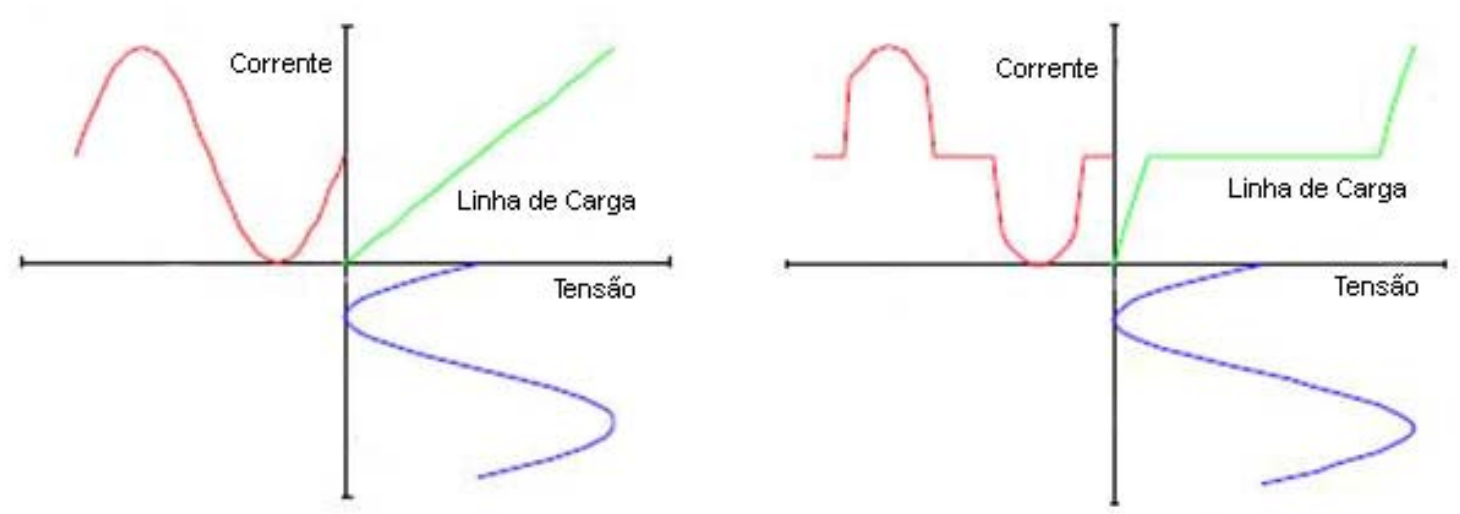

Figura 1.10. Carga Linear (a - direita) e Carga Não-linear (b - esquerda) 
Grandes níveis de distorções harmônicas causam problemas tanto para as redes de distribuição das concessionárias quanto para os consumidores (SHIPP, 1979). As conseqüências destes problemas são muitas, desde falhas em motores ou fontes de pequeno porte até a parada de grandes equipamentos, resultando em perdas de produtividade e de vendas. Segundo Oleskvicz (2006), os principais impactos das distorções harmônicas são erros nos relés de proteção, perdas Joule nos condutores dos alimentadores elétricos, sobrecarga no condutor de neutro pela soma dos harmônicos de $3^{a}$ ordem gerados pelas cargas monofásicas, redução da vida útil de transformadores, motores e capacitores, perturbações nas redes de comunicação,etc.

Conforme Schneider Electric (2002), os indicadores apresentados abaixo, indispensáveis para determinação das ações corretivas, permitem quantificar e avaliar a distorção harmônica de ondas de tensão e corrente, e são divididos em:

- Fator de potência

- Fator de crista

- Potência de distorção

- Espectro em freqüência

- Taxa de distorção harmônica

O apêndice do capítulo 8 traz informações adicionais sobre as grandezas citadas acima.

\section{Efeitos da Poluição Harmônica}

Segundo Dugan et al. (1996) e Oleskovicz (2006), a poluição harmônica, além da distorção na forma de onda, gera inúmeros problemas nos equipamentos, 
componentes, dispositivos e alimentadores no sistema elétrico. Alguns exemplos das desvantagens de uma distorção harmônica elevada podem ser citados:

- Redução da vida útil das máquinas rotativas: aquecimento, torques pulsantes, ruído, etc;

- Redução da vida útil das lâmpadas: flutuação da potência e consequentemente da intensidade luminosa;

- Erros nos medidores de energia elétrica e equipamentos de medição;

- Má operação de relés e equipamentos de proteção elétrica;

- Redução da vida útil de transformadores: aumento das perdas por aquecimento, saturação, ressonâncias, vibrações, etc;

- Má operação de dispositivos controlados por semicondutores disparos indevidos;

- Redução da vida útil de capacitores: aumento das perdas por aquecimento;

- Interferências eletromagnéticas nos equipamentos de comunicação e controle;

- Aumento das perdas nos alimentadores elétricos.

\section{Interharmônicos}

A definição de harmônicos segundo a teoria de Fourier é que uma onda periódica pode ser expressa pela soma de ondas senoidais puras de diferentes amplitudes onde a freqüência de cada onda senoidal é um inteiro múltiplo (harmônico) do componente de freqüência fundamental da onda periódica. 
Por analogia, interharmônico é o componente de formação da onda periódica cuja freqüência não é um inteiro múltiplo do componente de freqüência fundamental (IEEE1159-1995, 1995).

Portanto, as ondas de tensão ou corrente podem apresentar componentes de freqüência que não são múltiplos inteiros da onda de freqüência fundamental do sistema. Estes componentes de freqüências são chamadas interharmônicos.

Estes interharmônicos podem se apresentar como freqüências discretas ou largas faixas espectrais, podendo ser encontradas em diferentes classes de tensões.

As principais fontes de geração de interharmônicos são os conversores estáticos, motores de indução e equipamentos que utilizam arco elétrico para seu funcionamento, conforme apresentado por Serni (2006).

Pode-se observar na figura 1.13 os componentes interharmônicos discretos dispostos no domínio da freqüência, com maior amplitude entre as freqüências $240 \mathrm{~Hz}$ e $360 \mathrm{~Hz}$.

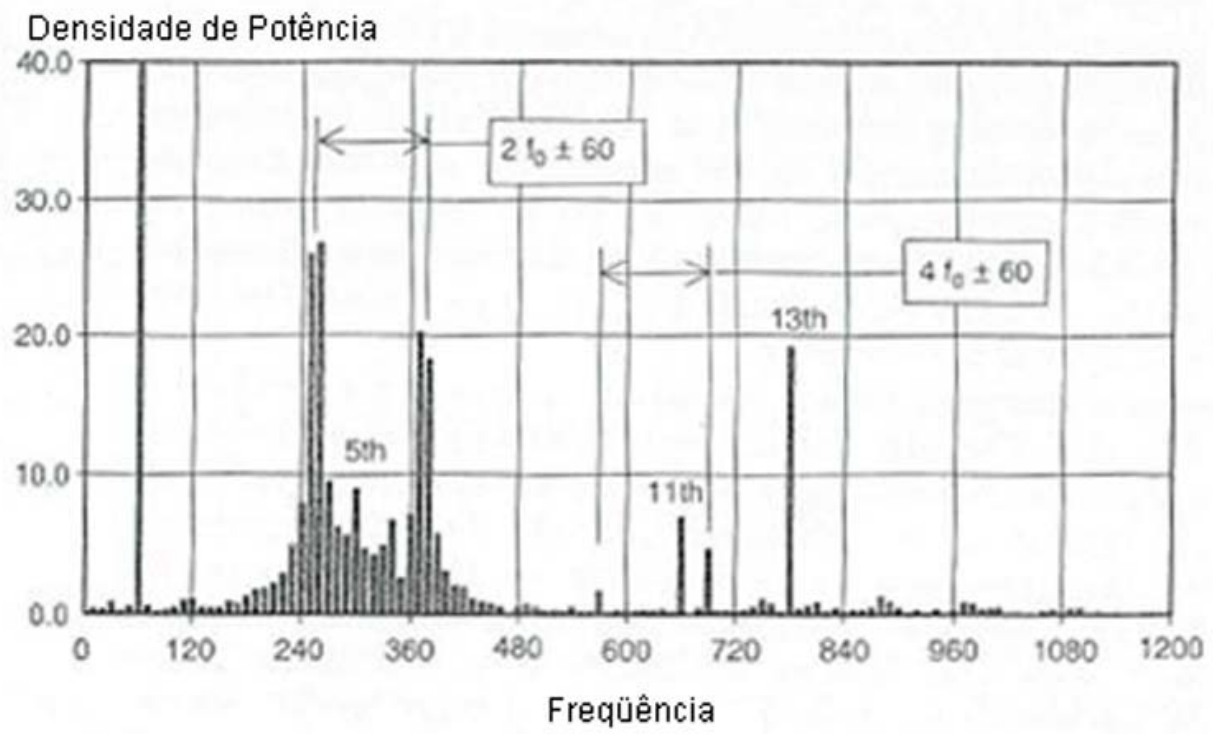

Figura 1.11. Espectro de potência de um forno de indução 


\section{$\underline{\text { Recortes (Notching) }}$}

Notch, entalhe ou recorte são distúrbios periódicos de tensão que oscilam a onda de tensão fundamental por pequenos instantes. Conforme Dugan et al. (1996) os recortes são causados pela operação normal de equipamentos eletrônicos quando a corrente é comutada de uma fase para outra.

No que se refere à qualidade de energia, alguns distúrbios podem ser originados dentro do próprio sistema das empresas, como as ações provocadas pela ação da natureza (relâmpagos, ventos fortes, contatos de animais), por causas aleatórias (acidentes de construção, falhas de dispositivos e equipamentos) ou por operações normais da empresa (manobra de motores e bancos de capacitores, atividades de manutenção).

As ondas de tensão que apresentam cortes, geralmente, têm componentes de freqüência elevada, o que dificulta muito a leitura pelos equipamentos de medição atuais.

A figura 1.14 exemplifica uma onda de corrente senoidal contendo recortes.

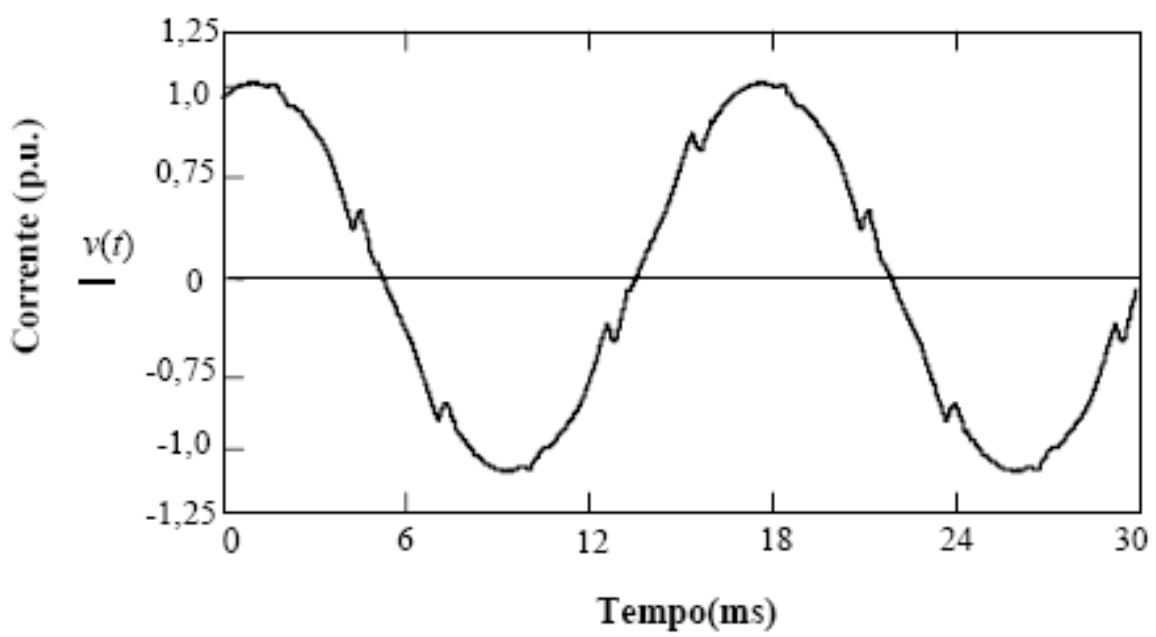

Figura 1.12. Recortes na onda de corrente de um conversor trifásico 


\section{$\underline{\text { Ruídos (Noise) }}$}

Ruídos são definidos como qualquer distorção indesejada nas ondas de tensão ou corrente, formado pela superposição de uma onda com conteúdo espectral abaixo de $200 \mathrm{KHz}$ com a onda fundamental. Este tipo de distúrbio pode ser encontrado nos condutores de fase, neutro ou sinais.

As causas mais comuns dos ruídos elétricos são os dispositivos eletrônicos, equipamentos que funcionem com base em arcos elétricos e conversores estáticos.

Dos muitos problemas causados pelos ruídos que podemos citar, os mais graves são os impactos negativos nos equipamentos eletrônicos que operam com microcontroladores, onde um ruído intenso poderá até danificá-los. Geralmente os problemas causados pelos ruídos são amenizados por um sistema conveniente de aterramento, podendo chegar ao uso de filtros passivos e transformadores de isolação.

Na figura 1.15 temos um exemplo de onda senoidal de tensão contendo ruído.

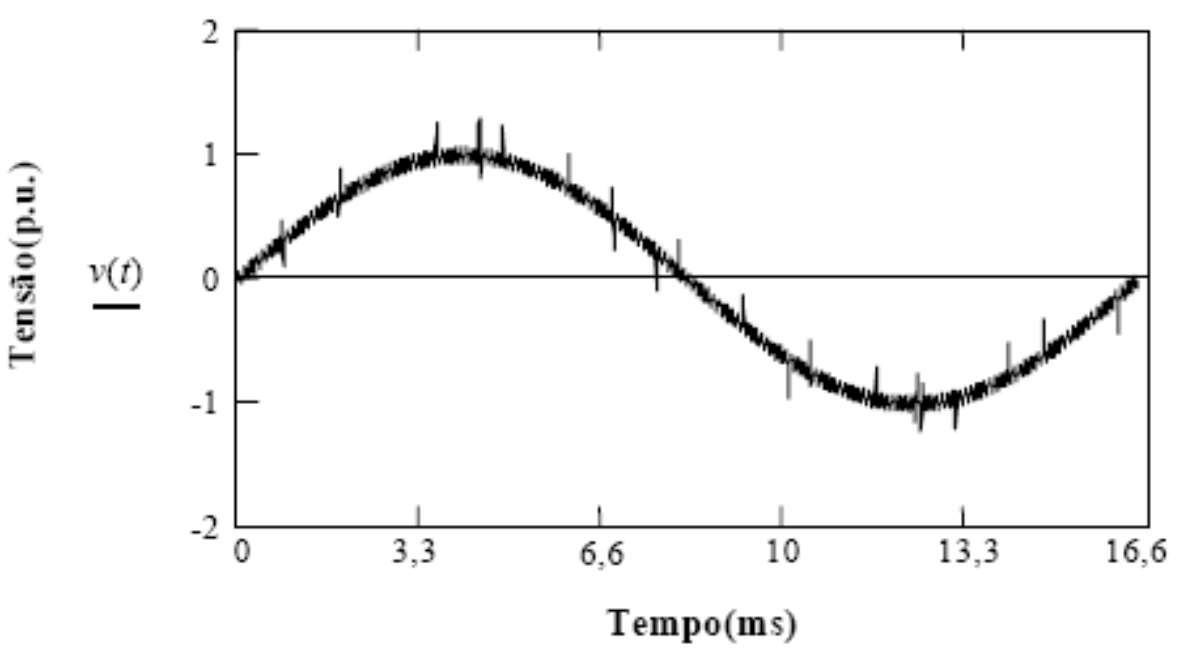

Figura 1.13. Ruído elétrico superposto na forma de onda da tensão em p.u. 


\subsubsection{Flutuação de Tensão}

Flutuações de tensão são variações sistemáticas nos valores eficazes da tensão ou uma série aleatória de mudanças, onde a magnitude da onda permanece entre 0,93 e 1,07 p.u., conforme tabela 1.1 .

Em certas cargas quando alimentadas por ondas que sofrem variações na amplitude da corrente ou tensão de forma continua e rápida, são vistos um resultado indesejado chamado cintilação (flicker). Estas cintilações são comumente sensíveis ao olho humano causando sensações desagradáveis e desconforto visual quando aplicadas aos sistemas de iluminação.

Um exemplo de flutuação do valor eficaz da tensão pode ser visto analisandose a alteração da amplitude da onda em função do tempo da figura 1.16.

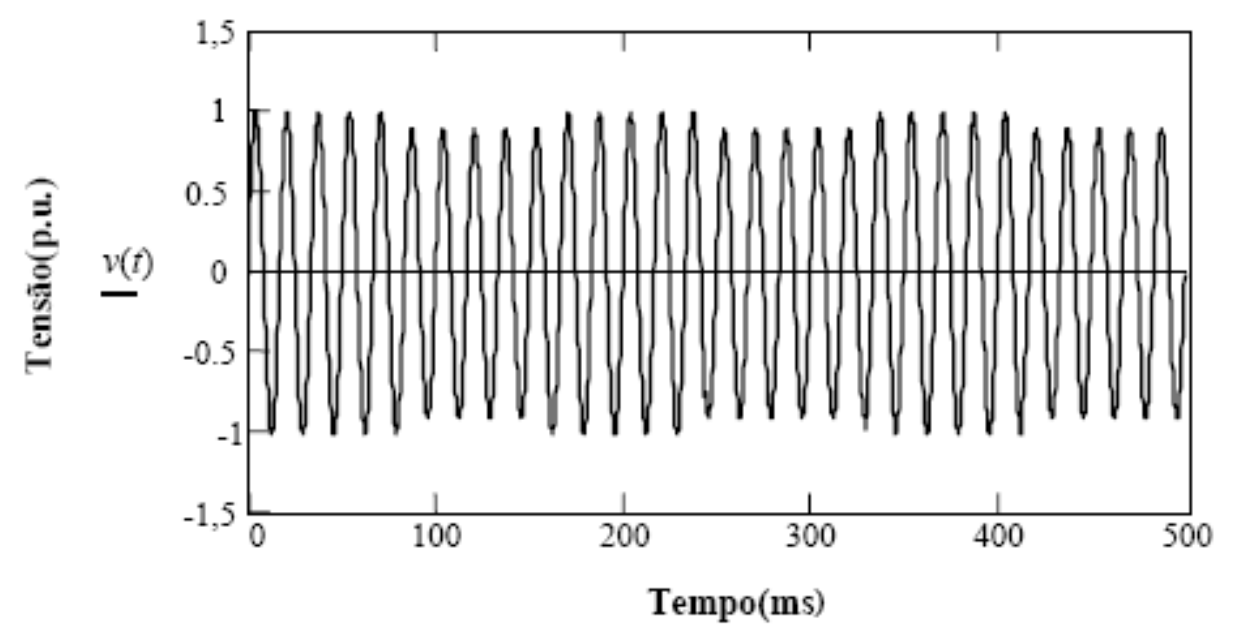

Figura 1.14. Flutuação da tensão em p.u. 


\subsubsection{Variações na Freqüência}

Variações na freqüência são definidas como alterações na freqüência fundamental do sistema.

Existe uma relação direta entre a freqüência do sistema e a velocidade de rotação dos geradores. Devemos considerar pequenas variações na freqüência do sistema devido as alterações de carga e geradores, onde estas amplitudes e durações dependem da robustez do sistema de controle do sistema de geração às mudanças de carga.

Variações de tensão consideráveis e freqüentes são comumente vistas nos sistemas supridos por concessionárias isoladas. Nos sistemas interconectados de geração e distribuição de energia estas variações são de ocorrência muito baixa.

As variações de freqüência são principalmente geradas por faltas no sistema de transmissão, desconexão de grandes cargas ou de grandes fontes de geração ou pela falha dos controles de geradores.

Pode-se observar na figura 1.17 um exemplo de onda de tensão com variação na sua freqüência.

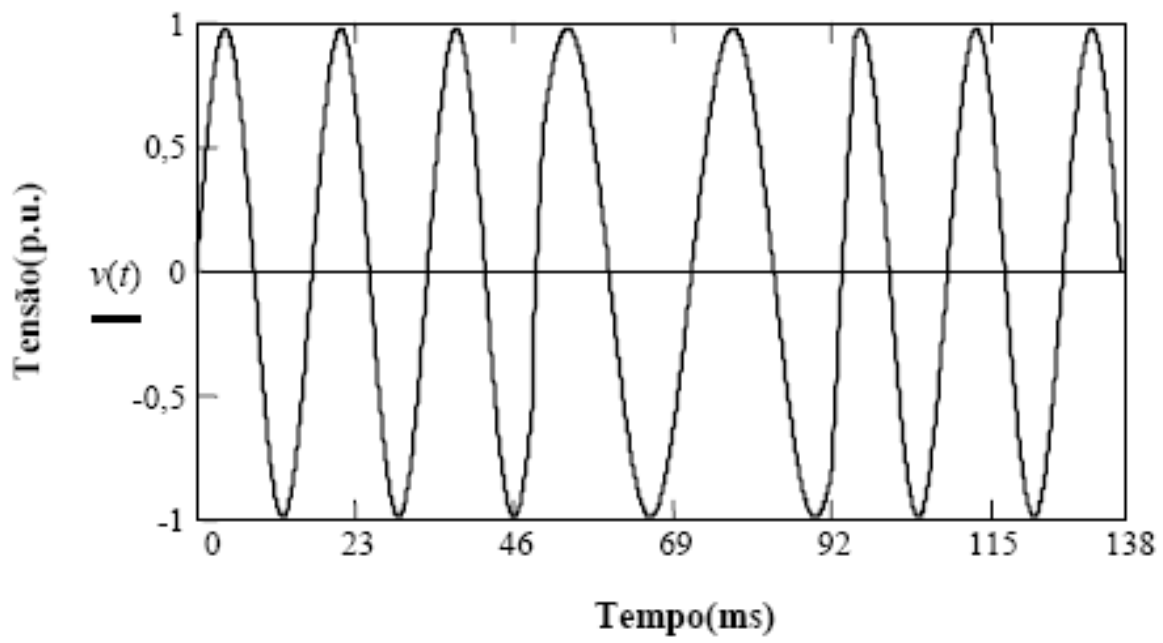

Figura 1.15. Variação da freqüência na forma de onda da tensão 


\subsubsection{Interferência Eletromagnética}

Se um dispositivo eletroeletrônico durante seu funcionamento produzir variações rápidas de tensão e/ou corrente, este equipamento se tornará uma fonte de emissão de ondas eletromagnéticas podendo interferir no funcionamento de outros equipamentos que estejam conectados à mesma rede de distribuição ou relativamente próximos deste.

A Interferência Eletromagnética (Electromagnetic Interference - EMI) se propaga de duas formas: conduzida e irradiada.

A EMI conduzida é a que é transmitida através dos condutores. Onde pode ser dividida em:

- EMI de modo comum (transmitida entre condutores de fase e o terra)

- EMI de modo diferencial (transmitida entre condutores de fase)

A EMI irradiada é gerada principalmente pelo uso de equipamentos eletrônicos de chaveamento de cargas. Conforme Ataíde (1997), as influências deste tipo de EMI são amenizadas com o uso de gabinetes metálicos que envolvem todo o equipamento, fazendo assim uma blindagem eletromagnética (gaiola de Faraday).

\subsection{Visão Nacional sobre Qualidade da Energia Elétrica}

O tema Qualidade da Energia Elétrica é muito estudado atualmente no Brasil, visto que o setor elétrico nacional passa por um processo de reestruturação, onde 
são levadas em consideração as responsabilidades de cada agente em relação à qualidade da energia fornecida e consumida.

Segundo Bronzeado (1997), QEE está relacionada ao funcionamento correto e seguro das máquinas e equipamentos assegurando a devida utilização para qual foi destinada e sem comprometer negativamente o meio ambiente. Observando este conceito, Borestein (1997), propôs a divisão da qualidade do fornecimento de energia elétrica em quatro conceitos distintos: disponibilidade, conformidade, restabelecimento e flexibilidade.

Disponibilidade é a capacidade do fornecimento de energia na quantidade em que os consumidores necessitam e com um mínimo de interrupções. A energia elétrica deve ser disponibilizada ao consumidor e ter um índice cada vez menor de interrupções, pois são regulamentadas por legislação. Esta parte é diretamente vinculada à continuidade do fornecimento de energia.

A conformidade é o fornecimento de uma energia limpa, com um nível mínimo de variações ou distorções na forma de onda de tensão, corrente ou freqüência do sistema de distribuição. Com o grande crescimento de cargas não-lineares alimentadas pela rede aumentou em muito os problemas relacionados a esta parte.

Restabelecimento é a capacidade de correções de falhas em um sistema, com um menor tempo de duração de interrupção. Com um corpo técnico dimensionado, qualificado e habilitado em manutenção no sistema de distribuição de energia elétrica pode-se melhorar em muito o índice de restabelecimento.

A flexibilidade é a capacidade da variação da quantidade e tipos das cargas alimentadas e/ou suas estruturas suportadas pelo sistema elétrico.

Estes itens fazem parte do conceito de qualidade do fornecimento de energia e influenciam diretamente nesta área. Mas outros itens devem ser incorporados a 
este conceito para que se torne completo, como por exemplo: atendimento rápido às reclamações, relacionamento adequado e suporte técnico.

Em 1997, a Comissão de Serviços Públicos de Energia (CSPE) elaborou cinco aspectos básicos para avaliação da qualidade da energia distribuída no estado de São Paulo, que são: qualidade intrínseca, qualidade de atendimento, segurança, satisfação e custos.

O principal aspecto para avaliação da qualidade da energia elétrica é a qualidade intrínseca, pois tem relação direta com a qualidade do serviço e do produto. A garantia da continuidade do fornecimento está diretamente relacionada à qualidade do serviço. Da mesma forma, a qualidade do produto está relacionada à manutenção do nível adequado de tensão, controle da forma de onda, freqüência nominal da rede e fator de potência.

Observando estes aspectos, não podemos considerar que a qualidade da energia elétrica é somente da responsabilidade das concessionárias, pois os sistemas de potência podem ser afetados de diversas formas, muitas das quais fogem de seus controles. Alguns exemplos são ações da natureza ou mesmo pelos equipamentos dos consumidores com cargas significativas que causam distúrbios à rede.

\subsection{Visão Internacional sobre QEE}

O termo Qualidade da Energia Elétrica derivou-se do correspondente na língua inglesa Power Quality, que é utilizado para agregar vários fenômenos eletromagnéticos que geram problemas para os usuários de energia elétrica, em um 
único tema. Estes fenômenos durante anos são pesquisados para melhor entendêlos e executar-se um diagnóstico de maneira correta e precisa, levando a uma melhor caracterização e solução dos distúrbios apresentados. As pesquisas são executadas, até hoje, por todas as áreas envolvidas no setor elétrico, sejam elas as concessionárias, os grandes consumidores, as universidades, os centros de pesquisa, etc.

No contexto internacional, a preocupação com os problemas gerados por estes fenômenos eletromagnéticos indesejáveis sempre existiu. Segundo Campos (2001), em meados de 1960, os problemas de harmônicos nos sistemas de transmissão começaram a preocupar seus usuários. Na década de 70 , os problemas relativos aos componentes harmônicos nas linhas de distribuição foram ainda mais pesquisados e muitas publicações contribuíram para uma melhor compreensão e estudo deste assunto. Sendo assim, os problemas gerados por componentes harmônicos nas linhas de transmissão e distribuição foram os principais objetos de preocupação desta época.

Conforme Key (1979), o distúrbio que mais gerava problemas para a sociedade não eram os componentes harmônicos presentes na rede, mas o afundamento de tensão, que cada vez mais ocorria com maior freqüência. Muitos problemas operacionais com computadores neste período foram devidos à má qualidade da energia elétrica, especificamente aos afundamentos de tensão.

Em meados da década de 80, o IEEE publicou algumas normas para auxiliar os projetos de sistemas elétricos, com a finalidade de amenizar os impactos dos problemas de QEE. Em 1984, o IEEE organizou o primeiro International Conference on Harmonics in Power Systems (ICHPS), que tratou de alguns assuntos referentes aos distúrbios eletromagnéticos que são abrangidos atualmente pelos estudos de 
QEE, porém com maior ênfase aos conceitos, origens e problemas dos componentes harmônicos nos sistemas de transmissão e distribuição.

A partir disto, com o passar dos anos e segundo cada necessidade, o tema QEE começou a agregar mais fenômenos eletromagnéticos para caracterizarem-se os problemas existentes nos sistemas de transmissão e distribuição que impactavam diretamente nos fabricantes de equipamentos e consumidores.

Martzloff e Gruzs (1988), apresentam uma visão geral dos fenômenos eletromagnéticos que causam mau funcionamento ou até danificam os equipamentos eletrônicos sensíveis, relacionando-os aos tipos de distúrbios e suas origens, indicando assim, a forte interação entre o aumento das cargas e equipamentos sensíveis e a rede de distribuição de energia.

A IEC, na década de 1990, publicou muitas normas, as quais vem sofrendo constante manutenção para manterem-se atualizadas, que caracterizam e conceituam os fenômenos eletromagnéticos referentes à QEE. Em especial, estas normas especificam termos técnicos, definições e forma de medição destes distúrbios. A IEC vem trabalhando para uma maior divulgação dos conceitos, unificação dos termos utilizados e especificação dos limites mínimos adequados para esta área.

Key (1992), apresenta a grande relação existente, na visão de QEE, entre os equipamentos cada vez mais sensíveis e o sistema de distribuição. Mostra que com o aumento das cargas e equipamentos cada vez mais sensíveis, aumentam-se consideravelmente os problemas relacionados ao assunto e consequentemente a necessidade de serem solucionados para o bem da instalação. Os pontos mais importantes para uma boa qualidade da energia, segundo o autor são uma alimentação elétrica dentro dos padrões exigidos e um bom aterramento. 
O ICHPS, onde se dialogava sobre os problemas que afetavam os equipamentos instalados no sistema elétrico, em especial os componentes harmônicos, em 1996, teve seu nome alterado para International Conference on Harmonics and Quality of Power (ICHQP), pois os trabalhos apresentados englobavam muitos fenômenos eletromagnéticos para caracterizarem os problemas relacionados a QEE, diferentes dos iniciais em 1984.

Kodali (1996), em sua apresentação sobre o assunto, passa por um breve histórico de QEE, abrangendo um período antes da segunda guerra mundial quando o tema começava a ser discutido. Apresenta também, algumas considerações e conceitos sobre Electromagnetic Interference (EMI) e Electromagnetic Compatibility (EMC), onde são observadas várias normas e suas relações, utilizadas pelos principais países que detinham a tecnologia da época, como Reino Unido, Estados Unidos, e muitos países da Europa. Kodali (1996), define distúrbio eletromagnético como qualquer fenômeno eletromagnético que comprometa o funcionamento do dispositivo, equipamento ou sistema, incluindo ruído eletromagnético, ondas indesejadas ou alterações no meio de distribuição. O autor define também interferência eletromagnética e compatibilidade eletromagnética, onde interferência eletromagnética é vista como a alteração do desempenho de um dispositivo, equipamento ou sistema, e compatibilidade eletromagnética é considerada como a capacidade destes dispositivos, equipamentos ou sistemas funcionarem satisfatoriamente sem induzir distúrbios eletromagnéticos que afetem outro dispositivo que esteja no mesmo ambiente ou sistema.

A união de quatro autores destacados na área R. Dugan, M. McGranaghan, Surya Santoso e H. Beaty (DUGAN et al., 1996), apresenta a referência bibliográfica fortemente utilizada como base para os conceitos sobre QEE. Por esta publicação, 
aborda-se os termos e definições sobre as grandezas referentes à qualidade da energia, que é definida como qualquer problema apresentado pela tensão, corrente ou variações de freqüência que resulte em falha ou má operação dos equipamentos do cliente. São apresentados na descrição do trabalho os conceitos, princípios geradores e protetores e possíveis soluções para cada um dos problemas envolvidos. Os autores demonstram que um dos principais processos para se solucionar eficazmente um problema e/ou manter uma boa qualidade de energia é através do monitoramento da rede e a transformação das medições, informações, análises e interpretações, em informações confiáveis e sólidas que possam ser utilizadas por profissionais competentes.

No trabalho de Bollen (2000), é enfatizado que o conceito de QEE pode ser dividido em vários termos para ser melhor analisado, como exemplo temos: EMC, qualidade do fornecimento, qualidade da corrente, qualidade da tensão e qualidade do consumo. Este documento também apresenta alguns tipos de distúrbios e define que distúrbio é toda variação da forma de onda perfeita. Apresenta especificamente as normas da International Eletrotechnical Commission (IEC) e da Comunidade Européia, dentre outras, que são apresentadas sem muitos detalhes. Entre estas as normas do Institute of Electrical and Electronics Enginners (IEEE). O autor define o conceito de QEE como qualquer desvio da forma de onda de tensão dos seus parâmetros considerados ideais. Uma das partes da QEE citadas pelo autor e a mais explanada em seu trabalho é a qualidade de fornecimento. Esta enquadra tecnicamente os desvios na forma de onda da tensão e corrente e politicamente contempla a integração entre as concessionárias de energia elétrica e os consumidores, com relação à qualidade da energia entregue no ponto de uso. 
McGranaghan (2002), defendendo as concessionárias, diz que em sua maioria, os problemas referentes à qualidade de energia são gerados dentro da própria indústria ou instalação, onde cada vez mais aumentam-se as cargas nãolineares, a manobra de grandes cargas e a inclusão de variadores de velocidade de motores elétricos. O autor deixa bem claro, que o início do projeto de normas sobre o assunto e as possíveis soluções devem começar em entender plenamente os conceitos e problemas relacionados à QEE.

Em um panorama geral, muitos pesquisadores vêm contribuindo para o aumento do conhecimento dos distúrbios, das caracterizações dos fenômenos eletromagnéticos relacionados e da diversificação de soluções economicamente viáveis para os problemas relacionados à QEE. Muitas instituições trabalham para, cada vez mais, diminuírem os problemas de QEE nos setores do sistema elétrico, com novas tecnologias, com novos materiais e produtos, ou mesmo com normas para regulamentar a emissão de fenômenos eletromagnéticos indesejáveis e os níveis mínimos aceitáveis dos parâmetros da onda da tensão. 


\section{Normas Técnicas}

\subsection{Introdução}

Uma das principais causas de problemas relacionados com a QEE está ligada à evolução da tecnologia e ao aumento das necessidades dos consumidores em controle da energia, pois levaram ao crescimento das cargas não-lineares instaladas no sistema elétrico. Com uma maior quantidade destes equipamentos instalados aumentou-se os problemas referentes à qualidade da onda de tensão e da corrente.

A evidência do aumento de problemas relativos à QEE somado aos prejuízos financeiros, leva a um esforço na busca de soluções práticas e economicamente viáveis entre as áreas de atuação do setor elétrico, sendo as maiores áreas as concessionárias, os fabricantes de equipamentos e os consumidores.

Pelas principais áreas de atuação do setor elétrico terem suas próprias características, necessidades e anseios com relação aos parâmetros, formas de medição e penalidades referentes à QEE, estas ainda não chegaram ao consenso e definições sobre o assunto.

Para as concessionárias, a confiabilidade do suprimento elétrico em níveis aceitáveis de tensão equivale à qualidade da energia elétrica fornecida. Estas vem sofrendo desgastes na sua imagem empresarial e tem aumentado os gastos com pedidos de ressarcimento de prejuízos sofrido pelos consumidores, muitas das vezes gerados pelos equipamentos instalados pelos próprios consumidores. 
Para os fabricantes de máquinas e equipamentos a qualidade do suprimento de energia que atendam às necessidades de suas fontes de alimentação para garantir a operação adequada de suas máquinas é a sua prioridade em termos de qualidade da energia elétrica utilizada. Devido ao mercado de equipamentos ser altamente competitivo buscando custos cada vez menores, há um desinteresse na flexibilização das características dos equipamentos produzidos quanto à suportabilidade e proteção dos distúrbios provenientes da e/ou gerados para a rede. Alguns fabricantes desconhecem ou simplesmente ignoram estes problemas, alocando a responsabilidade de possíveis falhas para as concessionárias ou para os próprios consumidores.

Por sua vez, para os consumidores a qualidade da energia está vinculada ao suprimento contínuo de uma energia elétrica senoidal dentro de uma faixa que não cause danos ou falhas em seus equipamentos. Os consumidores, devido à deficiência de um conhecimento técnico adequado para o reconhecimento e análise de problemas no sistema elétrico, além de aumentarem o problema referente à grande quantidade de equipamentos não-lineares, sofrem com as perdas de produção e danos em suas máquinas.

Nos últimos anos têm se intensificado os estudos dos fenômenos que envolvem a qualidade da energia elétrica pelas concessionárias junto às instituições de pesquisas, aos fabricantes de equipamentos e ainda junto aos consumidores, buscando minimizar os prejuízos causados pelos distúrbios no sistema energético. Devido às características do sistema elétrico serem muito amplas e os fenômenos referentes à QEE não poderem ser analisados como causas e efeitos isolados em uma determinada área, os pesquisadores estudam as características dos fenômenos observando as correlações entre todas elas. 
Nesta nova realidade que o setor elétrico está, baseada nas necessidades do mercado e na competição, a qualidade do produto eletricidade é determinante para os clientes que buscam ter suas necessidades atendidas, para que por sua vez possam atender às exigências em satisfação e produtividade do mercado.

Sendo assim muitas definições, esclarecimentos e soluções ainda são necessários e associado à falta de um interesse comum, torna-se difícil a elaboração de uma padronização para as necessidades do sistema elétrico quanto à Qualidade da Energia Elétrica.

\subsection{A Importância da Normatização}

\subsubsection{Origem e Evolução}

Tanto o desenvolvimento da fala quanto o da escrita, para a habilidade de comunicação entre os homens, podem ser considerados como as primeiras formas de normatização. Durante a antiguidade muitas ações foram tomadas com a tendência de definir, unificar, simplificar, ou seja, padronizar elementos utilizados nas fabricações de diversos produtos (MANFĖ; POZZA; SCARATO, 1977). Como exemplo podemos citar:

- Adoção do primeiro padrão de comprimento (distância entre dois nós de uma vara de bambu que, quando soprada, permitia reproduzir um determinado som com freqüência específica) na China, no século XXVII a.C. 
- Construção das pirâmides com blocos de pedra de dimensões unificadas, no Egito, por volta de 2500 a.C.

- Existência de regras escritas para construção de obras públicas (Códigos do Templo de Elêusis) na Grécia, no século IV a.C.

- Utilização de tijolos e diâmetros de tubos para aquedutos normatizados, em Roma.

- Padronização de navios com mastros, velas e remos, com características unificadas, em Veneza, no século XV.

- Adoção do Sistema Métrico Decimal, na França, pela lei de 1 de Agosto de 1793.

- Introdução do Princípio da Intermutabilidade na indústria de armamento, por Whitney, nos USA, no século XVIII.

- Estabelecimento de um sistema de diâmetros e passos normatizados para elementos roscados, por Sir Joseph Whitworth, em 1841, no Reino Unido.

Conforme Cunha (1999), um grande alavancamento na área de normatização surgiu com a Revolução do século XIX e com a produção em série de automóveis, pois houve a necessidade de ampliar a normatização nos níveis industriais nacionais. Mais tarde, devido às dificuldades de intercambiabilidade das peças e equipamentos produzidos, a necessidade de normatização expandiu-se internacionalmente. Olhando por esta perspectiva, algumas instituições merecem destaque pelas contribuições com a expansão das informações normativas: 
- VDE - Verband Der Elektrotechnik (Associação dos Eletrotécnicos Alemães), primeiro organismo de normatização para o estabelecimento de normas para a construção e instalação de aparelhos elétricos, em 1893.

- IEC - International Electrotechnical Commission (Comissão Eletrotécnica Internacional), para o desenvolvimento da atividade normativa internacional no campo eletrotécnico, em Londres, em 1906.

- DIN - Deutsches Institut für Normung (Instituto Alemão de Normatização), em 1917.

- ISA - International Federation of the National Standardizing Associations (Federação Internacional das Associações Nacionais Normativas), para o desenvolvimento da atividade normativa internacional, nos outros campos e em particular na engenharia mecânica, em 1926. As atividades da ISA cessaram em 1942.

- ISO - International Organization for Standardization (Organização Internacional para Normatização), com sede em Genebra, para facilitar a coordenação e a unificação internacional das normas industriais, em 1947.

- CEN - Comité Européen de Normalisation (Comitê Europeu de Normatização), em 1961, com o objetivo de permitir a elaboração de normas européias destinadas a promover a competitividade da industria européia no mundo e contribuir para a criação de um mercado interno europeu, com sede em Bruxelas, deste 1975.

- CENELEC - Comité Européen de Normalisation Electrotechinique (Comitê Europeu de Normatização Eletrotécnica), em 1973. 
- ETSI - Institut Européen des Normes de Télécommunication (Instituto Europeu de Normas de Telecomunicações), em 1988.

\subsubsection{Objetivos e Importância da Normatização}

Pela norma NP EN 45020:2001 (2001):

[...] a Normatização é a atividade destinada a estabelecer, face a problemas reais ou potenciais, as disposições para utilização comum e repetida, tendo em vista a obtenção do grau ótimo de ordem, num determinado contexto. Consiste, em particular, na elaboração, publicação e promoção do emprego das normas.

A importância da normatização pode ser constatada em várias atividades desenvolvidas por pessoas e instituições, como por exemplo, o formato de papéis, parâmetros para construções, instalações e funcionamento de equipamentos, etc.

A normatização busca a definição, a unificação e a simplificação, de forma racional, quer dos produtos acabados, quer dos elementos que se empregam para os produzir, através do estabelecimento de documentos chamados Normas. O termo definição significa precisar qualitativamente todos os materiais, objetos e elementos que se utilizam, bem como os próprios produtos finais. Os termos unificação e simplificação têm em vista a redução, ao mínimo, das variedades dos materiais, das ferramentas e das operações do processo produtivo e ainda dos produtos acabados (NICOLAS; REPUSSARD, 1988).

Conforme Nicolas e Repussard (1988) e ISO Online (2006), algumas das vantagens mais observadas, que resultam da atividade normativa, são enumeradas resumidamente: 
- Fornecimento de meios de comunicação entre todas as partes interessadas

- Simplificação e a redução do tempo de projeto

- Economia de matéria-prima

- Economia de tempos de produção

- Melhor organização e coordenação do processo produtivo

- Proteção do interesse dos consumidores, garantia da qualidade adequada dos bens e serviços desenvolvidos de forma coerente

- Melhor especificação dos produtos

- Maior economia resultante da intermutabilidade das peças

- Promoção da qualidade de vida: segurança, saúde e proteção

- Promoção do comércio, através da supressão dos obstáculos originados pelas diferentes práticas nacionais.

A NP EN 45020:2001 (2001) define Norma como:

[...] um documento, estabelecido por consenso e aprovado por um organismo de normatização reconhecido, que define regras, linhas de orientação ou características para atividades ou seus resultados, destinadas à utilização comum e repetida, visando atingir um grau ótimo de ordem num dado contexto. As normas deverão ser baseadas nos resultados consolidados da ciência, da tecnologia e da experiência, visando a otimização de benefícios para a comunidade.

As normas definem características de bens ou serviços, tais como os níveis de qualidade ou de eficiência, a segurança ou as dimensões. Deve registrar-se que, embora, normalmente a sua aplicação não seja obrigatória, as normas têm hoje um papel relevante nas relações industriais e comerciais. A utilização da marca de 
conformidade com as normas dá, aos consumidores, um determinada garantia de qualidade dos respectivos bens ou serviços.

\subsection{Normatização sobre QEE no Brasil}

\subsubsection{Obrigatoriedade do uso de normas}

As normas brasileiras são desenvolvidas e utilizadas voluntariamente. Elas tornam-se obrigatórias somente quando explicitadas em um documento de Poder Público (lei, decreto, portaria, etc.) ou quando citadas em contratos.

Mesmo não sendo obrigatórias, as normas são sistematicamente adotadas em questões judiciais por conta do inciso VIII do Artigo 39 do Código de Defesa do Consumidor (Lei nº 8.078 de 11 de Setembro de 1990), estabelecendo que

É vedado ao fornecedor de produtos ou serviços, dentre outras práticas abusivas, colocar, no mercado de consumo, qualquer produto ou serviço em desacordo com as normas expedidas pelos órgãos oficiais competentes ou, se Normas específicas não existirem, pela Associação Brasileira de Normas Técnicas ou outra entidade credenciada pelo Conselho Nacional de Metrologia, Normalização e Qualidade Industrial - CONMETRO. 


\subsubsection{Entidades Normativas}

\section{$\underline{\text { Sinmetro }}$}

O Sistema Nacional de Metrologia, Normalização e Qualidade Industrial (Sinmetro) é o sistema brasileiro que exerce atividades referentes à metrologia, normatização, qualidade industrial e certificação da conformidade, formado de entidades públicas e privadas.

O Sinmetro foi instituído pela lei $n^{\circ} 5.966$ de 11 de Dezembro de 1973 para criar uma infra-estrutura de serviços tecnológicos capaz de avaliar e certificar a qualidade de produtos, processos e serviços através de organismos de certificação, laboratórios de ensaio e de calibração, organismos de treinamento, organismos de ensaios de proficiência e organismos de inspeção, sendo todos eles credenciados junto ao Inmetro.

Uma das atividades do Sinmetro é a de elaborar normas para dar suporte à regulamentação técnica, facilitar o comércio e fornecer a base para melhorar a qualidade de processos, produtos e serviços.

Apóiam esse sistema os organismos de normatização, os laboratórios de metrologia científica e industrial e os institutos de metrologia legal dos estados. Esta estrutura está formada para atender as necessidades da indústria, do comércio, do governo e do consumidor.

Abaixo temos as principais organizações entre as que compõem o Sinmetro:

- Conselho Nacional de Metrologia, Normalização e Qualidade Industrial (Conmetro) e seus comitês técnicos 
- Instituto Nacional de Metrologia, Normalização e Qualidade Industrial (Inmetro)

- Organismos de Certificação Credenciados (Sistemas de Qualidade, Sistemas de Gestão Ambiental, Produtos e Pessoal) (OCC)

- Organismos de Inspeção Credenciados (OIC)

- Organismos de Treinamento Credenciados (OTC)

- Organismo Provedor de Ensaio de Proficiência Credenciado (OPP)

- Laboratórios Credenciados - Calibrações e Ensaios (RBC/RBLE)

- Associação Brasileira de Normas Técnicas (ABNT)

- Institutos Estaduais de Pesos e Medidas (IPEM)

- Redes Metrológicas Estaduais

$\mathrm{Na}$ área de avaliação da conformidade o Sinmetro oferece aos consumidores, fabricantes, governos e exportadores uma infra-estrutura tecnológica baseada em princípios internacionais, considerada de grande confiabilidade. Para possibilitar este trabalho, todos os serviços nesta área são executados por organizações credenciadas pelo Inmetro.

\section{$\underline{\mathrm{ABNT}}$}

A Associação Brasileira de Normas Técnicas (ABNT) é uma entidade privada, sem fins lucrativos e de utilidade pública, fundada em 1940, é membro fundador da International Organization for Standardization (ISO), da Comissão Panamericana de Normas Técnicas (COPANT) e da Associação Mercosul de Normalização (AMN), 
sendo responsável pela gestão do processo de elaboração de normas e certificação de produtos e sistemas. Tem como missão harmonizar os interesses da sociedade brasileira, provendo-a de referenciais através da normatização e atividades afins. Com a finalidade de alinhar-se às normas internacionais, a ABNT é associada da International Electrotechnical Commission (IEC).

A ABNT é o organismo reconhecido pelo Conmetro como o fórum único de normatização no Brasil, em que suas normas, podem ser utilizadas para defesa do mercado nacional e para facilitar o acesso de empresas brasileiras ao mercado internacional.

As normas brasileiras elaboradas e gerenciadas pela ABNT recebem prefixo NBR (Norma Brasileira).

Pelo Acordo de Barreiras Técnicas da Organização Mundial do Comércio $(\mathrm{OMC})$, somente poderão ser estabelecidos requisitos em um regulamento técnico se estes estiverem de acordo com a norma mundial. O país tem, portanto, que ter sua própria normatização para levá-la ao conhecimento da ISO, a fim de influenciar as normas mundiais.

Toda normatização levada à ABNT parte de um trabalho voluntário. A norma deve ser feita por entidades representativas do setor, ser simples e manter uma paridade na sua discussão, levando em conta interesses das diversas áreas da sociedade, dos órgãos governamentais, dos setores públicos e privados e dos consumidores. Sua aprovação é obtida através de um consenso entre estas entidades em reuniões ordinárias da ABNT, como representado na figura 2.1. 


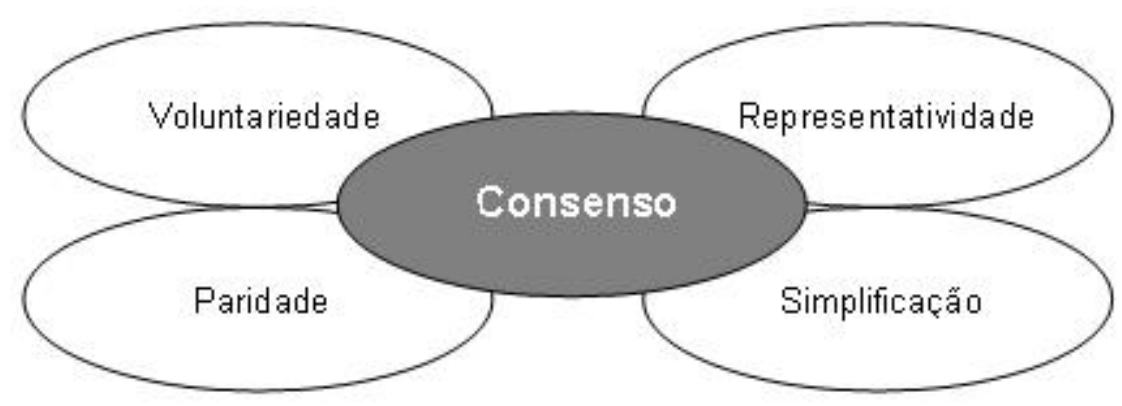

Figura 2.1. Princípio da normatização

A ABNT possui atualmente 54 Comitês Técnicos de Normatização e 4 Organismos de Normatização Setorial, trabalhando em suas respectivas áreas gerenciando os processos de criação e divulgação de normas.

O Comitê Técnico responsável pela elaboração e manutenção das normas relativas à área de eletricidade é o CB-03.

O Comitê Técnico de Normatização em Eletricidade - CB-03, tem o objetivo de coordenar e participar dos processos de criação de normas e certificar produtos e sistemas no contexto referente à trabalhos e processos em eletricidade.

Este comitê atua em normatização no campo da eletricidade, eletrônica e telecomunicações compreendendo geração, transmissão e distribuição de energia; instalações elétricas e equipamentos eletro-eletrônicos, inclusive para atmosferas explosivas; dispositivos e acessórios elétricos; instrumentação; bens de consumo; condutores elétricos; iluminação; compatibilidade eletromagnética, no que concerne a terminologia, requisitos, métodos de ensaio e generalidades.

Para a preparação de uma norma brasileira em eletricidade, o CB-03 executa as fases apresentadas na figura 2.2 . 
Sociedade manifesta a necessidade

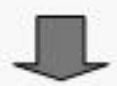

Comissẫo de Estudo elabora o Projeto de Norma

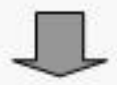

Projeto de Norma é submetido a Consulta Pública

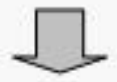

Norma é aprovada e colocada a disposiçẫo da sociedade

ABNT faz gestẫo deste processo através dos CBs

Figura 2.2. Desenvolvimento de uma norma brasileira

\subsubsection{Evolução normativa nacional sobre QEE}

No Decreto $n^{\circ} 24.643$, de 10 de Julho de 1934, do Código de Águas, foi feita a primeira citação sobre qualidade de energia, informando que o suprimento de energia deveria ser entregue de forma adequada.

O Departamento Nacional de Águas e Energia (DNAEE), em Abril de 1978, editou as Portarias $n^{\circ} 046$, no contexto de continuidade de serviço e $n^{\circ} 047$ sobre os níveis de tensões de fornecimento e limites de variações de tensão, regulamentando assim tanto a área técnica quanto a área de qualidade do serviço a serem seguidas por todas as áreas do sistema elétrico. Estas revisões das portarias foram realizadas devido às muitas reclamações dos consumidores, na década de 1970, referentes à qualidade do fornecimento de energia elétrica quanto às interrupções. Com base nestas reclamações o DNAEE parametrizou os níveis de tensão e qualidade de fornecimento de energia elétrica. 
Desde então, os índices referentes à continuidade do serviço, que são utilizados até hoje, permitiram o acompanhamento das durações e quantidades de faltas de energia.

Na seqüência, o DNAEE escreveu a Portaria nº31, em Abril de 1980, que estabeleceu os índices de continuidade de serviço com relação ao suprimento, onde foi descrita a metodologia a ser utilizada pelas concessionárias para avaliação dos índices de continuidade de fornecimento de energia.

A Portaria DNAEE $n^{\circ}$ 047/78, foi revisada em 1989, alterando os limites de variações de tensões para índices mais compatíveis com as tecnologias e produtos da época, porém não foram estabelecidas penalidades para as variações fora destes limites.

Após esta edição em 1989, da Portaria n 047/78, muitas discussões foram geradas entre as áreas do setor energético, principalmente entre as concessionárias, os fabricantes de equipamentos e os consumidores. Durante estas discussões houve grande reivindicação por parte dos consumidores para participar no processo de definição dos padrões de qualidade de energia. Houve também, grandes contribuições das instituições de pesquisa nestas discussões, onde os estudos que foram desenvolvidos focavam a influência das cargas dos consumidores e as influências das cargas não-lineares e seus controles, nos problemas de qualidade de energia.

Com a globalização da economia mundial, foi notória a necessidade de um programa que melhorasse a eficiência do setor elétrico. No contexto deste programa seria indicado a importância dos índices de continuidade de fornecimento apresentados na Portaria DNAEE nº 046/78. 
Nesta situação, o DNAEE publicou a Portaria n² 293/92, onde regulamenta a criação de um grupo de trabalho para reavaliar os índices existentes e moldá-los à realidade do país. Os membros deste grupo eram representantes da ELETROBRÁS, do Comitê Coordenador de Operações do Norte/Nordeste (CCON), da Associação Brasileira de Concessionários de Energia Elétrica (ABCE), do Grupo Técnico Operacional da Região Norte (GTON) e do Comitê de Distribuição (CODI).

Este grupo de trabalho, após estudos na área de qualidade de energia elétrica, apresentou ao DNAEE a edição da Portaria n 163/93, que aumentou a abrangência dos estudos solicitados na Portaria DNAEE n² 293/92.

O I Seminário Brasileiro sobre Qualidade de Energia Elétrica (SBQEE), foi realizado em 1996. Neste seminário foi discutido amplamente o tema, que levou principalmente a uma grande troca de informações e o alinhamento de pensamentos entre os diversos pesquisadores da área. Sendo assim, houve um grande progresso na distribuição e unificação das informações causando uma melhor interação entre as áreas do sistema de energia, principalmente entre os fabricantes de equipamentos.

Em Janeiro de 1998, ocorreu a emissão do Manual de implantação da Qualidade do Fornecimento de Energia Elétrica, pela ANEEL. Este manual teve a função de apresentar as fórmulas para cálculo dos índices de qualidade e as metodologias para obtenção dos parâmetros relacionados e a forma de coleta dos dados para as informações pertinentes. É importante evidenciar também que foi apresentado neste manual a maneira de implementação do modelo, informando detalhadamente a abrangência e as formas de organização e gerenciamento dos dados, bem como também o procedimento de coleta, transmissão, tratamento e apresentação. 
A Secretaria de Energia do Estado de São Paulo, através da Comissão de Serviços Públicos de Energia do Estado de São Paulo (CSPE), criou em 1998, um documento conhecido por Qualidade do Fornecimento de Energia Elétrica - Manual da Implantação da Qualidade, que apresentou uma metodologia para controlar os parâmetros que influenciam diretamente na qualidade da prestação do serviço do produto energia elétrica.

O documento apresentado pela CSPE proporcionou as premissas para formação dos índices de qualidade, pois, como pontos principais, tem os cálculos dos componentes do sistema executados em diferentes níveis de agregação, como global, regional, local, por modo de falha, etc, Houve também um atendimento a empresas com portes distintos, sendo apresentados novos indicadores de continuidade e conformidade do suprimento de energia elétrica, além do índice de satisfação do consumidor.

Num contexto mais atual do setor energético brasileiro ocorreu o desmembramento de várias empresas vinculadas ao setor elétrico, onde foi reduzida a força do Estado nas funções empresariais, então surgiram constantes privatizações das empresas existentes e apresentou-se um novo modelo de instituições especializadas para executar e fiscalizar as funções de regulação, planejamento da expansão, operação e financiamento do setor. Podemos destacar o Operador Nacional do Sistema Elétrico (ONS) e a Agência Nacional de Energia Elétrica (ANEEL) como os dois principais orgãos que surgiram, nos últimos anos, diante dos acontecimentos dinâmicos das empresas vinculadas ao mercado de energia elétrica.

A ANEEL tem como objetivo promover condições adequadas para o crescimento do mercado de energia elétrica estabelecendo um equilíbrio entre as 
diversas áreas do setor elétrico. A ONS tem a missão de manter os ganhos da otimização da operação do sistema de transmissão e geração de energia. O Mercado Atacadista de Energia (MAE) executa o processamento de atividades comerciais de compra e venda de energia elétrica através de contratos bilaterais e de acordos de curto prazo. Com a criação da ANEEL, em 1997, o DNAEE foi extinto, porém a busca da melhoria da qualidade de energia não cessou e os estudos sobre este tema ainda são desenvolvidos.

A ANEEL em Novembro de 2000, criou a Resolução n 456/2000 para unificar diversas portarias do DNAEE e atualizar as disposições referentes às condições gerais do fornecimento de energia elétrica. Esta resolução unificou as legislações existentes, principalmente as que tratam do relacionamento entre as áreas do setor elétrico.

A Resolução n 024/2000, apresentada pela ANEEL em Janeiro de 2000, estabeleceu disposições referentes à continuidade da distribuição de energia elétrica. Nesta resolução foram apresentados novos índices de avaliação das interrupções individuais das unidades consumidoras e descreveu os cálculos dos índices de continuidade individuais e coletivos, as metas de continuidade e a forma de cálculo das penalidades por variações fora do estabelecido.

A ANEEL, em Novembro de 2001, estabeleceu a Resolução n 505/2001, onde é apresentada as disposições relativas à conformidade dos níveis de tensão de energia elétrica em regime permanente, onde foram revisadas as portarias DNAEE $n^{\circ}$ 047/78 e n 04/89. É apresentado detalhadamente nesta resolução a classificação das tensões de suprimento, as fórmulas de cálculo dos indicadores individuais e coletivos, os critérios de medições e registros dos dados, bem como dos 
equipamentos de medição e penalidade pelo fornecimento de um serviço que não esteja adequado ao estabelecido nesta resolução.

A ONS trabalhou juntamente a vários agentes do setor energético nacional na elaboração de um Procedimento de Rede, para melhoria e o controle da qualidade da energia elétrica. Este procedimento apresentou os procedimentos e requisitos técnicos que devem ser utilizados para planejamento, implantação, uso e operação do sistema elétrico interligado, bem como definiu as responsabilidades dos agentes e do próprio ONS. As metodologias apresentadas nos Procedimentos de Rede influenciam diretamente os padrões de qualidade das instalações de transmissão, distribuição e subtransmissão do setor elétrico.

Um ponto importante a enfatizar é a falta de um documento legal para estabelecimento de procedimentos e índices para controle das condições de fornecimento que abranja problemas momentâneos na tensão, visto que as resoluções apresentadas somente estabelecem metas para as interrupções com duração maior ou igual a um minuto.

Vê-se que ainda não há uma norma nacional que defina todos os parãmetros dos fenômenos realtivos à QEE. Consumidores e fabricantes, necessitam destas normas para identificação dos equipamentos necessários para cada ambiente. Estes parâmetros devem incluir características quanto a interrupções, sobretensões, subtensões, desequilíbrio de tensão, distorções da forma de onda e transitórios.

\section{Parâmetros da QEE no Sistema Elétrico Nacional}


A qualidade da energia elétrica é estudada pelos vários segmentos do sistema energético nacional para definição de normas, parâmetros e procedimentos que garantam as necessidades mínimas do serviço prestado para cada área.

Deste modo, a qualidade da energia elétrica vem sendo analisada como um processo global, porém considerando suas subdivisões em: produto e serviço. Onde o produto se relaciona com a energia entregue aos consumidores e serviço concentra as partes técnicas e comerciais necessárias ao fornecimento do produto (SILVEIRA, 2002).

Produto e serviço, entre outros, servem de base para a formação dos indicadores da qualidade existentes atualmente.

\section{$\underline{\text { Qualidade do Produto }}$}

A qualidade do produto se relaciona diretamente ao uso da energia elétrica, englobando o atendimento às solicitações do consumidor durante o período necessário. A qualidade do produto é caracterizada pelos parâmetros da energia fornecida.

A primeira iniciativa em estabelecer limites de variações das tensões a serem cumpridas pelas concessionárias para garantir o cumprimento das necessidades técnicas mínimas e a qualidade necessária, foi a portaria DNAEE nº47/78.

$\mathrm{Na}$ portaria DNAEE n04/89 foram estabelecidos os limites adequados $\mathrm{e}$ precários para as variações de tensão. Estes limites situam-se na faixa de $-8,6 \%$ a $+4,2 \%$ para os adequados e $-14,0 \%$ a $+6,1 \%$ para os precários, porém sem determinar multas ou qualquer forma de avaliação para a variação da tensão. 
Na resolução ANEEL n505/01 foram previstas faixas de classificação, sendo elas: adequada, precária e crítica. Onde para cada uma destas faixas foram previstos pontos de limites para a variação da tensão de leitura em relação à tensão nominal (TN), como exemplo, para a faixa de 0 a $1 \mathrm{KV}$, conforme figura 1.18.

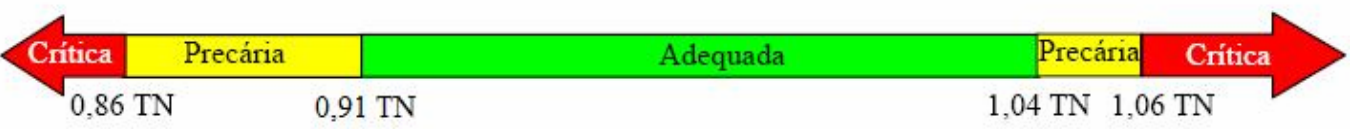

Figura 2.3. Limites de tensão para tensões nominais iguais ou inferiores a $1 \mathrm{KV}$

A resolução ANEEL $n^{\circ} 505 / 01$ também definiu critérios para medições amostrais, execução das medições, requisitos dos equipamentos a serem utilizados e os mais importantes, os indicadores individuais e coletivos que limitam o nível de variação dos valores estabelecidos.

O índice individual foi utilizado para avaliar a restituição ao consumidor pelo fornecimento de um serviço inadequado. Os indicadores são:

- DRP - Duração Relativa da Transgressão de Tensão Precária Duração relativa das leituras da tensão nas faixas de tensão precária no período de observação definido [\%].

- DRC - Duração Relativa da Transgressão de Tensão Crítica - Duração relativa das leituras da tensão nas faixas de tensão crítica, no período de observação definido [\%].

- ICC - Proporção de Unidades Consumidoras com Tensão Crítica Percentual da amostra com transgressão da tensão crítica [\%]. 
Em 1998 a ANEEL disponibilizou o Manual de Implantação da Qualidade do Fornecimento de Energia Elétrica, onde foram descritos indicadores de conformidade para auxiliar tecnicamente nas decisões administrativas preventivas ou corretivas, permitindo o gerenciamento econômico da qualidade, possibilitando assim a quantificação e qualificação do desempenho do sistema.

Os indicadores do Manual de Implantação do Fornecimento de Energia Elétrica são:

1. Conformidade no fornecimento:

- FEV - Freqüência Equivalente de Violação de Tensão

Representa a proporção de consumidores que receberam energia com níveis de tensão de fornecimento fora dos limites

- NEV - Nível Equivalente de Violação de Tensão

Indica a média dos níveis de tensão fora dos limites legais, referenciada à tensão de fornecimento, dos consumidores considerados no FEV.

- VEV - Variação Equivalente de Violação de Tensão

Representa a variação relativa do NEV, significando o grau de dispersão de cada medida, em torno da média NEV. Indica o desvio padrão relativo à média NEV.

- DEV - Duração Equivalente de Violação de Tensão

Indica a média dos espaços de tempo e ultrapassagem dos limites legais de tensão de cada consumidor, com duração igual ou superior a cinco minutos, no período de observação de vinte e quatro horas. 
2. Conformidade no suprimento:

- FREQ - Freqüência Equivalente de Interrupção

Indica o número de interrupções que em média, a demanda máxima verificada do conjunto considerado sofreu, no período de observação.

- DREQ - Duração Equivalente de Interrupção

Representa o espaço de tempo que, em média a demanda máxima verificada do conjunto considerado ficou privada do suprimento de energia elétrica, no período de observação.

- ENES - Energia Interrompida

Contabiliza a quantidade estimada de energia elétrica não suprida, no período considerado.

\section{Qualidade do Serviço}

A satisfação do cliente, que está sempre acostumado a ter sempre disponível a energia elétrica, está diretamente ligado à continuidade do serviço. Portanto a qualidade do serviço é avaliada mediante a minimização das interrupções no suprimento da energia elétrica.

Na portaria DNAEE $n^{\circ} 046 / 78$ foi estabelecido os indicadores para análise da continuidade do fornecimento da energia elétrica. São eles:

- DEC - Duração Equivalente de Interrupção 
Indica o espaço de tempo em que, em média, cada consumidor do conjunto considerado ficou privado de fornecimento de energia elétrica, no período analisado.

- FEC - Freqüência Equivalente de Interrupção

Representa o número de interrupções que, em média, cada consumidor do conjunto considerado sofreu, no período analisado.

Nesta portaria foram determinados os cálculos, maneiras de medições e os objetivos para os indicadores e estabelecidas as metas específicas para as interrupções individuais para cada consumidor. Contudo, nenhuma forma de multa para aplicação quanto aos desvios dos objetivos é citada neste documento.

Na portaria DNAEE $n^{\circ} 031 / 80$ os índices para análise das falhas que ocorrem no sistema de fornecimento geradas por interrupção ocasionadas por qualquer dos segmentos do sistema foram definidas. São elas:

- DEKS - Duração Equivalente de Interrupção em Suprimento Espaço de tempo em que, em média, cada consumidor ou ponto de interligação considerado ficou privado do suprimento de energia elétrica, no período analisado.

- FEKS - Freqüência Equivalente de Interrupção em Suprimento Número de interrupções que, em média cada consumidor ou ponto de interligação considerado sofreu, no período analisado.

Estes indicadores foram somente utilizados para formação de um banco de informações sobre o sistema elétrico somente, não sendo aplicado assim nenhuma forma de multa pela falta do levantamento destes dados pelas entidades 
responsáveis. Também não foram estabelecidas multas pelo não cumprimento dos objetivos propostos nesta portaria.

O Manual de Implantação da Qualidade do Fornecimento de Energia Elétrica (1998) foi utilizado para análise e monitoração da continuidade do fornecimento de energia elétrica, e indicou alguns índices para este fim:

- DEP - Duração Equivalente de Interrupção por Potência

Indica o espaço de tempo que, em média, a potência do conjunto considerado ficou privado do suprimento de energia elétrica, no período analisado.

- FEP - Freqüência Equivalente de Interrupção por Potência

Representa o número de interrupções que, em média, a potência do conjunto considerado sofreu, no período analisado.

- ICD/ILD - Número de Interrupções de Curta e Longa Duração

O ICD indica o número de interrupões com duração inferior a um minuto e o ILD indica o número de interrupções para intervalos com duração igual ou maiores que um minuto.

A forma de obtenção dos indicadores também foi definida pelo Manual de Implantação da Qualidade do Fornecimento de Energia Elétrica, porém não foram definidos parâmetros ou objetivos a serem cumpridos pelas concessionárias.

Na resolução ANEEL n024/00, além da aplicação dos indicadores DEC e FEC, são criados também outros três indicadores individuais:

- DIC - Duração de Interrupção por Unidade Consumidora

Tempo que uma unidade consumidora ficou sem energia elétrica durante um período considerado. 
- FIC - Freqüência de Interrupção por Unidade Consumidora

Numero de vezes que uma unidade consumidora ficou sem energia elétrica durante um período considerado.

- DMIC - Duração Máxima de Interrupção por Unidade Consumidora Limita o tempo máximo de cada interrupção. Esse indicador passou a ser controlado a partir de 2003 e tem como objetivo fazer com que a concessionária não deixe o consumidor sem energia elétrica durante um período muito longo.

Nesta resolução foram impostas as multas pelo descumprimento dos objetivos e dos índices de continuidade, que as outras portarias não estabeleciam.

São elas:

- Violação de padrão do indicador de continuidade individual

A penalidade será a compensação ao consumidor de valor a ser creditado na fatura de energia elétrica no mês subseqüente à apuração.

- Violação de padrão do indicador de continuidade de conjunto

A penalidade será o pagamento de multa à ANEEL.

\section{Qualidade do Atendimento}

A qualidade do atendimento apesar de não estar diretamente ligado ao produto energia elétrica ou aos serviços técnicos prestados nesta área, são muito importantes para a total satisfação dos clientes, pois tratam das relações entre 
cliente e fornecedor do serviço/produto. O atendimento aos clientes está dividido em comercial e emergencial.

O atendimento comercial engloba os serviços prestados casualmente e os serviços rotineiros como: estudos de cargas, novas ligações, religações, faturamento, etc.

O atendimento emergencial são os realizados pelas concessionárias com base nas reclamações dos clientes devido às ocorrências na rede de fornecimento que podem causar interrupção no fornecimento.

Em 1997, a Comissão de Serviços Públicos de Energia (CSPE), estabeleceu alguns indicadores para avaliação dos serviços. Alguns destes indicadores foram mais tarde, incorporados à resolução ANEEL n057/2004.

- TA - Tempo de Atendimento

Tempo total de atendimento a uma ocorrência, excluindo as relativas a iluminação pública.

- TAI - Tempo de Atendimento Individual Tempo máximo para atendimento a uma ocorrência, de forma individual, até o restabeleciemnto do serviço.

- TMA - Tempo Médio de Atendimento

Quociente entre o somatório dos tempos decorrido desde o momento da informação de cada ocorrência até o restabelecimento do serviço ou finalização do atendimento, e o número de ocorrências verificadas no período.

- TME - Tempo Médio de Elaboração de Estudos e orçamentos de Serviços em Rede 
Tempo médio que cada consumidor aguarda para ser informado dos resultados dos estudos e projetos a serem envolvidos para atendimento à sua solicitação, assim como do valor referente ao orçamento dos serviços a serem realizados na rede em função desta.

- TML - Tempo Médio de Ligação Nova

Período médio em que cada novo consumidor a ser ligado à rede de baixa tensão espera pela efetivação do serviço, considerando ser desnecessária a realização de obras na rede.

- TMR - Tempo Médio de Religação

Tempo médio que cada consumidor ligado em baixa tensão aguarda a efetivação do serviço de religação, após a verificação de inexistência do fato gerador de corte.

- TMS - Tempo Médio de Execução de Serviços na Rede

Tempo médio que cada consumidor ligado em baixa tensão aguarda pela realização de obras na rede de distribuição necessárias ao atendimento da solicitação do consumidor, após a apresentação do orçamento e do projeto ao consumidor e sua aprovação e pagamento, caso exista.

- TX\% - Tempo X\% de Atendimento

Maior tempo de atendimento das primeiras $\mathrm{X} \%$ ocorrências de um conjunto, no período de apuração, considerando-se a ordenação do universo das ocorrências segundo os tempos de atendimentos. 
A resolução ANEEL $n^{\circ} 456$, publicada em Novembro/2000, veio atualizar e reforçar as Condições Gerais de Fornecimento de Energia Elétrica. Nesta resolução são estabelecidos critérios e prazos para os diversos procedimentos voltados ao atendimento comercial.

Para uma total avaliação dos serviços de suprimento de energia elétrica, outros aspectos devem ser considerados, como segurança, perdas, satisfação dos clientes, etc.

A satisfação do cliente pode ser monitorada através do Índice de Satisfação do Consumidor informado pelo Serviço de Atendimento ao Cliente (SAC), que é determinado a partir de um conjunto de indicadores definidos por uma pesquisa de opinião realizada com os consumidores sobre a conscientização em relação à qualidade do serviço ofertado pela concessionária. Este indicador pode ser utilizado durante fiscalizações e auditorias realizadas pelos órgãos fiscalizadores como orientação durante tais procedimentos.

O índice de segurança informado pelos relatórios de ocorrências de acidentes nas instalações, permite que se acompanhe a atuação das concessionárias na segurança das instalações esse otimize o tempo desperdiçado com as correções dos problemas ocorridos.

Devido ao forte impacto na operação das empresas de energia, gerados pelas perdas comerciais, este indicador serve para avaliarmos a eficiência das mesmas. Na definição da CSPE de 1997 é orientado o uso de alguns índices para análise destas perdas:

- PPC - Porcentagem de Perdas Comerciais

Relação entre as perdas em determinado sistema e a soma da energia faturada e do consumo próprio [\%]. 
- PPT - Porcentagem de Perdas Totais

Energia total perdida em determinado sistema, expressa em relação à energia comprada somada à energia gerada pela concessionária $[\%]$

Um último aspecto é o custo da implementação dos requisitos da qualidade do fornecimento da energia elétrica. Este aspecto deve ser avaliado para que o bom equilíbrio custo/benefício da concessão seja mantido e os objetivos comuns estabelecidos sejam cumpridos. As necessidades dos consumidores sempre devem ser analisadas, pois cada vez mais aumenta o número de equipamentos sensíveis e que requerem um fornecimento mais confiável. Sendo assim a responsabilidade sobre o custo da energia elétrica fornecida deve ser dividida de forma satisfatória tanto à concessionária quanto ao cliente.

A ANEEL iniciou em 2007 o desenvolvimento de um documento nomeado Procedimentos de Distribuição de Energia Elétrica no Sistema Elétrico Nacional PODIST, onde o módulo 8 deste documento trata dos fenômenos sobre QEE. O PRODIST ainda está em fase de revisão e aprovação.

O objetivo do PRODIST módulo 8 é estabelecer os procedimentos relativos à QEE abordando a qualidade do produto e a qualidade do serviço prestado. A seção 8.1 do PRODIST refere-se à qualidade do produto e caracteriza os fenômenos de QEE, estabelece os critérios de amostragem e os valores de referência quanto à tensão em regime permanente, fator de potência, harmônicos, desequilíbrio de tensão, flutuação de tensão, variações de tensão de curta duração e variação de freqüência. A qualidade do serviço prestado pelas distribuidoras aos consumidores é estabelecida pelo item 8.2 do PRODIST, onde são definidos os indicadores e padrões de forma a acompanhar e controlar o desempenho das distribuidoras, 
fornecidos subsídios para os planos de reforma, melhoramento e expansão da infraestrutura e oferecidos aos consumidores parâmetros para avaliação do serviço.

Há a necessidade de definição dos níveis adequados para melhor qualificar o sistema de fornecimento, porém é imprescindível que todas as áreas do setor energético (concessionárias, consumidores e fabricantes) participem das discussões, para assim melhorar as definições consideradas aceitáveis por todos, tanto técnica quanto economicamente. Então, todos serão os responsáveis pela qualidade da energia elétrica.

Analisando o contexto geral, as agências responsáveis no Brasil pelas normas, portarias, resoluções e fiscalizações estão caminhando para uma definição unificada dos requisitos e parâmetros para uma boa qualidade de energia, levando em consideração as diversas áreas do setor energético e seus interesses individuais.

A legislação no Brasil, ainda não apresenta um acervo legal suficiente para as necessidades do setor. O principal objetivo das resoluções nacionais vigentes é somente a continuidade do serviço, referente à continuidade do fornecimento de energia e duração das interrupções e variações de tensão.

\subsection{Normatização sobre QEE nos Demais Países}

A freqüência e a tensão são características que conceituam o sistema elétrico, porém não somente estas características formam o conceito de qualidade de energia. Existem outros aspectos que devem ser considerados quando se analisa 
este assunto, pois este é um tema muito complexo e envolve todas as áreas do setor elétrico.

Mundialmente, o tema qualidade de energia está em discussão e o resultado destas são as formações e revisões de normas e regulamentos. Diversos organismos estão trabalhando para 0 desenvolvimento de parâmetros, características, conceituação, metas, índices e objetivos para a qualidade da energia nos diversos setores desta atividade. As exigências e o cumprimento destes padrões descritos nas normas são cada vez mais exigidos comercialmente nos contratos de fabricação de produtos ou prestações de serviço.

Diversos organismos competentes estão realizando, em todo o mundo, estudos nas causas e efeitos dos distúrbios causadores da má qualidade de energia na rede elétrica. Revisões em normas existentes sobre o tema estão sendo realizadas e também, estudos para criação de novas normas para alinhar os conceitos e abranger aspectos ainda não cobertos pelas normas atuais.

Os principais organismos que estão liderando os estudos, bem como a elaboração de normas e revisão das existentes são a IEC e o IEEE. Outras entidades independentes também desenvolvem pesquisas, principalmente junto aos consumidores com objetivo de identificar problemas regionais.

Com a globalização e a formação de blocos econômicos, houve a necessidade de unificação de terminologias, normas, legislações e controles. A falta destes conceitos torna-se um ponto crítico que influem diretamente na compreensão e na troca de conhecimento entre as diversas áreas de legislação e pesquisa. Notase nos diversos materiais bibliográficos existentes diversas formas de referência a um mesmo assunto ou problema, dificultando o entendimento dos distúrbios que caracterizam a qualidade de energia elétrica. 
Porém houve pouco desenvolvimento da área legislativa neste aspecto. É visto que a maioria dos países refere-se especificamente somente a algumas das normas que podem ser seguidas ou estabelecem apenas alguns critérios simples com relação a poucos distúrbios que as concessionárias devem obedecer, entretanto poucas são as exigências e quase não há multas pelo não cumprimento destes critérios. A fiscalização não é rígida, visto que as punições são pouco aplicadas, sendo os parâmetros da qualidade do produto energia elétrica monitorados pontualmente de acordo com a necessidade, ficando este trabalho normalmente por conta do consumidor.

\subsubsection{Evolução normativa internacional sobre qualidade de energia}

A importante necessidade de suprir o fornecimento de energia com tensão e freqüência a valores aceitáveis pela carga, conhecido como compatibilidade cargafonte, é necessário desde o início das indústrias de energia (IEEE1100-1999, 1999). Esta necessidade direcionou o desenvolvimento de normas e regulamentos para atenuar os problemas que ocorriam nestes aspectos.

A expectativa de uma boa qualidade da energia surgiu com as indústrias e o aumento do uso de iluminação e motores elétricos. $\mathrm{Na}$ década de 30 as concessionárias atentaram-se aos distúrbios de tensão causados pelos consumidores na rede de distribuição. Outro problema surgiu em meados dos anos 50, devido a alta corrente de partida de grandes motores elétricos, causando assim quedas significativas nos valores de tensão, afetando os equipamentos daquela região (SILVEIRA, 2002).

Segundo Bollen (2000), a qualidade da energia começou a ser difundida em todo mundo pelos projetistas de sistema de potência industriais, adicionado à 
segurança, confiabilidade e baixos custos iniciais de operação. O termo qualidade de tensão começou a ser empregado nos países escandinavos e na União Soviética para caracterizar as variações lentas na amplitude da tensão.

Normas para conceituar, caracterizar e solucionar os problemas referente a qualidade da energia elétrica são um interesse urgente mundial. Muitos projetos de normas sobre qualidade da energia vêm sendo desenvolvidos por organizações privadas sem fins lucrativos (fabricantes, laboratórios, setores governamentais, outros) voluntárias sem poder legal. Algumas legislações são emitidas, neste contexto, por agências reguladoras ou órgãos governamentais.

Uma das entidades internacionais que mais desenvolveram estudos referentes à qualidade da energia é a International Eletrotechnical Commission (IEC), com sede na Suíça. A IEC vem trabalhando em normas referentes a compatibilidade eletromagnética, a interação entre os equipamentos e a influência entre os equipamentos e a rede de alimentação.

Outra entidade muito respeitada que também vem desenvolvendo normas e estudos a respeito da qualidade da energia é o Institute of Electrical and Electronics Engineers (IEEE), com sede nos EUA. Outros organismos americanos formados principalmente por fabricantes de equipamentos, que também estabelecem normas são a National Electrical Manufacturers Association (NEMA), e o Information Technology Industry Council (ITIC).

O American National Standards Institute (ANSI), é um organismo de administração e coordenação das propostas de normatizações voluntárias nos EUA. Esta entidade não desenvolve normas, mas sua missão principal é de promover a elaboração destas normas, trabalhando em consenso com as diversas áreas de atuação nacionais que têm interesse na específica norma. A ANSI também trabalha 
para incentivar o uso de normas internacionais, como a ISO e a IEC, desde que atendam às necessidades e interesses do mercado em questão.

O grande crescimento dos equipamentos microprocessados, caracterizados pelas suas sensibilidades quanto aos distúrbios da rede elétrica, frente às variações de tensão, levaram à necessidade de se estabelecerem padrões e limites para estas variações. A Computer and Business Equipment Manufacturers Association (CBEMA), elaborou uma curva de suportabilidade para estes equipamentos, em 1977. O ITIC, em 2000, atualizou a curva da CBEMA, para níveis mais adequados de acordo com as características atuais do sistema de distribuição de energia elétrica e a suportabilidade dos equipamentos, agora mais modernos. A curva da figura 2.3 indica como os equipamentos de informática devem responder às variações de tensão em função da duração do distúrbio e se aplica aos equipamentos com tensão de alimentação de 120V, 208/120V e 120/240V (SARAIVA FILHO, 2002). 


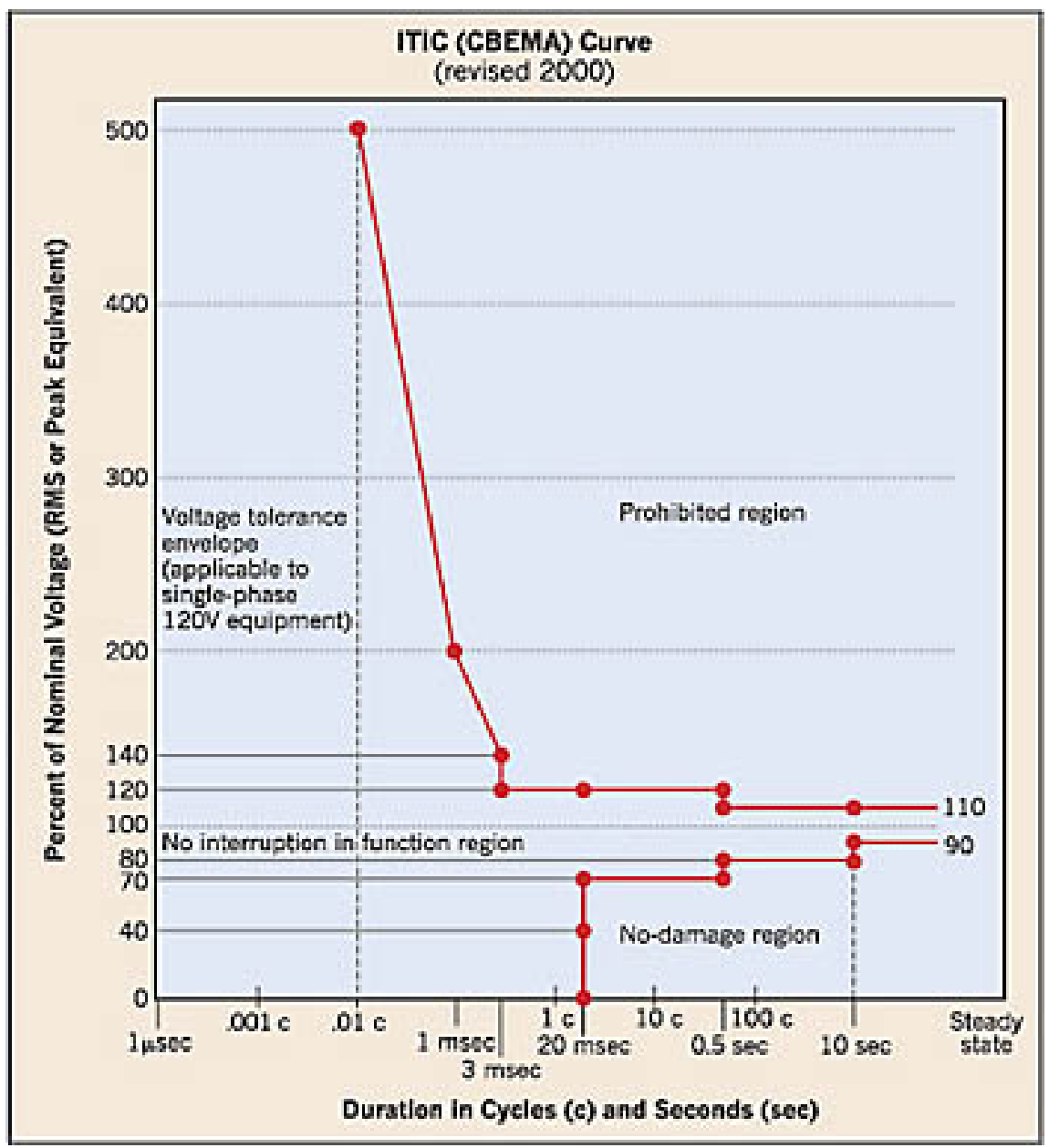

Figura 2.4. Curva do ITIC revisada no ano 2000

$\mathrm{Na}$ Europa os produtos comercializados devem ser certificados em um processo de aprovação, pela European Economic Community (EEC) ou Comunidade Econômica Européia (CEE) para receber a marca "CE”, mostrada pela figura 2.4, indicando assim que está de acordo com as normas harmonizadas (normas reconhecidas pela União Européia (EU) e publicadas no Jornal Oficial da EU, cuja identificação é feita pelo prefixo EN).

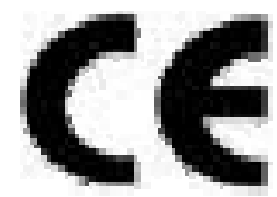

Figura 2.5. Marca de certificação CE 
Dependendo do tipo de produto a ser certificado, as diretrizes se dividem em básicas, genéricas e produtos específicos.

Nos aspectos de comercialização, segurança e responsabilidade as diretrizes básicas são empregadas a todos os fabricantes. A certo grupo de produtos, como os que operam em certa faixa de tensão ou produtos que podem gerar interferências eletromagnéticas, são aplicadas as diretrizes genéricas, que atendem o setor não regulamentado de produtos. As diretrizes de produtos específicos abrangem o setor de produtos regulados, sendo os de telecomunicações e dispositivos médicos ou produtos considerados de alto risco exemplos destes produtos.

Os produtos comercializados na Austrália também devem ser aprovados. Para isto precisam ser certificados pelo órgão responsável pela elaboração de normas, a Australian Communications and Media Authority (ACMA), que aplica a estes produtos a marca "C-tick", indicada pela figura 2.5 .

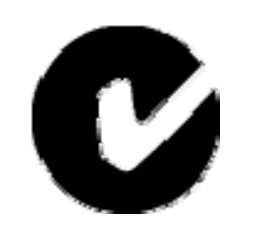

Figura 2.6. Marca de certificação C-tick

A Nova Zelândia segue as normas da ACMA, com algumas modificações apenas, devido às suas necessidades.

No Brasil a marca do Inmetro, conforme figura 2.6, indica que o produto está fabricado e atende as expectativas do usuário conforme as normas existentes, que foram elaboradas pelos comitês técnicos da ABNT. 


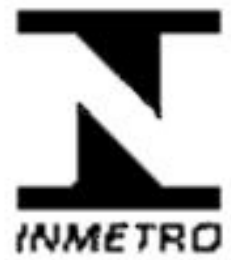

Figura 2.7. Marca de certificação Inmetro

Conforme Silveira (2002), referente às legislações, existe em geral, publicações de documentos que definem padrões mínimos de qualidade utilizando índices e a aplicação de punições em caso do não cumprimento destas. Porém, estes não são procedimentos e metodologias adotados por todos os países, ocorrendo uma grande diversificação de métodos.

Percebe-se então que não há uma nomenclatura, norma ou legislação concisa nacional ou internacional que agrupe e caracterize os termos e distúrbios associados à qualidade da energia e facilite uma unificação e troca de informação.

A existência de uma norma internacional consistente e o alinhamento dos pensamentos e pesquisas nesta área ajudariam a melhorar ainda mais na disseminação do conhecimento neste assunto, levando assim a uma utilização da energia elétrica da forma mais eficiente e mais rentável tanto às concessionárias, quanto aos consumidores e fabricantes de equipamentos. 


\section{Normatização Internacional sobre QEE}

\subsection{Introdução}

Normas internacionais e sua utilização no desenvolvimento do projeto dos produtos, métodos de produção e serviços têm um importante papel no desenvolvimento sustentado e na facilitação do comércio através da promoção da segurança, qualidade e compatibilidade técnica.

As normas técnicas internacionais são normas estabelecidas por um organismo internacional de normatização e são de uso mundial. Muitos organismos internacionais de normatização estão espalhados pelo mundo, atuando em campos específicos, como exemplos, a International Electrotechnical Commission (IEC), o Institute of Electrical and Electronics Engineers (IEEE), a International Telecommunication Union (ITU) e a International Organization for Standardization (ISO).

As normas nacionais ou regionais, em sua maioria, são adoções de alguma outra norma internacional, que auxiliam nas operações do mercado interno, aumentam a competitividade e provêem uma fonte de transferência de tecnologia. Elas desenvolvem um papel essencial na proteção dos consumidores e do meio ambiente.

As normas internacionais são reconhecidas pela World Trade Organization (WTO) (Organização Mundial do Comércio) como princípio técnico para o comércio internacional. O seu atendimento significa ter as condições necessárias para 
ultrapassar as eventuais barreiras técnicas entre os países, regiões ou organizações.

O Technical Barriers to Trade (TBT) (Acordo de Barreiras Técnicas) da WTO estabelece inúmeros princípios com a missão de eliminar problemas desnecessários ao comércio. De uma forma particular, atua em relação às barreiras técnicas, que podem dificultar o acesso de produtos com baixa qualidade ou funcionamento que não corresponda com a necessidade aos mercados de outros países.

Um dos pontos importantes do acordo é o entendimento de que as normas internacionais, elaboradas pelos organismos internacionais de normatização, constituem referência para o comércio internacional. O acordo considera que as normas internacionais constituem barreiras técnicas e recomenda que estas normas sejam usadas como referência para o projeto de produtos e serviços e que também sejam adotadas como normas nacionais (ISO, 2006). Por estas razões existe uma forte tendência que os organismos de normatização nacionais adotem as normas internacionais na íntegra como normas nacionais. Atualmente, nos países europeus, poucas normas que são adotadas anualmente pelos países da Comunidade Européia são normas especificamente nacionais. Muitas das novas normas nacionais provêem de normas européias que unificam vários países e de normas internacionais.

Com o crescimento globalizado dos mercados, as normas internacionais tornaram-se fator crítico dos processos de comércio, assegurando um campo de exportação seguro e confirmando os níveis de reconhecimento internacional dos desempenhos de importação e segurança.

Hoje em dia, é de extrema importância que as indústrias e profissionais que querem ser competitivos sigam os trabalhos de normatização internacional e 
procurem que seus serviços, produtos e sistemas atendam aos requisitos das normas internacionais.

Há, então, a necessidade de uma norma internacional abrangente, porém concisa, para não impor uma barreira técnica desnecessária. Por este motivo as normas internacionais estabelecem os princípios básicos de projeto e/ou os resultados esperados destes produtos e processos. Uma norma internacional deve conter todas as especificações mínimas que um produto ou processo deve obedecer, para que assim, todos estes produtos e serviços possam ter qualidade, segurança e funcionamento correto assegurados.

Sendo assim, torna-se cada vez mais importante participar do processo de normatização internacional agindo de forma pró-ativa nos seus resultados. Não basta apenas conhecer as normas internacionais uma vez publicadas, mas também acompanhar os programas de trabalho dos diversos comitês técnicos, de modo a intervir no processo tendendo a adequá-lo às necessidades dos países envolvidos e aos interesses das diversas áreas da sociedade em que estas normas atuarão.

Para os fins de qualidade da energia, a IEC e o IEEE são as organizações internacionais de normatização que mais se destacam pela quantidade de normas publicadas, pelos esforços nesta área e pela contínua pesquisa (DUGAN et al., 2006).

As recomendações do IEEE são focadas no comportamento do sistema elétrico ou na instalação industrial como um todo. Suas normas limitam os níveis de distúrbios sobre QEE no Ponto de Acoplamento Comum (PAC), a todos os equipamentos. Com isto, não são os equipamentos específicos que são avaliados, mas as instalações em geral. Deve-se levar em consideração que apesar dos indicadores gerais estarem dentro dos limites aceitáveis, pode-se ter na instalação 
equipamentos com uma alta taxa de emissão de distúrbios ou causando perdas de energia e consequentemente prejuízos (SERNI, 2006).

As definições da IEC focam o funcionamento específico do equipamento ou categoria de equipamentos pelas normas de compatibilidade eletromagnética (EMC). São estabelecidos então, limites de emissão de distúrbios ao sistema e quão imune aos distúrbios um equipamento é ou deve ser. Através destas normas avaliase junto aos parâmetros de QEE se um equipamento traz problemas à rede ou não e se este é sensível à rede a qual será instalado. Analisando a instalação em geral, vê-se que se todos os equipamentos atenderem individualmente as recomendações, o sistema geral estará dentro das especificações estabelecidas (SERNI, 2006).

O conjunto de normas da IEC, em especial a família IEC 61000-4, especifica, entre outros, os conceitos de projeto dos medidores, formas de medição, tratamento dos dados e classificação dos resultados para análise dos distúrbios englobados pela QEE.

Muitas normas internacionais utilizam estes conceitos de medidores da IEC como requisitos para obtenção dos valores das medidas dos fenômenos eletromagnéticos envolvidos e suas análises, como exemplo a recomendação IEEE 1453 que estabelece que o medidor de flicker deva atender a norma IEC 61000-415, para medição das flutuações de tensão do sistema. Baseado nisto pode-se afirmar que as normas da IEC são as mais específicas para equipamentos de medição sobre QEE que as outras normas internacionais vigentes.

Portanto, as normas da IEC serão adotadas como base para o projeto do protótipo do equipamento de medição dos fenômenos eletromagnéticos relativos à qualidade da energia utilizando conceitos de instrumentos virtuais proposto neste trabalho. 


\section{2. $\underline{\text { A IEC }}$}

\subsubsection{Introdução}

As normas internacionais da IEC facilitam o comércio mundial pela definição das barreiras técnicas, lideram os novos comércios e fazem a economia crescer. Fazem com que um produto ou sistema utilizado em um determinado país possa ser comercializado sem problemas em outro país.

As normas da IEC são vitais desde quando elas representam o TBT, em que mais de 100 membros do governo central reconhecem que as normas internacionais da IEC fazem um papel crítico em promover a eficiência industrial e o desenvolvimento do comércio mundial.

Os esquemas de avaliação da conformidade da IEC, baseados nas normas internacionais, são realmente globais no conceito e na prática, reduzindo as barreiras geradas pelos diferentes critérios de certificação em vários países e auxiliando a indústria a abrir suas fronteiras. Removendo o significante atraso e custos dos inúmeros testes e aprovações, as normas da IEC permitem que a manufatura seja rápida e de preço reduzido com relação a seus produtos.

Como a tecnologia se torna mais complexa a cada ano, usuários e consumidores estão cada vez mais dependentes dos produtos que, em muitas vezes, desconhecem seu desenvolvimento e construção. Nestas situações, as normas da IEC atuam como despreocupações para os usuários, pois garantem um produto confiável que atende as expectativas em termos de desempenho, segurança, durabilidade entre outros critérios. 
O IEC suporta as indústrias e usuários com uma economia de desenvolvimento, grandes produtos e serviços de qualidade, mais interoperabilidade, melhores produções e eficiência de entrega. Ao mesmo tempo, as normas do IEC também incentivam a melhora da qualidade de vida contribuindo para a segurança, saúde humana e proteção do meio ambiente.

Usando as normas do IEC para certificação no nível nacional asseguramos que os produtos certificados foram fabricados e testados conforme o estabelecido nas normas internacionais. O usuário final pode ter certeza que o produto atende no mínimo (geralmente alto) as normas de qualidade e não precisam ser confirmados por um teste adicional de avaliação do produto.

\subsubsection{Histórico}

Em 15 de Setembro de 1904, representantes do Congresso Internacional de Eletricidade, reunidos em Saint Louis, USA, adotaram o relatório que incluía o texto:

$$
\begin{aligned}
& \text { [...] passos devem ser dados para segurar a cooperação das } \\
& \text { sociedades técnicas no mundo, pelo apoio de sua comissão } \\
& \text { representativa para considerar a questão da normalização, da } \\
& \text { nomenclatura e o padrão dos equipamentos elétricos e das máquinas. }
\end{aligned}
$$

Como resultado, o IEC foi oficialmente fundado em Junho de 1906, em Londres, Inglaterra.

Durante 1914 o IEC teve como formação quatro comitês técnicos para estabelecer as nomenclaturas, símbolos e padrões de máquinas elétricas. A comissão gerou a primeira lista de termos e definições que cobririam as máquinas elétricas e equipamentos, uma lista de símbolos internacionais para quantidades e 
sinais dos nomes das unidades, uma norma internacional para a resistência do cobre, uma lista de definições das conexões com turbinas hidráulicas e inúmeras definições e recomendações relacionadas às máquinas rotativas e transformadores.

O IEC engloba todas as eletro-tecnologias, incluindo eletrônica, magnética e eletromagnética, eletroacústica, multimídia, telecomunicação e produção de energia e distribuição, tanto quanto disciplinas gerais associadas como as terminologias e símbolos, compatibilidade eletromagnética, medição e desempenho, dependência, desenvolvimento e construção, segurança e meio ambiente.

A missão da IEC é ser uma organização líder global que gera e publica normas internacionais para todas as eletro-tecnologias.

Através de seus membros, o IEC promove cooperação internacional em todas as questões de normatização internacional e assuntos relacionados, como o acesso a normas de conformidade.

Sendo assim, os objetivos da IEC são :

- Associar as necessidades para promover a eficiência do mercado global

- Assegurar a máxima utilização das normas e esquemas de avaliação da conformidade

- Avaliação e melhoria da qualidade de produtos e serviços abrangidos por estas normas

- Estabelecer a condição de interoperabilidade de sistemas complexos

- Aumentar a eficiência de processos industriais

- Contribuir para a saúde e segurança da sociedade

- Contribuir para a proteção do meio ambiente 


\subsubsection{A Estrutura da IEC}

A figura 3.1 apresenta o organograma da IEC.

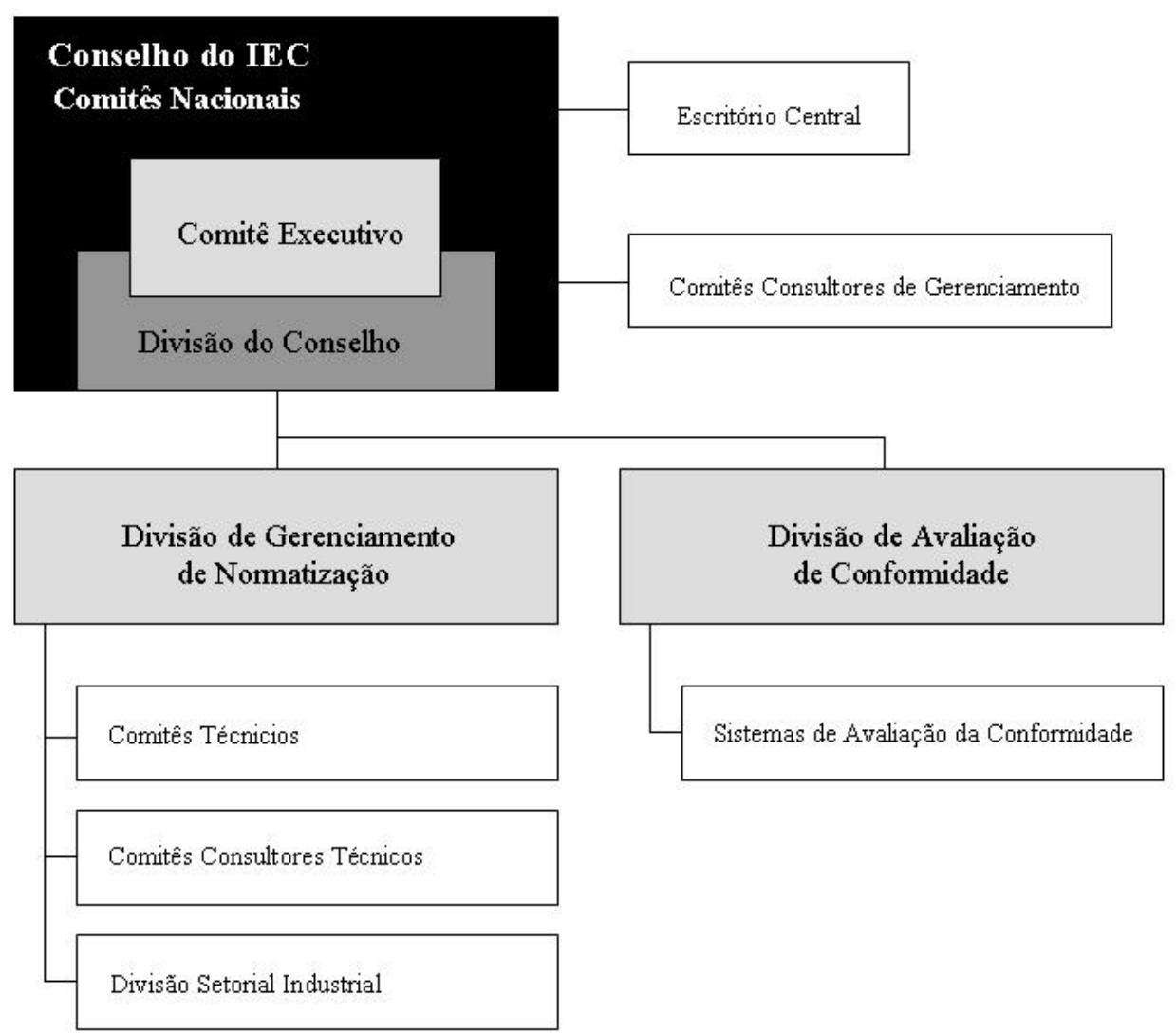

Figura 3.1. Organograma da IEC

Os 179 Comitês Técnicos (Technical Committees) (TC), seus Sub-Comitês (Sub-Committee) (SC) e cerca de 700 grupos de projetos e de manutenção são os responsáveis pela elaboração das normas da IEC. Estes grupos de trabalhos são compostos por pessoas de todo o mundo que têm qualificação em eletro-tecnologia. A grande maioria deles vêm das indústrias, enquanto outros vêm de grupos do comércio, governo, laboratórios de testes, laboratórios de pesquisa, centros de desenvolvimento e de grupos de consumidores, que também contribuem para o trabalho. 
Os TCs fazem os documentos técnicos com objetivos específicos com cada respectivo escopo, que são submetidos para aprovação de todos os Comitês Nacionais para votação e aprovações como normas internacionais. Sobre tudo, mais de 10.000 especialistas em todo o mundo participam dos trabalhos técnicos do IEC. A distribuição dos documentos de normatização é eletrônica, para aumentar a eficiência e reduzir os custos.

Outro fato importante, administrado pelos TCs, é que uma norma deve ser submetida a consulta pública em todos os países. Então, através de ferramentas democráticas de consenso e consulta pública, qualquer parte interessada pode argumentar e ter sua palavra no desenvolvimento e publicação de uma norma internacional.

A adoção de uma norma IEC por um país, se ele for um membro de Comissão ou não, é inteiramente voluntária.

Os representantes do Brasil na IEC são a ABNT e o Comitê Brasileiro de Eletricidade, Eletrônica, Iluminação e Telecomunicações (COBEI) e atuam através do Comitê Nacional do Brasil.

\section{Comitês e Sub-Comitês Técnicos referentes à Qualidade da Energia}

\section{Comitê Técnico $\mathrm{n}^{\circ}$ 77: Compatibilidade Eletromagnética}

O CT $\mathrm{n}^{077}$ elabora as normas e relatórios técnicos no campo da compatibilidade eletromagnética (EMC), com ênfase particular nas aplicações de equipamentos. 
Seu escopo de trabalho cobre os seguintes aspectos de EMC:

- Itens relacionados à EMC e à imunidade, em freqüências inteiras

- Emissões em faixas de baixa freqüência $(\leq 9 \mathrm{KHz})$

- Emissões em faixas de alta freqüência $(>9 \mathrm{KHz})$

Seu principal grupo de trabalho é o WG13 - Normas Genéricas sobre EMC.

Seus Sub-Comitês são:

- SC 77A: Fenômenos de Baixa Freqüência

- SC 77B: Fenômenos de Alta Freqüência

- SC 77C: Fenômenos Transitórios de Alta Potência

Como este trabalho tem por objetivo abordar os fenômenos eletromagnéticos em faixa de freqüência de até $9 \mathrm{kHz}$ os sub-comitês $77 \mathrm{~B}$ e $77 \mathrm{C}$ não serão abordados.

\section{Sub-Comitê 77A: Fenômenos de Baixa Freqüência}

O SC $n^{\circ} 77 \mathrm{~A}$ cuida da normalização no campo da compatibilidade eletromagnética com relação a fenômenos de baixa freqüência $(\leq 9 \mathrm{KHz})$.

Seus principais grupos de trabalhos são:

- WG1 - Harmônicos e outros distúrbios em baixa freqüência

- WG2 - Flutuações de tensão e outros distúrbios em baixa freqüência

- WG6 - Testes de imunidades em baixa freqüência 
- WG8 - Descrição do ambiente eletromagnético associado com os distúrbios apresentados em redes de fornecimento de energia

- WG9 - Métodos de medição de Qualidade da Energia

Grupo de Trabalho SC 77A/WG9: Métodos de Medição de Qualidade da Energia

Este grupo de trabalho tem como escopo definir os parâmetros de Qualidade da Energia e prover métodos e medidas padrões para caracterizar estes parâmetros e uma interpretação real destas medidas, sem contradizer as aplicações de segurança. A definição dos métodos de medição é necessária para obter a confiabilidade, reprodutibilidade e resultados comparáveis das diferentes medidas realizadas por diferentes organizações usando diferentes instrumentos certificados pela mesma norma da IEC.

\subsection{Normas da IEC relacionadas à QEE}

\subsubsection{Introdução}

As normas da IEC 61000 são referentes a produtos e serviços industriais com relação à compatibilidade eletromagnética. Estabelecem, portanto, todas as normas que abrangem os fenômenos eletromagnéticos relativos à QEE, expressos na tabela 
1.1. Por este motivo estas normas foram elaboradas pelo Comitê Técnico 77 e seus sub-comitês.

Esta família de norma abrange o contexto dos fenômenos relacionados à energia elétrica emitidos por um determinado equipamento, que se propagam pela rede do sistema elétrico e podem danificar ou causar mau funcionamento de outros aparelhos conectados à mesma rede. Estas normas também englobam os conceitos de imunidade destes equipamentos específicos em meios contendo distúrbios eletromagnéticos.

A IEC 61000 trata dos termos utilizados no ambiente eletromagnético, da descrição dos fenômenos de compatibilidade eletromagnética, da especificação de limites para estas compatibilidades, dos testes e métodos de medição e avaliação dos fenômenos, da instalação dos equipamentos com a finalidade de mitigar os problemas e conceitos genéricos de imunidade e emissão.

Sendo assim, a norma IEC 61000 está dividida em 6 partes para melhor interpretação e entendimento:

IEC 61000-1: generalidades

IEC 61000-2: ambiente

IEC 61000-3: limites

IEC 61000-4: ensaios e métodos

IEC 61000-5: instalação e mitigação

IEC 61000-6: normas genéricas

A parte da IEC 61000-1 tem como objetivo definir e apresentar os termos e as generalidades para se ingressar ao meio da compatibilidade eletromagnética e entender os conceitos relacionados com a mesma. 
$\mathrm{Na}$ parte da norma IEC 61000-2 estão descritos os fenômenos de compatibilidade eletromagnética do ambiente em que serão instalados os equipamentos. Nesta parte são apresentadas as descrições dos fenômenos, como estes atuam e influenciam no meio e os níveis de compatibilidade eletromagnética para produtos e equipamentos.

A parte IEC 61000-3 estabelece os limites de compatibilidade e emissão dos fenômenos eletromagnéticos apresentados por produtos e equipamentos focando na melhor interação entre estes com outros equipamentos e/ou com o meio em que estão instalados.

$\mathrm{Na}$ parte IEC 61000-4 são estabelecidos os conceitos de projetos de medidores e métodos de testes e medições para garantir a repetibilidade e a reprodutibilidade dos equipamentos de medição. Sendo assim são estabelecidas as formas de medição, a tolerância dos equipamentos utilizados e os procedimentos para leitura, para assegurar a conformidade com outras partes da norma.

A parte da IEC 61000-5 estabelece os métodos de instalação dos equipamentos ou utilização dos produtos de forma a amenizar sua influência no meio em que está instalado. Estes procedimentos auxiliam na mitigação dos problemas relacionados à imunidade e a qualidade da energia.

$\mathrm{Na}$ parte da norma IEC 61000-6 são fornecidas normas genéricas com relação à imunidade e emissão eletromagnética. Estas normas são ditas genéricas, pois não apresentam nenhum tipo de limites dos produtos ou equipamentos, mas reúnem todas as características que estes devem possuir para garantir o maior nível de imunidade e compatibilidade possível aos distúrbios eletromagnéticos existentes. 


\subsubsection{IEC 61000 na Qualidade da Energia}

Dentre todas as normas da IEC 61000 relacionadas à compatibilidade eletromagnética, muitas são comumente utilizadas e aceitas internacionalmente como referência para normatização em qualidade da energia. Estas normas que relacionam níveis de compatibilidade eletromagnética, limites aceitáveis dos fenômenos, métodos de medição e análise destas grandezas são muito consultadas e exigidas por fazerem parte dos itens que influenciam diretamente no ponto econômico do mercado de energia elétrica.

As normas da IEC com referência em qualidade da energia estabelecem padrões onde todas as partes do sistema de energia devem segui-las, sendo elas a concessionária, o fabricante e até mesmo o consumidor.

Conforme Dugan et al. (1996), as normas da IEC 61000 mais utilizadas internacionalmente para medição e análise da QEE são:

IEC 61000-2-2: Níveis de compatibilidade de condução de distúrbios em baixa freqüência

IEC 61000-3-2: Limites de corrente harmônica (In $\leq 16 \mathrm{~A})$

IEC 61000-3-3: Limites de variação de tensão e flicker (In $\leq 16 \mathrm{~A})$

IEC 61000-4-7: Guia geral de medição de harmônicos

IEC 61000-4-15: Flickermeter - especificações funcionais e de projeto

IEC 61000-4-30: Métodos de medição de qualidade da energia

Sendo assim, as normas citadas acima serão a base normativa para o desenvolvimento do protótipo do equipamento de medição dos fenômenos relativos à qualidade da energia utilizando os conceitos de ferramentas virtuais. 


\section{Qualímetro Baseado em Instrumentos Virtuais}

\subsection{Introdução}

Entre as muitas razões para se monitorar o sistema elétrico focando os fenômenos referentes à qualidade da energia, a principal, é a economia, principalmente se há a existência de cargas de processos críticos sendo alimentadas por este sistema. Os problemas de QEE, dependendo da sua intensidade e duração, podem gerar paradas nas máquinas, quebras e mau funcionamento, entre outros exemplos que resultam em perda financeira.

Conforme a norma IEEE 1159 (1995), as causas dos problemas de QEE são determinadas utilizando-se como ferramenta fundamental os analisadores de qualidade da energia, que auxiliam de forma decisiva nas investigações necessárias. Entre os casos mais comuns, o objetivo do monitoramento é o de diagnosticar a incompatibilidade entre a fonte e a carga ou o de avaliar o sistema elétrico de uma região específica.

Para Dugan et al. (1996), as medições são muito importantes para qualquer avaliação de problemas relacionados à QEE. A medição é o primeiro método de caracterização do problema ou do sistema que está sendo avaliado. Então, no processo de monitoramento há a reunião, análise e interpretação dos dados provenientes das medições, transformando-os em informações úteis. Estas informações, por sua vez, são utilizadas por profissionais competentes para caracterizar o desempenho de sistemas, caracterizarem problemas específicos, 
alertar para a manutenção preditiva ou corretiva do sistema ou partes dele, entre outros.

O equipamento de medição proposto neste capítulo está baseado nas normas da IEC61000, apresentadas no capítulo 3, garantindo repetibilidade e a precisão necessárias para assegurar resultados confiáveis de medição e harmonizar com os limites e processos das outras normas.

\subsection{Conceito das normas IEC relacionadas à QEE}

\subsubsection{IEC 61000-2-2}

Nesta norma são estabelecidos os níveis de compatibilidade de condução de distúrbios em baixa freqüência. São estes distúrbios, conduzidos pela rede de energia elétrica, em uma freqüência entre 0 a $9 \mathrm{kHz}$. Esta norma apresenta também a compatibilidade eletromagnética para sistemas de alimentação elétrica na rede pública de baixa tensão.

Estão contidos nesta norma os seguintes fenômenos:

- flutuação de tensão

- harmônicos

- subtensões e interrupções de tensão

- desequilíbrio de tensão

- sobretensões causadas por transitórios

- variações de freqüência

- componentes cc 


\section{Flutuação da Tensão}

Para os fenômenos de flutuação da tensão são apresentados os níveis de compatibilidade eletromagnética para estes equipamentos se adaptarem com o meio onde serão instalados.

A flutuação de tensão é limitada a 3\% do valor da tensão nominal declarada da rede de alimentação.

O flicker deve ser medido segundo a IEC 61000-4-15 para harmonizar com os níveis de compatibilidade desta norma.

Para estabelecer os limites do flicker foram criados dois indicadores de irritabilidade humana frente a este fenômeno, o Pst e o PIt.

O Pst é o indicador de flicker de curta duração, onde a severidade do flicker é avaliada por um período de tempo curto, geralmente 10 minutos. Para Pst=1 temos o limite convencional da irritabilidade humana.

Para o Plt temos o indicador de flicker de longa duração, onde a severidade do flicker é avaliada por um longo período de tempo de 2 horas. Para se calcular o PIt são utilizadas as medidas realizadas para o Pst.

Para se evitar irritabilidade nas pessoas e problemas com aparelhos o Pst medido em 10 minutos é limitado em 1 e o Plt medido em 2 horas é limitado em 0,8.

A figura 4.1 apresenta a curva do Pst igual a 1 (IEC61000-2-2, 2002). 


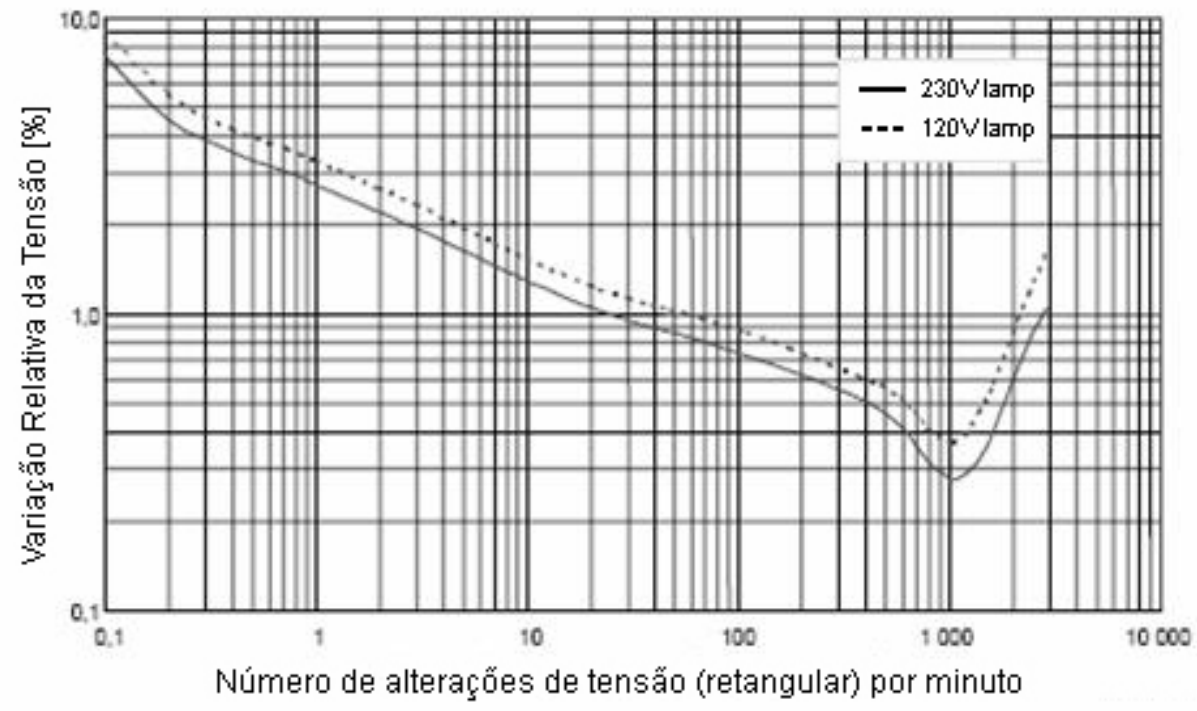

Figura 4.1. Curva para Pst=1

\section{Harmônicos}

Nesta parte são descritos os valores de compatibilidade de tensão para os equipamentos emissores de componentes harmônicos.

Os níveis de distorção harmônica com duração maior que 10 minutos $\left(h_{10 \min }\right)$, devem ser limitados a um THD de $8 \%$, porém cada componente harmônico de tensão deverá ficar dentro dos limites da tabela 4.1 (IEC61000-2-2, 2002).

\begin{tabular}{|c|c|c|c|c|c|}
\hline \multicolumn{2}{|c|}{$\begin{array}{c}\text { Harmônicos Ímpares nẫo } \\
\text { múltiplos de 3 }\end{array}$} & \multicolumn{2}{c|}{$\begin{array}{c}\text { Harmônicos Ímpares } \\
\text { múltiplos de 3 }\end{array}$} & \multicolumn{2}{c|}{ Harmônicos Pares } \\
\hline $\begin{array}{c}\text { Ordem do } \\
\text { Harmônico } \\
h\end{array}$ & $\begin{array}{c}\text { Tensẫo do } \\
\text { Harmônico \% }\end{array}$ & $\begin{array}{c}\text { Ordem do } \\
\text { Harmônico } \\
\mathrm{h}\end{array}$ & $\begin{array}{c}\text { Tensão do } \\
\text { Harmônico \% }\end{array}$ & $\begin{array}{c}\text { Ordem do } \\
\text { Harmônico } \\
\mathrm{h}\end{array}$ & $\begin{array}{c}\text { Tensẫo do } \\
\text { Harmônico \% }\end{array}$ \\
\hline 5 & 6 & 3 & 5 & 2 & 2 \\
7 & 5 & 9 & 1,5 & 4 & 1 \\
11 & 3,5 & 15 & 0,4 & 6 & 0,5 \\
13 & 3 & 21 & 0,3 & 8 & 0,5 \\
$17 \leq h \leq 49$ & $2,27 \times(17 / h)-0,27$ & $21<h \leq 45$ & 0,2 & $10 \leq h \leq 50$ & $0,25 \times(10 / h)+0,25$ \\
\hline
\end{tabular}

Tabela 4.1. Tabela de compatibilidade eletromagnética para emissão de harmônicos 
Para as emissões de harmônicos de tensão de duração até 3 segundos, os níveis de distorção total (THD) devem ser limitados a $11 \%$ e cada componente harmônico é limitado conforme a expressão 4.1.

$$
\text { Limite }_{\mathrm{h}}=k \times h_{10 \min } \quad\left[\mathrm{V}_{\mathrm{rms}}^{2} / \mathrm{Hz}\right]
$$

Onde:

$$
k=1,3+\frac{0,7}{45}(h-5)
$$

\section{Subtensão e interrupção de tensão}

Estes fenômenos especificados nesta seção da norma devem ser medidos em duas dimensões, sendo, amplitude x duração.

Devido a estes estudos serem recentes, a IEC ainda não tem dados que julguem ser suficientes para estabelecer uma compatibilidade eletromagnética para este fim. Outro motivo desta falta de compatibilidade é a discordância dos diversos ramos do sistema de energia elétrica, entre as diferentes necessidades de tolerância para os valores de tensão.

\section{Desequilíbrio de tensão}

Com relação à compatibilidade eletromagnética para desequilíbrio de tensão, a IEC 61000-2-2 (2002), considera um tempo maior que 10 minutos para sua classificação e eventuais efeitos. 
Este fenômeno deve ser medido somente em relação à seqüência negativa e seu nível de compatibilidade limite é $2 \%$.

\section{Sobretensões causada por transitórios}

Devido às muitas diferenças de pensamentos das várias entidades do sistema de energia elétrica, com respeito à origem dos transitórios e o nível de compatibilidade destes, o nível de sua compatibilidade eletromagnética não é especificado.

Estudos estão sendo dirigidos por entidades de pesquisas vinculadas a IEC para melhor esclarecer este assunto e possivelmente estabelecer parâmetros para estas grandezas.

\section{Variações de freqüência}

A IEC 61000-2-2 (2002) trata nesta seção a importância de uma freqüência em regime permanente ter uma variação muito pequena, pois equipamentos tomam a passagem por zero da onda de tensão como referência para várias finalidades.

O limite de compatibilidade eletromagnética de freqüência é $\pm 1 \mathrm{~Hz}$.

\section{Componentes CC}

Como o componente de corrente $\mathrm{CC}$ é determinado pela resistência em corrente contínua do circuito e para cada equipamento os mesmos causam problemas diferentes, a tolerância e a compatibilidade eletromagnética devem ser determinadas para cada caso por um profissional responsável. 


\subsubsection{IEC $61000-3-2$}

Por esta norma são estabelecidos os limites de emissão de harmônicos de corrente para equipamentos com corrente nominal até $16 \mathrm{~A}$ por fase.

Os limites de emissão de harmônicos de corrente para equipamentos com corrente nominal acima de 16A devem ser consultados na norma IEC 61000-3-4 (1998).

\section{Classificação dos Equipamentos}

Para determinar os limites de componentes harmônicos esta norma classificou os equipamentos elétricos em 4 classes distintas, como segue:

- Classe A: equipamentos trifásicos balanceados e todos os outros equipamentos com exceção dos listados nas classes abaixo

- Classe B: ferramentas portáteis

- Classe C: equipamentos para iluminação

- Classe D: equipamentos que tenham uma "forma de onda especial" de corrente e uma potência nominal menor ou igual a 600W

Sendo assim classificados, foram então estabelecidos seus limites para emissão de harmônicos. 
Os limites de componentes harmônicos de corrente para equipamentos classe A são dados pela tabela 4.2 (IEC61000-3-2, 2000).

\begin{tabular}{|c|c|}
\hline $\begin{array}{c}\text { Ordem do Harmônico } \\
h\end{array}$ & $\begin{array}{c}\text { Corrente Harmônica Máxima } \\
\text { Permissivel } \\
\mathrm{A}\end{array}$ \\
\hline \multicolumn{2}{|c|}{ Harmônicos İmpares } \\
\hline 3 & 2,30 \\
5 & 1,14 \\
9 & 0,77 \\
11 & 0,40 \\
13 & 0,33 \\
$15 \leq h \leq 39$ & 0,21 \\
\hline \multicolumn{2}{|c|}{ Harmônicos Pares } \\
\hline 2 & $0,15 \frac{15}{h}$ \\
\hline 6 & 1,08 \\
$8 \leq h \leq 40$ & 0,43 \\
\hline
\end{tabular}

Tabela 4.2. Limites de componentes harmônicos de corrente para equipamentos Classe A

Os limites dos componentes de corrente harmônica para classe B são calculados como sendo 1,5 vezes os valores da tabela da Classe $A$.

Para a classe $\mathrm{C}$, os limites de componentes harmônicos de corrente são apresentados na tabela 4.3 (IEC61000-3-2, 2000).

\begin{tabular}{|c|c|}
\hline Ordem do Harmônic 0 & $\begin{array}{c}\text { Corrente Harmônica Máxima Permissivel } \\
\text { expressa em porcentagem da corrente de } \\
\text { entrada na freqüência fundamental } \\
\text { h }\end{array}$ \\
\hline 2 & 2 \\
3 & $30 \cdot \lambda$ \\
5 & 10 \\
7 & 7 \\
9 & 5 \\
$11 \leq h \leq 39$ & 3 \\
(somente harmônicos ímpares) & \\
\hline$\lambda$ é o fator de potência do circuito \\
\hline
\end{tabular}

Tabela 4.3. Limites de componentes harmônicos de corrente para equipamentos Classe C 
Os limites de componentes harmônicos de corrente para os equipamentos classe D são mostrados na tabela 4.4 (IEC61000-3-2, 2000).

\begin{tabular}{|c|c|c|}
\hline Ordem do Harmônico & $\begin{array}{c}\text { Corrente Harmônica Máxima } \\
\text { Permissivel por Watt } \\
\text { mAMN }\end{array}$ & $\begin{array}{c}\text { Corrente Harmônica Máxima } \\
\text { Permissivel } \\
\text { A }\end{array}$ \\
\hline 3 & 3,4 & 2,3 \\
5 & 1,9 & 1,14 \\
7 & 1 & 0,77 \\
9 & 0,5 & 0,4 \\
11 & 0,35 & 0,33 \\
$13 \leq h \leq 39$ & 3,85 & ver tabela classe A \\
\hline
\end{tabular}

Tabela 4.4. Limites de componentes harmônicos de corrente para equipamentos Classe D

\subsubsection{IEC $61000-3-3$}

A norma IEC 61000-3-3 (1995) estabelece os limites das flutuações de tensão produzidos por equipamentos com corrente nominal de até $16 \mathrm{~A}$ por fase.

Os limites de flutuação de tensão produzidos por equipamentos com corrente nominal superior a 16A são estabelecidos pela norma IEC 61000-3-5 (1994).

A medição dos níveis de tensão para avaliação das flutuações de tensão deve ser realizada diretamente nos terminais de alimentação do equipamento.

Os limites estabelecidos por esta norma para os parâmetros dos indicadores de flicker são Pst $\leq 1$ e Plt $\leq 0,65$.

Para os limites de variação de tensão os parâmetros abaixo devem ser seguidos, baseados na figura 4.2 (IEC61000-3-3, 1995). 
- $\mathrm{d}(\mathrm{t}) \leq 3,3 \% / 500 \mathrm{~ms}$

- $\mathrm{d}_{\mathrm{c}} \leq 3,3 \%$

- $\mathrm{d}_{\max }$ :

$\leq 4 \%$ sem condições adicionais

$\leq 6 \%$ para equipamentos comandados manualmente ou menos de 2 vezes/dia

$\leq 7 \%$ para equipamentos comandados automaticamente ou mais de 2 vezes/dia

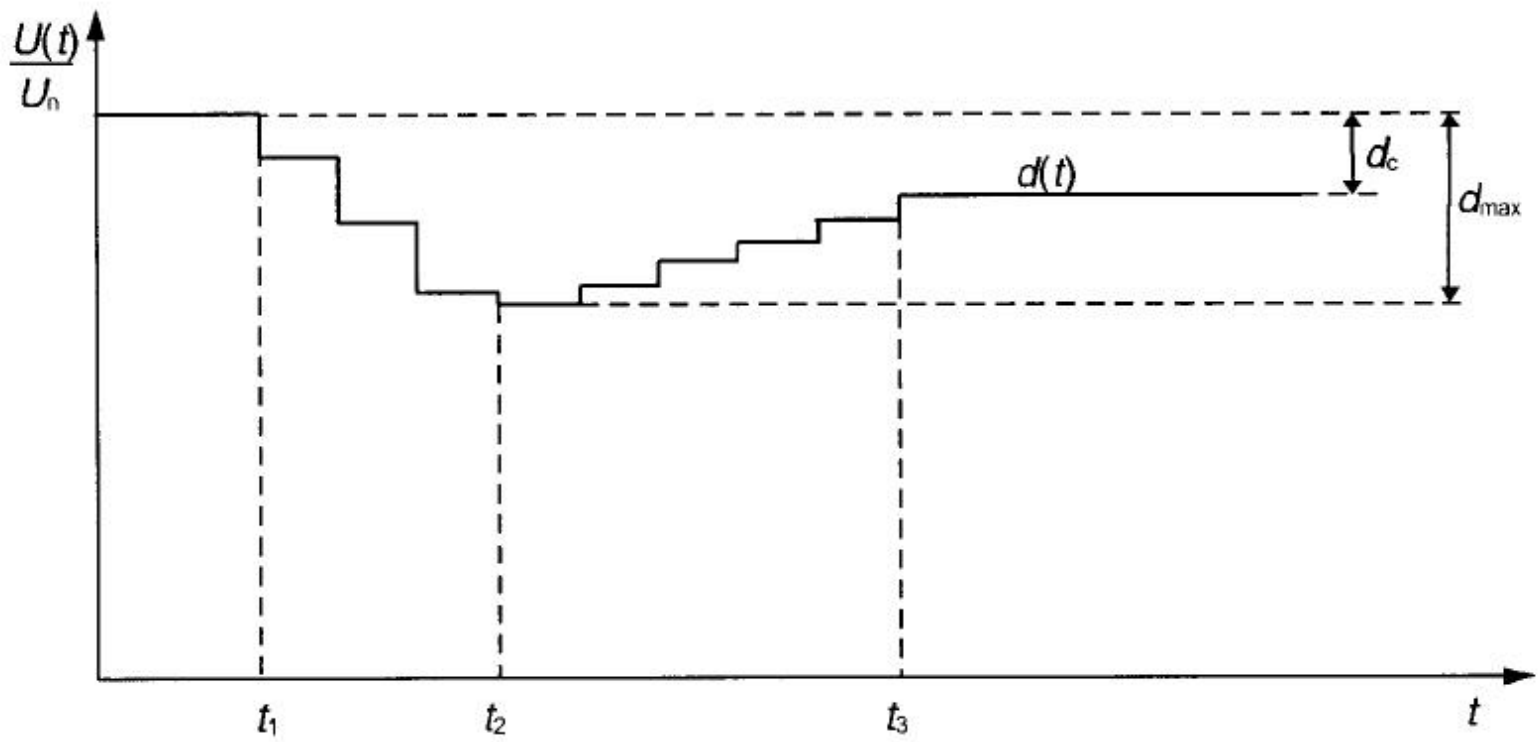

Figura 4.2. Análise da variação de tensão em p.u.

\subsubsection{IEC 61000-4-7}

Esta norma é utilizada como um guia geral para medição e análise de harmônicos. É aplicável a todos os instrumentos destinados a medição de componentes espectrais em uma faixa de freqüência até $9 \mathrm{kHz}$ que são superpostas à onda fundamental do sistema de suprimento de energia elétrica de $50 \mathrm{~Hz}$ e $60 \mathrm{~Hz}$. 
A IEC 61000-4-7 (2002) tem como objetivo base estabelecer padrões na forma de medição dos harmônicos para que haja uma considerável repetibilidade e confiabilidade por qualquer equipamento que fora certificado por esta norma, visando assim um parâmetro único com ótima garantia de confiança.

A medição de harmônicos conforme o indicado nesta norma é realizada em períodos de amostragem do sinal, sendo 10 períodos de onda para $50 \mathrm{~Hz}$ e 12 períodos de onda para $60 \mathrm{~Hz}$, caracterizando assim uma janela de medição.

Para execução do instrumento de medição em questão deve-se obrigatoriamente estabelecer as cinco fases características do medidor de harmônicos:

- Circuito de entrada

- Conversor A/D

- Sincronizador

- Processador

- Agrupamento e Linearização

\section{Circuito de Entrada}

Neste circuito deverão ser instalados os componentes para regulação e compatibilização da tensão da rede com a tensão a ser medida pelo equipamento, tanto quanto as devidas proteções e meios pelo qual o sinal chegue até a etapa do conversor A/D.

Alguns equipamentos trazem neste estágio um circuito gerador de sinal para calibração do equipamento. 


\section{Conversor A/D}

É o circuito responsável pela amostragem do sinal e a conversão do sinal amostrado em sinais digitais para o processador realizar os devidos cálculos.

Os sinais amostrados devem ser amostrados segundo o teorema de Nyquist para evitar o efeito aliasing (OPPENHEIM; SCHAFER; BUCK, 1999).

\section{Sincronizador}

O circuito sincronizador realiza o sincronismo entre os sinais amostrados e as devidas janelas de medição, para que haja uma correspondência direta entre os sinais medidos e a janela amostrada.

\section{Processador}

O processador DFT (Discrete Fourier Transform) é o responsável pela transformação do sinal amostrado em freqüência para o sinal em componentes discretas no tempo. O processador na saída de seu estágio de transformação DFT fornece os valores dos coeficientes de Fourier $a_{m}$ e $b_{m}$ para que seja elaborado o gráfico de densidade espectral de potência $x$ freqüência.

As expressões de 4.3 a 4.10 apresentam os cálculos executados pelo processador. 


$$
f(t)=c_{0}+\sum_{m=1}^{\infty} c_{m} \sin \left(\frac{m}{N} \omega_{1} t+\theta_{m}\right)
$$

Onde:

$$
\begin{aligned}
& c_{0}=\frac{1}{T_{w}} \int_{0}^{T_{w}} f(t) d t \\
& a_{m}=\frac{2}{T_{w}} \int_{0}^{T_{w}} f(t) \cos \left(\frac{m}{N} \omega_{1} t+\theta_{m}\right) d t \\
& b_{m}=\frac{2}{T_{w}} \int_{0}^{T_{w}} f(t) \sin \left(\frac{m}{N} \omega_{1} t+\theta_{m}\right) d t \\
& T_{m}=\frac{1}{f_{1}} b_{m}+j a_{m} \mid=\sqrt{a_{m}{ }^{2}+b_{m}{ }^{2}} \\
& T_{w}=N T_{1} \\
& \omega_{1}=\frac{1}{f_{1}}
\end{aligned}
$$

com: $\mathrm{N}=$ número de períodos da componente fundamental na janela 


\section{Agrupamento e Linearização}

Na etapa de agrupamento são unificados os componentes interharmônicos que tem influência no harmônico mais próximo, conforme apresentado nas equações $4.11(50 \mathrm{~Hz})$ e $4.12(60 \mathrm{~Hz})$ e mostrado na figura 4.3 (IEC61000-4-7, 2002).

$$
\begin{array}{ll}
G_{n}{ }^{2}=\frac{C_{k=-5}^{2}}{2}+\sum_{i=-4}^{4} C_{k+i}+\frac{C_{k=5}^{2}}{2} & {\left[\mathrm{Arms}^{2} / \mathrm{Hz}\right]} \\
G_{n}{ }^{2}=\frac{C_{k=-6}{ }^{2}}{2}+\sum_{i=-5}^{5} C_{k+i}+\frac{C_{k=6}^{2}}{2} & {\left[\mathrm{Arms}^{2} / \mathrm{Hz}\right]}
\end{array}
$$

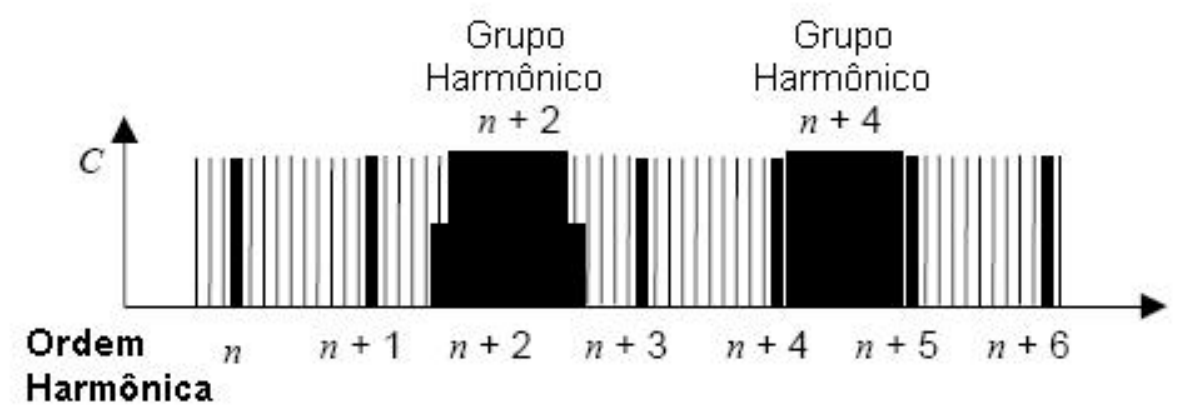

Figura 4.3. Agrupamento dos harmônicos

No estágio de linearização é utilizado um filtro passa-baixa de $1^{\circ}$ ordem, apresentado na figura 4.4 (IEC61000-4-7, 2002).

Seus coeficientes são $\alpha=8,012$ e $\beta=7,012$.

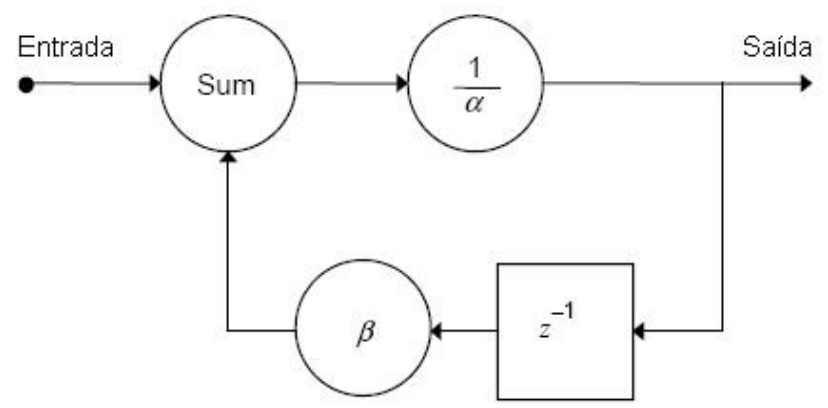

Figura 4.4. Filtro passa-baixa de $1^{\circ}$ ordem 
$\mathrm{Na}$ figura 4.5 é apresentado um fluxograma de um equipamento segundo a IEC 61000-4-7 (2002), contendo todos os blocos básicos e algumas saídas sugeridas.

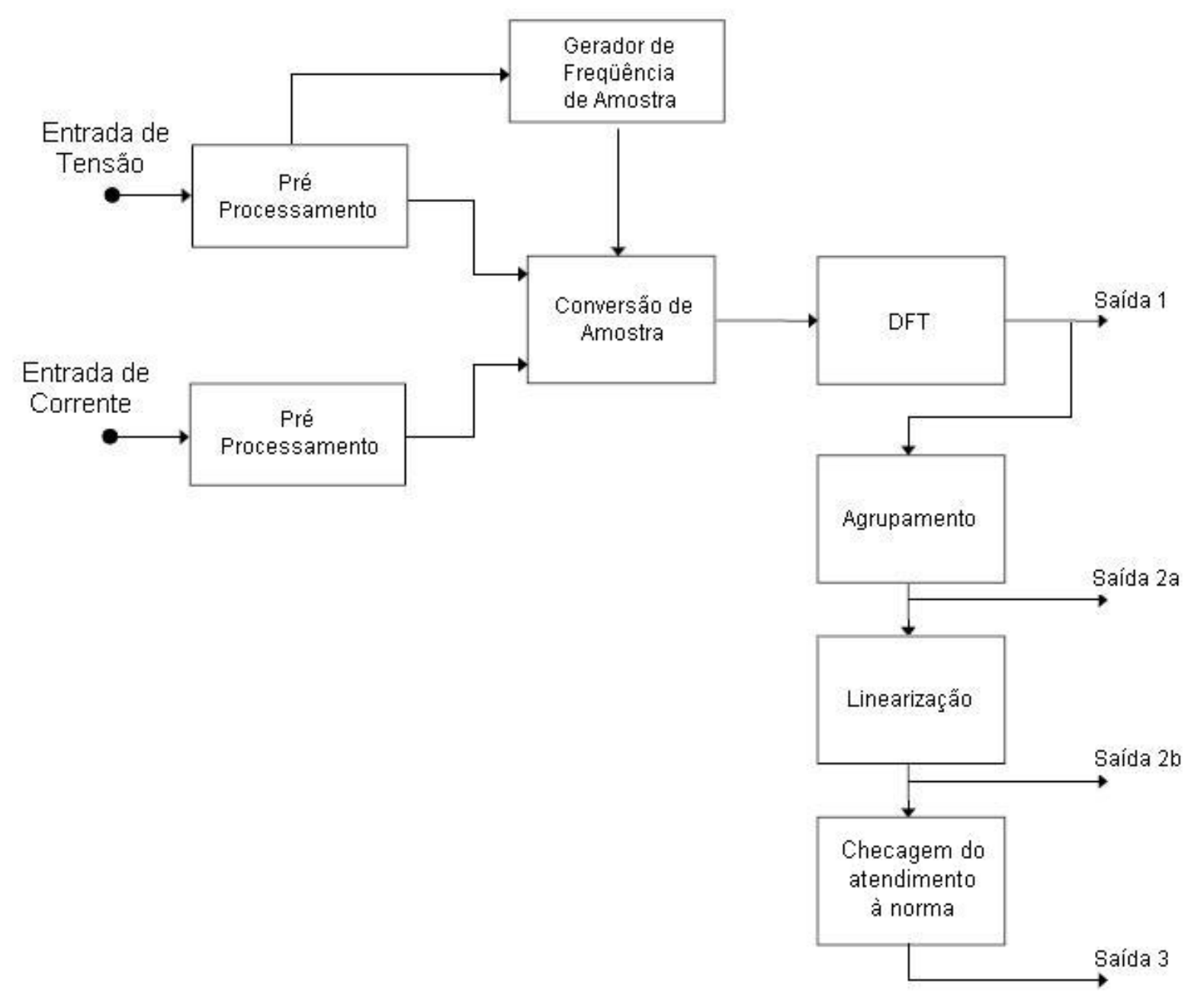

Figura 4.5. Fluxograma de equipamento para medição de harmônicos segundo a IEC61000-4-7

\subsubsection{IEC61000-4-15}

A norma internacional IEC61000-4-15 (2003), é aplicável aos instrumentos destinados à medição de flicker para indicação do correto nível de percepção para ondas de flutuação de tensão. 
Um aparelho que atenda as características expostas nesta norma garante a confiabilidade da medição e a repetibilidade esperada em todas as normas IEC sobre este assunto.

Um equipamento especificado por esta norma tem sua arquitetura dividida em 5 partes:

- Circuito de entrada (bloco 1)

- Demodulador quadrático (bloco 2)

- Filtros de ponderação (bloco 3)

- Multiplicador quadrático e linearização (bloco 4)

- Análise estatística (bloco 5)

\section{Circuito de Entrada e Circuito de Calibração}

O circuito de entrada tem como responsabilidade ajustar os níveis de tensão de entrada para os níveis de tensão funcionais do equipamento. Este módulo, assim como no medidor da IEC61000-4-7, pode conter um circuito de calibração que tem como função a geração de um sinal padrão com resposta conhecida.

\section{Demodulador Quadrático}

No bloco contendo o demodulador quadrático, o sinal de entrada é dividido em sinal da onda e sinal de modulação da variação de amplitude da onda. Somente o sinal de variação da amplitude da onda será enviado ao próximo estágio, pois é este sinal que caracteriza a flutuação. 


\section{Filtros de Ponderação}

Este bloco é formado por dois filtros. O primeiro filtro elimina as componentes $\mathrm{CC}$ e as principais componentes com alta ondulação (ripple). O segundo filtro executa uma ponderação que simula a freqüência de resposta de uma onda senoidal em um filamento de uma lâmpada incandescente. A saída deste filtro é a resposta estimada de irritabilidade ao fenômeno de flicker, sendo a amostrada dada por $50 \%$ das pessoas testadas em várias freqüências de flutuação.

\section{Multiplicador Quadrático e Ponderação}

Este bloco executa um tratamento do sinal recebido similarmente à resposta da sensação lâmpada-olho-cérebro. A função deste bloco é simular a nãolinearidade e o efeito memória do olho-cérebro.

\section{Análise Estatística}

No bloco de análise estatística um microprocessador realiza uma análise do nível de flutuação vindo do bloco anterior com parâmetros significantes. O processador realiza uma classificação em 64 níveis para estabelecer o valor do Pst. Na figura 4.6 é apresentada uma representação de classificação em 10 níveis da amplitude da variação de tensão. A figura 4.7 apresenta a classificação de 10 níveis da amplitude da variação da tensão como função de probabilidade cumulativa (IEC61000-4-15, 2003). 


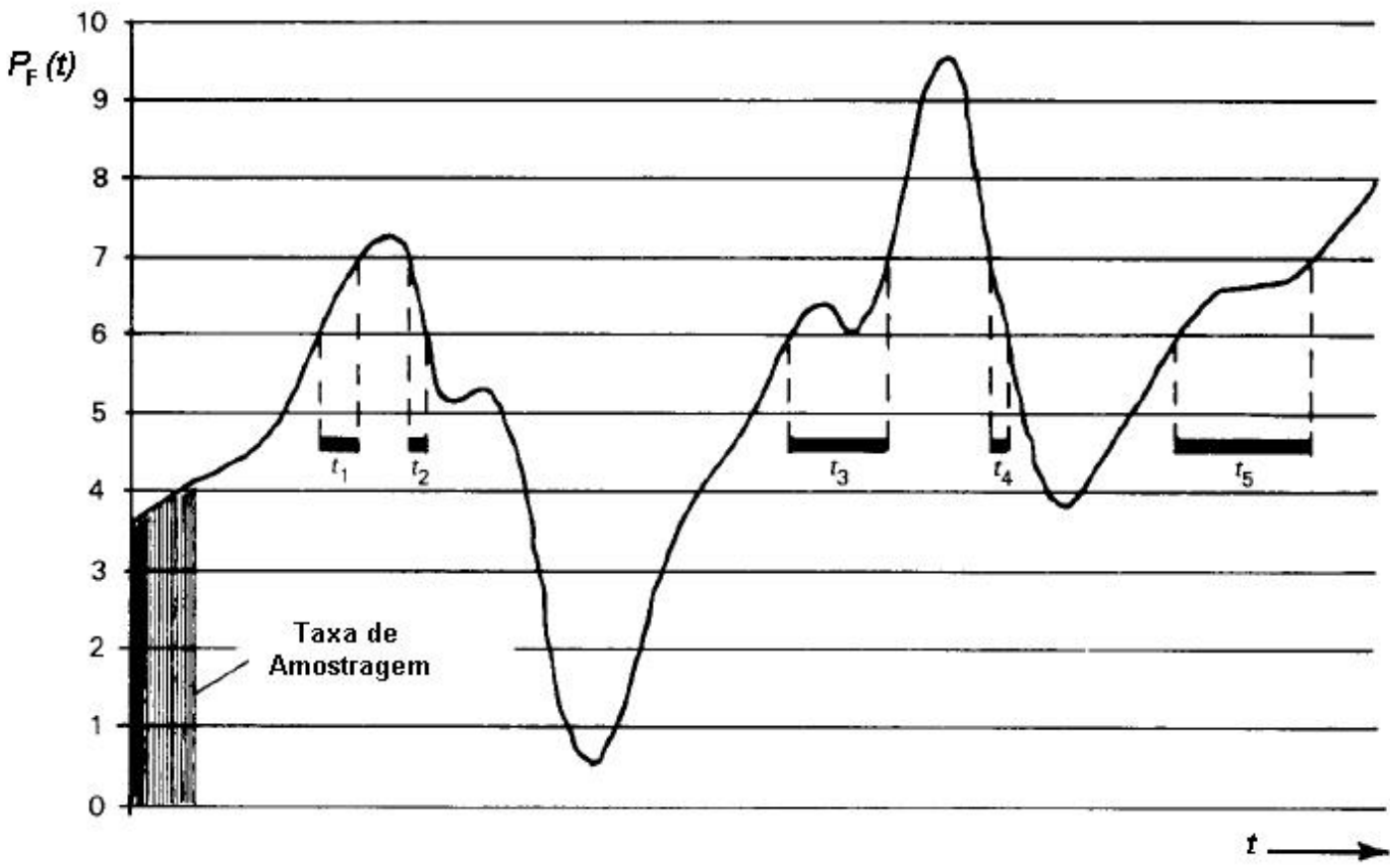

Figura 4.6. Níveis de flicker em função da variação do tempo

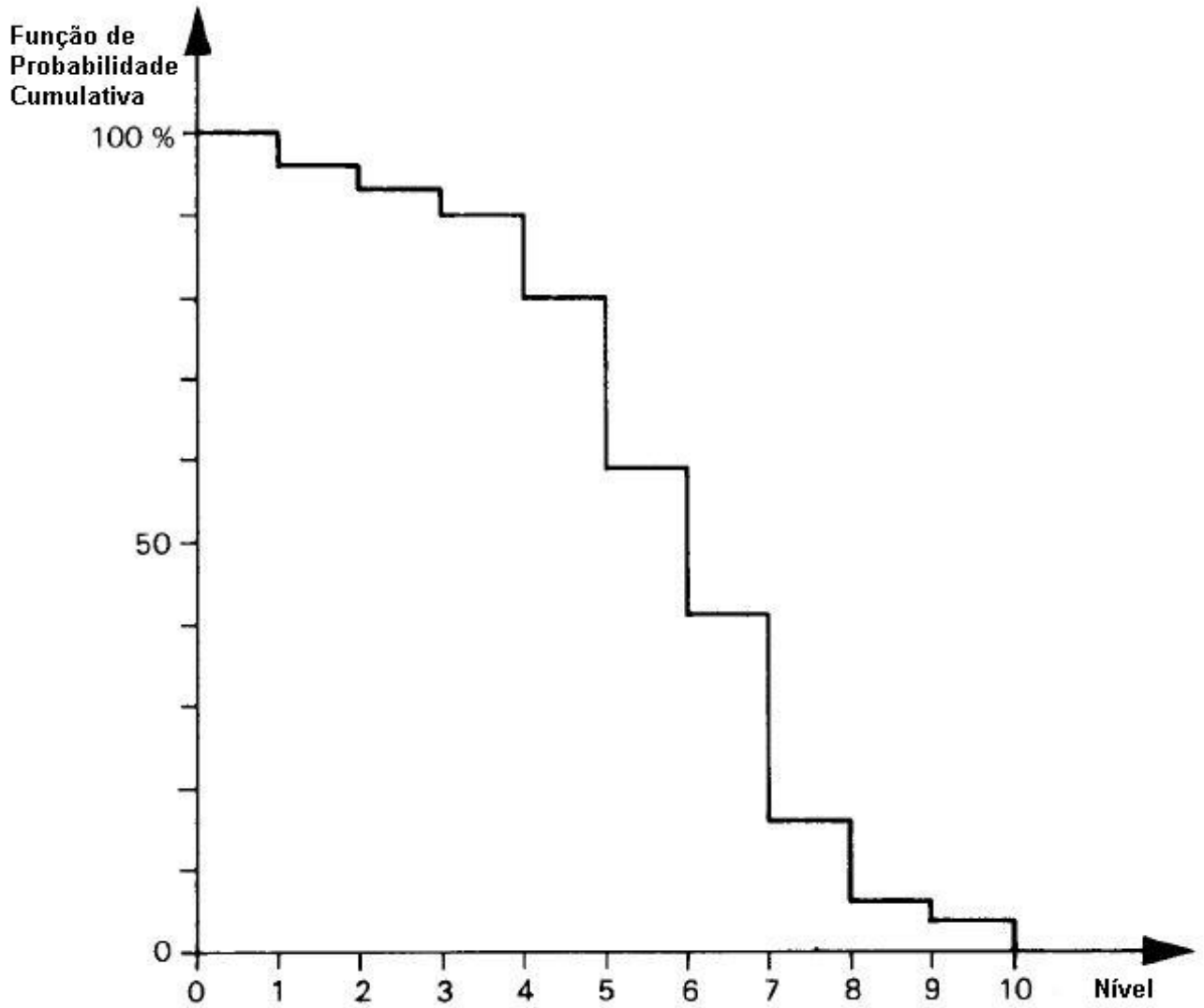

Figura 4.7. Função de probabilidade cumulativa de um sinal contendo flicker 
A avaliação do flicker de curta duração Pst, que é medida em 10 minutos, é então realizada sobre a função da probabilidade cumulativa e é obtida pela expressão 4.13.

$$
P s t=\sqrt{0.0314 P_{0.1}+0.0525 P_{1 s}+0.0657 P_{3 s}+0.28 P_{10 s}+0.08 P_{50 s}}
$$

Onde:

$P_{0.1}=$ função cumulativa de flicker em $0,1 \%$

$P_{1 s}=$ função cumulativa linearizada de flicker em 1\%

$$
P_{1 s}=\frac{P_{0.7}+P_{1}+P_{1.5}}{3}
$$

$P_{3 s}=$ função cumulativa linearizada de flicker em 3\%

$$
P_{3 s}=\frac{P_{2.2}+P_{3}+P_{4}}{3}
$$

$P_{10 s}=$ função cumulativa linearizada flicker em 10\%

$$
P_{10 s}=\frac{P_{6}+P_{8}+P_{10}+P_{13}+P_{17}}{5}
$$

$P_{50 s}=$ função cumulativa linearizada flicker em $50 \%$

$$
P_{50 s}=\frac{P_{30}+P_{50}+P_{80}}{3}
$$


A avaliação do flicker de longa duração PIt, é medida geralmente no período de 2 horas e baseia-se nas medidas do Pst. O valor de Plt é dado pela expressão 4.18.

$$
P l t=\sqrt[3]{\frac{\sum_{i=1}^{N} P s t_{i}^{3}}{N}}
$$

Onde:

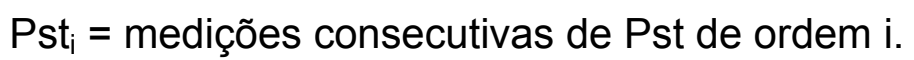

$\mathrm{N}=$ número de medidas de Pst necessárias para calcular o Plt no período desejado. No caso de período igual a 2 horas tem-se $\mathrm{N}=12$.

Na figura 4.8 (IEC61000-4-15, 2003), pode-se observar o diagrama funcional de um medidor de flicker contendo todos os blocos básicos e algumas saídas sugeridas (IEC61000-4-15, 2003). 


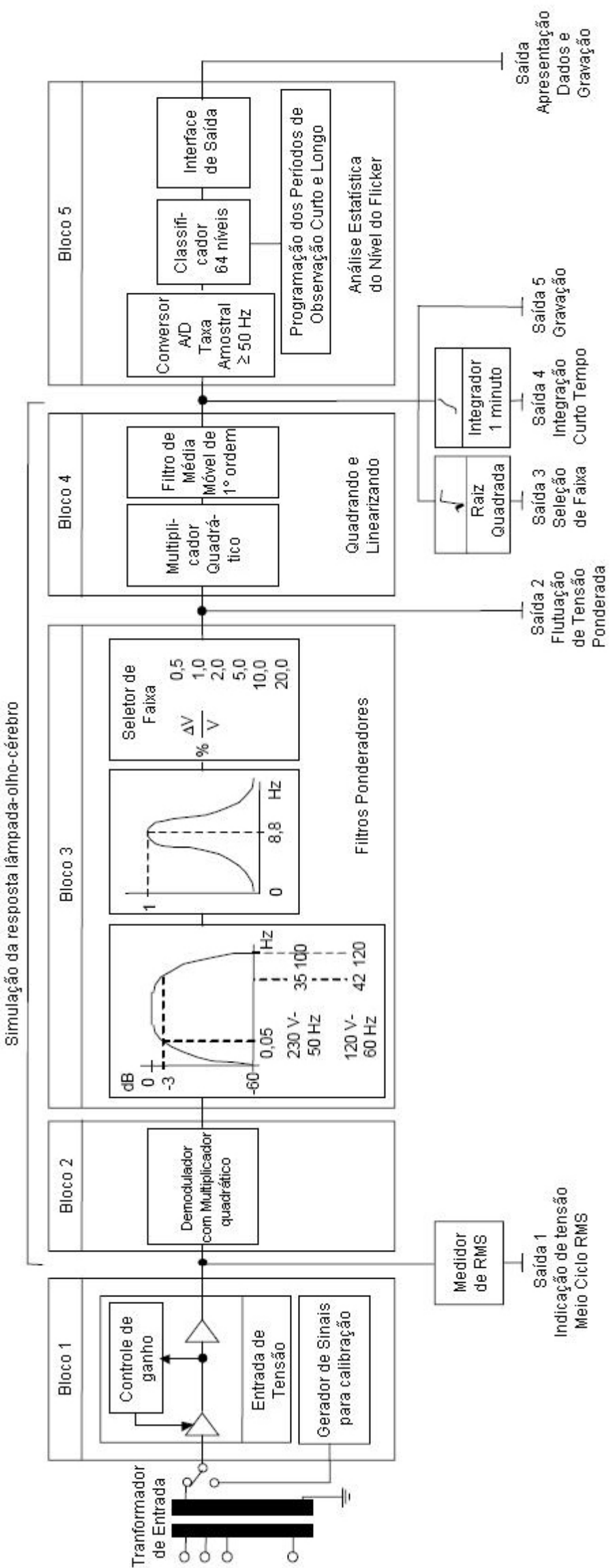

Figura 4.8. Diagrama funcional do medidor de flicker 


\subsubsection{IEC61000-4-30}

A norma mais abrangente e mais utilizada em qualidade da energia é a IEC61000-4-30 (2003), pois engloba praticamente todos os fenômenos que os pesquisadores caracterizam como QEE (ZIMATH; VIEIRA, 2005).

Esta norma define os métodos para medição e interpretação dos resultados dos parâmetros de qualidade da energia em $50 \mathrm{~Hz}$ e $60 \mathrm{~Hz}$ para redes de fornecimento de energia AC.

A IEC61000-4-30 tem como característica principal especificar o desempenho de resposta do equipamento e não explicar o projeto deste.

Os fenômenos abrangidos por esta norma são:

- Freqüência

- Magnitude de Tensão

- Subtensão e Sobretensão

- Interrupção

- Transitórios

- Desequilíbrio de Tensão

- Harmônicos

- Flutuação da Tensão

Deve-se observar algumas definições antes de iniciar os estudos dos métodos segundo a classificação desta norma (IEC61000-4-30, 2003). Seguem estas definições: 
- $\mathrm{U}_{\mathrm{rms}(1 / 2)}$

é o valor de tensão eficaz medido sobre um ciclo, iniciando na passagem por zero e reiniciado a cada semi-ciclo.

- Desempenho de medição classe A

é a classe de medição onde são necessárias medidas precisas. Por exemplo, para serem utilizadas como fonte de prova em um processo de indenização por problemas apresentados pela concessionária na rede elétrica. Nesta classe os tempos e métodos são especificados pela norma.

- Desempenho de medição classe B

é a classe de medição onde não é necessária uma grande precisão dos valores. Por exemplo, para pesquisas estatísticas. Nesta classe os tempos e métodos devem ser indicados pelo usuário conforme cada necessidade.

Os equipamentos que analisam a rede segundo a IEC61000-4-30 devem realizar uma agregação de tempo tendo como base períodos de 10 ciclos para $50 \mathrm{~Hz}$ e 12 ciclos para $60 \mathrm{~Hz}$, sendo agregados convenientemente em períodos de 3 segundos (150/180 ciclos), 10 minutos e 2 horas conforme cada necessidade, como é apresentado na figura 4.9 . 


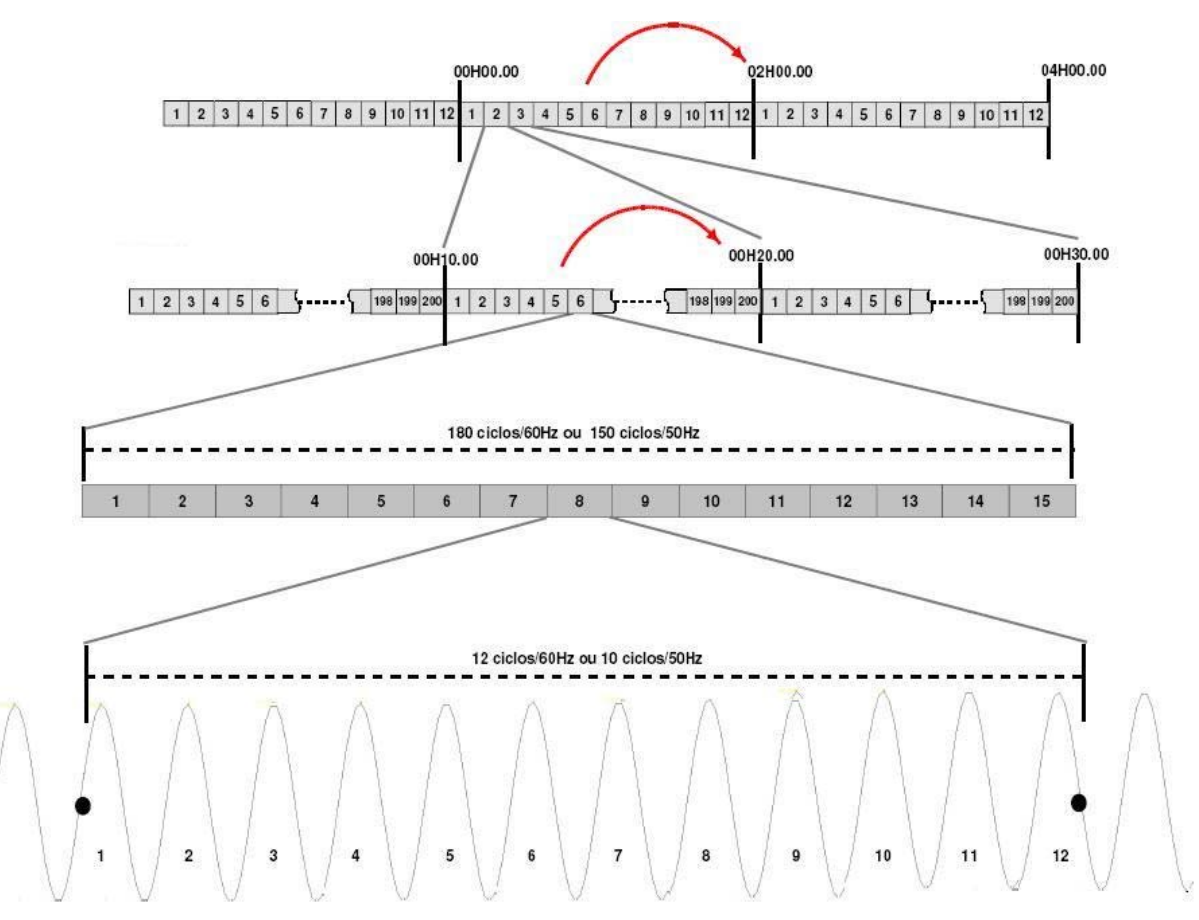

Figura 4.9. Agregação de tempo de um instrumento de medição

Para melhor busca no banco de dados do equipamento dos distúrbios relacionados a esta norma deve-se utilizar o conceito de "marcação" (flag) para indicação do local no tempo de agregação onde foi registrado este distúrbio, conforme pode ser observado na figura 4.10.

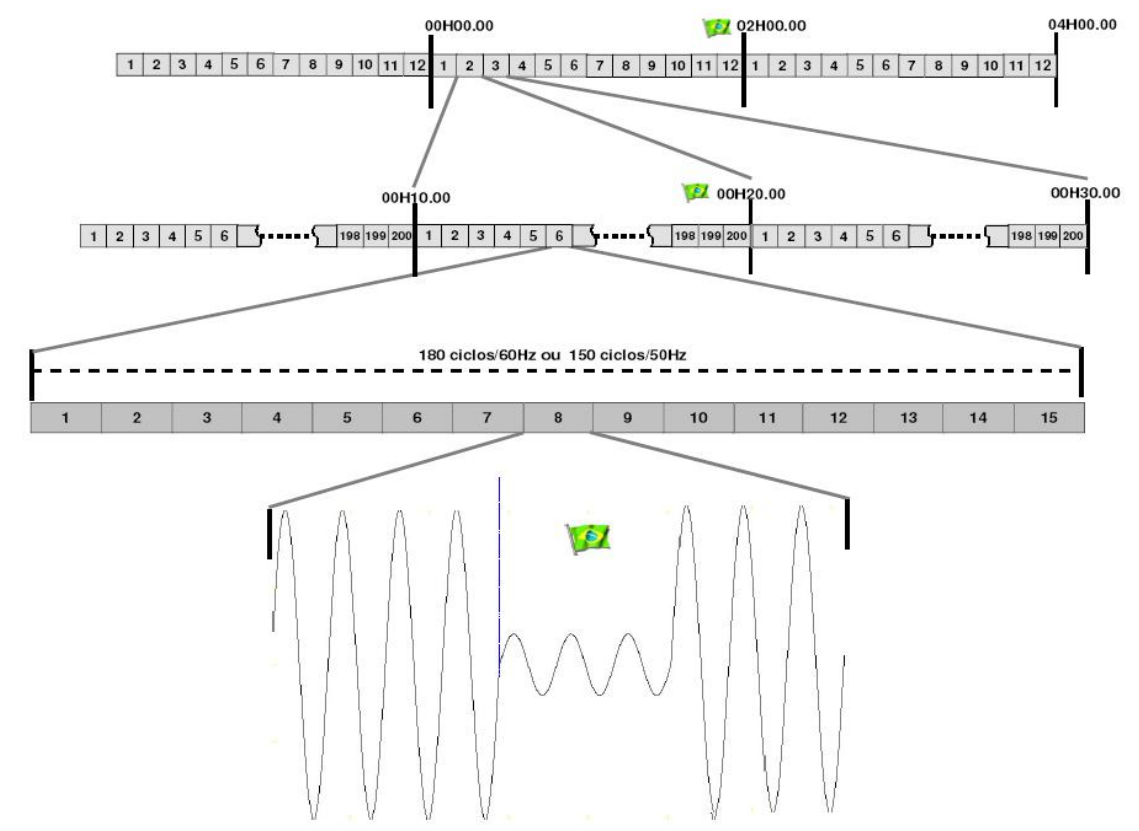

Figura 4.10. Conceito de flag para indicar o acontecimento de um distúrbio 


\section{Freqüência}

A freqüência da rede deve ser medida em períodos de 10 segundos. O valor da grandeza freqüência é a razão da quantidade de ciclos inteiros pelo período de observação como apresentado pela equação 4.19 e demonstrado na figura 4.11.

$$
f=\frac{n}{t}
$$

[Hz]

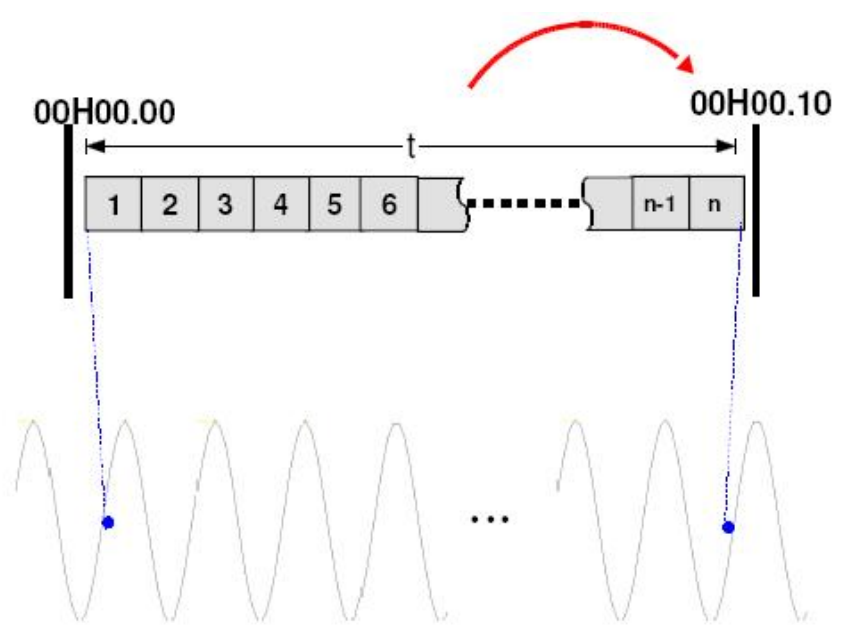

Figura 4.11. Medição da freqüência segundo IEC61000-4-30

\section{$\underline{\text { Magnitude de Tensão }}$}

A medição de magnitude de tensão deve ser o valor eficaz da magnitude da onda de tensão em um período de 10 ciclos para $50 \mathrm{~Hz}$ ou 12 ciclos para $60 \mathrm{~Hz}$. Devem ser agregados de acordo com o especificado e de medição contínua no tempo. 


\section{Subtensão e Sobretensão}

Tanto a medição de subtensão como a de sobretensão devem ser analisadas em meio ciclo $U_{\mathrm{rms}(1 / 2) \text {. }}$

Uma subtensão é caracterizada quando o valor de $U_{\mathrm{rms}(1 / 2)}$ cai abaixo da porcentagem especificada (usualmente entre 85 a 90\%) da tensão nominal declarada da rede de fornecimento de energia.

Uma sobretensão é caracterizada quando o valor de $U_{\mathrm{rms}(1 / 2)}$ sobe acima da porcentagem especificada (usualmente 110\%) da tensão nominal declarada da rede de fornecimento de energia.

Como durante a ocorrência destes fenômenos a freqüência poderá ser alterada, a freqüência para sincronizar $\bigcup_{\mathrm{rms}(1 / 2)}$ deverá ser a última freqüência medida sem a ocorrência de nenhum distúrbio.

Um exemplo da caracterização de subtensão e sobretensão, segundo a IEC61000-4-30 (2003), pode ser visto na figura 4.12.

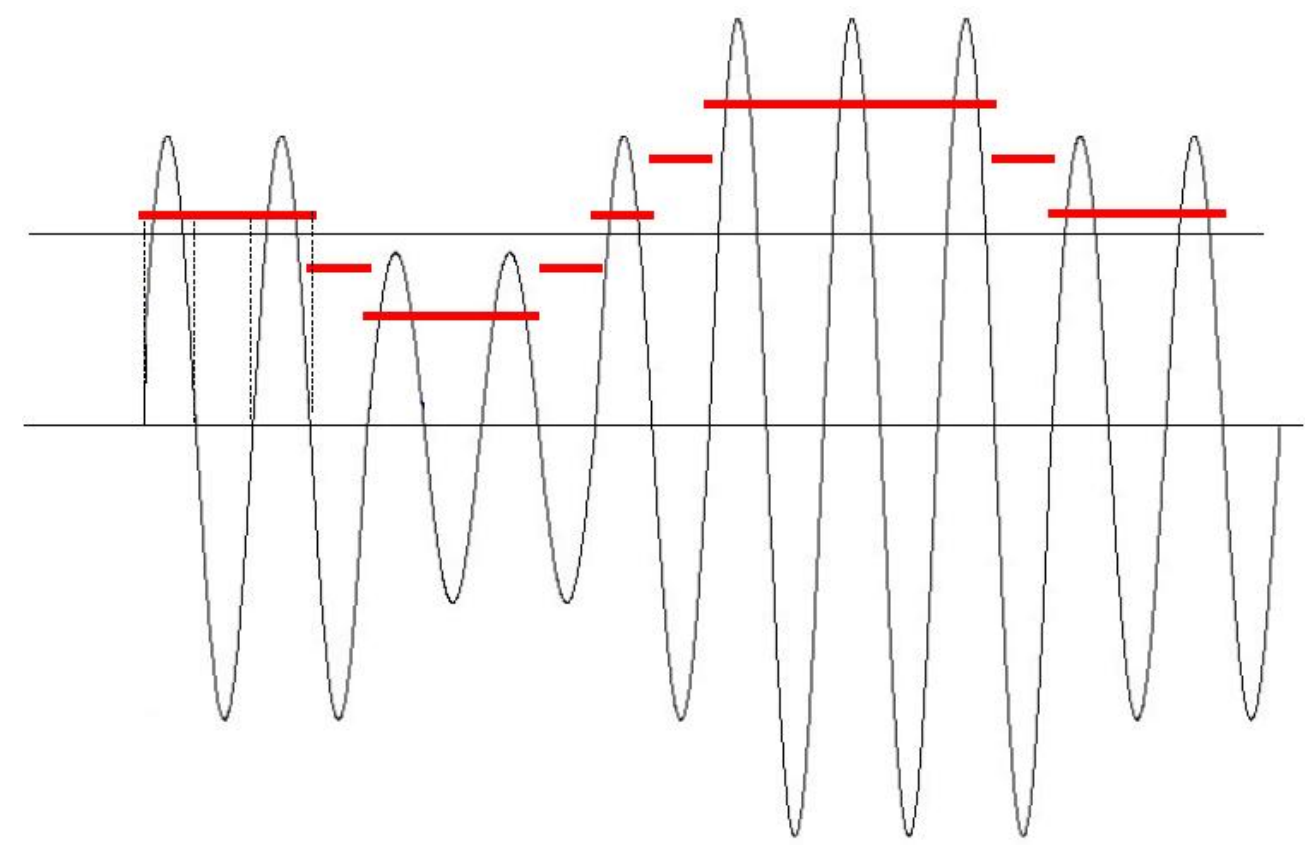

Figura 4.12. Análise do valor eficaz para caracterização de subtensão e sobretensão 
Interrupção

O fenômeno de interrupção tem a forma da medição análoga à medição de subtensão e sobretensão.

Sua caracterização se dá quando o valor de $U_{\mathrm{rms}(1 / 2)}$ cai abaixo de um valor específico (usualmente $5 \%$ ) da tensão nominal declarada da rede de energia.

\section{Desequilíbrio de Tensão}

A medição do desequilíbrio de tensão é realizada a cada 10 ciclos para $50 \mathrm{~Hz}$ ou 12 ciclos para $60 \mathrm{~Hz}$.

Para a análise deste fenômeno podemos utilizar os métodos de componentes simétricas. As componentes usadas são a de seqüência negativa, de seqüência zero e de seqüência positiva.

O valor da indicação do desequilíbrio de tensão é expresso por 4.20 para desequilíbrio de seqüência negativa e por 4.21 para desequilíbrio de seqüência zero (CORREIA; BRONZEADO, 2001).

$$
\begin{aligned}
& u_{2}=\frac{\text { componentes de seqüência negativa }}{\text { componentes de seqüência positiva }} \times 100 \quad[\%] \\
& u_{0}=\frac{\text { componentes de seqüência zero }}{\text { componentes de seqüência positiva }} \times 100
\end{aligned}
$$


Onde:

$$
\begin{aligned}
& \text { comp.seq.zero }=\sqrt{\left(V_{1 n}+\delta V_{2 n}+\gamma V_{3 n}\right)^{2}+(\sqrt{1-}} \gamma^{2} \\
& \text { comp.seq.positiva }=\sqrt{\frac{\left(V_{12}^{2}+V_{23}^{2}+V_{31}^{2}\right)(1+\lambda)}{6}} \\
& \text { comp.seq.negativa }=\sqrt{\frac{\left(V_{12}^{2}+V_{23}^{2}+V_{31}^{2}\right)(1-\lambda)}{6}} \\
& \delta=\frac{V_{1 n}^{2}+V_{2 n}^{2}-V_{12}^{2}}{2 V_{1 n} V_{2 n}} \\
& \lambda=\frac{\sqrt{3-\frac{6\left(V_{12}^{4}+V_{23}^{4}+V_{31}^{4}\right)}{\left(V_{12}^{2}+V_{23}^{2}+V_{31}^{2}\right)^{2}}}}{2 V_{1 n} V_{3 n}} \\
& \gamma=\frac{V_{3 n}^{2}-V_{13}^{2}}{6}
\end{aligned}
$$

\section{Transitórios}

A IEC61000-4-30 coloca o fenômeno de transitórios e sua forma de detecção, classificação e caracterização como assuntos complexos. Portanto não são 
definidos ainda nesta revisão da norma. Grupos de pesquisadores vinculados a IEC trabalham para análise deste fenômeno.

É recomendado que os transitórios sejam registrados pela oscilografia do equipamento. Para isto podem ser utilizadas pelo equipamento, como forma de gatilho para gravação e flag os seguintes conceitos:

- Método comparativo: estabelece um limite de tensão para o gatilho

- Método $d v / d t$ : estabelece uma brusca variação na tensão para o gatilho

- Método freqüência/amplitude: utiliza análises de Fourier ou Wavelet para detectar os distúrbios

- Outros métodos: inclui os métodos de análise da freqüência $x$ amplitude

$\underline{\text { Harmônicos }}$

Devem ser medidos e classificados segundo a norma IEC61000-4-7.

Flutuação da Tensão

Devem ser medidos e classificados segundo a norma IEC61000-4-15. 


\subsection{Hardware}

\subsubsection{Introdução}

O conhecimento geral dos pesquisadores e cientistas sobre os fenômenos relacionados à QEE vem aumentando com o passar dos anos. Somando o conhecimento adquirido ao histórico de eventos ocorridos e monitorados durante as últimas décadas, as instituições normativas criam e revisam suas normas constantemente para que estas sempre estejam alinhadas com as novas descobertas e que garantam uma implementação de forma correta e segura.

Os equipamentos de medição da área de QEE que são projetados conforme normas estão dispostos às alterações em seu hardware e software, pois devem acompanhar o estabelecido nestas normas, que por sua vez, estão em constante mudança para se adequarem às necessidades da sociedade e às novas descobertas, além das novas normas criadas introduzidas na comunidade técnica. Tanto as novas normas quanto as revisadas devem ser acrescidas ou alteradas nas funções ou formas de cálculo do instrumento de medição para que este equipamento não se torne obsoleto.

Para as medições dos fenômenos relativos à QEE os equipamentos de medição, existentes no mercado atual, são em sua maioria microprocessados. Estes instrumentos microprocessados com a finalidade de serem portáteis têm um hardware muito compacto, pois são projetados de forma a otimizar o espaço disponibilizado, conectando assim várias funções distintas em uma mesma placa. Pelo aglomerado de funções em uma mesma placa o equipamento perde sua 
flexibilidade de acompanhamento da evolução das normas, pois caso seja necessário uma alteração de hardware será obrigatório a troca de toda a placa do equipamento que engloba a função que deve mudar, levando a um custo relativamente alto se comparado ao preço total do equipamento. Outras observações importantes nos equipamentos microprocessados são as dificuldades de manutenção em seu hardware, as baixas possibilidades de expansão e as remotas oportunidades de reutilização do hardware obsoleto em outras aplicações.

Um dos objetivos deste trabalho é apresentar um protótipo de equipamento microcomputadorizado de medição dos fenômenos eletromagnéticos em faixa de freqüência de até $9 \mathrm{kHz}$, com conceitos de software multiplataforma baseados em instrumentos virtuais, que tenha relativa flexibilidade de alterações em seu hardware para acompanhar as necessidades das alterações das normas, seja de manutenção mais simples que os equipamentos microprocessados, tenha possibilidade de agregação de outras medições, relativa capacidade de expansão e que tenha uma oportunidade maior de utilização do hardware obsoleto em outras aplicações técnicas.

A figura 4.13 apresenta o diagrama de blocos do protótipo do instrumento de medição dos fenômenos relativos à QEE, que foi desenvolvido neste trabalho, onde pode ser observado a modularidade do equipamento. 


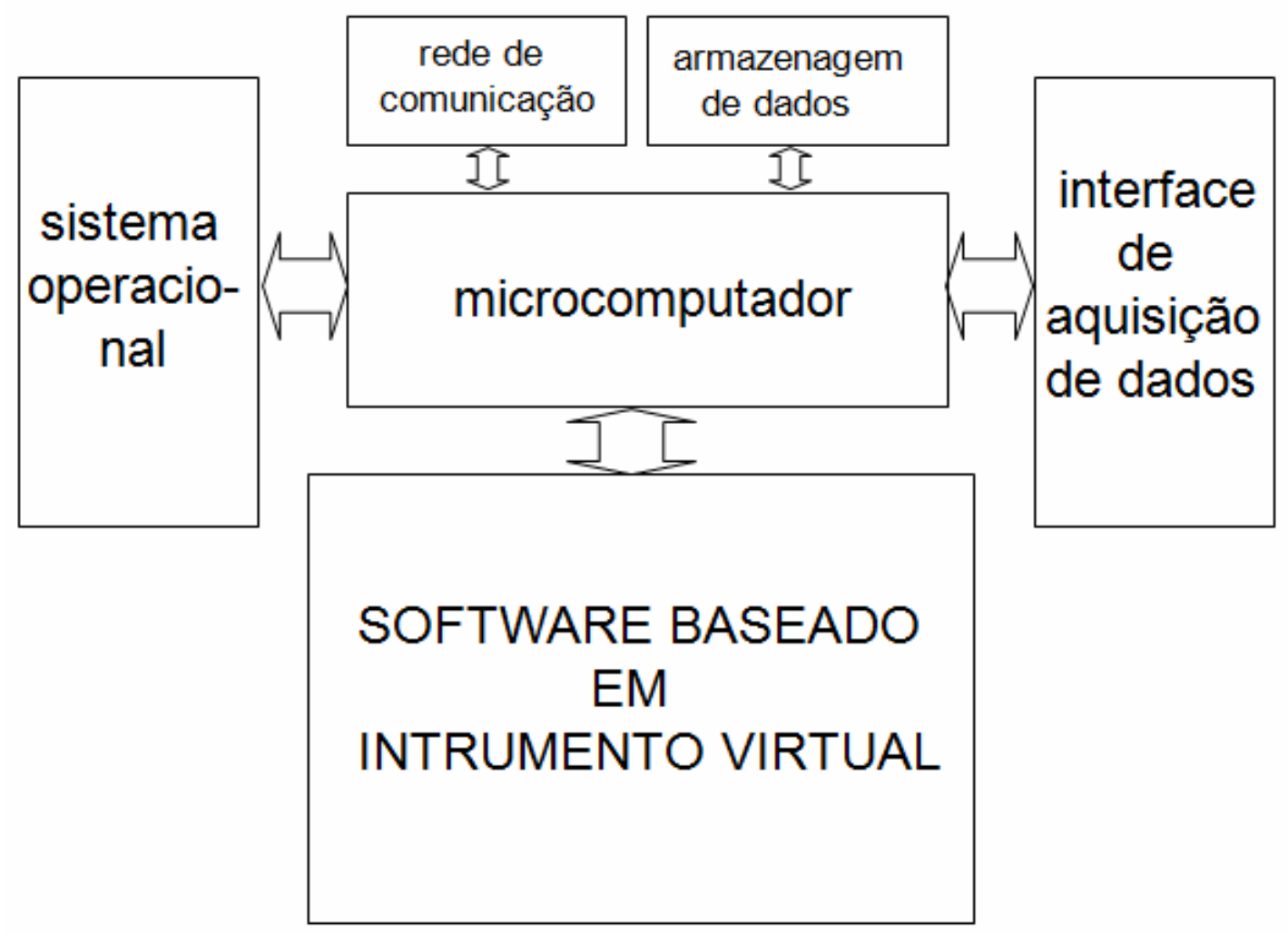

Figura 4.13. Diagrama de blocos do equipamento proposto

\subsubsection{Hardware desenvolvido}

O hardware desenvolvido foi escolhido junto ao software, pois o perfeito funcionamento esperado do protótipo do equipamento de medição depende do desempenho do conjunto hardware-software.

Analisando o diagrama de blocos da figura 4.13 e sendo necessário atender todos os requisitos das normas relacionadas à QEE citadas neste capítulo foi utilizado o seguinte hardware: 
- Microcomputador com processador Pentium 4 de $3 \mathrm{GHz}, 1 \mathrm{~Gb}$ de RAM, $\mathrm{HD}$ de $80 \mathrm{~Gb}$

- Placa de aquisição de dados National Instruments PCI NI 6220, part number $779065-01$

- Garra de corrente AC Minipa mod. 265

Como parte da etapa de aquisição de dados há a necessidade da compatibilização dos níveis de tensão e corrente dos circuitos a serem medidos para a entrada da placa de aquisição de sinais. Para isto foram utilizados os circuitos da figura 4.14 para alimentação das placas eletrônicas da interface de aquisição de tensão e corrente, o circuito da figura 4.15 para compatibilização do sinal de entrada de tensão de até $1000 \mathrm{~V}$ e o circuito da figura 4.16 para a compatibilização do sinal de entrada de corrente de até 1000A.

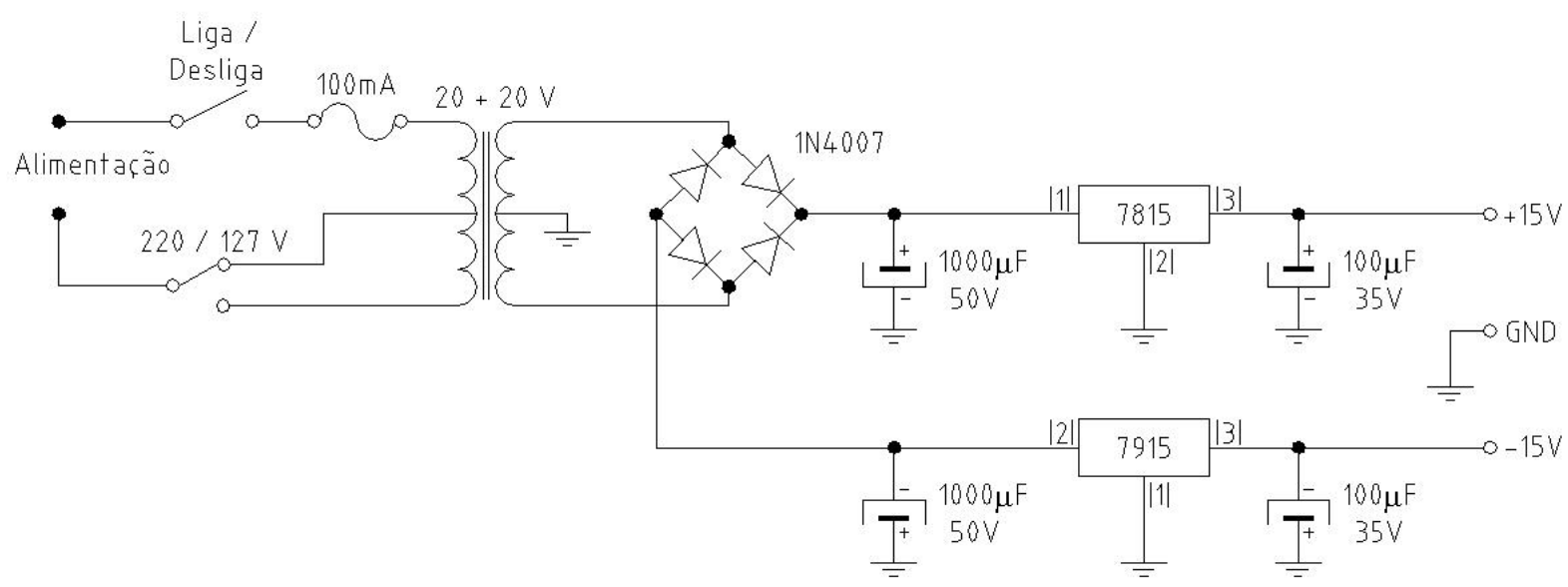

Figura 4.14. Alimentação das placas eletrônicas da interface de tensão e corrente 


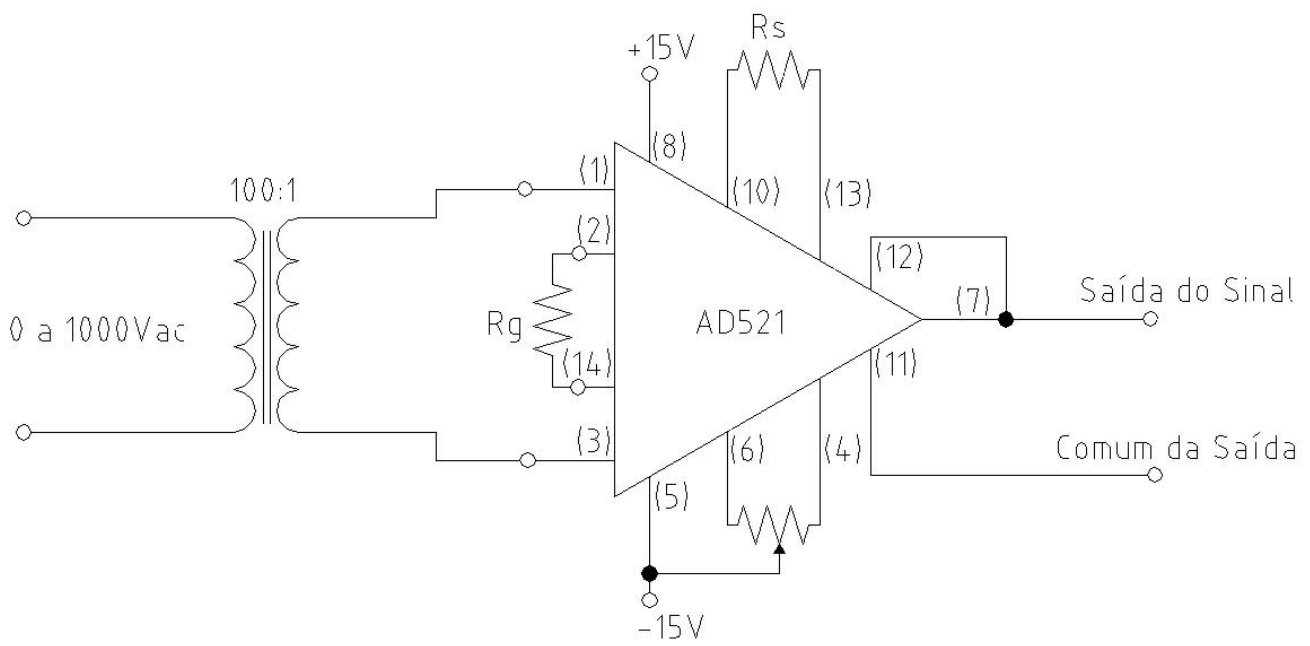

Figura 4.15. Interface de aquisição de tensão

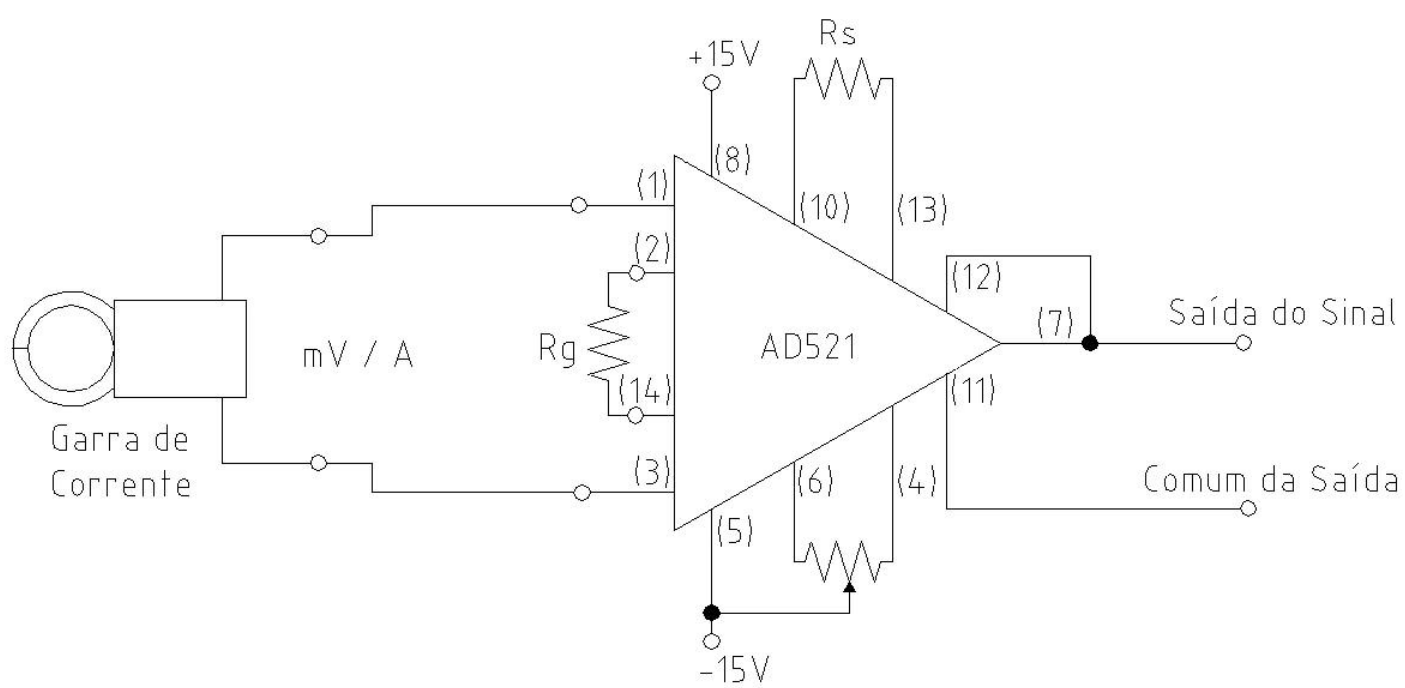

Figura 4.16. Interface de aquisição de corrente 


\subsection{Software}

\subsubsection{Introdução}

A utilização dos computadores nos últimos anos levou à evolução dos instrumentos de automação e medição. Uma das maiores vantagens resultantes do emprego dos computadores foi o desenvolvimento do conceito de instrumento virtual, que vem beneficiando os engenheiros e cientistas que necessitam aumentar a produtividade, precisão e desempenho.

Um instrumento virtual consiste em um computador padrão equipado com sua específica ferramenta de software para o programa e de hardware para aquisição dos dados e adequação dos níveis de sinais do meio a ser monitorado. O software é o componente mais importante de um instrumento virtual. Com as ferramentas corretas engenheiros e cientistas podem criar com eficiência suas próprias aplicações através do planejamento e integração das rotinas de acordo com as exigências do projeto $(\mathrm{NI}, 2006)$.

Uma vantagem importante que o software proporciona é modularidade. Quando os programadores deparam-se com grandes programas é conveniente que seja separado o projeto total em diferentes partes funcionais (módulos), pois são mais fáceis de gerenciar e testar, reduzindo assim as possibilidades e problemas indesejáveis durante a execução do projeto. Nos instrumentos virtuais, como o desenvolvimento é executado em software, funções semelhantes podem ser agrupadas facilmente em quantos módulos forem necessários para garantir as necessidades da arquitetura do programa. 
Os instrumentos virtuais têm como base funcional os computadores. Estes instrumentos, podem então utilizar-se de todas as vantagens atuais que os computadores oferecem, como uma grande capacidade de armazenamento de informações, comunicação por rede, entre outras.

No software LabVIEW a construção do programa é executada através da conexão de blocos, criando assim os módulos de execução. Este programa gráfico contribui para a rapidez e precisão no desenvolvimento ou alteração do programa, pois além de permitir uma identificação rápida da função de cada módulo ou bloco, muitos dos blocos possuem uma biblioteca interna já desenvolvida especificamente para determinadas funções, não sendo necessário realizar seu desenvolvimento novamente. Outras vantagens do software LabVIEW são sua abertura para vários ambientes e ferramentas de trabalho (ActiveX, DLL, OPC, SQL, etc.), seu funcionamento nos diversos sistemas operacionais (Windows, Mac OS, Linux, etc.) e sua alta velocidade na análise e processamento dos sinais.

Sendo assim, os instrumentos virtuais baseados no software LabVIEW podem ser implementados em qualquer computador existente no mercado trabalhando em um sistema operacional conhecido atualmente e oferecendo a capacidade de criar e definir seu próprio sistema de trabalho baseado em uma interface visual gráfica com o usuário. Esse conceito garante uma alta flexibilidade nas alterações de hardware e software, permite ampliações do equipamento conforme necessário, tem uma manutenção simples e modular e admite que os módulos obsoletos em uma determinada aplicação de trabalho sejam reutilizados em outra. 


\subsubsection{Software desenvolvido}

Com base nas vantagens descritas no item 4.4.1. foi utilizado o software LabVIEW para desenvolvimento do programa do protótipo do equipamento de medição de fenômenos relativos à QEE, utilizando o conceito de instrumento virtual.

Para a perfeita associação ao hardware proposto, com base nos requisitos das normas aplicadas à QEE, o sistema operacional utilizado foi o Windows XP Professional e para o software de desenvolvimento do programa, LabVIEW National Instruments versão 7.1 .

O equipamento proposto teve seu software dividido inicialmente em 7 módulos principais, sendo eles apresentados na figura 4.17. 


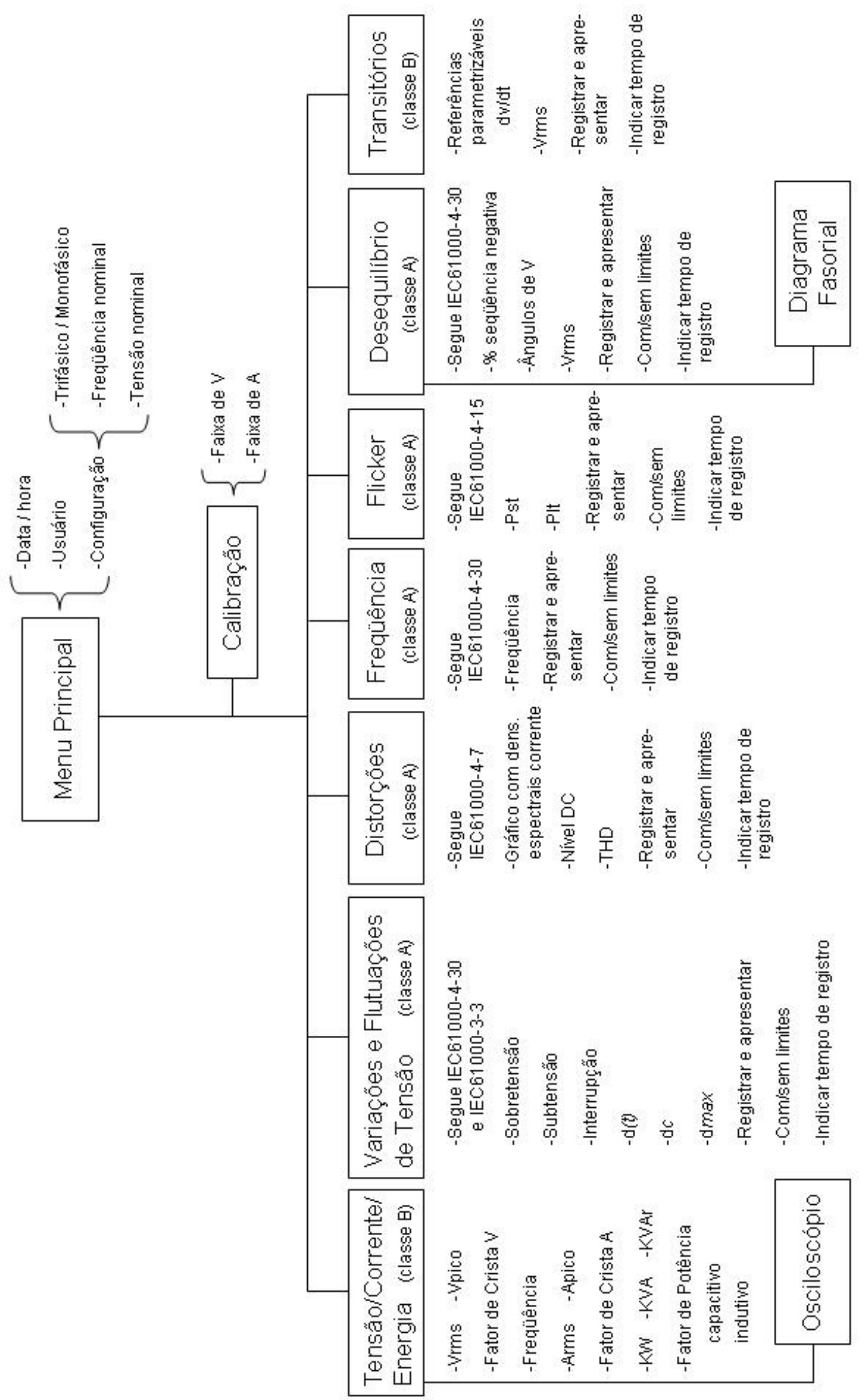

Figura 4.17. Diagrama de blocos do software do equipamento proposto 


\subsubsection{Módulo Menu Principal}

A tela do menu principal foi elaborada para inicialização do aparelho. Neste módulo é registrada a data e hora da medição e a configuração do sistema elétrico a ser medido. Na tela de configuração do sistema é necessária a especificação da quantidade de fases, a freqüência e a tensão nominal do sistema a ser medido para as classes de medição $A$ e $B$ e os valores de limites dos fenômenos eletromagnéticos desejados pelo usuário para o equipamento de classe $B$.

Na figura 4.18 é observado a tela do módulo do menu principal e a figura 4.19 apresenta as telas de configuração, onde poder ser visto os limites para as classes do equipamento.

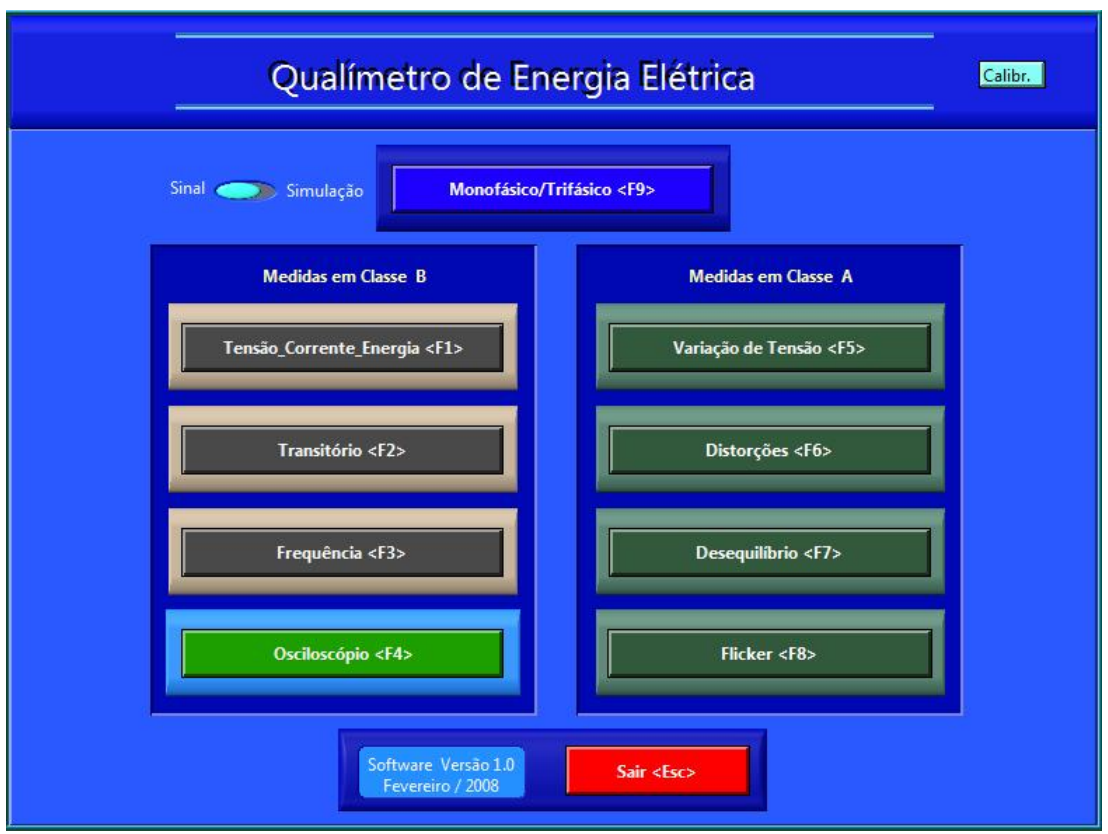

Figura 4.18. Tela do módulo do Menu Principal 

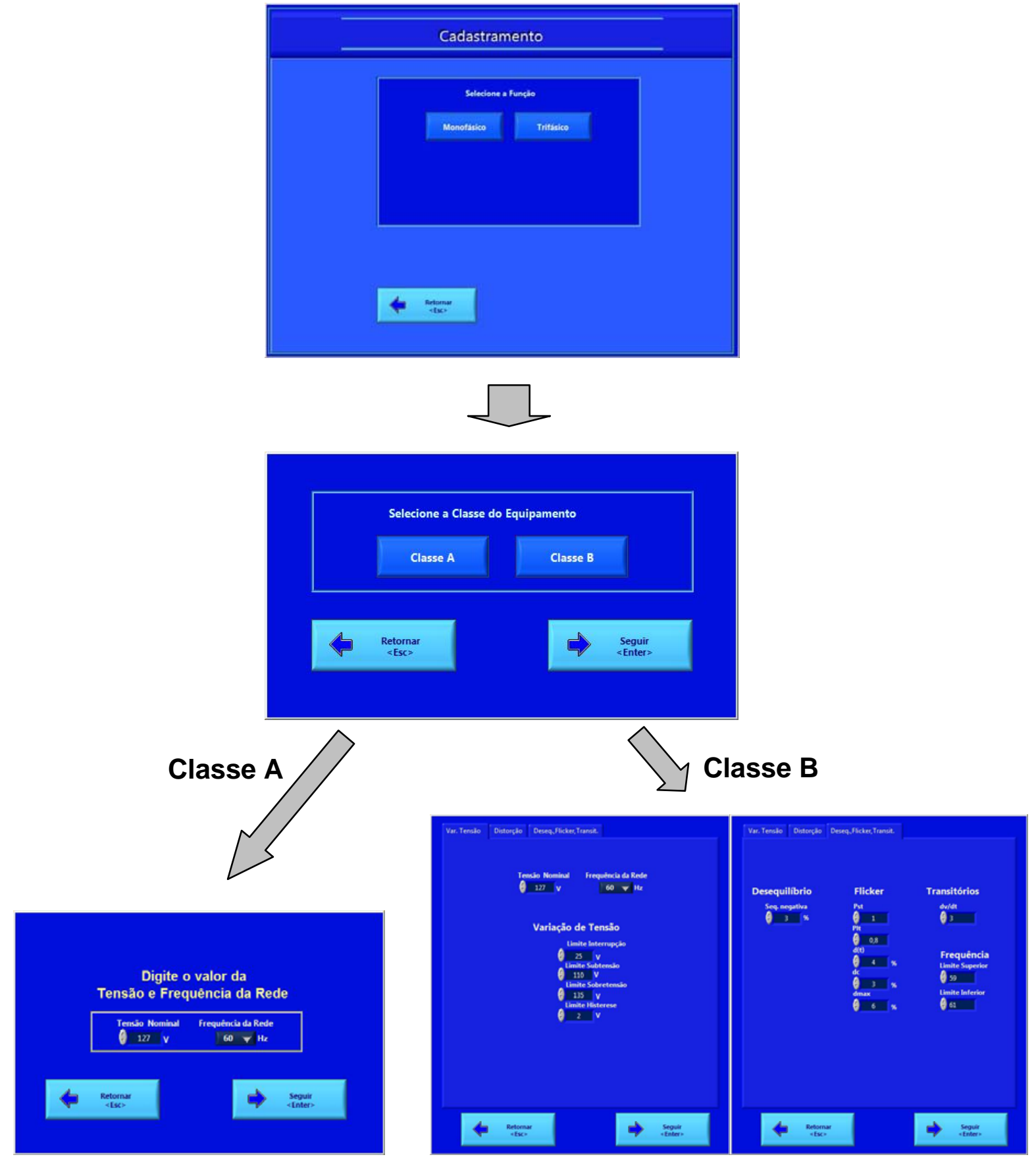

Figura 4.19. Telas de Configuração do Protótipo

\subsubsection{Módulo de Calibração}

Para a calibração das entradas de tensão e corrente é utilizado o módulo de calibração, visando a conformação das magnitudes dos valores dos fenômenos 
eletromagnéticos com as exigências apresentadas nas normas. Cada canal de tensão e corrente deve ser calibrado individualmente para atingir o nível de precisão e tolerância esperada por cada módulo de medição.

$\mathrm{Na}$ figura 4.20 onde é apresentado o módulo de calibração pode ser observado as faixas de calibração dos canais de aquisição.

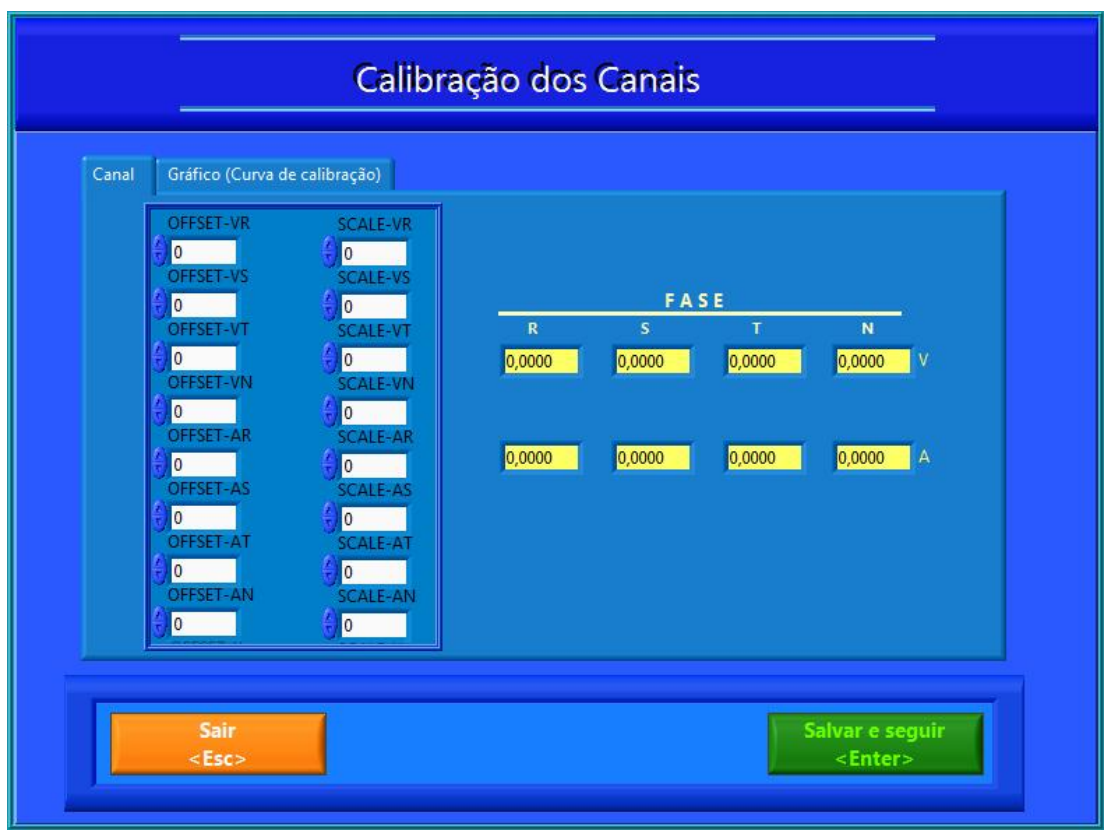

Figura 4.20. Tela do módulo de Calibração

\subsubsection{Módulo Tensão / Corrente / Energia}

O módulo de tensão / corrente foi desenvolvido para visualização das formas de onda das tensões e correntes que estão sendo monitoradas no sistema, podendo também serem analisadas com maior precisão no submódulo de osciloscópio. Também é possível neste módulo medir as grandezas de tensão / corrente eficaz, de pico, valor de crista, período e freqüência da onda. 
O módulo correspondente a energia apresenta os valores instantâneos de potência consumida pela carga (KW, KVA, KVAr), fator de potência (capacitivo e indutivo) e tensão e corrente eficaz.

Este módulo não segue nenhuma norma específica, portanto é considerado como classe B.

A figura 4.21 apresenta as telas do módulo de tensão/corrente com suas devidas grandezas de tensão e corrente e as formas de onda individuais. A figura 4.22 apresenta as telas do módulo de medição de energia com suas grandezas associadas e o diagrama fasorial. Na figura 4.23 pode-se observar a tela do submódulo osciloscópio.
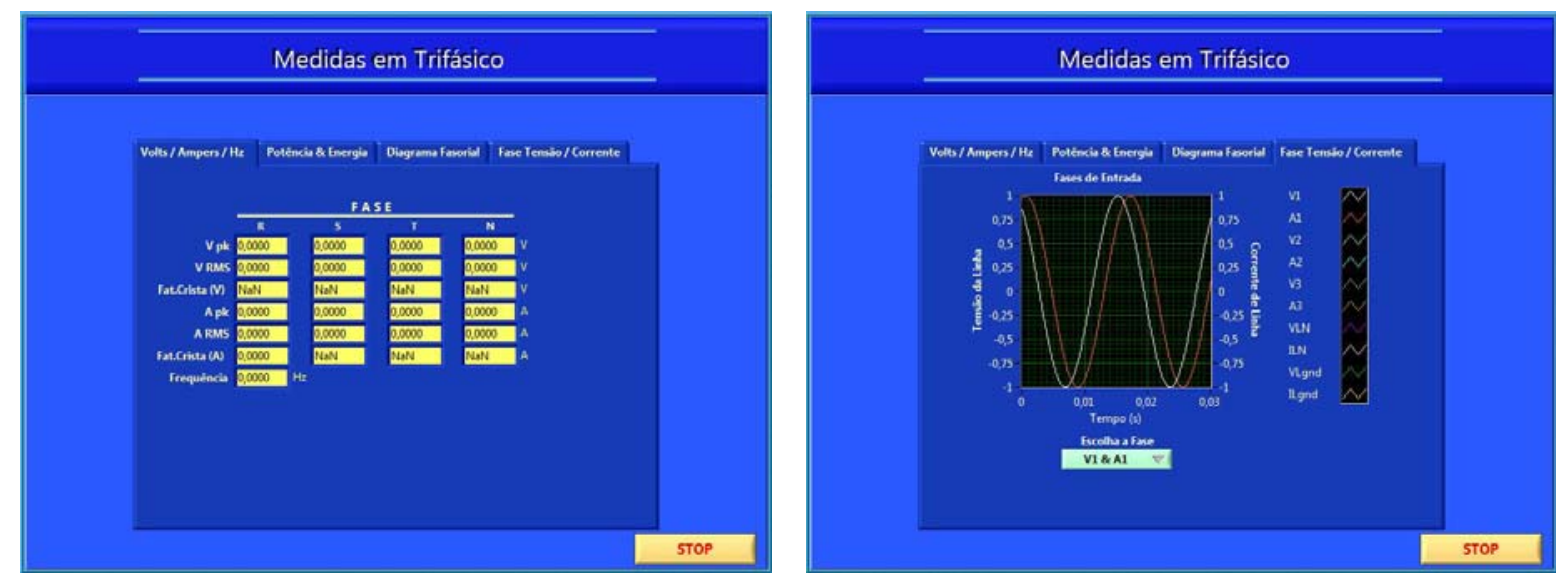

Figura 4.21. Telas do módulo de Tensão / Corrente
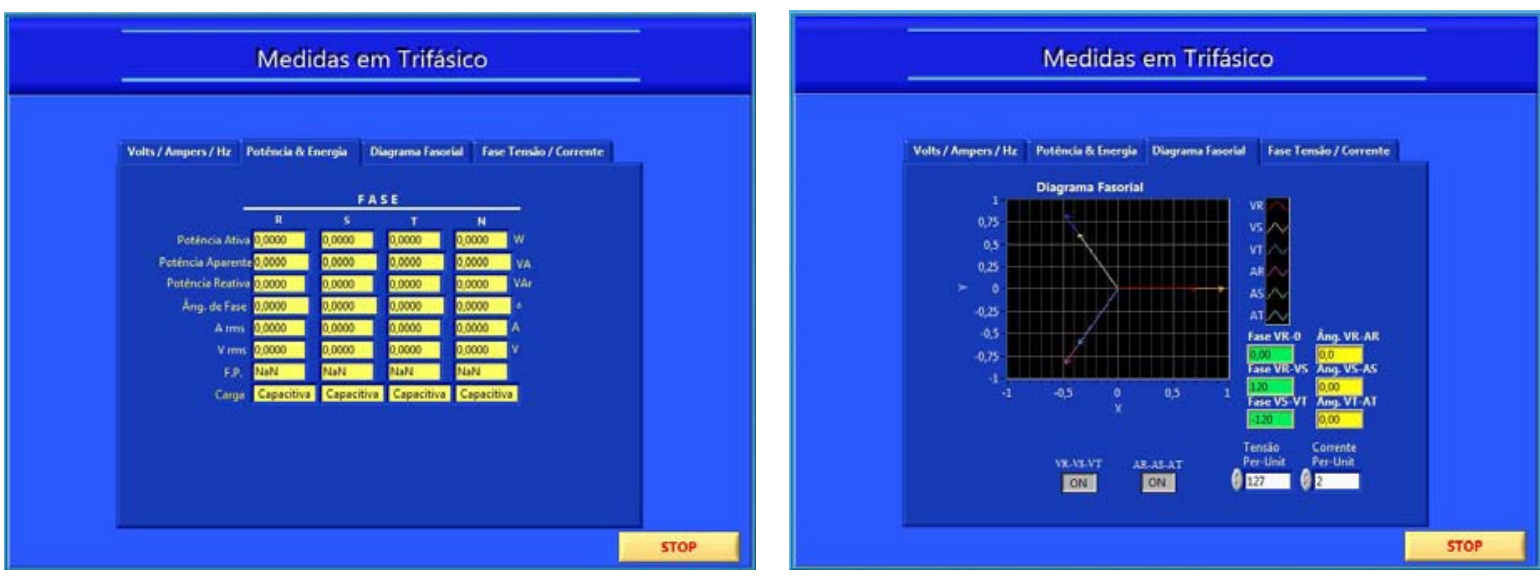

Figura 4.22. Telas do módulo de Energia 


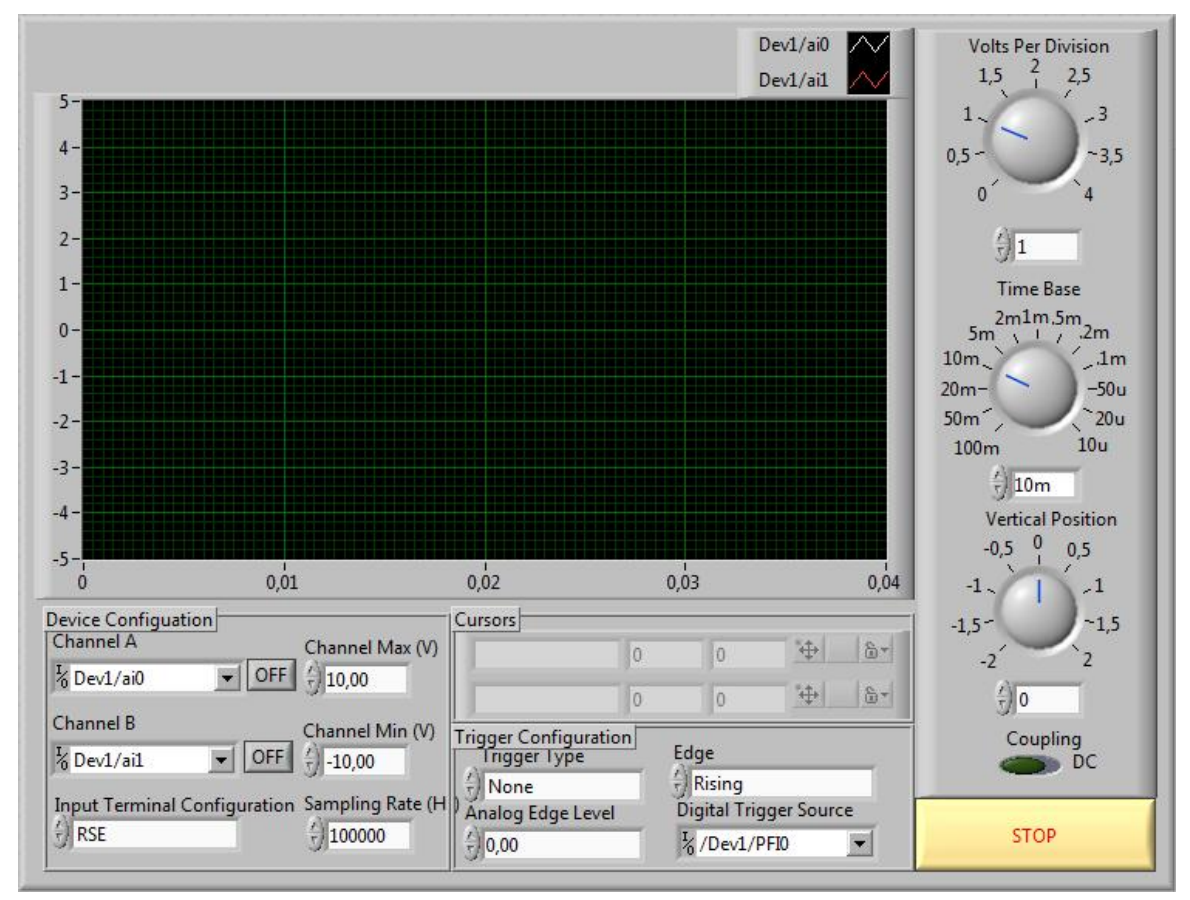

Figura 4.23. Tela do submódulo de Osciloscópio

\subsubsection{Módulo de Variações e Flutuações de Tensão}

Atendendo a norma IEC61000-4-30 e IEC61000-3-3 respectivamente, o módulo de variações e flutuações de tensão apresenta as medições de sobretensão, subtensão, interrupção, $d c, d(t)$ e dmax. Portanto este módulo é considerado como classe A, com os limites informados na norma IEC61000-4-30 e IEC61000-3-3.

Neste módulo pode-se realizar tanto a seleção dos limites permitidos pela norma quanto aos fenômenos de variação ou flutuação de tensão ou inserir um limite à escolha do usuário para que ocorra a monitoração. Caso seja escolhido um valor limite que não seja especificado por norma, o equipamento é considerado classe B. 
A data, hora e amplitude dos fenômenos são registradas na ocorrência de um evento, checado de acordo com os limites estabelecidos e apresentadas em forma de relatório.

Pode ser observado na figura 4.24 o fluxograma de execução do software para variação de tensão, na figura 4.25 o fluxograma de execução de software para flutuação de tensão e na figura 4.26 a tela do módulo de medição com o valor da tensão eficaz instantânea e os valores limites permitidos pelas respectivas normas.

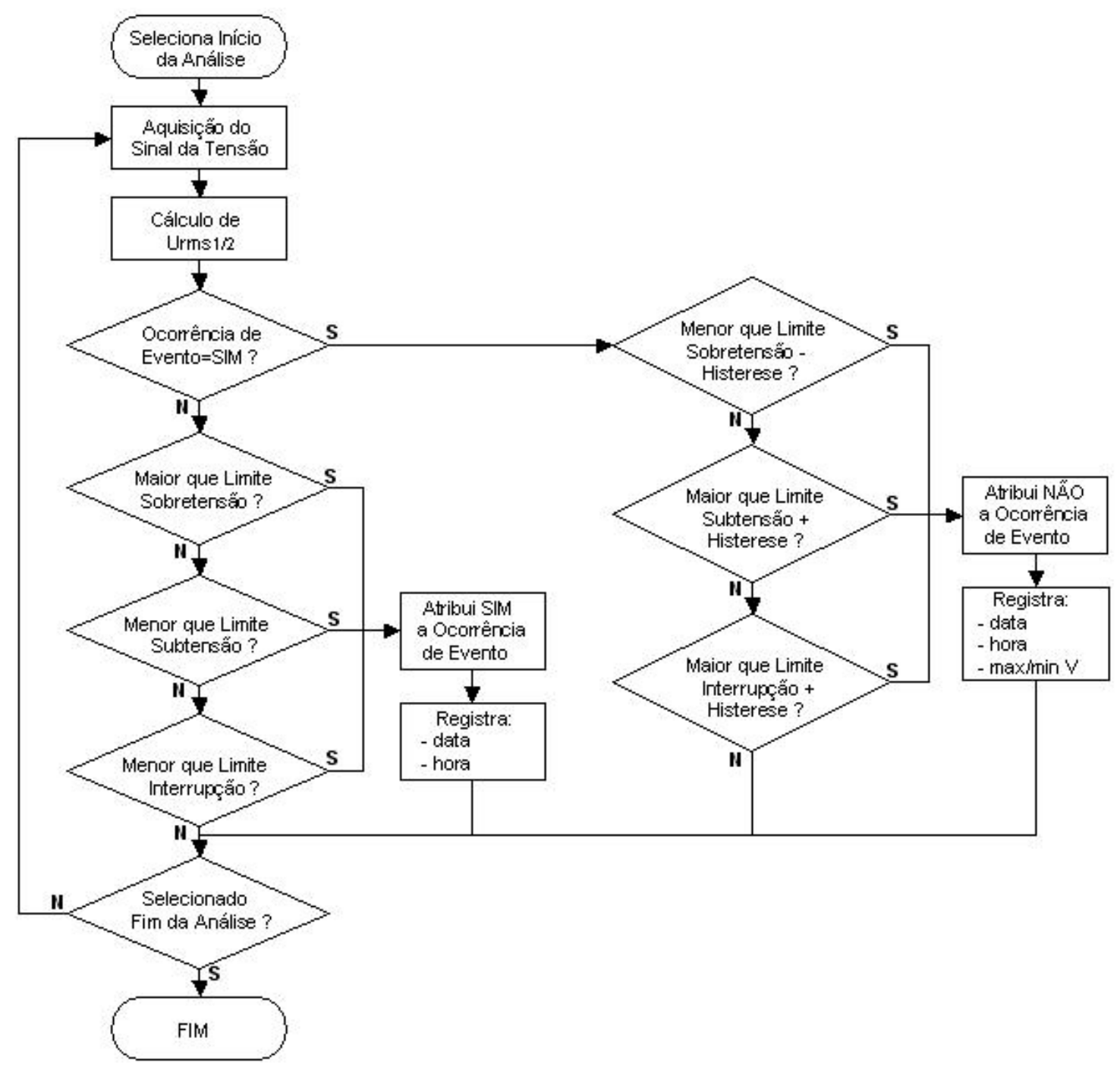

Figura 4.24. Fluxograma do módulo de Variação de Tensão 


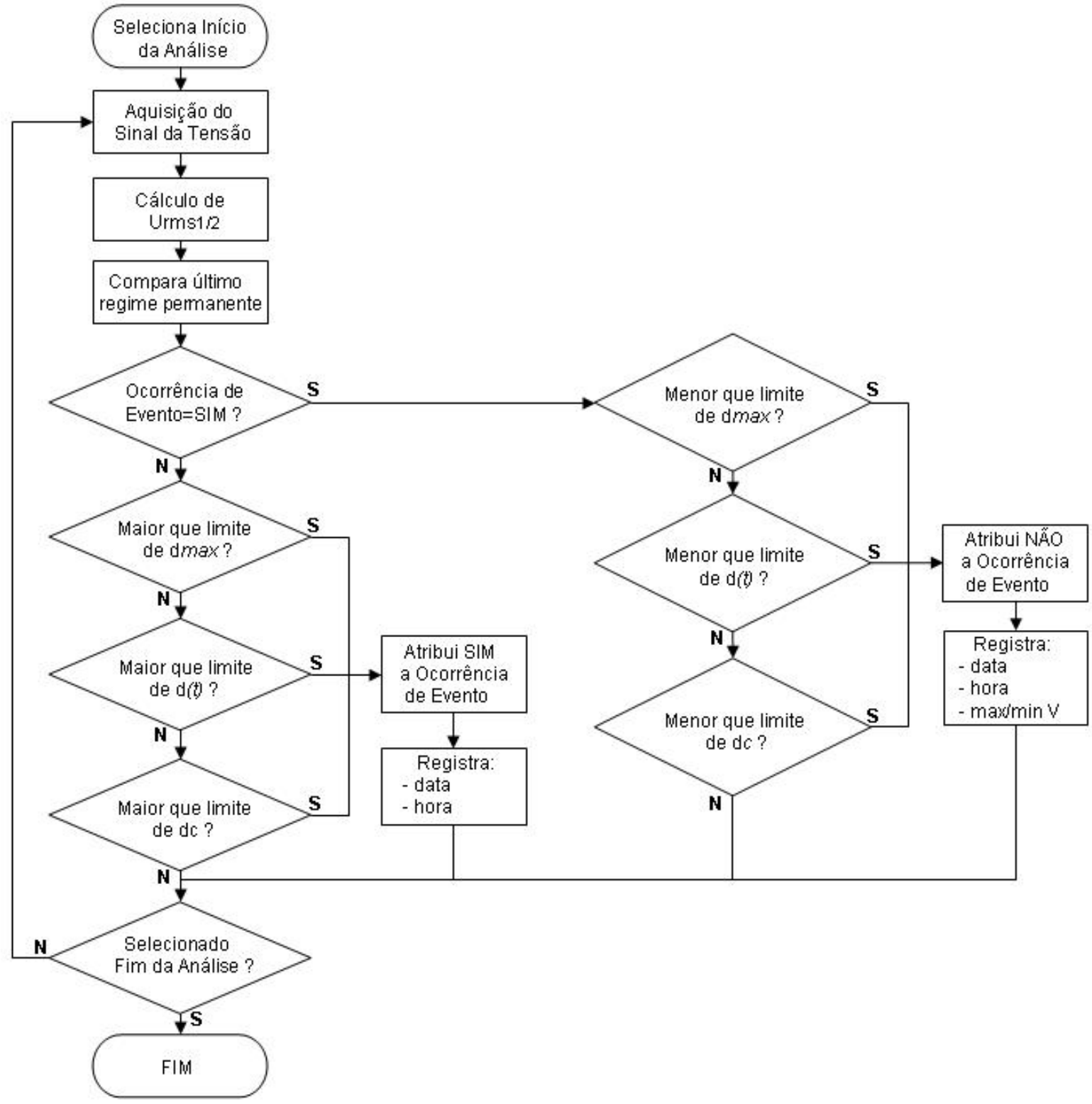

Figura 4.25. Fluxograma do módulo de Flutuação de Tensão 


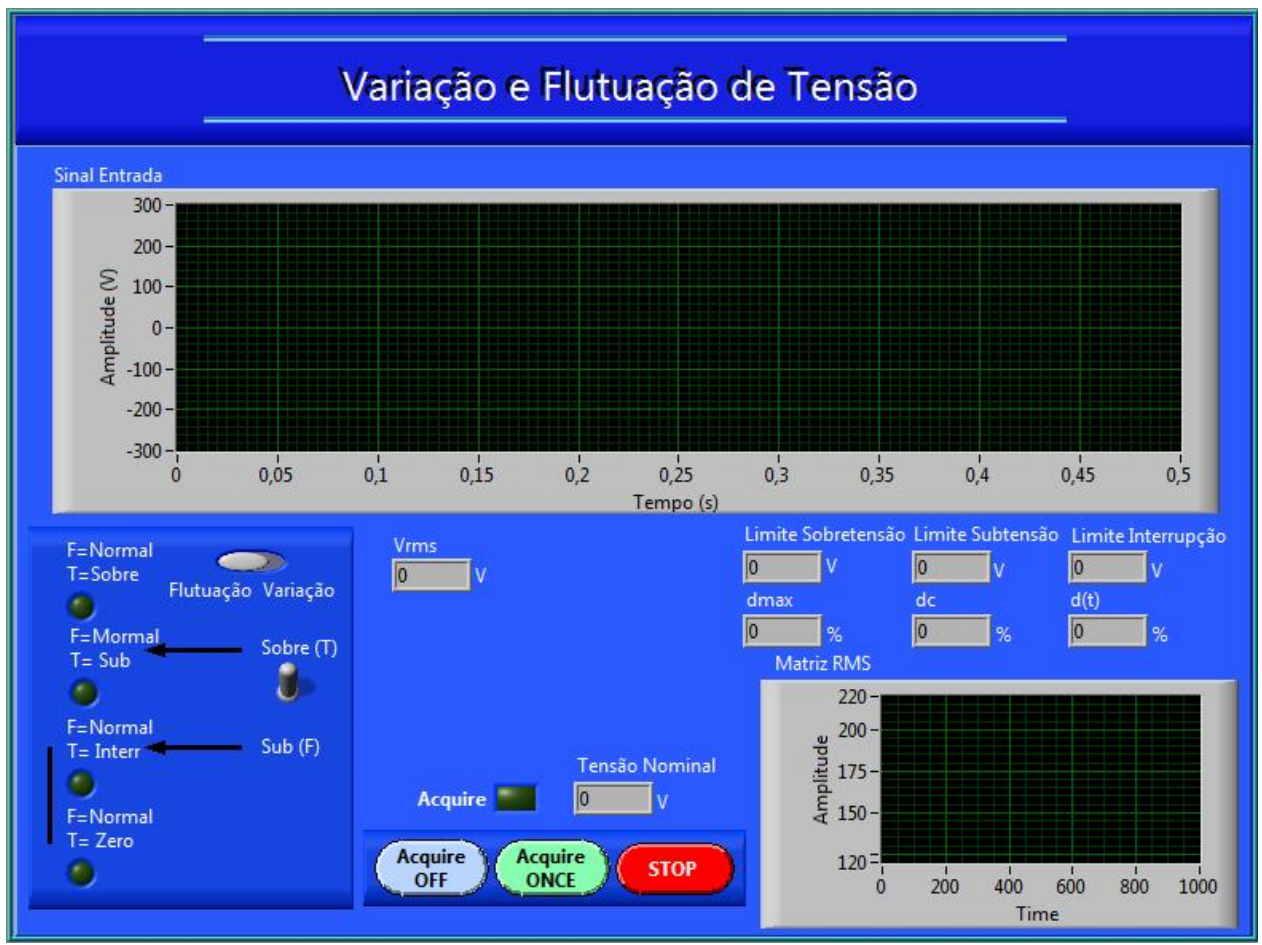

Figura 4.26. Tela do módulo de Variações e Flutuação de Tensão

\subsubsection{Módulo de Distorções da Forma de Onda}

A norma IEC61000-4-7 é a base de desenvolvimento para este módulo do protótipo, onde são medidas as distorções na forma de onda. Sendo assim este módulo é classificado como classe A.

Neste módulo é checado o atendimento aos limites de componentes harmônicos dispostos na norma IEC61000-3-2 e emitido um relatório contendo data, hora, nível CC, THD e a máxima densidade espectral de potência de cada componente harmônico selecionado durante o período de ocorrência do evento.

Assim como no módulo anterior também é possível a escolha dos valores limites para registro de um evento, respeitando que o protótipo torna-se um medidor classe B. 
A figura 4.27 apresenta o fluxograma de execução do software e a figura 4.28 a tela do módulo de distorções contendo o gráfico das densidades espectrais de potência.

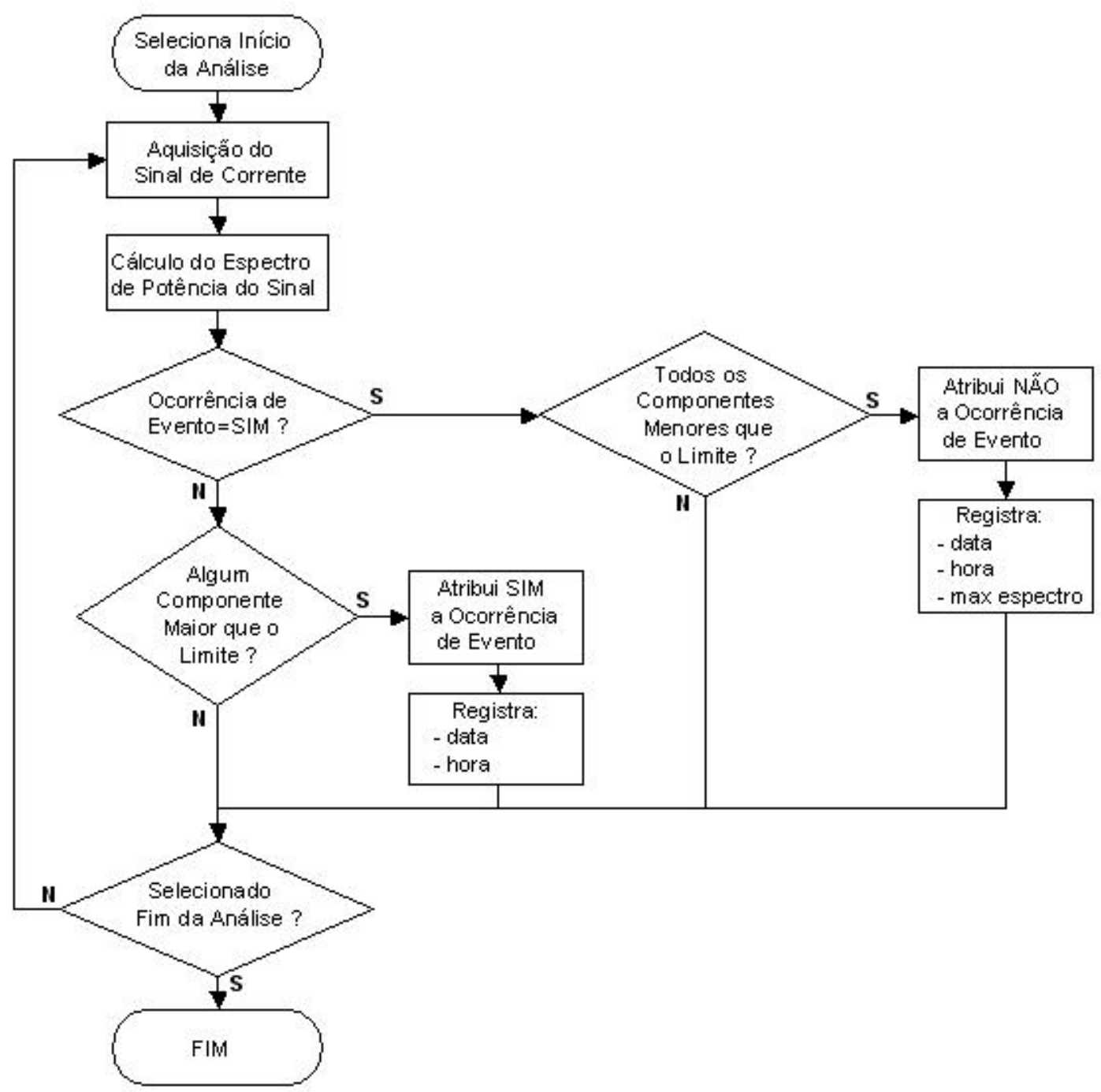

Figura 4.27. Fluxograma do módulo de Distorções da Forma de Onda 


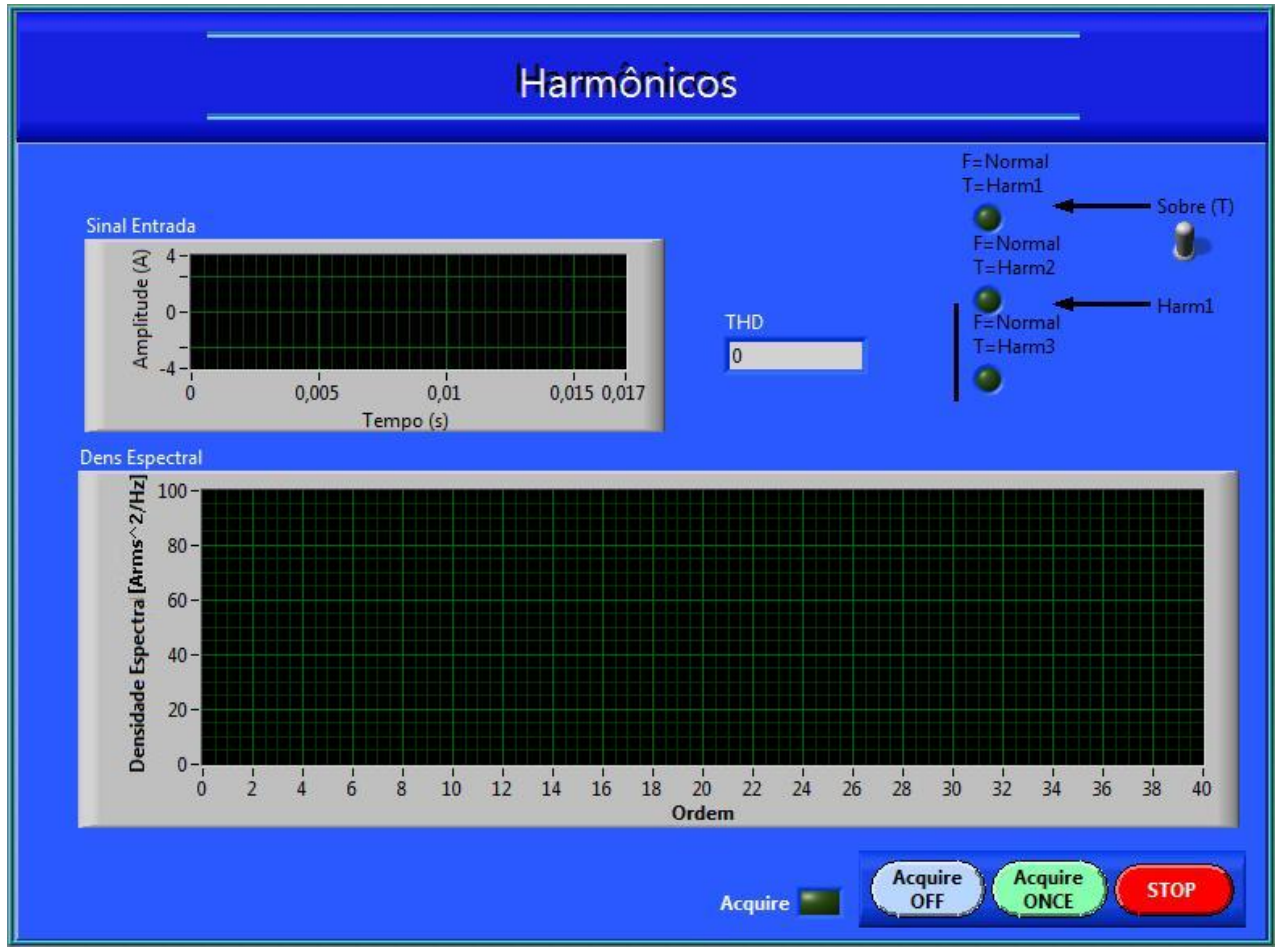

Figura 4.28. Tela do módulo de Distorções da Forma de Onda

\subsubsection{Módulo de Freqüência}

Este módulo apresenta a freqüência medida de acordo com a norma IEC61000-4-30, portanto é considerado como medidor classe A com os limites informados nesta mesma norma. Também é possível a escolha dos limites para registro do evento, sendo assim o protótipo passa a ser considerado como classe B.

Neste módulo é checado se o valor da freqüência está dentro dos limites selecionados e caso os limites sejam ultrapassados é gerado o relatório contendo a data, hora e valor da freqüência máxima ou mínima durante a ocorrência do evento.

Na figura 4.29 é apresentado o fluxograma de execução do software e na figura 4.30 a tela de medição do módulo de freqüência. 


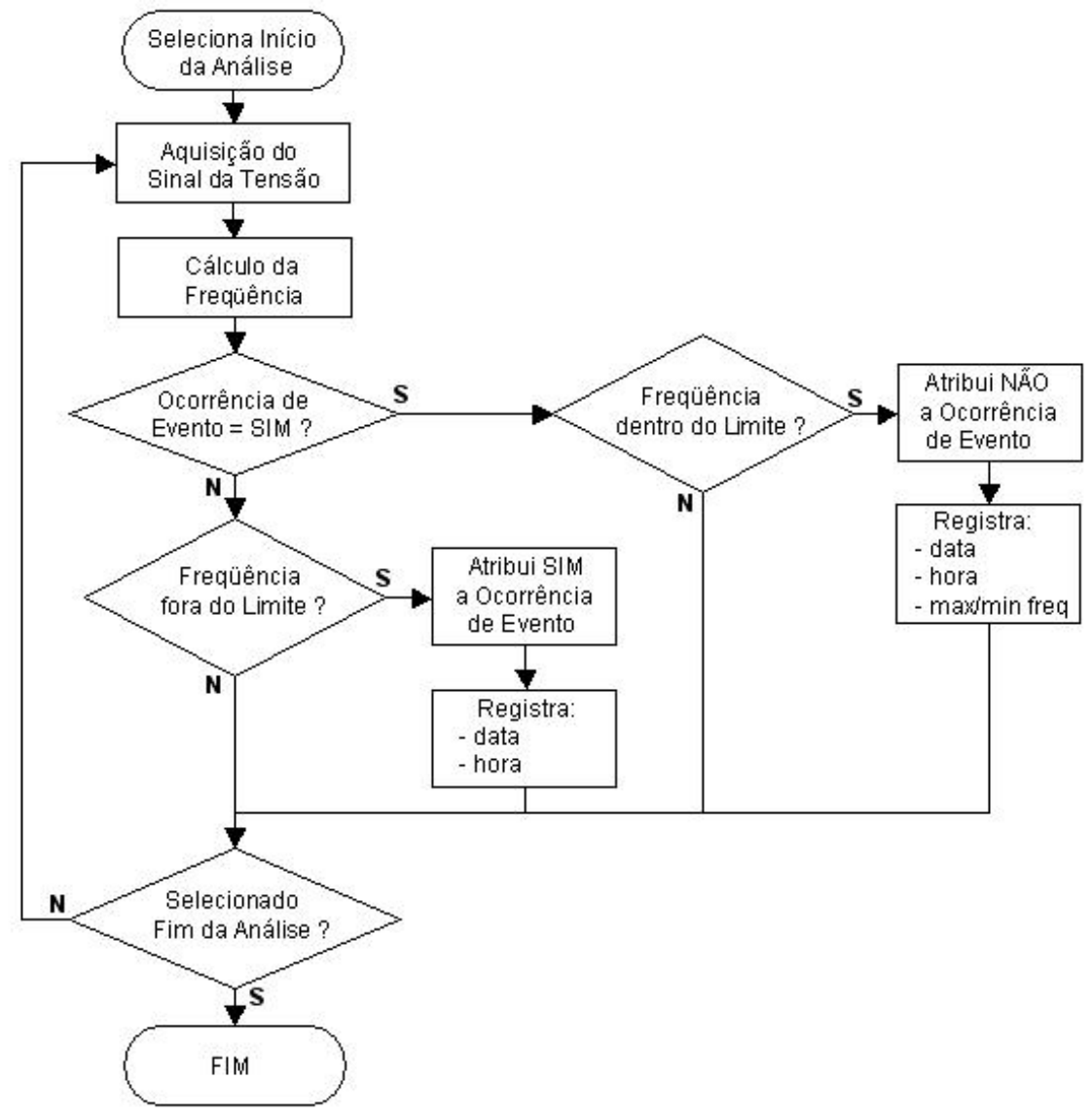

Figura 4.29. Fluxograma do módulo de Freqüência

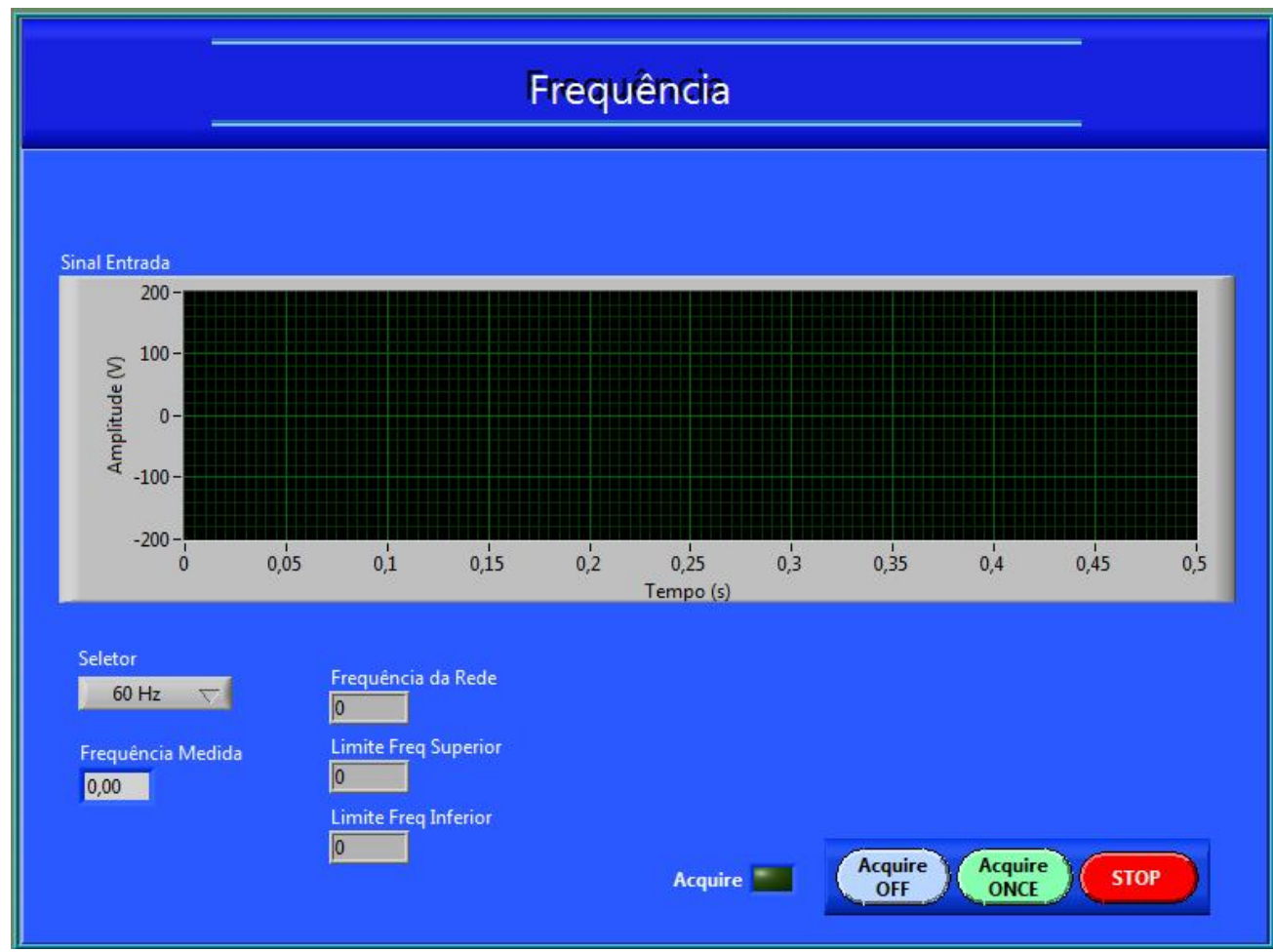

Figura 4.30. Tela do módulo de Freqüência 


\subsubsection{Módulo de Flicker}

Este módulo apresenta as medições dos índices de Pst e Plt para o fenômeno de flicker. A norma IEC61000-4-15 foi base para o desenvolvimento deste módulo, portanto um equipamento classe $\mathrm{A}$.

É apresentado neste módulo um relatório contendo a data, hora e os níveis máximos de Pst e/ou Plt quando há a ocorrência de um evento fora dos limites previstos pela IEC61000-3-3.

Há também a possibilidade da seleção dos valores limites para registro de um evento, assim como em alguns módulos anteriores. Uma vez selecionado um valor que não seja especificado por norma, este equipamento se torna pertencente à classe B.

É apresentado o fluxograma de execução do software na figura 4.31 e a tela do módulo de flicker com seus valores de Pst e Plt na figura 4.32. 


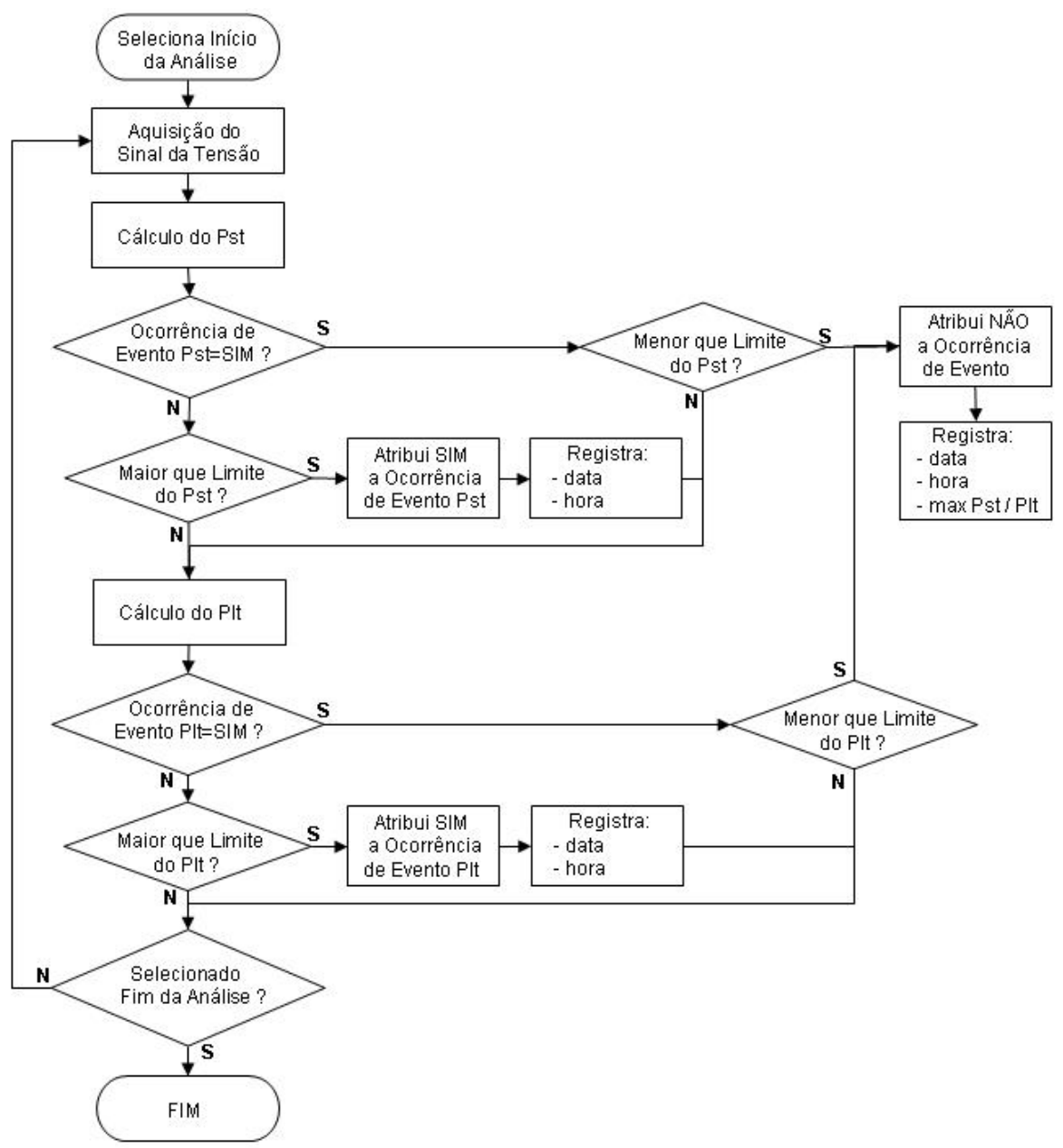

Figura 4.31. Fluxograma do módulo de Flicker

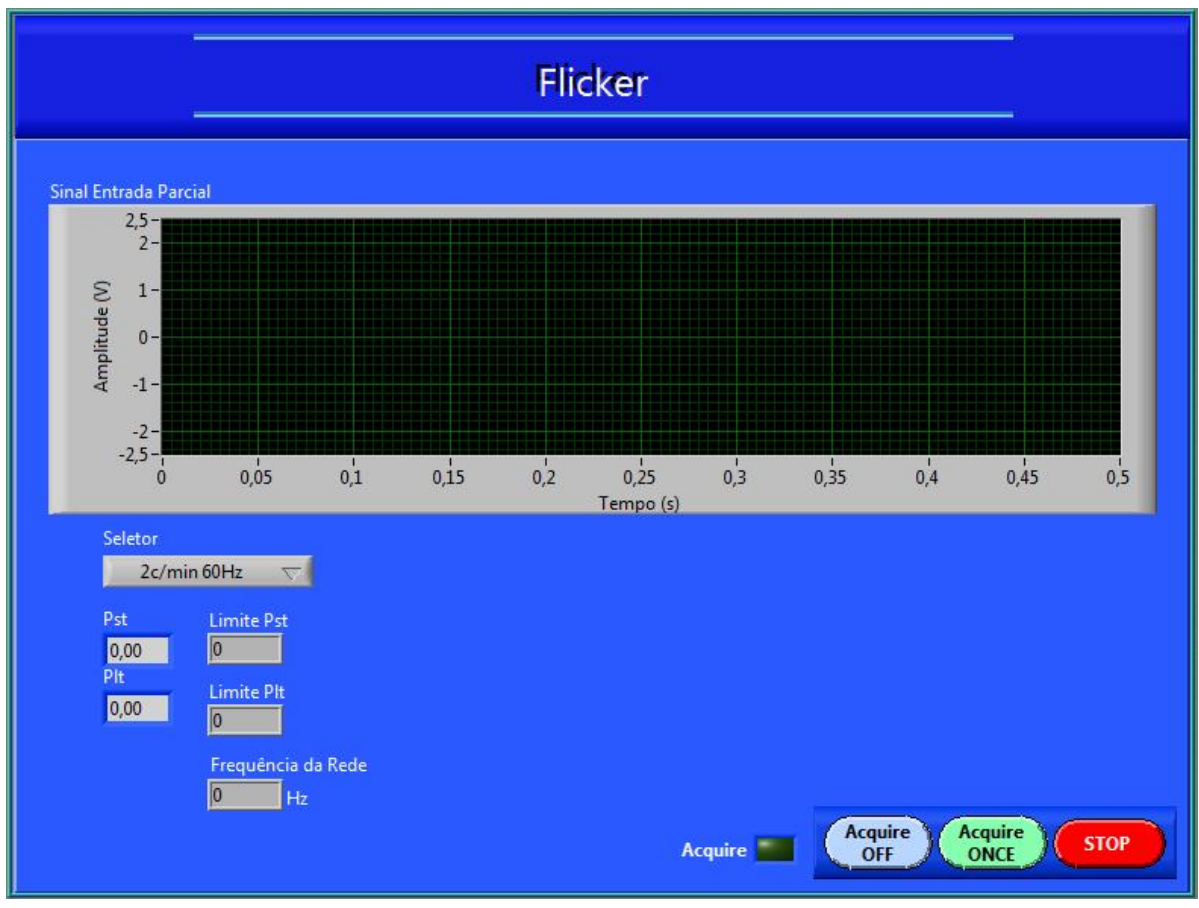

Figura 4.32. Tela do módulo de Flicker 


\subsubsection{Módulo de Desequilíbrio de Tensão}

A norma IEC61000-4-30 foi a base para o desenvolvimento deste módulo dedicado à medição do desequilíbrio de tensão entre as fases, portanto este módulo é considerado como sendo classe A.

O módulo de medição de desequilíbrio de tensão apresenta a porcentagem de desequilíbrio entre as fases para a seqüência negativa e a tensão eficaz das ondas de tensão.

Um relatório contendo a data, hora, os valores eficazes instantâneos de tensão e a porcentagem máxima do desequilíbrio é gerado por este módulo quando ocorre um evento fora dos limites selecionados. O limite de desequilíbrio para caracterização do evento é especificado pela norma IEC61000-2-2.

Este módulo apresenta também possibilidade da seleção de um valor limite a escolha do usuário para identificação do evento, sendo então classificado como equipamento classe $B$.

Na figura 4.33 pode-se observar o fluxograma de execução do software e na figura 4.34 a tela do módulo de desequilíbrio de tensão com os respectivos valores de tensão eficaz por fase, percentual de desequilíbrio e o diagrama fasorial. 


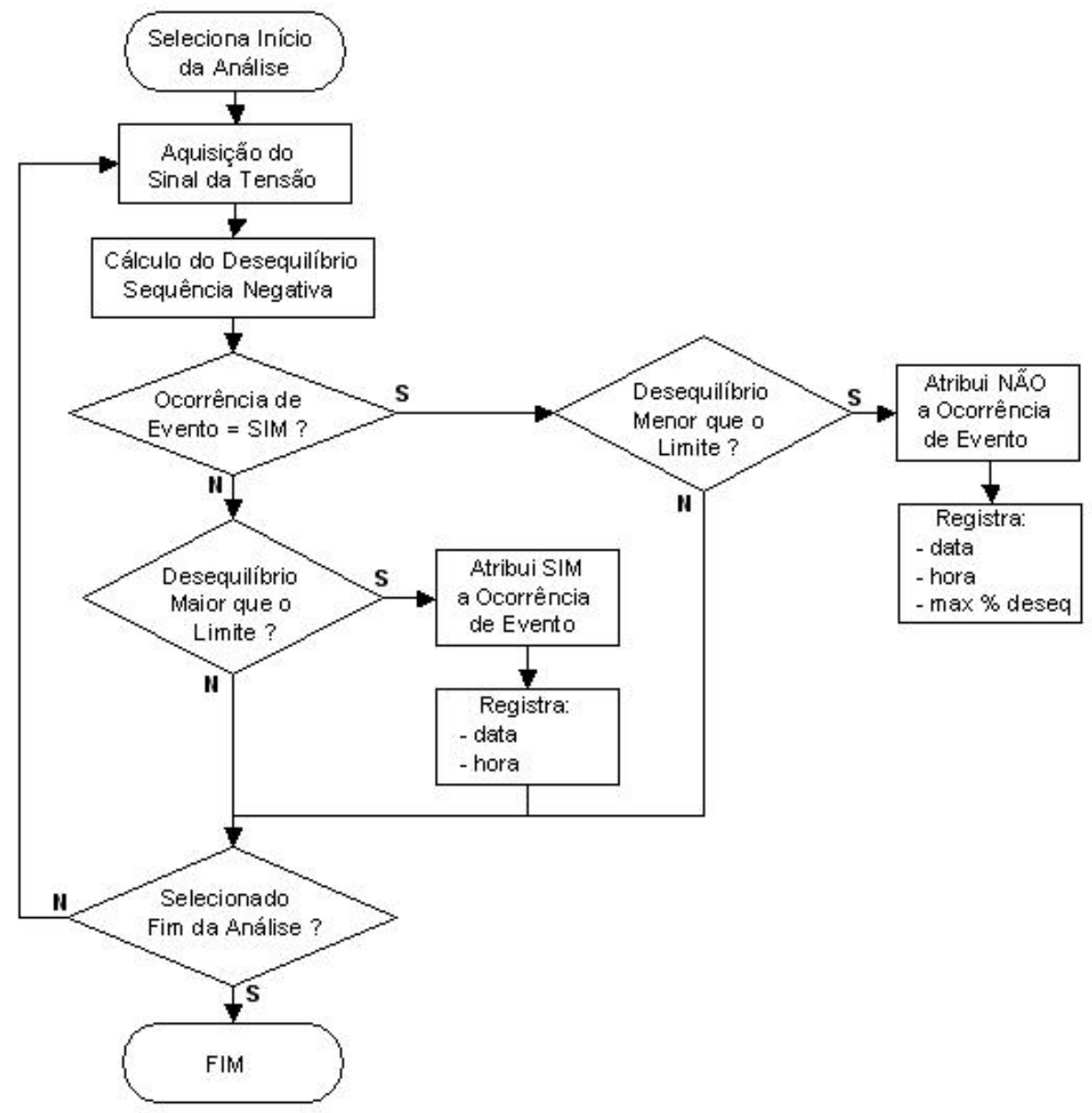

Figura 4.33.Fluxograma do módulo de Desequilíbrio

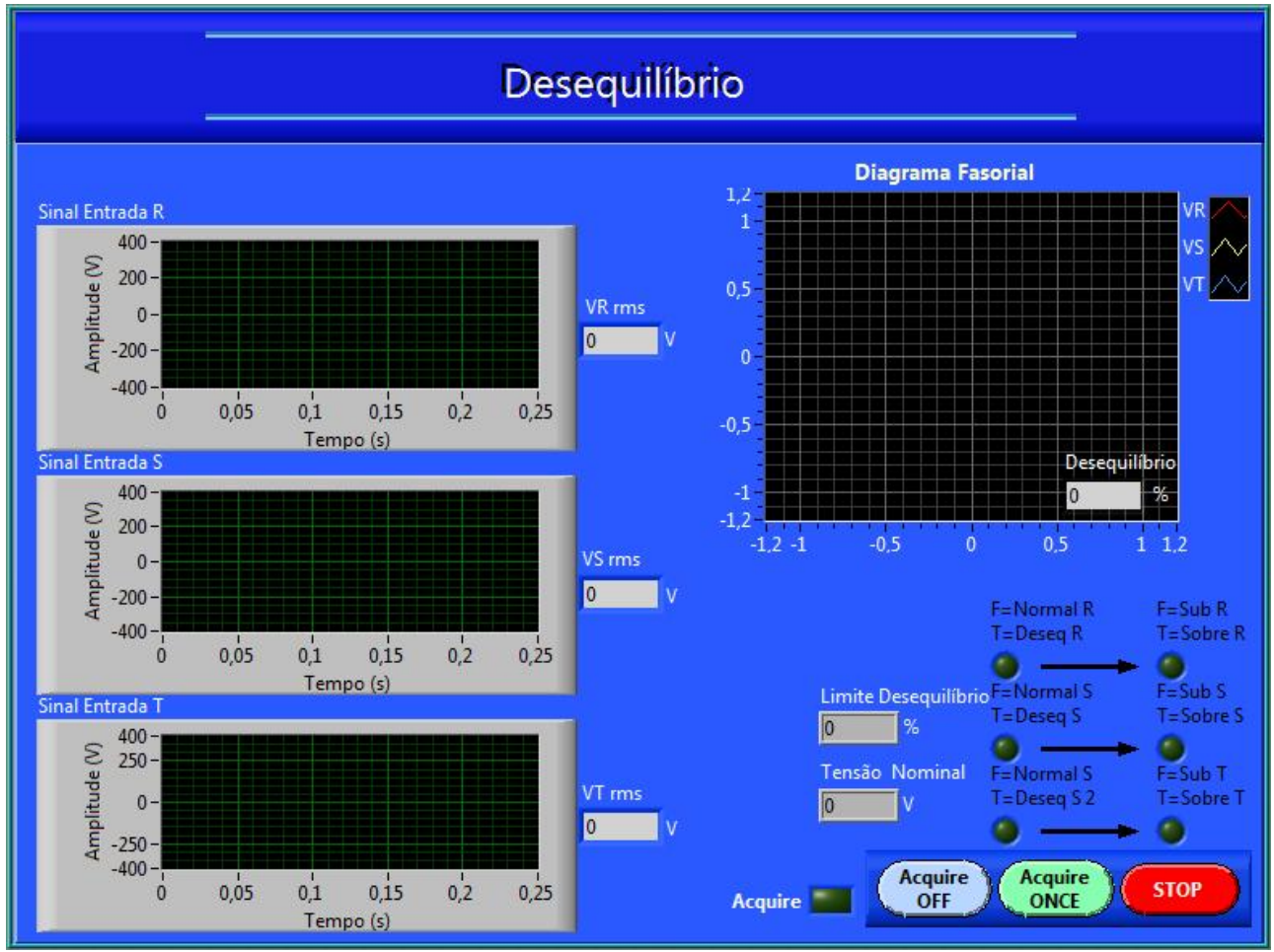

Figura 4.34. Tela do módulo de Desequilíbrio 


\subsubsection{Módulo de Transitórios}

Como a norma IEC61000-4-30 não define uma forma clara e concisa para a medição do fenômeno de transitórios, foi escolhido, baseado no anexo A.3. desta mesma norma, o registro por oscilografia da forma de onda que está em monitoramento a partir do instante que a correspondente variação $d v / d t$ seja maior que o limite estabelecido. Este módulo, então, é considerado classe B.

O valor limite para $d v / d t$ deve ser selecionado pelo usuário de forma a atender as expectativas da captura da onda esperada.

A figura 4.35 apresenta o fluxograma de execução do software e a figura 4.36 a tela do módulo de transitórios onde poderá ser observada a forma de onda de tensão capturada a partir do instante em que o limite de $d v / d t$ for ultrapassado.

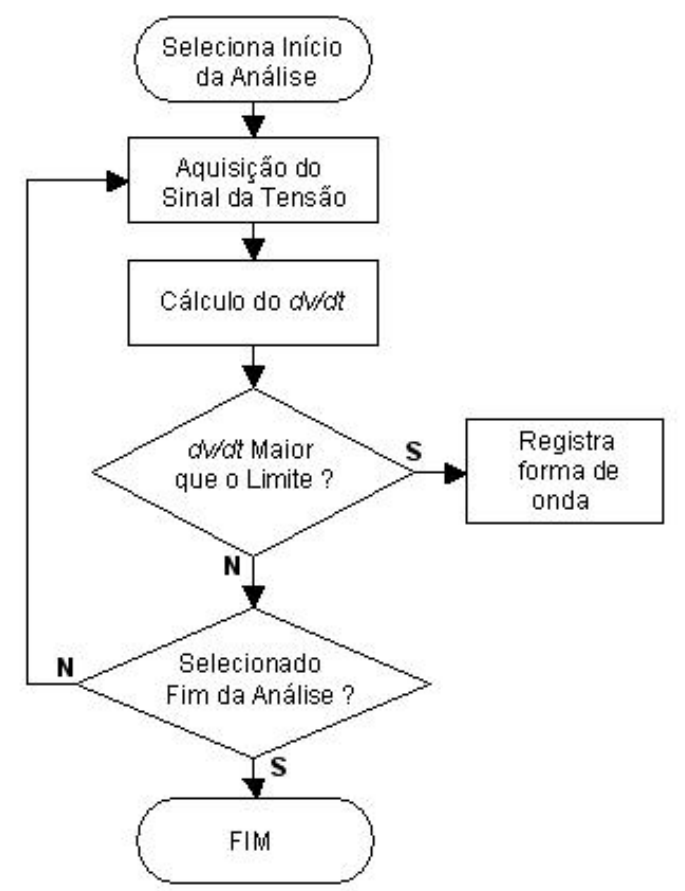

Figura 4.35. Fluxograma do módulo de Transitórios 


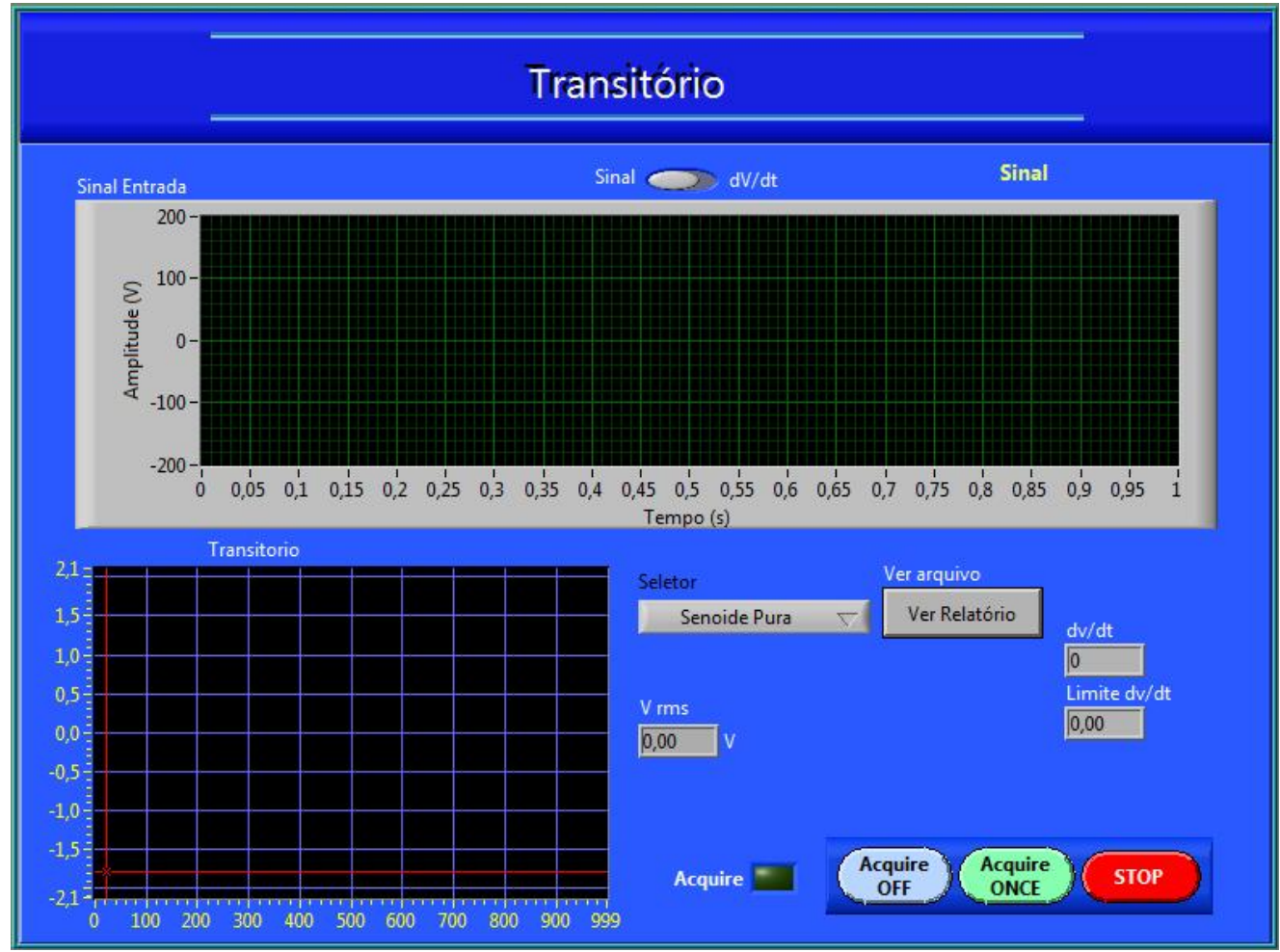

Figura 4.36. Tela do módulo de Transitórios 


\section{Resultados Experimentais}

\subsection{Introdução}

Neste capítulo é apresentado o resultado experimental do protótipo implementado operando em um sistema monofásico com a presença de uma carga linear de 200W (lâmpada incandescente), carga não linear de 27W (lâmpada fluorescente compacta) ou inversor de freqüência WEG-CFW02 ligadas convenientemente conforme cada caso.

O sistema experimental é alimentado por um gerador arbitrário de sinais modelo iX Series II da California Instruments, onde é possível simular individualmente a presença dos fenômenos eletromagnéticos desejados, bem como garantir o desempenho e a resposta do equipamento proposto diante dos testes exigidos pelas normas e na falta destes testes requeridos, simulações de comparação entre a resposta do equipamento proposto e a resposta teórica do sinal aplicado.

\subsection{Configuração e calibração do equipamento}

Neste módulo foram inseridos os valores para as devidas calibrações das fases do protótipo e feito as escolhas dos valores limites nas classes A e B para que sejam preenchidos e gerados os devidos relatórios. Foi também selecionado a configuração do sistema elétrico a ser medido. 
Para a calibração do equipamento são geradas tensões e correntes conhecidas nas devidas pontas de prova do equipamento e ajusta-se o valor do ganho até que o erro entre grandeza lida e grandeza gerada seja menor que o permitido de 0,1\%, conforme definido na norma IEC61000-4-30.

A figura 5.1 apresenta a tela de calibração dos canais de medição do protótipo onde são selecionados os respectivos ganhos.

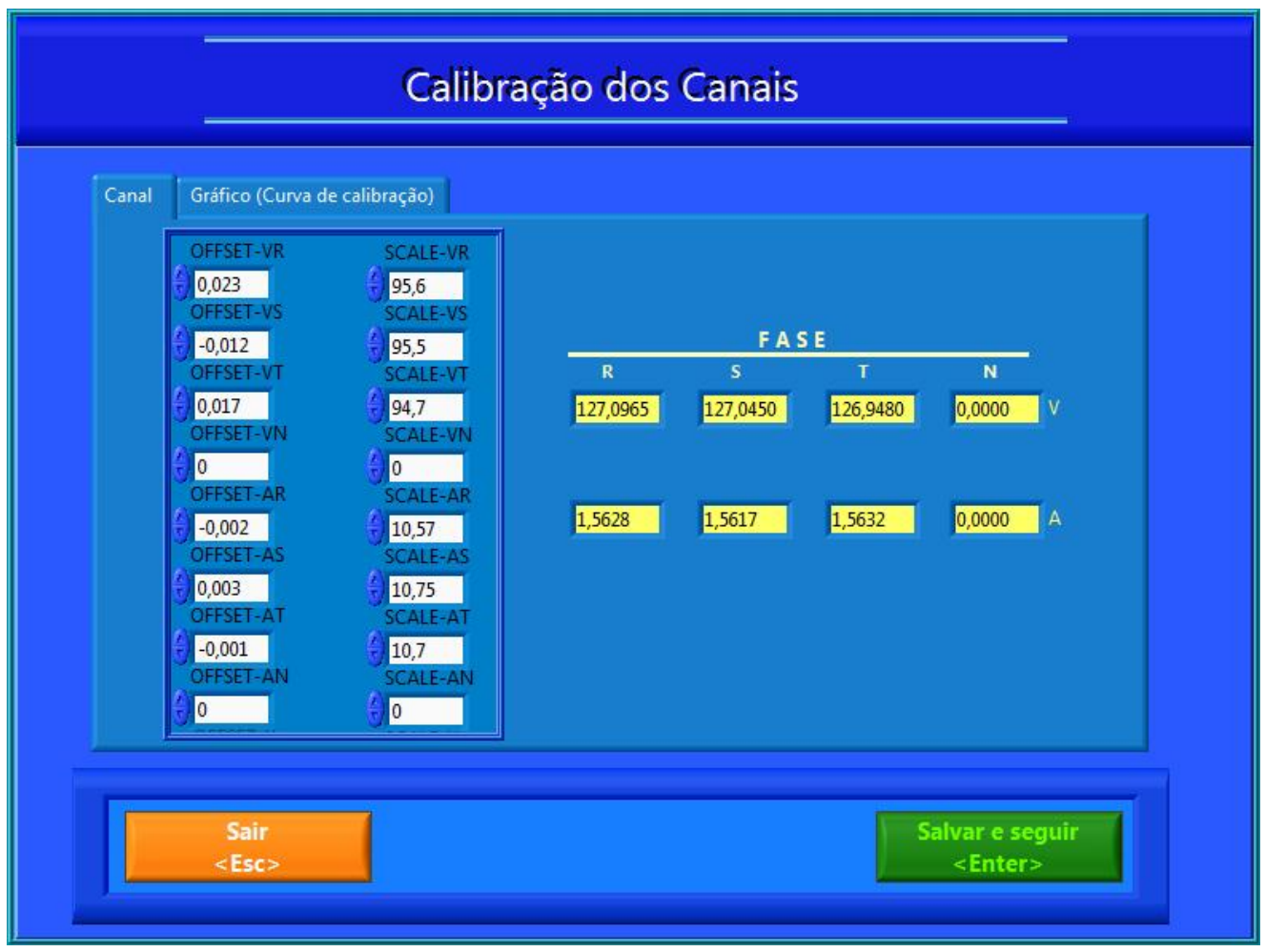

Figura 5.1. Tela de Calibração

Uma vez finalizada a calibração do equipamento, todos os testes foram inicializados e a calibração não foi mais alterada. 


\subsection{Simulação no módulo de Tensão / Corrente / Energia}

No módulo de simulação de tensão / corrente / energia foi gerada primeiramente uma onda senoidal $127 \mathrm{Vrms} / 60 \mathrm{~Hz}$ e aplicada sob a carga linear. $\mathrm{O}$ resultado da tensão, corrente e potência medidas, bem como as demais grandezas, podem ser observados na figura 5.2 .
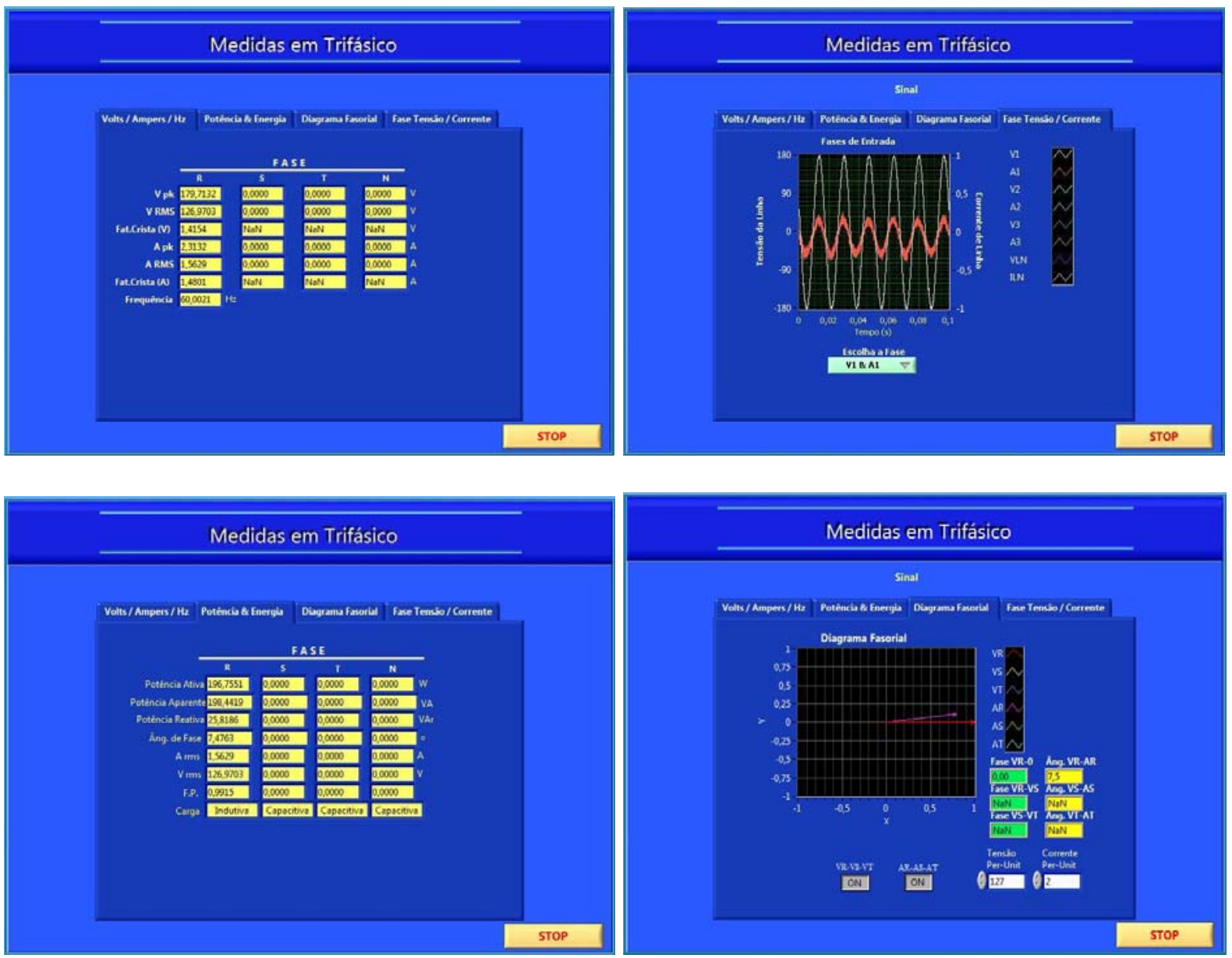

Figura 5.2. Telas de simulação do módulo de tensão/corrente/energia - carga linear

Após isto, a onda senoidal de $127 \mathrm{Vrms} / 60 \mathrm{~Hz}$ foi aplicada sob a carga nãolinear, levando aos valores apresentados na figura 5.3. 

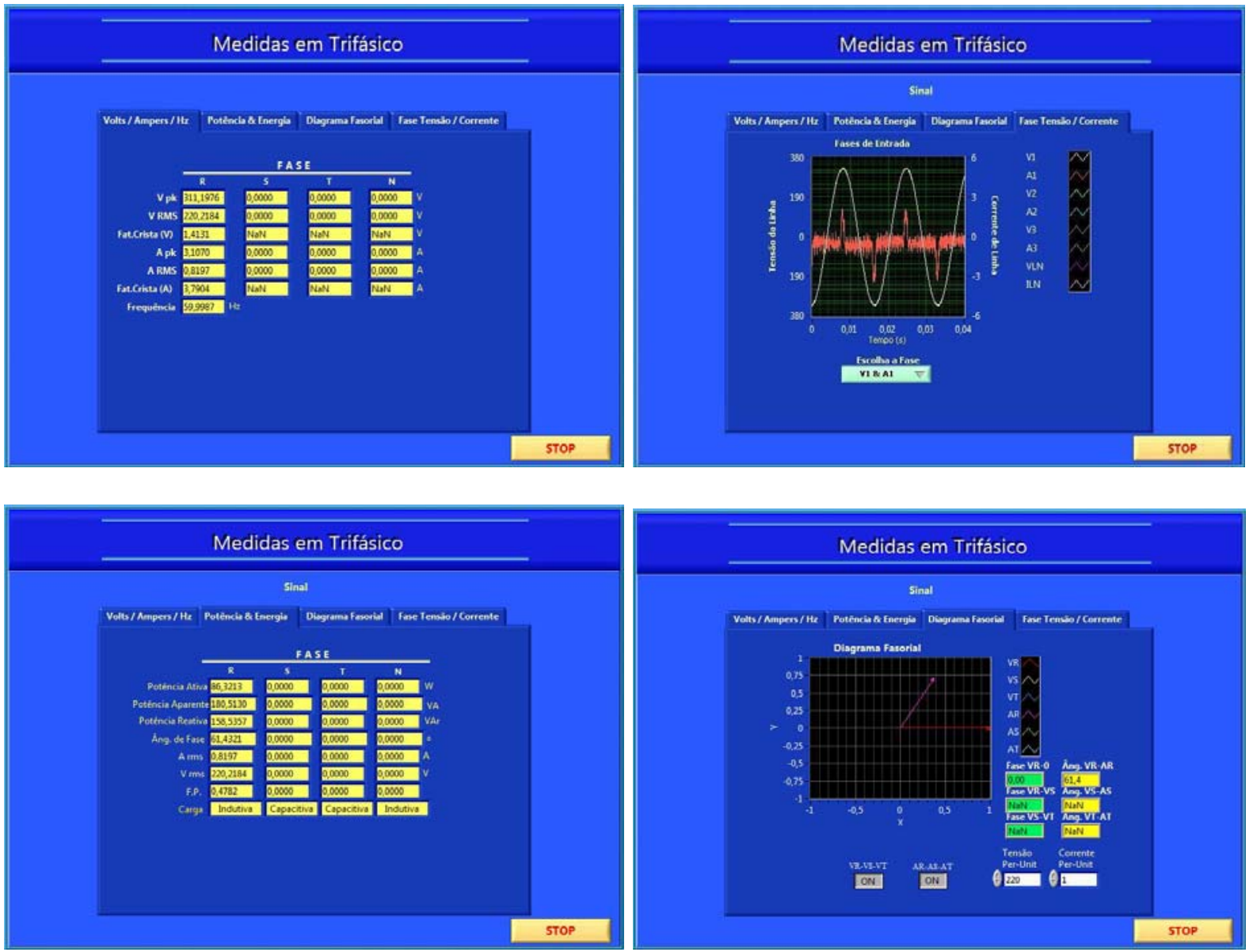

Figura 5.3. Tela de simulação do módulo de tensão/corrente/energia - carga não-linear

Os erros entre os valores aplicados e os valores medidos são apresentados nas tabelas 5.1 .

\begin{tabular}{|c|c|c|c|c|}
\cline { 2 - 5 } \multicolumn{1}{c|}{ Linear } & Valores Aplicados & Valores Medidos & Erro Abs & Erro \% \\
\hline Vpico & 179,547 & 179,713 & 0,166 & 0,093 \\
\hline Vrms & 126,960 & 126,970 & 0,010 & 0,008 \\
\hline FC V & 1,414 & 1,415 & 0,001 & 0,085 \\
\hline Apico & 2,291 & 2,313 & 0,022 & 0,969 \\
\hline Arms & 1,562 & 1,563 & 0,001 & 0,058 \\
\hline FC A & 1,460 & 1,480 & 0,020 & 1,375 \\
\hline Freqüência & 60,000 & 60,002 & 0,002 & 0,003 \\
\hline
\end{tabular}

\begin{tabular}{|c|c|c|c|c|}
\cline { 2 - 5 } \multicolumn{1}{c|}{ Linear } & Valores Aplicados & Valores Medidos & Erro Abs & Erro \% \\
\hline Pot. Ativa & 198,000 & 196,755 & 1,245 & 0,629 \\
\hline Pot. Aparente & 200,000 & 198,442 & 1,558 & 0,779 \\
\hline Pot. Reativa & 28,213 & 25,819 & 2,395 & 8,488 \\
\hline Ângulo Fase & 8,110 & 7,476 & 0,634 & 7,816 \\
\hline Arms & 1,566 & 1,563 & 0,001 & 0,058 \\
\hline Vrms & 126,960 & 126,970 & 0,010 & 0,008 \\
\hline FP & 0,990 & 0,992 & 0,002 & 0,152 \\
\hline Carga & Indutiva & Indutiva & Ok & Ok \\
\hline
\end{tabular}




\begin{tabular}{|c|c|c|c|c|}
\cline { 2 - 5 } \multicolumn{1}{c|}{ Não Linear } & Valores Aplicados & Valores Medidos & Erro Abs & Erro \% \\
\hline Vpico & 311,478 & 311,198 & 0,280 & 0,090 \\
\hline Vrms & 220,250 & 220,218 & 0,032 & 0,014 \\
\hline FC V & 1,414 & 1,413 & 0,001 & 0,076 \\
\hline Apico & 3,074 & 3,107 & 0,033 & 1,074 \\
\hline Arms & 0,819 & 0,820 & 0,001 & 0,085 \\
\hline FC A & 3,740 & 3,790 & 0,050 & 1,348 \\
\hline Freqüência & 60,000 & 59,999 & 0,001 & 0,002 \\
\hline
\end{tabular}

\begin{tabular}{|c|c|c|c|c|}
\cline { 2 - 5 } \multicolumn{1}{c|}{ Não Linear } & Valores Aplicados & Valores Medidos & Erro Abs & Erro \% \\
\hline Pot. Ativa & 88,000 & 86,321 & 1,679 & 1,908 \\
\hline Pot. Aparente & 183,333 & 180,513 & 2,820 & 1,538 \\
\hline Pot. Reativa & 160,833 & 158,536 & 2,297 & 1,428 \\
\hline Ângulo Fase & 61,315 & 61,432 & 0,117 & 0,192 \\
\hline Arms & 0,819 & 0,820 & 0,001 & 0,085 \\
\hline Vrms & 220,250 & 220,218 & 0,032 & 0,014 \\
\hline FP & 0,480 & 0,478 & 0,002 & 0,375 \\
\hline Carga & Indutiva & Indutiva & Ok & Ok \\
\hline
\end{tabular}

Tabela 5.1. Erro entre valores aplicados e medidos - módulo Tensão / Corrente / Energia

Observa-se que os erros exigidos pelas normas pertinentes (em azul) entre valores medidos e valores aplicados estão abaixo de $0,1 \%$, segundo a definição da norma IEC61000-4-30.

A figura 5.4 apresenta a tela do submódulo de osciloscópio sobre a carga linear.

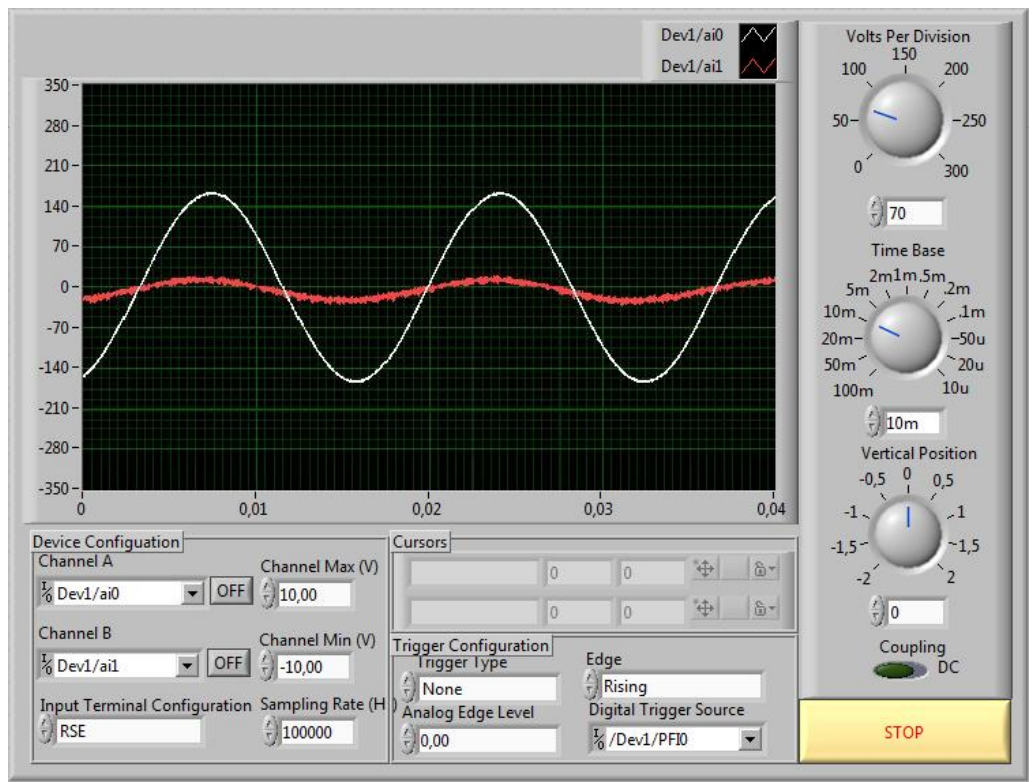

Figura 5.4. Telas do submódulo de Osciloscópio durante a simulação 


\subsection{Simulação no Módulo Variação e Flutuação de Tensão}

Para a simulação do módulo de Variação de Tensão foram aplicados ao protótipo os valores de tensão durante diferentes durações, conforme demonstrado na tabela 5.2.

\begin{tabular}{|c|c|}
\hline Tensão Eficaz (V) & Tempo (s) \\
\hline 127 & 5 \\
\hline 108 & 3 \\
\hline 115,6 & 1 \\
\hline 127 & 5 \\
\hline 146 & 3 \\
\hline 138,4 & 1 \\
\hline 127 & 5 \\
\hline 101,6 & 1 \\
\hline 2,5 & 2 \\
\hline 101,6 & 1 \\
\hline 127 & 5 \\
\hline 63,5 & 1 \\
\hline 0 & 2 \\
\hline 63,5 & 1 \\
\hline 127 & 5 \\
\hline
\end{tabular}

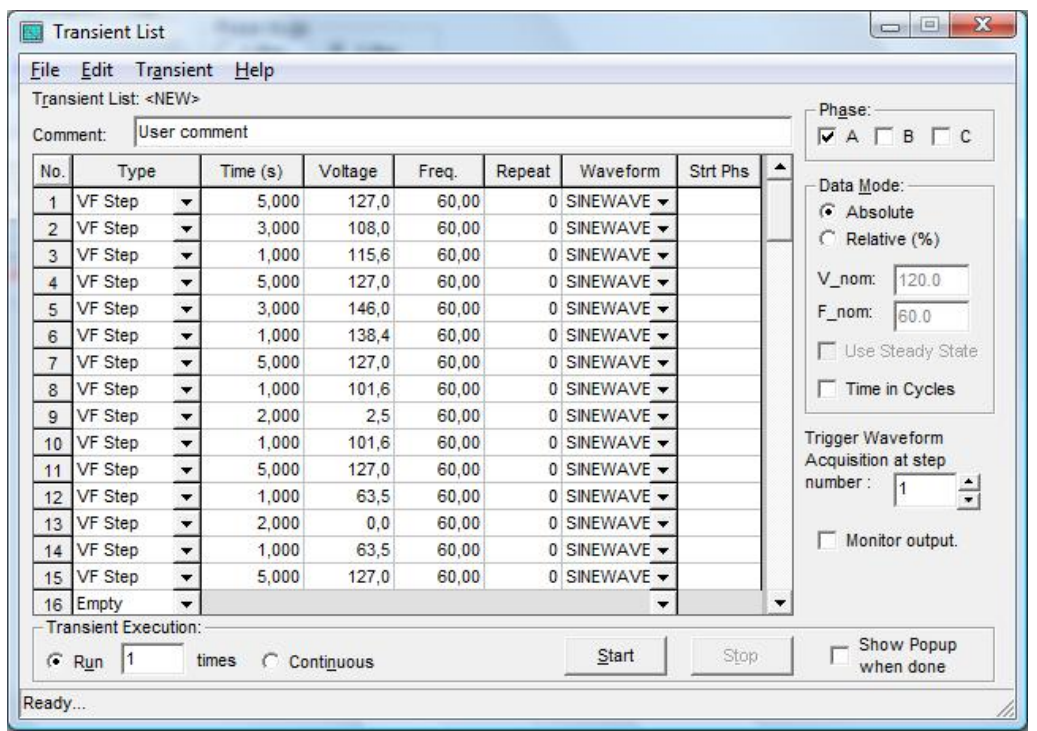

Tabela 5.2. Valores de tensão aplicados ao - módulo Variação de Tensão

A figura 5.5 apresenta a tela de simulação do módulo de Variação de Tensão para limites de acordo com a classe A do equipamento. 


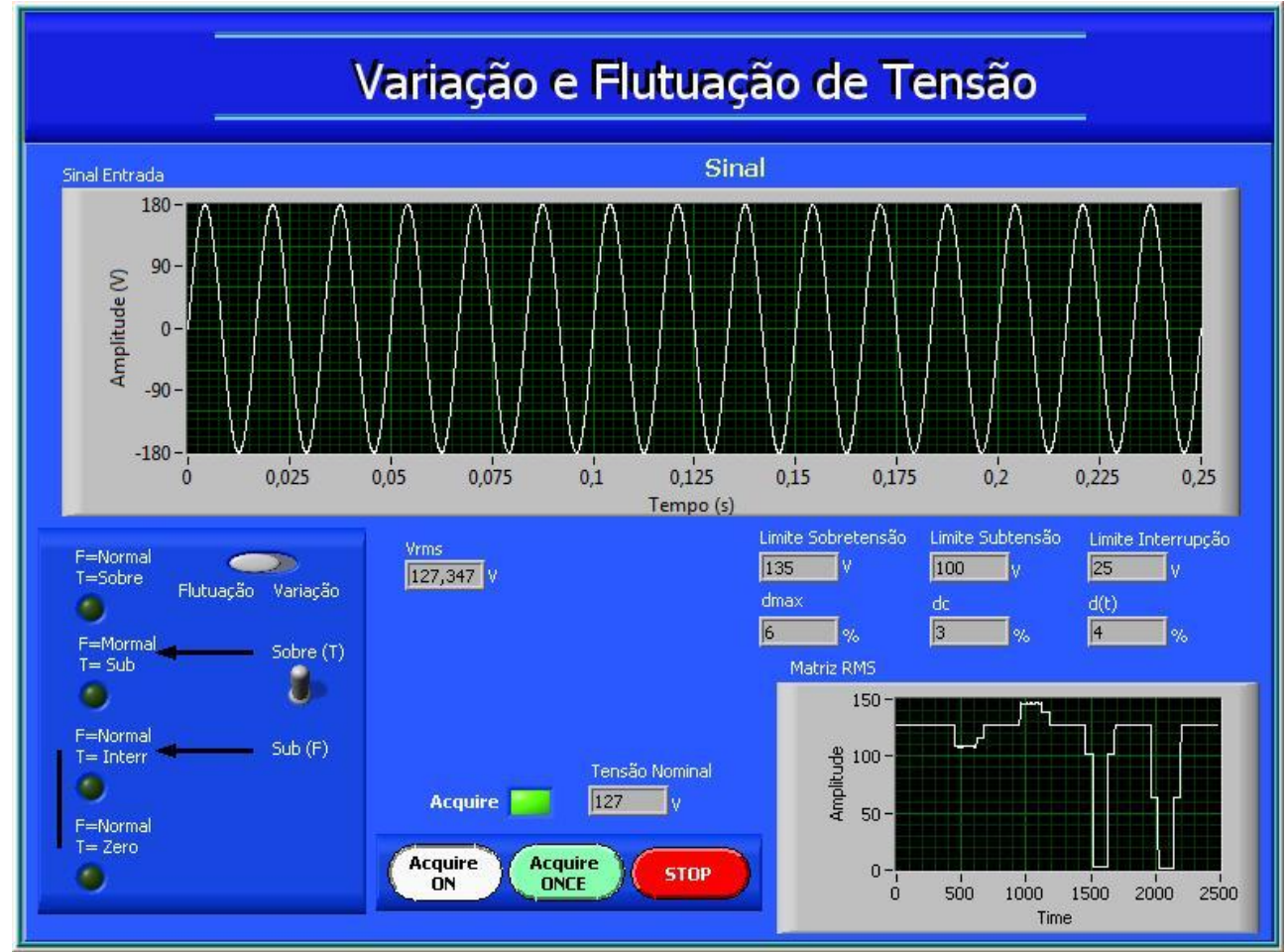

Figura 5.5. Tela de simulação módulo Variação de Tensão

Para os valores descritos na tabela 5.2 o equipamento gerou o relatório de análise, apresentado na figura 5.6, comprovando os distúrbios simulados pelo gerador arbitrário.

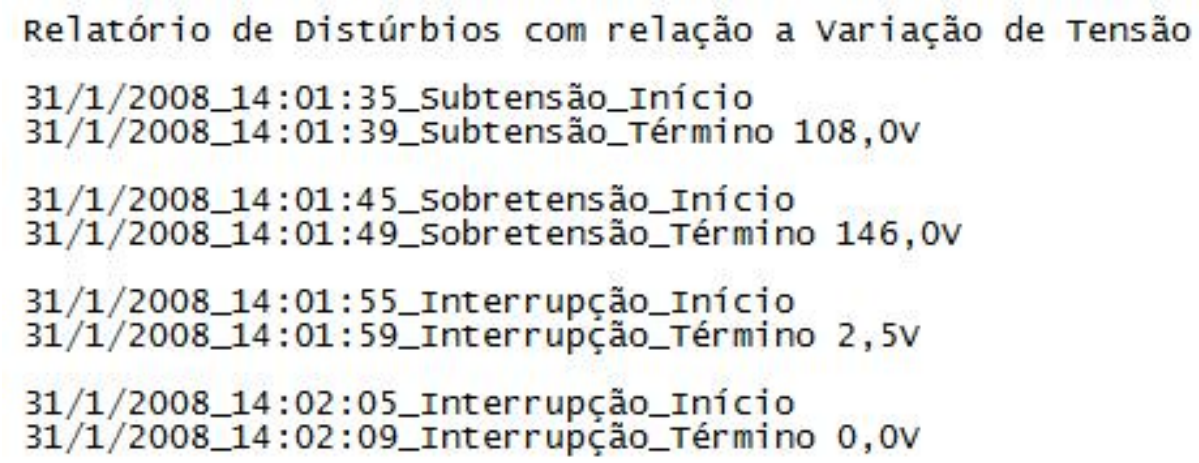

Figura 5.6. Relatório de simulação do módulo de Variação de Tensão

O erro entre os valores máximos / mínimos dos distúrbios gerados e os valores registrados pelo protótipo estão apresentados na tabela 5.3. 


\begin{tabular}{|l|c|c|c|c|}
\cline { 2 - 5 } \multicolumn{1}{c|}{} & Valores Aplicados & Valores Registrados & Erro Abs & Erro \% \\
\hline Subtensão & 108,0 & 108,0 & 0,0 & 0,00 \\
\hline Sobretensão & 146,0 & 146,0 & 0,0 & 0,00 \\
\hline Interrupção & 2,5 & 2,5 & 0,0 & 0,00 \\
\hline Interrupção & 0,0 & 0,0 & 0,0 & 0,00 \\
\hline
\end{tabular}

Tabela 5.3. Erro entre valores aplicados e valores registrados - módulo Variação da Tensão

Na tabela 5.3. pode-se observar que os erros entre valores medidos e valores registrados (em azul) encontram-se abaixo de 0,2\% que é o erro permitido neste módulo, conforme norma IEC61000-4-30.

A rotina de simulação do módulo de Flutuação de Tensão aplicou sobre o protótipo tensões em diferentes durações, conforme disposto na tabela 5.4.

\begin{tabular}{|c|c|}
\hline Tensão Eficaz (V) & Tempo (s) \\
\hline 100 & 5 \\
\hline 98 & 5 \\
\hline 93 & 0,4 \\
\hline 98 & 5 \\
\hline 93 & 0,6 \\
\hline 98 & 5 \\
\hline 90 & 0,2 \\
\hline 98 & 5 \\
\hline 97 & 0,2 \\
\hline 96 & 0,2 \\
\hline 95 & 0,2 \\
\hline 94,5 & 5 \\
\hline 88 & 5 \\
\hline
\end{tabular}

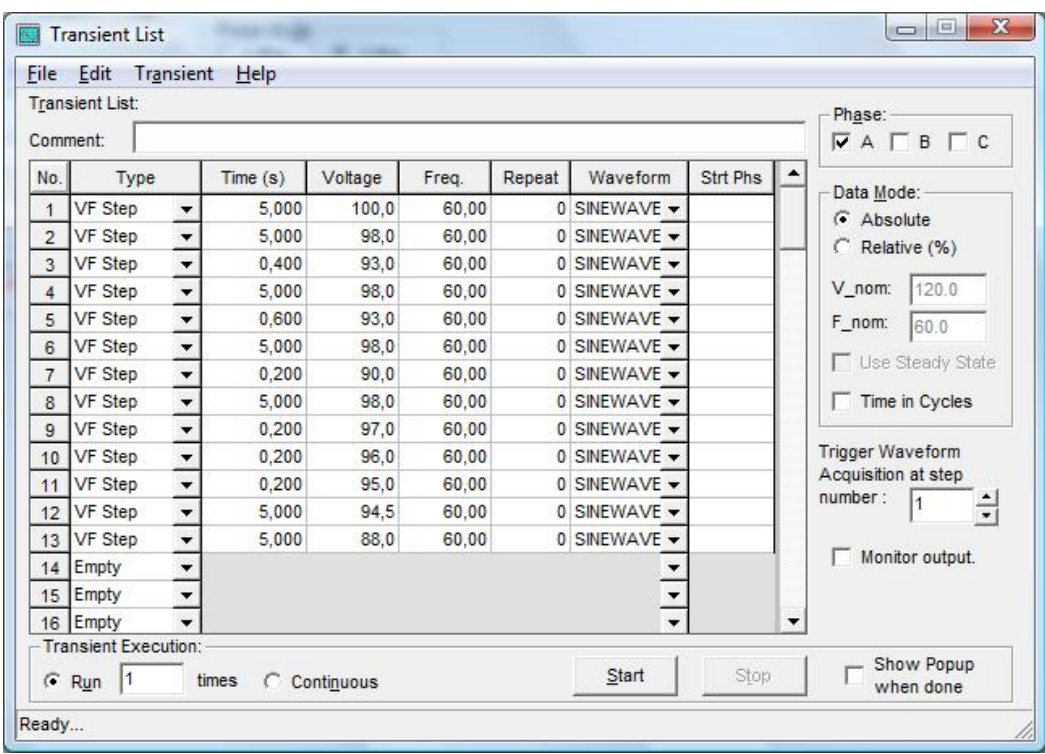

Tabela 5.4. Valores de tensão aplicados ao protótipo - módulo Flutuação de Tensão

A figura 5.7 mostra a tela de simulação do módulo de Flutuação de Tensão onde foram impostos limites de $d(t)=4 \%, d c=3 \%$ e $d \max =6 \%$ (classe B) para que se possa observar melhor a ocorrência dos distúrbios. 


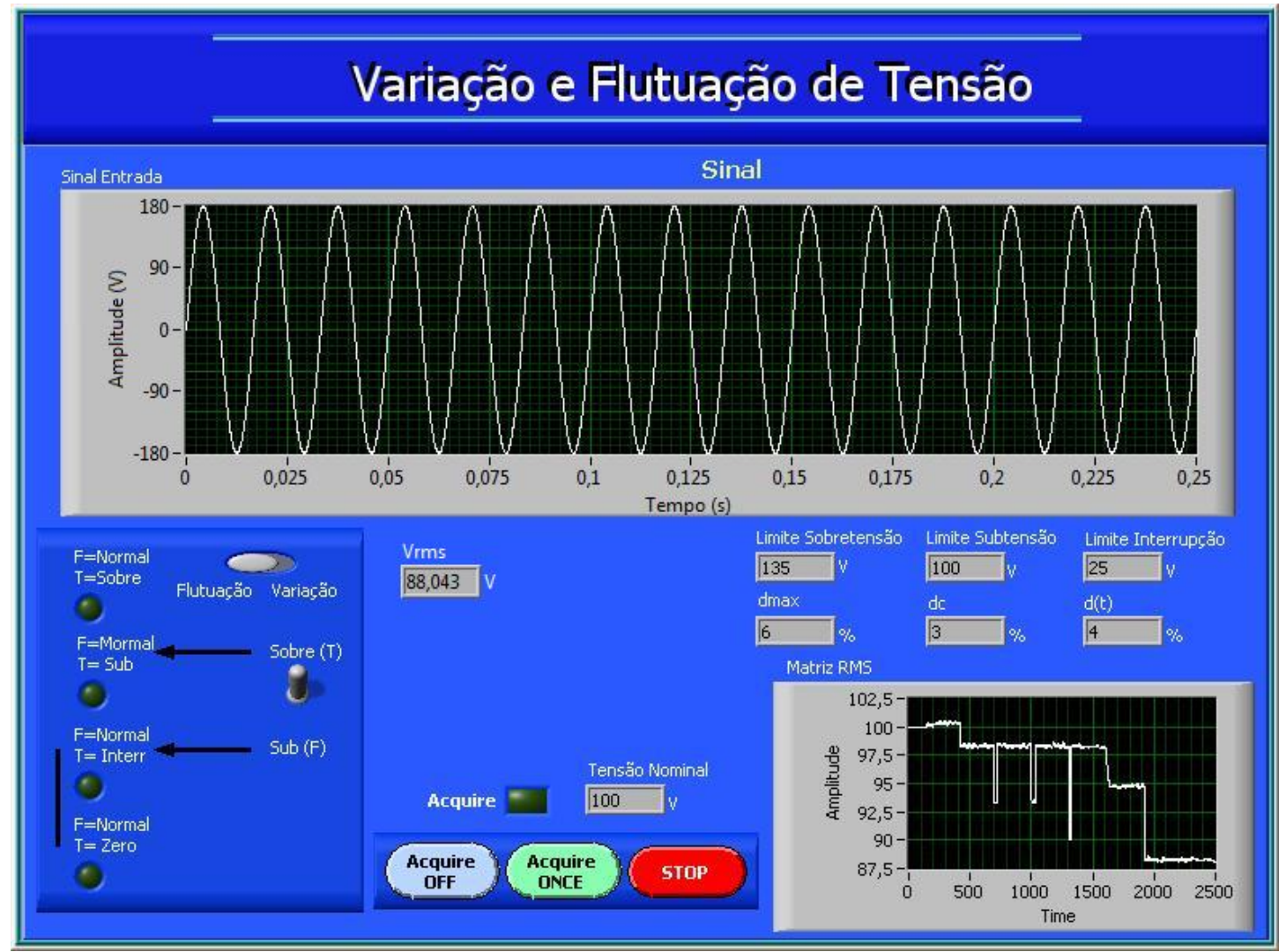

Figura 5.7. Tela de simulação módulo Flutuação de Tensão

Para o teste com os valores da tabela 5.4 o protótipo gerou o relatório apresentado na figura 5.8 .

Relatório de Distúrbios com relação a Flutuação de Tensão

31/1/2008_14:11:20_ocorrência d(t) inf 93,0V

31/1/2008_14:11:25_ocorrência dmax inf 90,0V

31/1/2008_14:11:31_ocorrência dc inf 94,5v

31/1/2008_14:11:36_ocorrência $d(t)$ inf 88,0V

31/1/2008_14:11:36_ocorrência dc inf 88,0V

31/1/2008_14:11:36_ocorrência dmax inf 88,0V

Figura 5.8. Relatório de simulação do módulo de Flutuação de Tensão 
A tabela 5.5 mostra o erro entre os valores esperados e os valores registrados no relatório da figura 5.8 .

\begin{tabular}{|l|c|c|c|c|}
\cline { 2 - 5 } \multicolumn{1}{c|}{} & Valores Aplicados & Valores Registrados & Erro Abs & Erro \% \\
\hline $\mathbf{d}(\mathbf{t})$ & 93,0 & 93,0 & 0,0 & 0,00 \\
\hline $\mathbf{d m a x}$ & 90,0 & 90,0 & 0,0 & 0,00 \\
\hline $\mathbf{d c}$ & 94,5 & 94,5 & 0,0 & 0,00 \\
\hline $\mathbf{d}(\mathbf{t})$ & 88,0 & 88,0 & 0,0 & 0,00 \\
\hline $\mathbf{d c}$ & 88,0 & 88,0 & 0,0 & 0,00 \\
\hline $\mathbf{d m a x}$ & 88,0 & 88,0 & 0,0 & 0,00 \\
\hline
\end{tabular}

Tabela 5.5. Erro entre valores aplicados e valores registrados - módulo Flutuação de Tensão

Vê-se na tabela 5.5. que o erro entre valores aplicados e valores registrados (em azul) está abaixo dos 0,2\% permitidos pela norma IEC61000-4-30, atendendo assim as exigências.

\subsection{Simulação no Módulo de Distorções da Forma de Onda}

Gerou-se uma onda senoidal $127 \mathrm{Vrms} / 60 \mathrm{~Hz}$ e aplicou-se sobre a carga linear de classe C, onde foi obtida a densidade espectral de potência vista na figura 5.9. Nesta figura vê-se à esquerda a densidade espectral de potência medida pelo gerador arbitrário e à direita esta mesma grandeza medida pelo protótipo. 

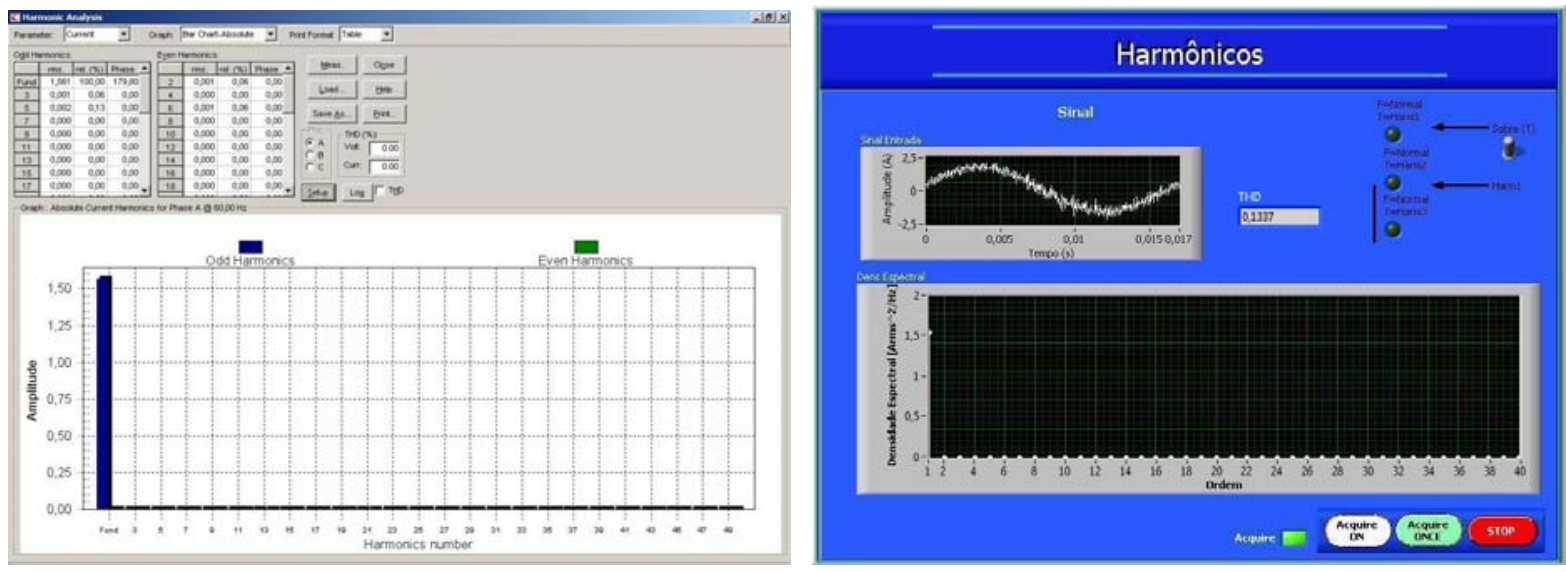

Figura 5.9. Densidade espectral de potencial da carga linear - gerador x protótipo

Após isto, foi substituída a carga linear pela não-linear (inversor de freqüência), de classe D. A figura 5.10 apresenta as medições de densidade espectral de potência realizada pelo gerador arbitrário e pelo protótipo.
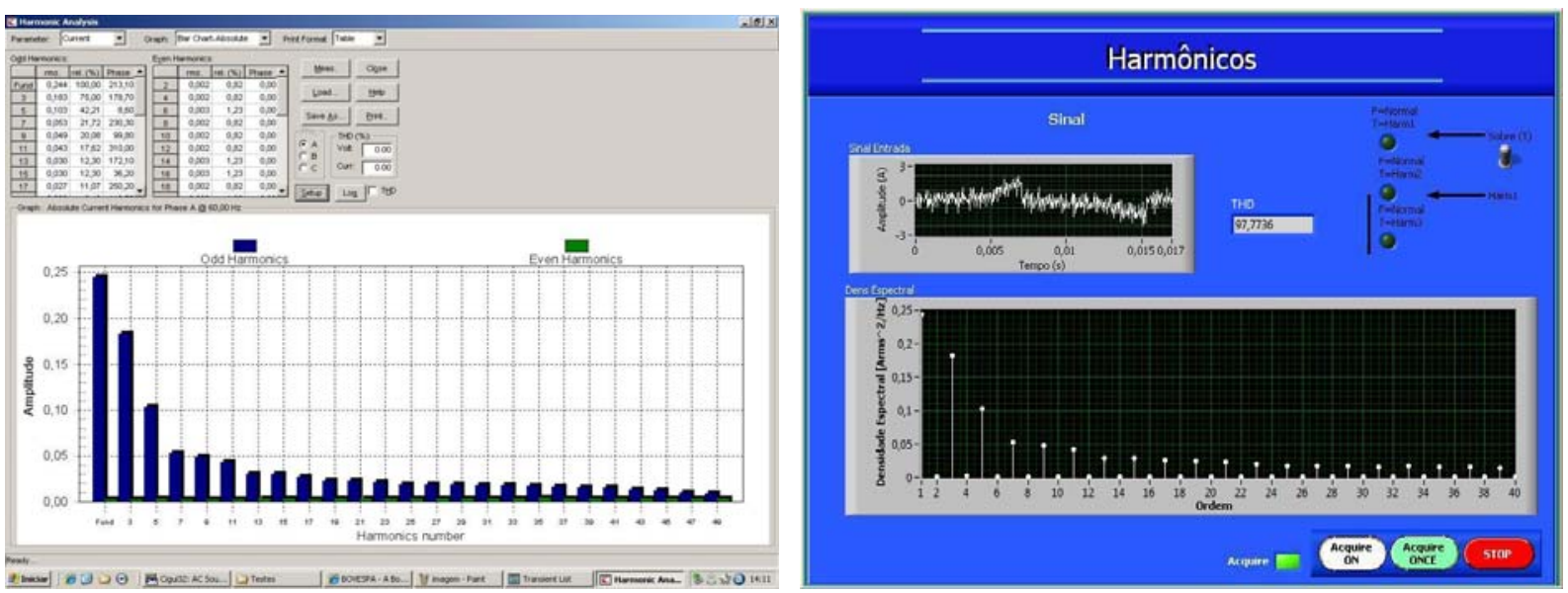

Figura 5.10. Densidade espectral de potência da carga não-linear - gerador x protótipo

Os erros entre os valores medidos pelo gerador arbitrário e os valores medidos pelo protótipo são apresentados na tabela 5.6, onde tem-se a medição da carga linear na tabela à esquerda e a medição da carga não linear na tabela à direita. 


\begin{tabular}{|c|c|c|c|c|}
\hline Ordem & Valor Aplicado & Valor Medido & Erro Abs & Erro \% \\
\hline 1 & 1,561 & 1,563 & 0,002 & 0,13 \\
\hline 2 & 0,001 & 0,001 & 0,000 & 0,00 \\
\hline 3 & 0,001 & 0,000 & 0,001 & 100,00 \\
\hline 4 & 0,002 & 0,001 & 0,001 & 50,00 \\
\hline 5 & 0,000 & 0,000 & 0,000 & 0,00 \\
\hline 6 & 0,000 & 0,000 & 0,000 & 0,00 \\
\hline 7 & 0,000 & 0,000 & 0,000 & 0,00 \\
\hline 8 & 0,000 & 0,000 & 0,000 & 0,00 \\
\hline 9 & 0,000 & 0,000 & 0,000 & 0,00 \\
\hline 10 & 0,000 & 0,000 & 0,000 & 0,00 \\
\hline 11 & 0,000 & 0,000 & 0,000 & 0,00 \\
\hline 12 & 0,000 & 0,000 & 0,000 & 0,00 \\
\hline 13 & 0,000 & 0,000 & 0,000 & 0,00 \\
\hline 14 & 0,000 & 0,000 & 0,000 & 0,00 \\
\hline 15 & 0,000 & 0,000 & 0,000 & 0,00 \\
\hline 16 & 0,000 & 0,000 & 0,000 & 0,00 \\
\hline 17 & 0,000 & 0,000 & 0,000 & 0,00 \\
\hline 18 & 0,000 & 0,000 & 0,000 & 0,00 \\
\hline 19 & 0,000 & 0,000 & 0,000 & 0,00 \\
\hline 20 & 0,000 & 0,000 & 0,000 & 0,00 \\
\hline 21 & 0,000 & 0,000 & 0,000 & 0,00 \\
\hline 22 & 0,000 & 0,000 & 0,000 & 0,00 \\
\hline 23 & 0,000 & 0,000 & 0,000 & 0,00 \\
\hline 24 & 0,000 & 0,000 & 0,000 & 0,00 \\
\hline 25 & 0,000 & 0,000 & 0,000 & 0,00 \\
\hline 26 & 0,000 & 0,000 & 0,000 & 0,00 \\
\hline 27 & 0,000 & 0,000 & 0,000 & 0,00 \\
\hline 28 & 0,000 & 0,000 & 0,000 & 0,00 \\
\hline 29 & 0,000 & 0,000 & 0,000 & 0,00 \\
\hline 30 & 0,000 & 0,000 & 0,000 & 0,00 \\
\hline 31 & 0,000 & 0,000 & 0,000 & 0,00 \\
\hline 32 & 0,000 & 0,000 & 0,000 & 0,00 \\
\hline 33 & 0,000 & 0,000 & 0,000 & 0,00 \\
\hline 34 & 0,000 & 0,000 & 0,000 & 0,00 \\
\hline 35 & 0,000 & 0,000 & 0,000 & 0,00 \\
\hline 36 & 0,000 & 0,000 & 0,000 & 0,00 \\
\hline 37 & 0,000 & 0,000 & 0,000 & 0,00 \\
\hline 38 & 0,000 & 0,000 & 0,000 & 0,00 \\
\hline 39 & 0,000 & 0,000 & 0,000 & 0,00 \\
\hline 40 & 0,000 & 0,000 & 0,000 & 0,00 \\
\hline THD & 0,1569 & 0,1337 & 0,023 & 14,79 \\
\hline
\end{tabular}

\begin{tabular}{|c|c|c|c|c|}
\hline Ordem & Valor Aplicado & Valor Medido & Erro Abs & Erro \% \\
\hline 1 & 0,244 & 0,243 & 0,001 & 0,41 \\
\hline 2 & 0,002 & 0,001 & 0,001 & 50,00 \\
\hline 3 & 0,183 & 0,182 & 0,001 & 0,55 \\
\hline 4 & 0,002 & 0,002 & 0,000 & 0,00 \\
\hline 5 & 0,103 & 0,102 & 0,001 & 0,97 \\
\hline 6 & 0,003 & 0,001 & 0,002 & 66,67 \\
\hline 7 & 0,053 & 0,052 & 0,001 & 1,89 \\
\hline 8 & 0,002 & 0,001 & 0,001 & 50,00 \\
\hline 9 & 0,049 & 0,050 & 0,001 & 2,04 \\
\hline 10 & 0,002 & 0,001 & 0,001 & 50,00 \\
\hline 11 & 0,043 & 0,045 & 0,002 & 4,65 \\
\hline 12 & 0,002 & 0,002 & 0,000 & 0,00 \\
\hline 13 & 0,030 & 0,029 & 0,001 & 3,33 \\
\hline 14 & 0,003 & 0,001 & 0,002 & 66,67 \\
\hline 15 & 0,030 & 0,031 & 0,001 & 3,33 \\
\hline 16 & 0,003 & 0,002 & 0,001 & 33,33 \\
\hline 17 & 0,027 & 0,024 & 0,003 & 11,11 \\
\hline 18 & 0,002 & 0,001 & 0,001 & 50,00 \\
\hline 19 & 0,025 & 0,022 & 0,003 & 12,00 \\
\hline 20 & 0,002 & 0,000 & 0,002 & 100,00 \\
\hline 21 & 0,025 & 0,020 & 0,005 & 20,00 \\
\hline 22 & 0,002 & 0,000 & 0,002 & 100,00 \\
\hline 23 & 0,023 & 0,017 & 0,006 & 26,09 \\
\hline 24 & 0,002 & 0,000 & 0,002 & 100,00 \\
\hline 25 & 0,021 & 0,016 & 0,005 & 23,81 \\
\hline 26 & 0,002 & 0,000 & 0,002 & 100,00 \\
\hline 27 & 0,020 & 0,022 & 0,002 & 10,00 \\
\hline 28 & 0,002 & 0,000 & 0,002 & 100,00 \\
\hline 29 & 0,020 & 0,016 & 0,004 & 20,00 \\
\hline 30 & 0,002 & 0,000 & 0,002 & 100,00 \\
\hline 31 & 0,019 & 0,015 & 0,004 & 21,05 \\
\hline 32 & 0,002 & 0,000 & 0,002 & 100,00 \\
\hline 33 & 0,018 & 0,011 & 0,007 & 38,89 \\
\hline 34 & 0,002 & 0,000 & 0,002 & 100,00 \\
\hline 35 & 0,017 & 0,011 & 0,006 & 35,29 \\
\hline 36 & 0,002 & 0,000 & 0,002 & 100,00 \\
\hline 37 & 0,015 & 0,008 & 0,007 & 46,67 \\
\hline 38 & 0,002 & 0,000 & 0,002 & 100,00 \\
\hline 39 & 0,014 & 0,005 & 0,009 & 64,29 \\
\hline 40 & 0,002 & 0,000 & 0,002 & 100,00 \\
\hline THD & 98,8682 & 97,4916 & 1,377 & 1,39 \\
\hline
\end{tabular}

Tabela 5.6. Erro entre medição do gerador e medição do protótipo - módulo Distorções

Pode-se observar na tabela 5.6. que para os valores aplicados de densidade espectral acima de $0,03 \mathrm{Arms}^{2} / \mathrm{Hz}$ têm erro percentual abaixo de $5 \%$ (em azul) e portanto atendem o exigido pela norma IEC61000-4-7. Os demais valores não atedem a tolerância de $5 \%$. 


\subsection{Simulação no Módulo de Freqüência}

Sob tensão constante de $127 \mathrm{Vrms}$, foram aplicados os valores de freqüência conforme apresentados na tabela 5.7 sobre a carga resistiva linear (lâmpada incandescente).

\begin{tabular}{|c|c|}
\hline Frequiência $(\mathrm{Hz})$ & Tempo (s) \\
\hline 60,0 & 15 \\
\hline 59,2 & 20 \\
\hline 58,9 & 20 \\
\hline 60,0 & 20 \\
\hline 60,8 & 20 \\
\hline 61,1 & 20 \\
\hline 60,0 & 20 \\
\hline
\end{tabular}

\begin{tabular}{|c|c|c|c|c|c|c|c|c|c|c|}
\hline 圖 Tr & ransient $\mathrm{L}$ & & 2000 & & & & & & & 0 미 $x$ \\
\hline File & Edit & Isien & t Help & & & & & & & \\
\hline Trans & sient List: & & & & & & & & & Phase:- \\
\hline Comn & ment: & & & & & & & & & $\nabla A \Gamma B Г C$ \\
\hline No. & Typ & & Time (s) & Voltage & Freq. & Repeat & Waveform & Strt Phs & $\Delta$ & \\
\hline 1 & VF Step & - & 15,000 & 127,0 & 60,00 & 0 & SINEWAVE - & & & c. Ahsolute \\
\hline 2 & VF Step & 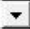 & 20,000 & 127,0 & 59,20 & 0 & SINEWAVE - & & & C Relative (\%) \\
\hline 3 & VF Step & 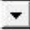 & 20,000 & 127,0 & 58,90 & 0 & SINEWAVE - & & & \\
\hline 4 & VF Step & 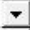 & 20,000 & 127,0 & 60,00 & 0 & SINEWAVE - & & & V_nom: 120.0 \\
\hline 5 & VF Step & 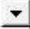 & 20,000 & 127,0 & 60,80 & 0 & SINEWAVE $\boldsymbol{\sim}$ & & & F_nom: $\quad 60.0$ \\
\hline 6 & VF Step & $=$ & 20,000 & 127,0 & 61,10 & 0 & SINEWAVE - & & & $\Gamma$ use steady state \\
\hline 7 & VF Step & 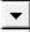 & 20,000 & 127,0 & 60,00 & 0 & SINEWAVE - & & & I. Use steday stale \\
\hline 8 & Empty & $=$ & & & & & \pm & & & $\Gamma$ Time in Cycles \\
\hline 9 & Empty & 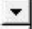 & & & & & 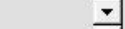 & & & \\
\hline 10 & Empty & 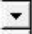 & & & & & $\overline{7}$ & & & Trigger Waveform \\
\hline 11 & Empty & 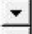 & & & & & - & & & $\begin{array}{l}\text { Acquistion at step } \\
\text { number: }\end{array}$ \\
\hline 12 & Empty & 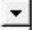 & & & & & 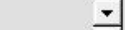 & & & $\left.\right|^{1}$ \\
\hline 13 & Empty & 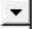 & & & & & 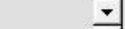 & & & Г Monitor outout \\
\hline 14 & Empty & - & & & & & - & & & Thonitor output. \\
\hline 15 & Empty & 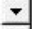 & & & & & - & & & \\
\hline 16 & Empty & -1 & & & & & - & & - & \\
\hline Tra & ansient Ex & & & & & & & & & \\
\hline c & Run $\mid 1$ & & $\mathrm{C}$ Co & ntinuous & & & Start & stop & & when done \\
\hline
\end{tabular}

Tabela 5.7. Valores de freqüência aplicados ao protótipo - módulo Freqüência

A figura 5.11 apresenta a tela de simulação do módulo de freqüência para os limites definidos para a classe A deste módulo. 


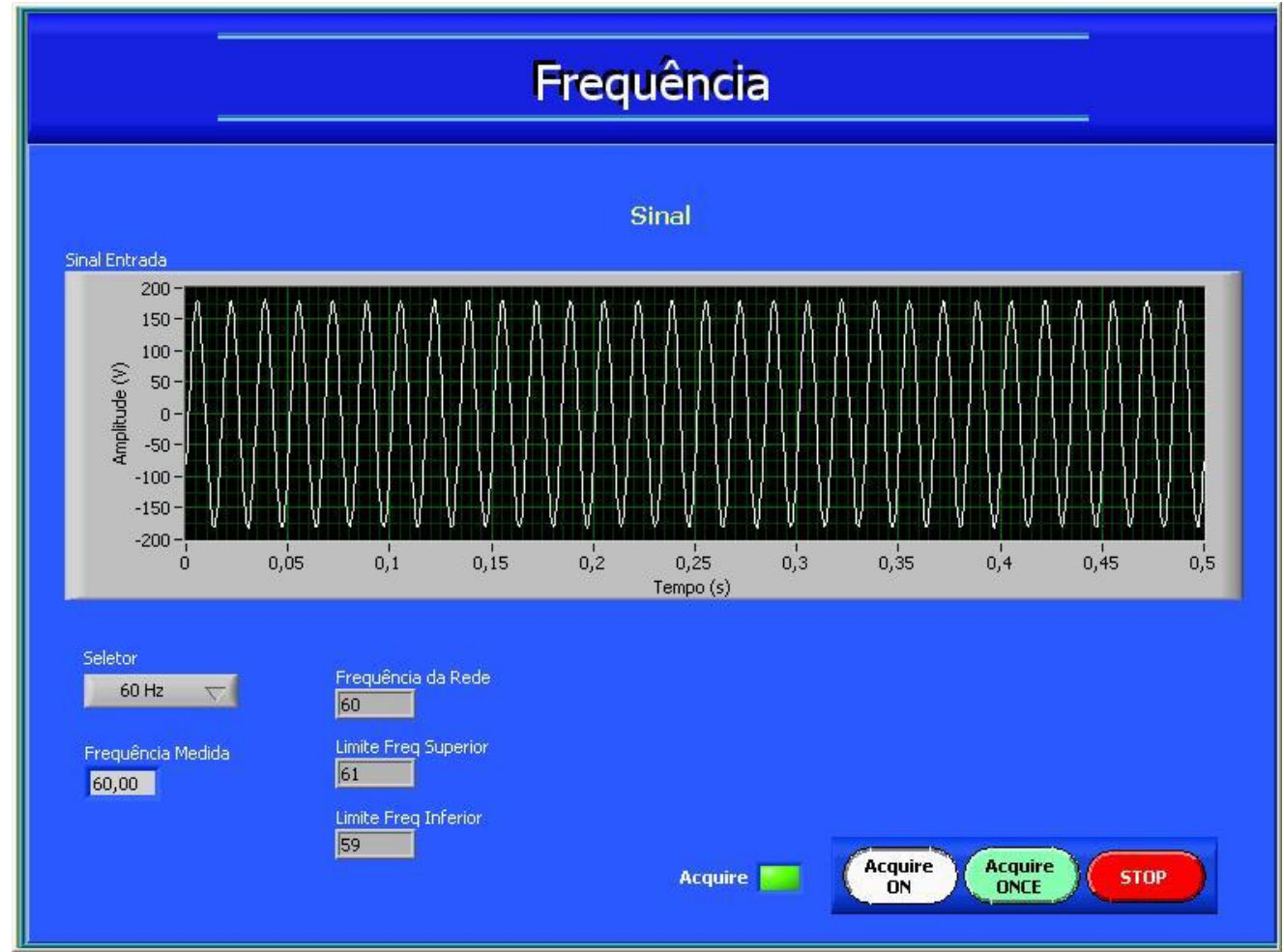

Figura 5.11. Tela de simulação módulo de Freqüência

O relatório de teste da figura 5.12 foi gerado pelo protótipo durante o teste com os valores da tabela. 5.7.

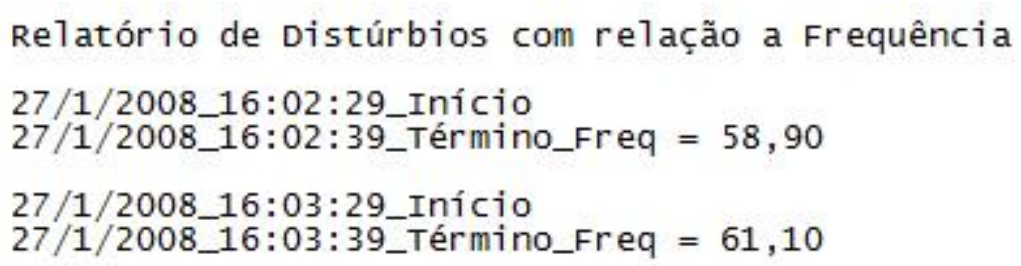

Figura 5.12. Relatório de simulação do módulo de Freqüência

O erro apresentado entre os valores aplicados e os valores registrados pelo protótipo estão dispostos na tabela 5.8 . 


\begin{tabular}{|l|c|c|c|c|}
\cline { 2 - 5 } \multicolumn{1}{c|}{} & Valores Aplicados & Valores Registrados & Erro Abs & Erro \% \\
\hline Subfrequência & 58,90 & 58,90 & 0,00 & 0,00 \\
\hline Sobrefrequência & 61,10 & 61,10 & 0,00 & 0,00 \\
\hline
\end{tabular}

Tabela 5.8. Erro entre valores aplicados e valores medidos - módulo Freqüência

Na tabela 5.8. observa-se que os erros entre valores aplicados e valores registrados (em azul) estão dentro da tolerância de $\pm 0,01 \mathrm{~Hz}$ especificada pela norma IEC61000-4-30.

\subsection{Simulação no Módulo de Flicker}

Para a simulação do módulo de flicker foram utilizados os valores padrões de desempenho da tabela 5 da norma IEC 61000-4-15. Conforme descrito por esta norma, o Pst esperado para cada teste deve ser $1+/-5 \%$. A tabela 5 da IEC $61000-$ 4-15 está apresentada na tabela 5.9 abaixo.

\begin{tabular}{|c|c|c|}
\hline Variações Retangulares & \multicolumn{2}{|c|}{ Variação Tensão $\mathbf{\Delta V} / \mathbf{V} \%$} \\
\cline { 2 - 3 } por Minuto & $\mathbf{1 2 0 \mathrm { V } / 6 0 \mathrm { Hz }}$ & $\mathbf{2 3 0 \mathrm { V } / 5 0 \mathrm { Hz }}$ \\
\hline 1 & 3,166 & 2,724 \\
\hline 2 & 2,568 & 2,211 \\
\hline 7 & 1,695 & 1,459 \\
\hline 39 & 1,044 & 0,906 \\
\hline 110 & 0,841 & 0,725 \\
\hline 1620 & 0,547 & 0,402 \\
\hline 4000 & não obrigatório & 2,400 \\
\hline 4800 & 4,834 & não obrigatório \\
\hline
\end{tabular}

Tabela 5.9. Valores padrões de testes do módulo flicker - conforme IEC 61000-4-15

A figura 5.13 apresenta a tela de medição de flicker, contendo as medidas de Pst e PIt. 


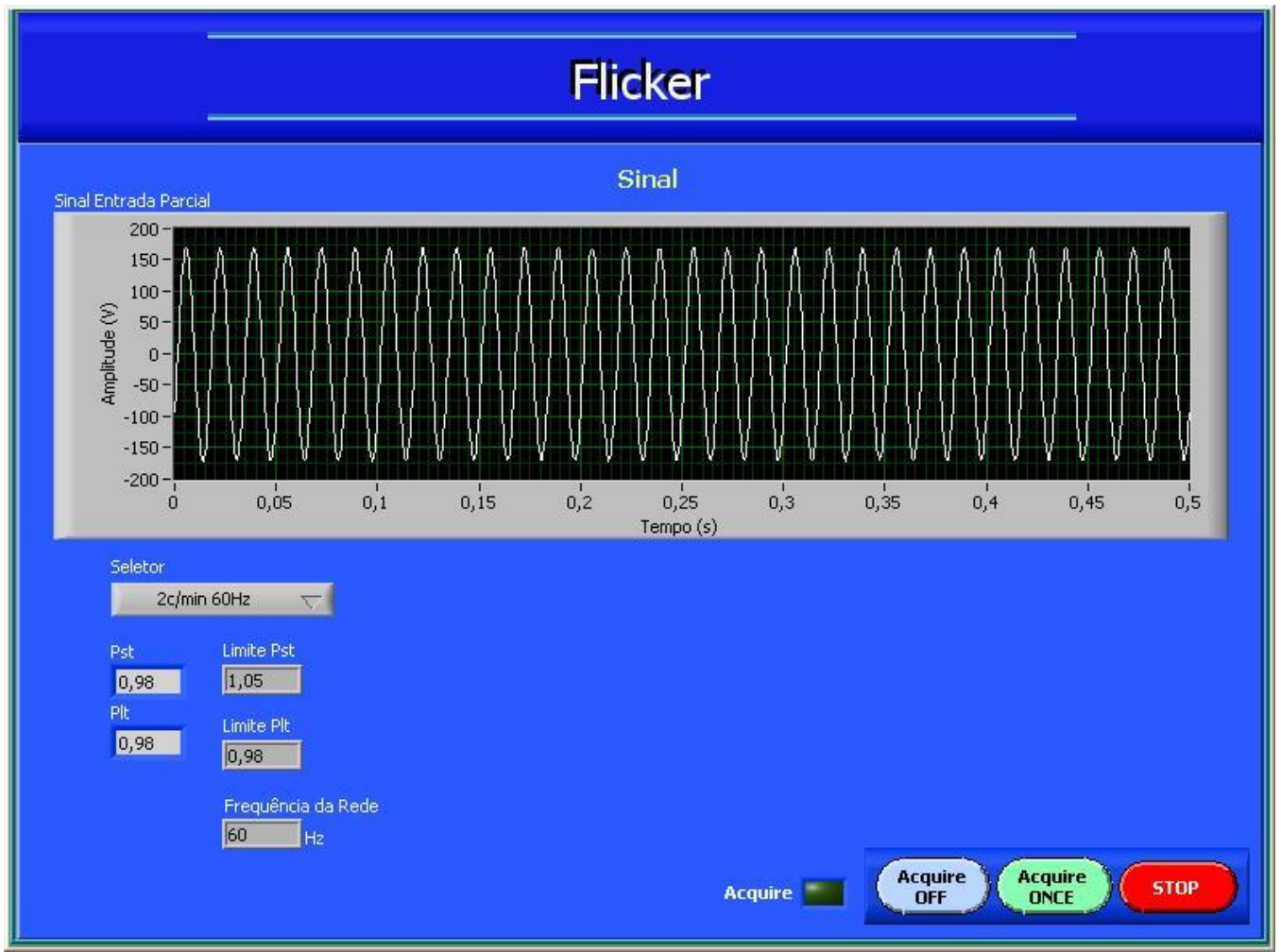

Figura 5.13. Tela de simulação módulo Flicker

Analisando os resultados do teste na tabela 5.10 vê-se que todos os valores estão dentro da faixa de tolerância de $+/-5 \%$, atendendo o estabelecido pela IEC61000-4-15.

\begin{tabular}{|c|c|c|c|c|c|}
\hline $\begin{array}{c}\text { Variações Retangulares } \\
\text { por Minuto }\end{array}$ & $\begin{array}{c}\text { Valor } \\
\text { Esperado }\end{array}$ & $\begin{array}{c}\text { Valor Medido } \\
\mathbf{6 0 H z}\end{array}$ & $\begin{array}{c}\text { Valor Medido } \\
\mathbf{5 0 H z}\end{array}$ & $\begin{array}{c}\text { Maior Erro } \\
\text { Absoluto }\end{array}$ & Erro $\%$ \\
\hline 1 & $0,95-1,05$ & 1,07 & 1,02 & 0,02 & 2,00 \\
\hline 2 & $0,95-1,05$ & 1,05 & 1,00 & 0,00 & 0,00 \\
\hline 7 & $0,95-1,05$ & 1,00 & 0,99 & 0,00 & 0,00 \\
\hline 39 & $0,95-1,05$ & 0,98 & 0,99 & 0,00 & 0,00 \\
\hline 110 & $0,95-1,05$ & 0,98 & 0,98 & 0,00 & 0,00 \\
\hline 1620 & $0,95-1,05$ & 0,95 & 0,98 & 0,00 & 0,00 \\
\hline 4000 & $0,95-1,05$ & - & 0,98 & 0,00 & 0,00 \\
\hline 4800 & $0,95-1,05$ & 0,97 & - & 0,00 & 0,00 \\
\hline
\end{tabular}

Tabela 5.10. Resultados dos valores de Pst para os testes padrões 


\subsection{S Simulação no Módulo de Desequilíbrio de Tensão}

Na simulação no módulo de desequilíbrio de tensão foi utilizada alimentação trifásica $60 \mathrm{~Hz}$ com $140 \mathrm{~V}$ eficaz máximo e defasagem de $120^{\circ}$ entre as fases.

O teste do protótipo foi executado em três passos conforme detalhado na tabela 5.11. Na mesma tabela são apresentados os valores esperados calculados e os valores medidos de desequilíbrio das tensões do sistema. O relatório gerado pelo teste está apresentado na figura 5.14.

\begin{tabular}{|c|c|c|c|c|c|}
\cline { 2 - 4 } \multicolumn{1}{c|}{ Passo 1 } & Valores Aplicados & Valores Medidos & Deseq. Calculado (\%) & Deseq. Medido (\%) & Erro \% \\
\hline Fase R & 127,00 & 127,03 & \multirow{2}{*}{0,00} & 0,00 & \multirow{2}{*}{0,00} \\
\hline Fase S & 127,00 & 126,97 & 126,91 & & \\
\hline Fase T & 127,00 & & & & \\
\hline
\end{tabular}

\begin{tabular}{|c|c|c|c|c|c|}
\cline { 2 - 4 } \multicolumn{1}{c|}{ Passo 2 } & Valores Aplicados & Valores Medidos & Deseq. Calculado (\%) & Deseq. Medido (\%) & Erro \% \\
\hline Fase R & 92,71 & 92,69 & \multirow{2}{*}{5,06} & \multirow{2}{*}{5,06} & \multirow{2}{*}{0,00} \\
\hline Fase S & 101,60 & 101,62 & & & \\
\hline Fase T & 110,49 & 110,44 & & & \\
\hline
\end{tabular}

\begin{tabular}{|c|c|c|c|c|c|}
\cline { 2 - 4 } \multicolumn{1}{c|}{ Passo 3} & Valores Aplicados & Valores Medidos & Deseq. Calculado (\%) & Deseq. Medido (\%) & Erro \% \\
\hline Fase R & 193,04 & 193,04 & \multirow{2}{*}{4,95} & \multirow{2}{*}{0,00} \\
\hline Fase S & 177,80 & 177,80 & & 4,95 & 0,00 \\
\hline Fase T & 162,56 & 162,56 & & & \\
\hline
\end{tabular}

Tabela 5.11. Valores de tensão aplicados e medidos - módulo Desequilíbrio de Tensão

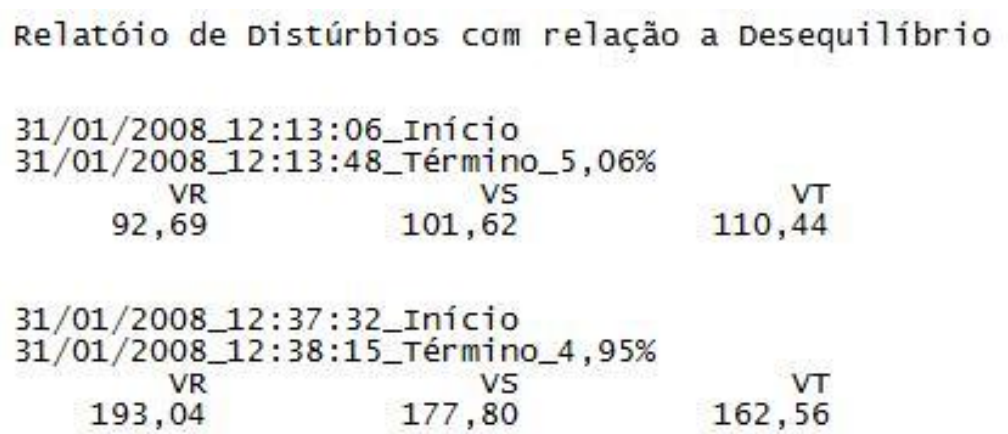


Para a execução do passo três utilizou-se a simulação virtual com recursos do software, uma vez que os equipamentos do laboratório não permitiram atingir tais tensões controladas em sistema trifásico.

Observa-se na tabela 5.11 que o erro entre valores de desequilíbrio calculados e valores medidos é menor que $0,15 \%$, atendendo o exigido pela norma IEC61000-4-30, uma vez que os valores de tensão já atendem o erro menor que $0,1 \%$.

A figura 5.15 apresenta a tela de simulação do módulo de desequilíbrio.

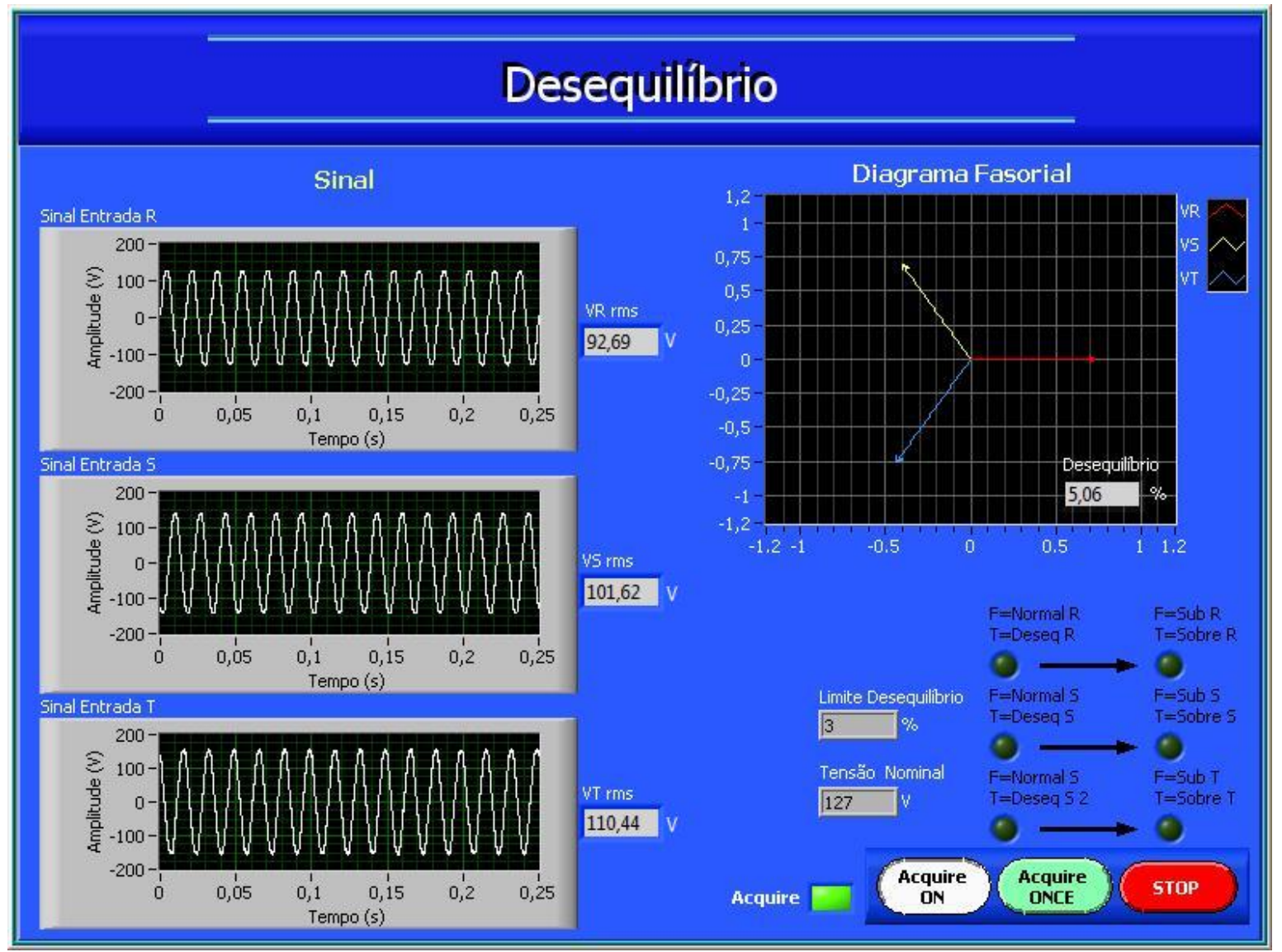

Figura 5.15. Tela da simulação módulo Desequilíbrio 


\subsection{Simulação no Módulo de Transitório}

Para a simulação no módulo de transitório foi aplicada ao protótipo uma onda senoidal 100V / $60 \mathrm{~Hz}$ com aproximadamente 3 ciclos de $120 \mathrm{~V}$ intermediários, conforme demonstrado na figura 5.16. O valor ajustado de gatilho para captura da onda foi ajustado para 2 vezes o $d v / d t$ normal da onda senoidal de amplitude $100 \mathrm{~V}$. A figura 5.17 apresenta a forma de onda aplicada ao protótipo e a figura 5.18 mostra o relatório contendo a forma de onda capturada em $50 \mathrm{~ms}$.

\begin{tabular}{|c|c|}
\hline Tensão Eficaz $\mathbf{M}$ ) & Tempo (s) \\
\hline 100 & 2,133 \\
\hline 120 & 0,050 \\
\hline 100 & 2,817 \\
\hline
\end{tabular}

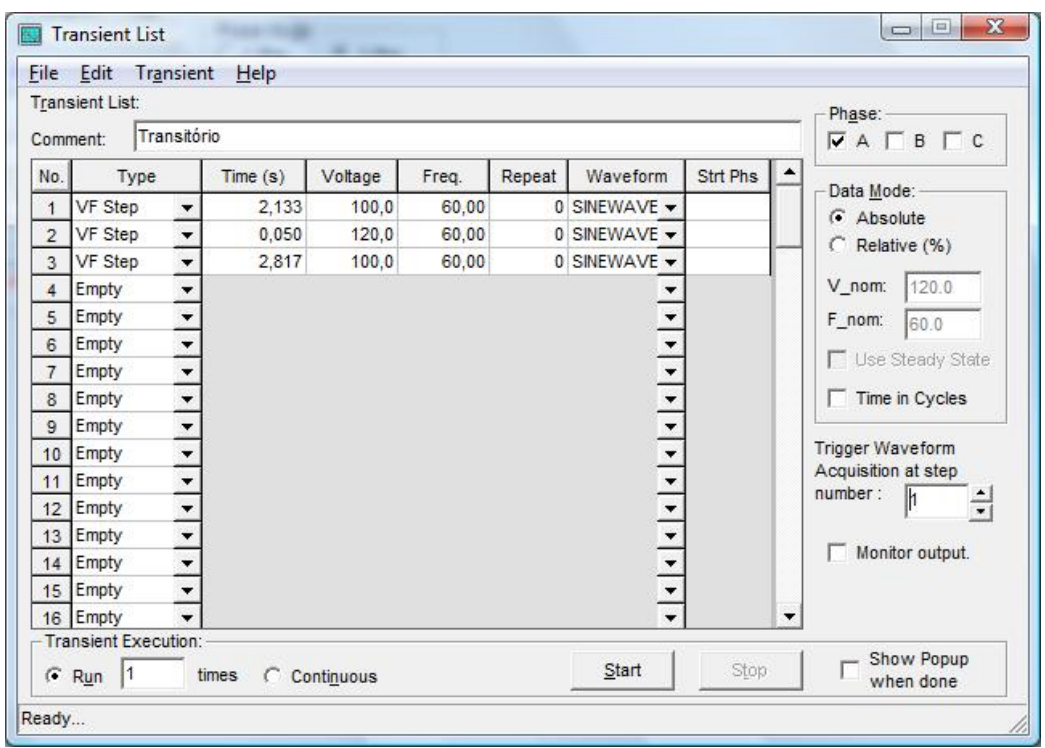

Figura 5.16. Tensão aplicada do protótipo - módulo de Transitório 


\section{Transitório}

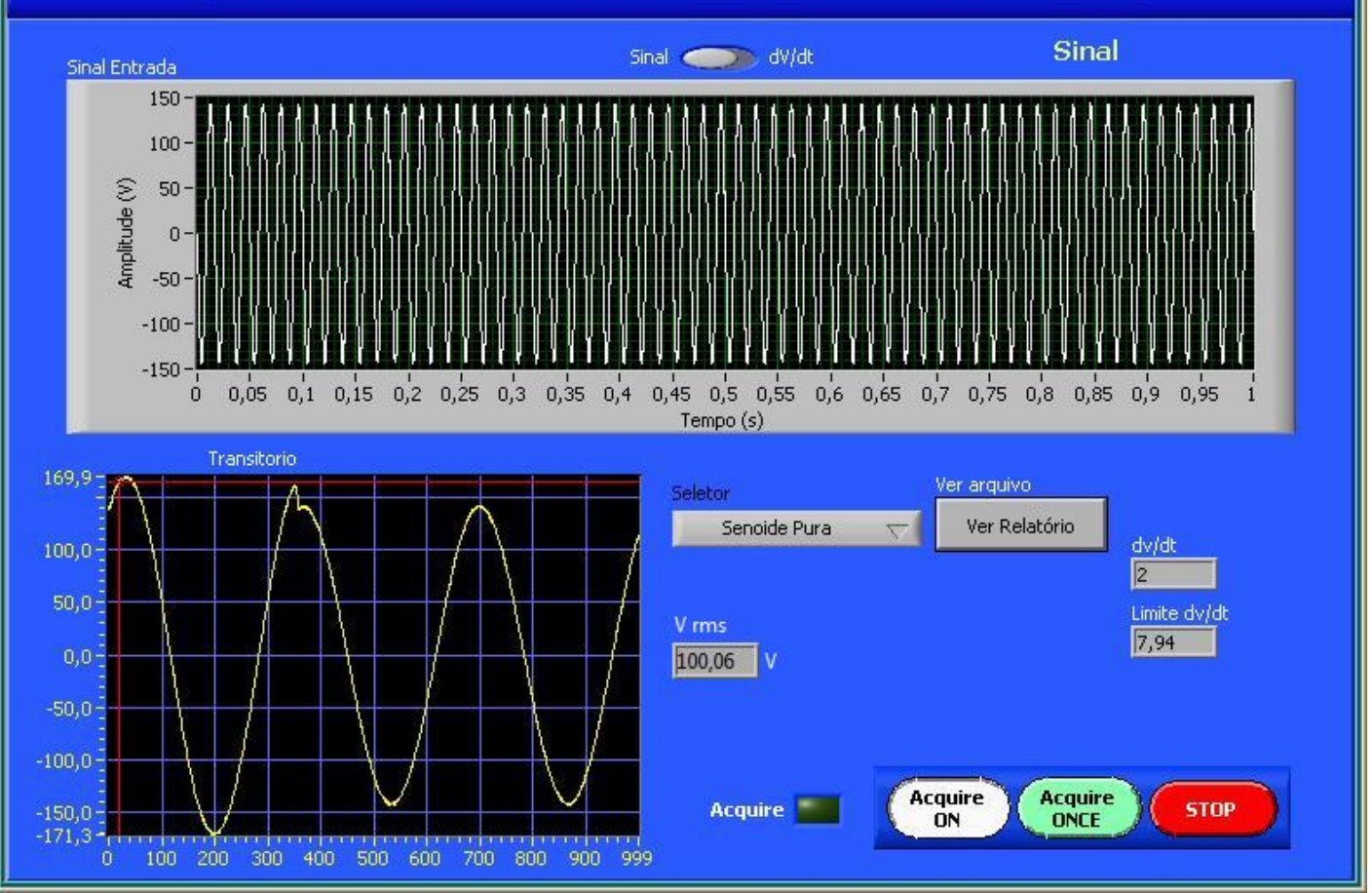

Figura 5.17. Tela de simulação módulo Transitório

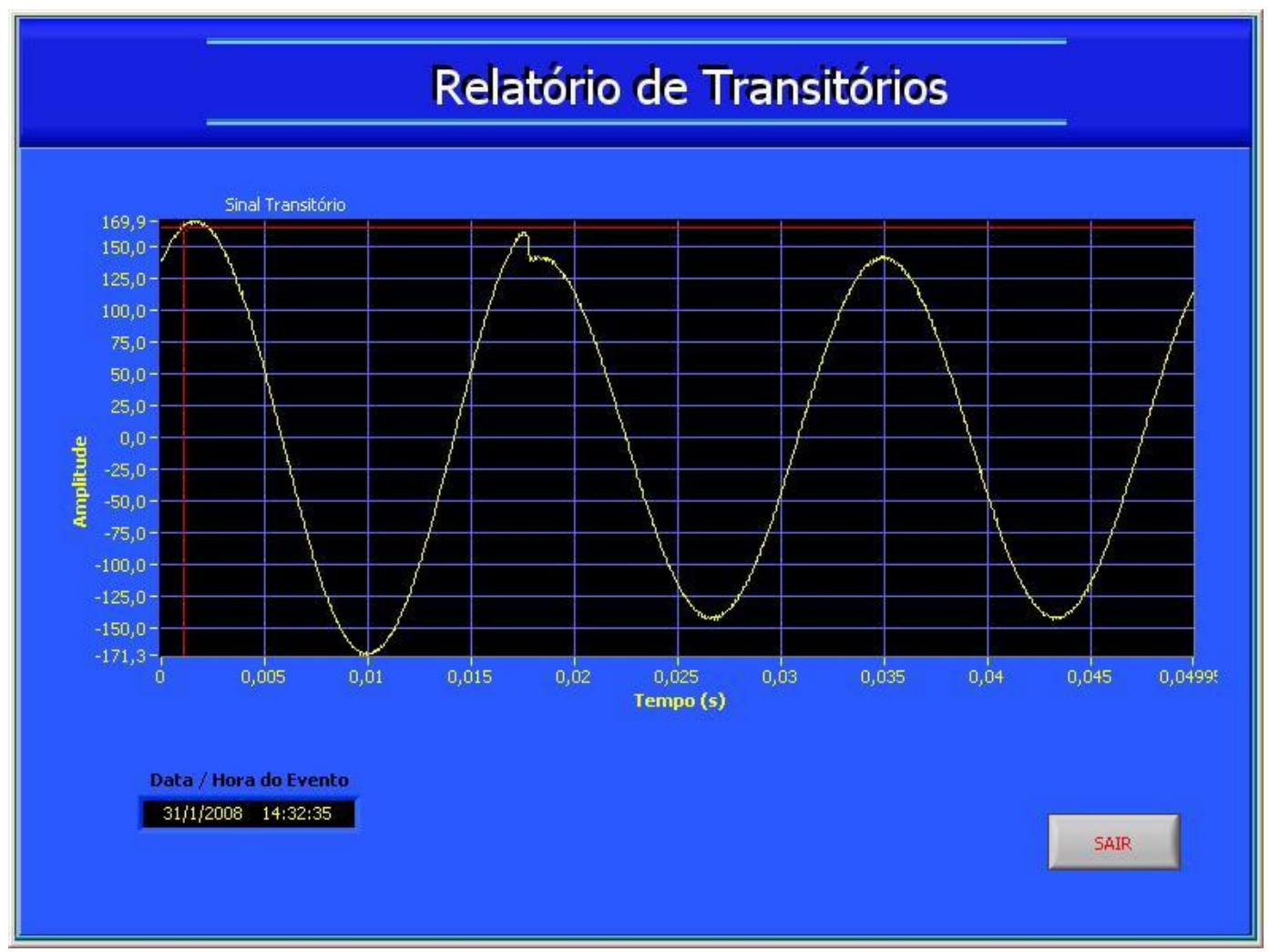

Figura 5.18. Relatório de simulação do módulo de Transitório 
Vê-se, então, que o protótipo registrou a onda no momento que $0 d v / d t$ gerado pelo distúrbio ultrapassou o limite imposto, conforme esperado pelo projeto inicial.

\subsection{Teste de Verificação de Implementação}

Foram realizados os testes de verificação de implementação, conforme exigido pela norma IEC 61000-4-30 em seu item 6.2 e apresentados aqui na tabela 5.12. Estes testes estão divididos em três passos e para cada passo é esperado que os módulos de medição possam mensurar os distúrbios apresentados sem interferência entre si.

\begin{tabular}{|c|c|c|c|}
\hline Influência & Passo 1 & Passo 2 & Passo 3 \\
\hline Freqüência & $\mathrm{f} \pm 0,5 \mathrm{~Hz}$ & $\mathrm{f}-1 \mathrm{~Hz} \pm 0,5 \mathrm{~Hz}$ & $\mathrm{f}+1 \mathrm{~Hz} \pm 0,5 \mathrm{~Hz}$ \\
\hline Amplitude de Tensão & $V \pm 1 \%$ & Deteminada pelo flicker, desequilibrio e harmônicas & Deteminada pelo flicker, desequilíbrio e harmônicas \\
\hline Flicker & Pst $<0,1$ & Pst $=1 \pm 0,1$ - 39 variações retangulares por minuto & Pst $=4 \pm 0,1$ - 110 variações retangulares por minuto \\
\hline Desequilíbrio & $0 \%$ a $0,5 \%$ de $\mathrm{V}$ & $0,73 \% \pm 5 \%$ de $\mathrm{V}$ & $1,52 \% \pm 5 \%$ de $\mathrm{V}$ \\
\hline Distorção & $0 \%$ a $3 \%$ de $\mathrm{V}$ & $\begin{array}{l}10 \% \pm 3 \% \text { de } V \text { na } 3^{\circ} \mathrm{h} \text { a } 0^{\circ} \\
5 \% \pm 3 \% \text { de } V \text { na } 5^{\circ} \mathrm{h} \text { a } 0^{\circ} \\
5 \% \pm 3 \% \text { de } V \text { na } 29^{\circ} \mathrm{h} \text { a } 0^{\circ}\end{array}$ & $\begin{array}{l}10 \% \pm 3 \% \text { de } V \text { na } 7^{\circ} \mathrm{h} \text { a } 180^{\circ} \\
5 \% \pm 3 \% \text { de } V \text { na } 13^{\circ} \mathrm{h} \text { a } 0^{\circ} \\
5 \% \pm 3 \% \text { de } V \text { na } 25^{\circ} \mathrm{h} \text { a } 0^{\circ}\end{array}$ \\
\hline
\end{tabular}

Tabela 5.12. Valores aplicados e medidos - teste de verificação de implementação

Para os testes de verificação de implementação foi retirado o distúrbio de distorção da forma de onda, pois não foi possível aplicar todos os distúrbios concomitantemente durante este teste devido aos módulos de geração de distúrbios do gerador arbitrário de sinais serem diferentes.

Observa-se na figura 5.19 as telas de medição de freqüência e variação de tensão, respectivamente, durante as medições do passo 2 . 

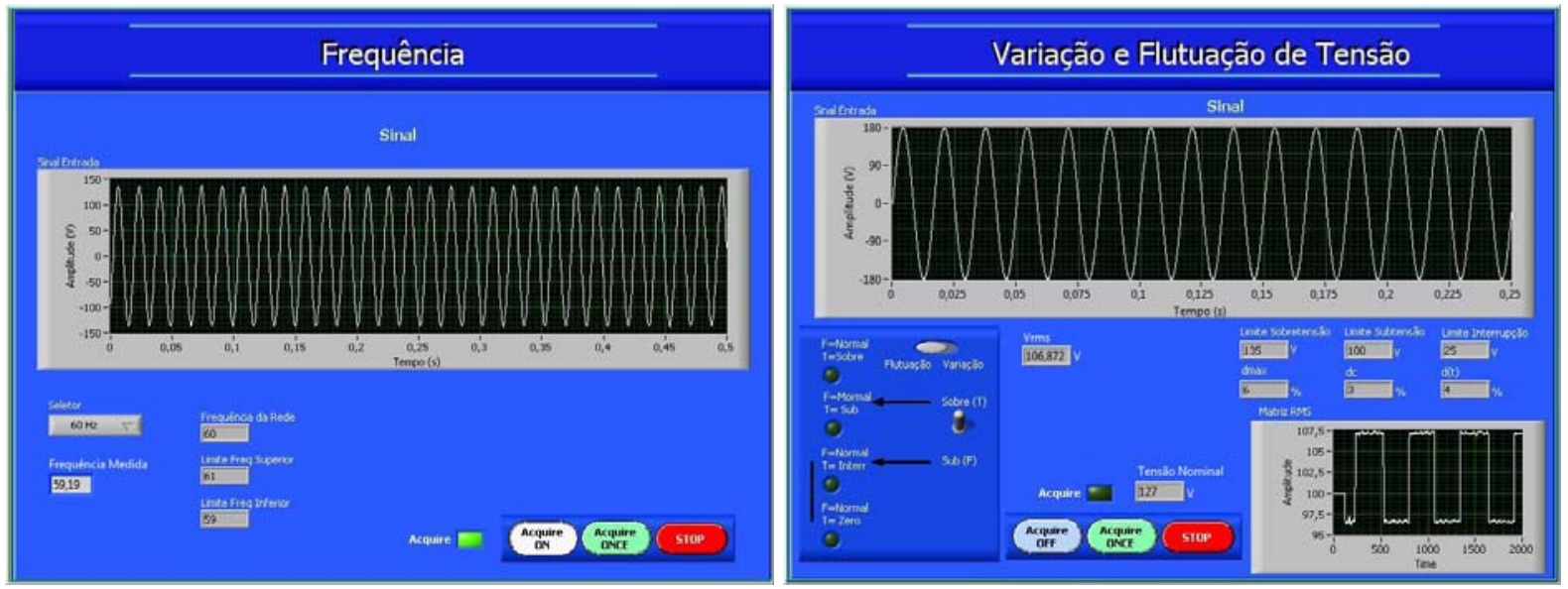

Figura 5.19. Tela de simulação de aceitação passo 2 - módulos Freqüência e Variação

Os valores medidos pelo protótipo durante os testes são apresentados na tabela 5.13. Vê-se que todos os erros medidos (em azul) estão dentro da tolerância de seus devidos módulos, atendendo assim as exigências da norma IEC61000-4-30.

\begin{tabular}{|l|c|c|c|c|c|c|c|c|c|}
\hline \multirow{2}{*}{ Módulos } & \multicolumn{3}{|c|}{ Passo 1 } & \multicolumn{3}{c|}{ Passo 2 } & \multicolumn{3}{c|}{ Passo 3 } \\
\cline { 2 - 10 } & Valor Aplicado & Valor Medido & Erro \% & Valor Aplicado & Valor Medido & Erro \% & Valor Aplicado & Valor Medido & Erro \% \\
\hline Frequiência (Hz) & 60,00 & 60,00 & 0,00 & 59,20 & 59,19 & 0,02 & 60,80 & 60,79 & 0,02 \\
\hline Desequilíbrio M) & 127,000 & 127,012 & 0,01 & $96,3-106,9$ & 106,872 & 0,03 & $174,8-180,8$ & 180,789 & 0,01 \\
\hline Distorçöes Forma Onda & - & - & - & - & - & - & - & - & - \\
\hline Flicker (Pst) & $<0,1$ & 0,03 & 0,00 & 1 & 0,98 & 2,00 & 4 & 3,81 & 4,75 \\
\hline
\end{tabular}

Tabela 5.13. Erro entre valores aplicados e valores medidos - Verificação da Implementação 


\section{Conclusões}

O conceito de Qualidade da Energia Elétrica (QEE) está relacionado diretamente com "qualquer problema manifestado na tensão, corrente ou desvio da freqüência que resulte em falha ou má operação de equipamentos elétricos dos consumidores". Para muitos dos pesquisadores da bibliografia consultada, os fenômenos eletromagnéticos que compreendem a QEE são variações de curta e longa duração, desequilíbrio, distorções na forma de onda, flutuação da tensão (flicker), transitórios e variações de freqüência na onda de tensão.

Para realizar-se uma análise sobre QEE é necessária a monitoração do sistema, pois além de conhecer os fenômenos eletromagnéticos e seus efeitos é de extrema importância quantificar a amplitude do problema e o tempo de ocorrência. Durante esta monitoração o equipamento deve garantir a confiabilidade e a repetibilidade nas medições para permanecer nas mesmas bases dos parâmetros definidos como aceitáveis pela sociedade técnica.

Baseado nos conceitos dos fenômenos eletromagnéticos relativos à QEE e nos requisitos mínimos dos equipamentos de medição, realizou-se um estudo para analisar as normas pertinentes. Verificou-se que as normas técnicas são importantes para a evolução sustentável da tecnologia das máquinas e equipamentos ofertados à sociedade, pois garantem principalmente a segurança do operador, um funcionamento correto conforme sua especificação e a difusão da tecnologia. No mundo existem várias entidades normativas que estudam os efeitos, as causas e propõem parâmetros para os distúrbios eletromagnéticos, porém as principais entidades normativas internacionais relacionadas à QEE são o IEEE e a IEC. As 
normas da IEC estabelecem muitos dos parâmetros de aceitação e são as mais utilizadas para análise de aparelhos e sistemas, pois garantem a confiabilidade e a repetibilidade consideradas aceitáveis pelas diversas áreas do setor de energia elétrica através da avaliação do desempenho esperado e da forma construtiva dos equipamentos de medição. As normas da IEC para certificação de equipamentos de medição e monitoramento de QEE são as normas da família IEC61000, da divisão 4, subdivisões 7, 15 e 30. Os níveis de compatibilidade eletromagnética para os fenômenos relacionados à QEE são definidos pelas normas da família IEC61000 da divisão 2-2 e das divisões 3-2 e 3-3.

Durante o desenvolvimento deste trabalho constatou-se que as inúmeras descobertas dos pesquisadores com relação aos fenômenos eletromagnéticos da QEE e a evolução dos equipamentos elétricos levam à necessidade atualização das normas. Sendo assim, normas são criadas e revisadas freqüentemente para atender as exigências da sociedade, levando a eminente necessidade de atualização constante dos conceitos do equipamento de medição às normas revisadas.

Para atender a necessidade de flexibilidade de atualização um dos conceitos mais utilizados para desenvolvimento de equipamentos de medição que sofrem constantes alterações é o conceito de instrumentos virtuais, pois a maior parte do projeto está concentrada no software, que proporciona uma maior facilidade e rapidez em sua modificação se comparado com as alterações em hardware.

Este trabalho teve como um dos objetivos o desenvolvimento de um protótipo de um equipamento para medição dos fenômenos eletromagnéticos relacionados à QEE, utilizando o conceito de instrumento virtual, obedecendo ao disposto nas normas da família IEC61000-4 relativas à QEE. O equipamento proposto é composto de microcomputador e interface de aquisição de dados, como parte do 
hardware. Como parte do conjunto de software, o medidor é composto por sistema operacional, software específico para instrumentação virtual e programa elaborado neste trabalho através dos devidos cálculos matemáticos baseados nas normas pertinentes. O protótipo do equipamento proposto foi desenvolvido abrangendo-se a medição de todos os fenômenos eletromagnéticos relativos à QEE apresentados nas normas escolhidas.

Para cada fenômeno eletromagnético foi elaborado, baseado nas normas selecionadas, um devido módulo de medição e apresentação dos resultados contendo suas respectivas grandezas características e relatórios pertinentes de registro de ocorrência de distúrbio. O módulo principal contempla os módulos de calibração, para conformação da magnitude dos sinais a serem medidos e o módulo de configuração, que possibilita a seleção da quantidade de fases, da classe do medidor e dos limites permitidos pelos distúrbios.

Cada módulo foi testado individualmente conforme as exigências impostas pelas normas pertinentes e na falta destas foi realizado a comparação entre sinal aplicado ou medição esperada e a medição do protótipo. Foram utilizadas cargas lineares e não lineares comerciais durante as simulações para garantir a máxima proximidade com o esperado nas aplicações de campo. A utilização de um gerador arbitrário de sinais foi necessária para assegurar as grandezas de valores aplicados e valores medidos, garantindo assim as faixas de tolerância exigidas pela norma de cada módulo.

Todos os módulos foram testados individualmente com respectivos procedimentos e valores aplicados apresentados nas tabelas do capítulo 5 . O atendimento às tolerâncias foram atingidos em todos os módulos, com particularidades no módulo de distorção da forma de onda. Mesmo as grandezas em 
que as devidas tolerâncias não são citadas pelas normas, foram alcançados bons resultados (cerca de $2 \%$ de tolerância relativa).

No módulo de distorção da forma de onda, das densidades de potência medidas, somente as maiores que $0,03 \mathrm{Arms}^{2} / \mathrm{Hz}$ atingiram a tolerância esperada. A causa provável do não atendimento da tolerância destas medidas é a faixa de medição da garra de corrente $(0$ a 1000A) ser muito alta em relação a medição executada, ou seja, a baixa precisão no início da faixa de medição da garra de corrente.

Interessantes análises poderão ser realizadas, futuramente, em comparações de equipamentos que atendam IEC $\times$ IEEE quanto as suas tolerâncias medidas, além de comparações entre o equipamento proposto e equipamentos comerciais. Estudos como melhorar a precisão deste medidor e a implementação de novos módulos para complementar o protótipo, como um módulo para classificação da "assinatura elétrica" que os equipamentos geradores de distúrbios imprimem na rede de distribuição durante um evento, podem levar também à continuação deste trabalho. 


\section{Referências Bibliográficas}

ABNT - Associação Brasileira de Normas Técnicas. Disponível em: <http://www.abnt.gov.br>. Acesso em: 04 de Abril. 2006.

ACA - Australian Communications and Media Authority. Disponível em: <http://www.acma.gov.au>. Acesso em: 16 de Abril. 2006.

AFONSO, J. L.; MARTINS, J. S. Revista O Eletricista: Qualidade da Energia Elétrica, n9, $3^{\circ}$ trimestre de 2004, ano 3, p.66-71.

AGÊNCIA NACIONAL DE ENERGIA ELÉTRICA. Estabelece disposições relativas à continuidade da distribuição da energia elétrica a unidades consumidoras. Resolução n²4, 27 de janeiro de 2000. Resolução n²4. 18p. janeiro de 2000 .

AGÊNCIA NACIONAL DE ENERGIA ELÉTRICA. Estabelece as condições de atendimento por meio de Central de Teleatendimento das concessionárias. Resolução n57, 12 de abril de 2004. Resolução n57, $11 \mathrm{p}$. , abril de 2004 .

AGÊNCIA NACIONAL DE ENERGIA ELÉTRICA. Estabelece as condições gerais de fornecimento de energia elétrica. Resolução $n^{\circ} 456$, 29 de novembro de 2000. Resolução n456, 62p., novembro de 2000. 
AGÊNCIA NACIONAL DE ENERGIA ELÉTRICA. Estabelece as disposições relativas à conformidade dos níveis de tensão de energia elétrica em regime permanente. Resolução n505, 26 de novembro de 2001. Resolução n505, 15p. novembro de 2001.

AGÊNCIA NACIONAL DE ENERGIA ELÉTRICA. Índices de Qualidade de Fornecimento de Energia Elétrica. Lex: Manual de Implantação da Qualidade do Fornecimento de Energia Elétrica, versão 4.0, 7p., 1998.

AINSWORTH, J. D. Harmonic Instability between Controlled Static Converters and AC Networks. Procedures IEE: vol. 114, July/Aug 1967, p. 949-957.

ANSI - American National Standards Institute. Disponível em: <http://www.ansi.org>. Acesso em: 15 de Abril. 2006.

ARRILAGA, J. et al. Power Systems Harmonic Analysis. New York: John Wiley \& Sons, 1997, 382 p.

ATAIDE, M. V. Contribuição ao Projeto de Filtros Ativos Monofásicos de Potência, 1997. Dissertação de Mestrado em Engenharia Elétrica, Universidade Estadual de Campinas, Campinas, 1997, 164 p.

BOLLEN, M. H. J. Understanding Power Quality Problems: Voltage, Sags, and Interruptions. New York: IEEE Press Marketing, 2000, 672 p. 
BORESTEIN, C. R.; CAMARGO, C. C. B. Alianças Estratégicas da Qualidade: dos desafios do passado às alternativas do futuro. Porto Alegre: Sagra Luzatto, 1997, 318 p.

BOWLES, J. B. AC Systems and Transformer Representation for HVDC Transmission Studies. IEEE - Power Apparatus and Systems, vol. PAS-89, Sept/Oct 1970, p. 1603-1608.

BRONZEADO, H. S. et al. Uma proposta de nomenclatura nacional de termos e definições associados à qualidade de energia elétrica. In: Seminário Brasileiro de Qualidade da Energia Elétrica - SBQEE, 2., 1997, São Lourenço. Anais do SBQEE II. São Lourenço: Seminário Brasileiro de Qualidade da Energia Elétrica, 1997, 6p.

CAMARGO, R. F. Contribuição ao Estudo de Filtros Ativos de Potência, 2002. Dissertação de Mestrado em Engenharia Elétrica, Universidade Federal de Santa Maria, Rio Grande do Sul, 2002, 258 p.

CAMPOS, J. C. Estratégias de Conservação e Qualidade de Energia Aplicadas na Indústria, 2001. Dissertação de Mestrado em Engenharia Elétrica, Universidade Estadual de Campinas, Campinas. 2001, 112 p.

CEN - Comitê Europeén de Normalisation. Disponível em: <http://www.cenorm.org>. Acesso em: 15 de Abril. 2006. 
CENELEC - Comitê Europeén de Normalisation Eletrotechnique. Disponível em: <http://www.cenelec.org>. Acesso em: 15 de Abril. 2006.

COBEI - Comitê Brasileiro de Eletricidade, Eletrônica, lluminação e Telecomunicações. Disponível em: <http://www.cobei.org.br>. Acesso em: 06 de Maio. 2006.

CORREIA, F.B.; BRONZEADO, H. S. Fator de Desequilíbrio em Sistemas Trifásicos. In: Seminário Brasileiro de Qualidade da Energia Elétrica SBQEE, 4., 2001, Porto Alegre. Anais do SBQEE IV. Porto Alegre: Seminário Brasileiro de Qualidade da Energia Elétrica, 2001, 7p.

CSPE - Comissão de Serviços Públicos em Eletricidade. Legislação Internacional para Fornecimento de Energia. Disponível em: <http://www.cspe.sp.gov/legislacao/fornecinterna.html>. Acesso em: 04 de Março. 2006.

CUNHA, L. V. Desenho Técnico: texto de apoio à disciplina desenho técnico. Lisboa: Fundação Calouste Gulbenkian, 1999.

DEPARTAMENTO NACIONAL DE ÁGUAS E ENERGIA ELÉTRICA. Altera as alíneas "a" e "b" do inciso II da Portaria n²4. Portaria n04, 10 de janeiro de 1989. Portaria nº4, Brasília, 4p., janeiro de1989. 
DEPARTAMENTO NACIONAL DE ÁGUAS E ENERGIA ELÉTRICA. Condições Técnicas e Qualidade do Serviço de Energia Elétrica. Portaria $n^{\circ} 31,11$ de abril de 1980. Portaria n³1, 5p., abril de 1980.

DEPARTAMENTO NACIONAL DE ÁGUAS E ENERGIA ELÉTRICA. Disposições relativas à continuidade do serviço de energia elétrica. Portaria n46, 17 de abril de 1978. Portaria n46, 6p., abril de 1978.

DEPARTAMENTO NACIONAL DE ÁGUAS E ENERGIA ELÉTRICA. Condições técnicas e qualidade do serviço energia elétrica. Portaria $n^{\circ} 47$, 17 de abril de 1978, Portaria n47, 5p. abril de 1978.

DIN - Deutsches Institut für Normung. Disponível em: <http://www.din.de>. Acesso em: 15 de Abril. 2006.

DUGAN, R. C. et al. Electrical Power Systems Quality. $1^{\circ}$ Ed., New York: McGraw-Hill, 1996, 528 p.

EMANUEL, A. E. In: International Conference on Harmonics and Quality of Power, 8., 1998, Atenas. Apparent Power: components and physical interpretation. Atenas: International Conference on Harmonics and Quality of Power, 1998, p. 1-13. 
EN - European Norme. NP EN 45020:2001. Normatização e atividades correlacionadas. International Organization for Standardization: NP EN 45020, 2001.

ETSI - Institut Europeén dês Normes de Télécommunication. Disponível em: <http://www.etsi.org>. Acesso em: 15 de Abril. 2006.

GALHARDO, M. B.; PINHO, J. T. Conceitos de Distorção e NãoLinearidades. In: Seminário Brasileiro de Qualidade da Energia Elétrica SBQEE, 5., 2003, Aracaju. Anais do SBQEE V. Aracaju: Seminário Brasileiro de Qualidade da Energia Elétrica, 2003, 10p.

IEC - International Electrotechnical Commission. Disponível em: <http://www.iec.ch>. Acesso em: 15 de Abril. 2006.

IEC - International Electrotechnical Commission. IEC 61000-2-2: Description of the Environment - Compatibility Levels for Low-Frequency Conducted Disturbances and Signaling in Public Low-Voltages Power Supply Systems. Electromagnetic Compatibility (EMC) - Part 2, Section 2. 2002.

IEC - International Electrotechnical Commission. IEC 61000-3-2: Limits Limits for Harmonic Current Emissions (equipment input current up to and including 16A per phase). Electromagnetic Compatibility (EMC) - Part 3, Section 2. 2000. 
IEC - International Electrotechnical Commission. IEC 61000-3-3: Limits Limitation of Voltage Changes, Voltage Fluctuations and Flicker in Public Low-Voltage Supply Systems, for equipment with rated current $\leq 16 \mathrm{~A}$ per phase and not subject to conditional connection. Electromagnetic Compatibility (EMC) - Part 3, Section 3. 1995.

IEC - International Electrotechnical Commission. IEC 61000-3-4: Limits Limitation of Emission of Harmonic Currents in Low-Voltage Power Supply Systems for Equipment with rated current greater than 16A. Electromagnetic Compatibility (EMC) - Part 3, Section 4. 1998.

IEC - International Electrotechnical Commission. IEC 61000-3-5: Limits Limitation of voltage fluctuations and flicker in low-voltage power supply systems for equipment with rated current greater than $16 \mathrm{~A}$. Electromagnetic Compatibility (EMC) - Part 3, Section 5. 1994.

IEC - International Electrotechnical Commission. IEC 61000-4-7: Testing and measurement techniques - General Guide on Harmonics and Interharmonic Measurements and Instrumentation, for power supply systems and equipment connected thereto. Electromagnetic Compatibility (EMC) - Part 4, Section 7, 2002. 
IEC - International Electrotechnical Commission. IEC 61000-4-15: Testing and measurement techniques - Flickmeter - functional and design specifications. Electromagnetic Compatibility (EMC) - Part 4, Section 15, 2003.

IEC - International Electrotechnical Commission. IEC 61000-4-30: Testing and Measurement Techniques - Power quality measurements methods. Electromagnetic Compatibility (EMC) - Part 4, Section 30, 2003.

IEEE - Institute of Electrical and Electronics Engineers. Disponível em: <http://www.ieee.org>. Acesso em: 15 de Abril. 2006.

IEEE - Institute of Electrical and Electronics Engineers. IEEE 100-1992: IEEE Standard Dictionary of Electrical and Electronic Terms. New York: Institute of Electrical and Electronics Engineers: IEEE100-1992, 1992.

IEEE - Institute of Electrical and Electronics Engineers. IEEE 519-1992: IEEE Recommended Practices and Requirements for Harmonic Control in Electrical Power Systems. New York: Institute of Electrical and Electronics Engineers: IEEE 519-1992, 1992.

IEEE - Institute of Electrical and Electronics Engineers. IEEE 1100-1999: IEEE Recommended Practice for Powering and Grounding Electronic Equipment. New York: Institute of Electrical and Electronics Engineers: IEEE 1100-1999, 1999. 
IEEE - Institute of Electrical and Electronics Engineers. IEEE 1159-1995: IEEE Recommended Practice for Monitoring Electric Power Quality. New York: Institute of Electrical and Electronics Engineers: IEEE 1159-1995, 1995.

IEEE - Institute of Electrical and Electronics Engineers. IEEE 1453-2004: IEEE Recommended Practice for Measurements and Limits of Voltage Fluctuations and Associated Light Flicker on AC Power Systems. New York: Institute of Electrical and Electronics Engineers: IEEE 1453-2004, 2004.

ISA - International Federation of the National Standardizing Association. Disponível em: <http://www.isa.org>. Acesso em: 15 de Abril. 2006.

ISO Online. How ISO standards benefit society. Disponível em: <http://www.iso.org/iso/en/aboutiso/introduction/index.html>. Acesso em: 08 de Março. 2006.

ISO - International Organization for Standardization. Disponível em: <http://www.iso.org>. Acesso em: 15 de Abril. 2006.

ITIC - Information Technology Institute Council. Disponível em: <http://www.itic.org>. Acesso em: 16 de Abril. 2006. 
ITU - International Telecommunication Union. Disponível em: <http://www.itu.int/home>. Acesso em: 06 de Maio. 2006.

KEY, T. S. Diagnosing Power Quality: related computer problems. IEEE Transactions on Industry Applications, vol. IA-15, July/Aug 1979, p.381-393.

KEY, T. S. IEEE Recommended Practice for Electric Powering and Grounding Sensitive Electronic Equipment. New York: IEEE Press Marketing, 1992, p.21-28.

KODALI, V. P. Engineering electromagnetic compatibility principles, measurements and technologies. New York: IEEE Press Marketing, 1996, p. 315 - 331.

MANFÈ, G.; POZZA R.; SCARATO. G. Desenho Técnico Mecânico. São Paulo: Hemus-Livraria Ltda, 1977, 277 p.

MARAFÃO, F. P. Análise e controle da energia elétrica através de técnicas de processamento digitais de sinais, 2004. Dissertação de Doutorado em Engenharia Elétrica, Universidade Estadual de Campinas, Campinas, 2004, 259 p. 
MARTZLOFF, F. D.; GRUZS, T. M. Power Quality site Surveys: facts, fiction and fallacies. IEEE - Transactions on Industry Applications, vol. 24, Nov/Dec 1988, p.1005-1018.

MCGRANAGHAN, M. F. (2002). Overview of Power Quality Standard. Disponível em: <http://www.pqnet.electrotek.com/pqnet/main/standard/ paper1/overview.htm>. Acesso em: 22 de Outubro. 2005.

NEMA - National Electrical Manufacturers Association. Disponível em: <http://www.nema.org>. Acesso em: 16 de Abril. 2006.

$\mathrm{Nl}$ - National Instruments. Disponível em: <http://www.ni.com>. Acesso em: 15 de Junho. 2006.

NICOLAS, F.; REPUSSARD, J. Common Standards for Industries. Luxemburgo: European Commission, 1988, 79 p.

OLESKOVICZ, M. Qualidade da Energia: Apostila de aula. São Carlos: Universidade de São Paulo (USP), SEL 5749, 2006, 129 p.

OPPENHEIM, A. V.; SCHAFER, R. W.; BUCK, J. R. Discrete-Time Signal Processing. $2^{\circ}$ edição. Upper Saddle River: Prentice-Hall, 1999, $870 \mathrm{p}$. 
PHADKE, A. G. HARLOW, J. H. Generation of Abnormal Harmonics in High Voltage AC/DC Power Systems. IEEE - Transactions on Power Apparatus and Systems, vol. PAS-87, Nov/Dec 1968, p. 873-883.

PHIPPS, J. K.; NELSON, J. P.; SEN P. K. Power Quality and Harmonic Distortion on Distribution Systems. IEEE Transactions on Industry Applications, vol. 30, Mar/Apr 1994, p.476-484.

SARAIVA FILHO, F. C. Proposta de um Recuperador Dinâmico para Correção de Afundamentos de Tensão, 2002. Dissertação de Mestrado em Engenharia Elétrica, Escola Politécnica da Universidade de São Paulo, São Paulo, 2002, 65 p.

SCHNEIDER ELECTRIC. Qualidade da Energia: Harmônicas. São Paulo, Instituto Brasileiro do Cobre - PROCOBRE, 2002, 19 p.

SERNI, P. J. A. Qualidade da Energia: Apostila de aula. São Carlos: Universidade de São Paulo (USP), SEL 5749, 2006, 146 p.

SHIPP, D. D. Harmonics analysis and suppression for electrical systems supplying static power converters and others nonlinear loads. IEEE Transactions on Industry Application. Vol. IA-15, Sep/Oct 1979, p. 453458. 
SILVA, B. A.; SOUZA, M. P.; MACHADO, O. F. Conservação de Energia: Eficiência Energética e Qualidade de Energia Elétrica. In: Seminário em Geração de Energia Elétrica da Universidade Federal de Minas Gerais, 2004, Belo Horizonte. Belo Horizonte: Seminário em Geração de Energia Elétrica, 2004, 9 p.

SILVEIRA, M. Qualidade de Energia em Estabelecimentos Assistenciais de Saúde, 2002. Dissertação de Mestrado em Engenharia Elétrica, Universidade de Salvador, Salvador, 2002, 141 p.

SINMETRO - Sistema Nacional de Metrologia, Normalização e Qualidade Industrial. Disponível em: <http://www.inmetro.gov.br/inmetro/ sinmetro.asp>. Acesso em: 04 de Abril. 2006.

VDE - Verband Der Elektrotechnik. Disponível em: <http://www.vde.com>. Acesso em: 15 de Abril. 2006.

WATANABE, E. H.; AREDES, M. Teoria da Potência Ativa e Reativa Instantânea e Aplicações - Filtros Ativos e FACTS. In: Congresso Brasileiro de Automática - CBA, 12., 1998, Uberlândia. Anais do $\mathbf{1 2}^{\circ}$ CBA. Uberlândia: Congresso Brasileiro de Automática, 1998, p. 81-122. 
ZIMATH, S. L; VIEIRA, G. R. IEC61000-4-30: A norma definitiva para medição de Parâmetros de Qualidade. In: Seminário Brasileiro de Qualidade da Energia Elétrica - SBQEE, 6., 2005, Pará. Anais do SBQEE VI. Pará: Seminário Brasileiro de Qualidade da Energia Elétrica, $2005,5 p$. 


\section{Apêndice}

\subsection{Apêndice A - Grandezas de Distorção da Forma de Onda}

\section{Fator de Potência}

O fator de potência (FP) é igual à relação entre a potência ativa $(P)$ e a potência aparente (S) (GALAHARDO; PINHO, 2003).

$$
F P=\frac{P}{S}=\frac{\frac{1}{T} \int v(t) i(t) d t}{V_{r m s} I_{r m s}}
$$

\section{Fator de Crista}

Fator de crista é a relação entre o valor de pico da tensão $\left(V_{p}\right)$ e o seu respectivo valor eficaz $\bigvee_{\text {rms. }}$. A expressão que representa o fator de crista é:

$$
k=\frac{V_{p}}{V_{r m s}}
$$

O fator de crista é muito útil para nos mostrar a presença de harmônicos, atraindo nosso foco para os valores de pico muito altos em relação ao eficaz. Quando o fator de crista é muito elevado significa a existência de sobrecargas pontuais, que detectadas pelos dispositivos de proteção podem gerar disparos inoportunos dos mesmos. 
Para um sinal puramente senoidal o fator de crista é $\sqrt{2}$. Para cargas nãolineares este fator pode assumir valores iguais a 1,5 ou 2 , podendo se elevar até 5 nos casos mais críticos, segundo Schneider Electric (2002).

\section{Potência de Distorção}

Na presença de harmônicos, como temos uma somatória de ondas de diversas freqüências, é apresentado uma potência aparente maior que a potência aparente somente com a componente fundamental (EMANUEL, 1998).

A potência aparente é calculada pelo produto da tensão eficaz e corrente eficaz.

$$
S=V_{r m s} I_{r m s}
$$

Valendo-se das expressões de Serni (2006), Emanuel (1998) e Watanabe e Aredes (1998), quando não há distorção na tensão, a potência aparente pode ser dividida em três potências distintas.

Separando a equação 8.3 em seus componentes temos:

$$
S^{2}=P^{2}+Q^{2}+D^{2}
$$

São estas as potências ativa, reativa e de distorção harmônica, respectivamente. Pode-se observar a relação entre estas potências na figura 8.1. 


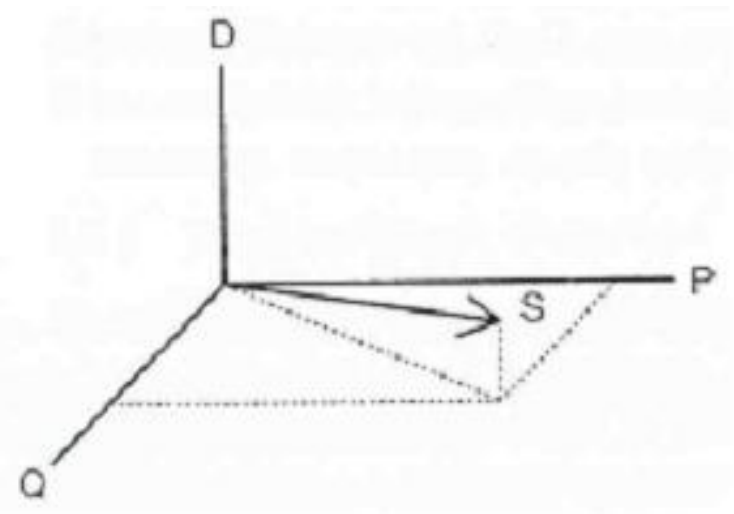

Figura 8.1. Relação entre as componentes da potência aparente

Temos então a potência aparente expressa como:

$$
S^{2}=V_{r m s}^{2} I_{r m s}^{2}=V_{r m s}^{2}\left(I_{1, r m s}^{2}+\sum_{h=2}^{\infty} I_{h, r m s}^{2}\right) \quad[\mathrm{VA}]
$$

$S^{2}=V_{r m s}^{2} I_{1, r m s}^{2}+V_{r m s}^{2} \sum_{h=2}^{\infty} I_{h, r m s}{ }^{2}$

$$
S^{2}=V_{r m s}{ }^{2} I_{1, r m s}{ }^{2} \cos ^{2}\left(\varphi_{1}\right)+V_{r m s}^{2} I_{1, r m s}^{2} \operatorname{sen}^{2}\left(\varphi_{1}\right)+V_{r m s}{ }^{2} \sum_{h=2}^{\infty} I_{h, r m s}{ }^{2}[\mathrm{VA}]
$$

Onde:

$\varphi_{1}$ é a defasagem entre a tensão e a corrente da componente fundamental

Então, a potência ativa é expressa como:

$$
P=V_{\text {rms }} I_{1, r m s} \cos \left(\varphi_{1}\right)
$$

Temos a potência reativa expressa como: 
$Q=V_{r m s} I_{1, r m s} \operatorname{sen}\left(\varphi_{1}\right)$

[VAr]

E, finalmente, a potência referente à presença de harmônicos, ou seja, a potência de distorção harmônica pode ser expressa como:

$$
D=V_{r m s} \sum_{h=2}^{\infty} I_{h, r m s}
$$

A potência de distorção representa uma interação entre tensão e corrente nas diferentes freqüências e só existirá se a corrente for não senoidal e/ou quando conter nível CC.

\section{Densidade Espectral de Potência}

As características de amplitude e defasagem da onda de tensão e corrente para cada dispositivo são diferentes. Então, para cada equipamento não-linear diferente, existe uma ordem de harmônico de diferente amplitude. Estas são de grande importância para uma correta análise de um problema envolvendo QEE.

A representação da densidade espectral de potência se dá em forma de um histograma representando a amplitude de cada ordem de harmônico na presença de sua freqüência, como na figura 8.2. 


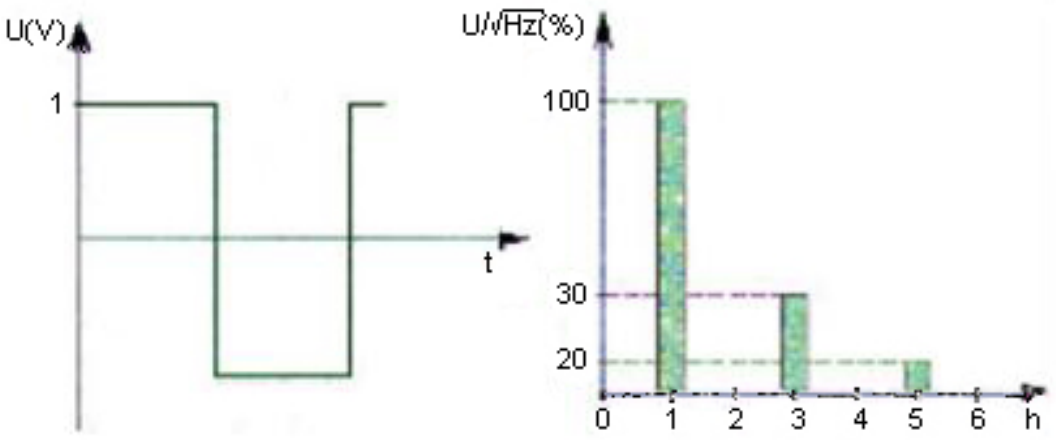

Figura 8.2. Espectro de potência de um sinal retangular

\section{Taxa de Distorção Harmônica}

Para se encontrar o valor eficaz da tensão na presença de harmônicos devese calcular o valor eficaz da tensão em função de cada harmônico:

$$
V_{r m s}=\sqrt{\sum_{h=1}^{\infty} V_{h, r m s}^{2}}
$$

A taxa individual de harmônicos ou taxa de harmônica da ordem "h" é expressa como a porcentagem de harmônicos de ordem $\mathrm{h}$ dividido pela fundamental:

$$
V_{h, r m s}(\%)=100 \frac{V_{h, r m s}}{V_{1, r m s}}
$$


A Distorção Harmônica Total (THD) (Total Harmonic Distortion) é a notação que define o nível do conteúdo harmônico de um sinal periódico. É a relação que expressa a quantidade de harmônicos em um sinal senoidal puro.

Para um sinal periódico $\mathrm{v}(\mathrm{t})$ a taxa de distorção harmônica total, THD, é expressa da seguinte forma:

$$
T H D=\frac{\sqrt{\sum_{h=2}^{\infty} V_{h, r m s}^{2}}}{V_{1, r m s}} \times 100
$$

Esta taxa nos auxilia a avaliar a partir de um único número a deformação da forma de onda da tensão transmitida na rede.

Uma corrente pode conter uma taxa de distorção harmônica total (THD) relativamente alta, mas não contribuir significativamente para os problemas do sistema, por ser de uma amplitude baixa em relação a corrente total do circuito alimentador.

Para avaliar a influência das distorções harmônicas no sistema de energia é utilizado o fator de Distorção de Demanda Total (TDD) (Total Demand Distortion), que é expresso pela equação:

$T D D=\frac{\sqrt{\sum_{h=2}^{h_{\max } I_{h, r m s}{ }^{2}}}}{I_{L}} \times 100$

Onde:

I é o máximo valor eficaz de corrente do sistema medido no alimentador geral comum a todas as cargas. 